UNIVERSIDADE DE SÃO PAULO

INSTITUTO DE PSICOLOGIA

DEPARTAMENTO DE PSICOLOGIA EXPERIMENTAL

SOCIOECOLOGIA DE MACACOS-PREGO (Cebus libidinosus) EM ÁREA DE ECÓTONO CERRADO/CAATINGA

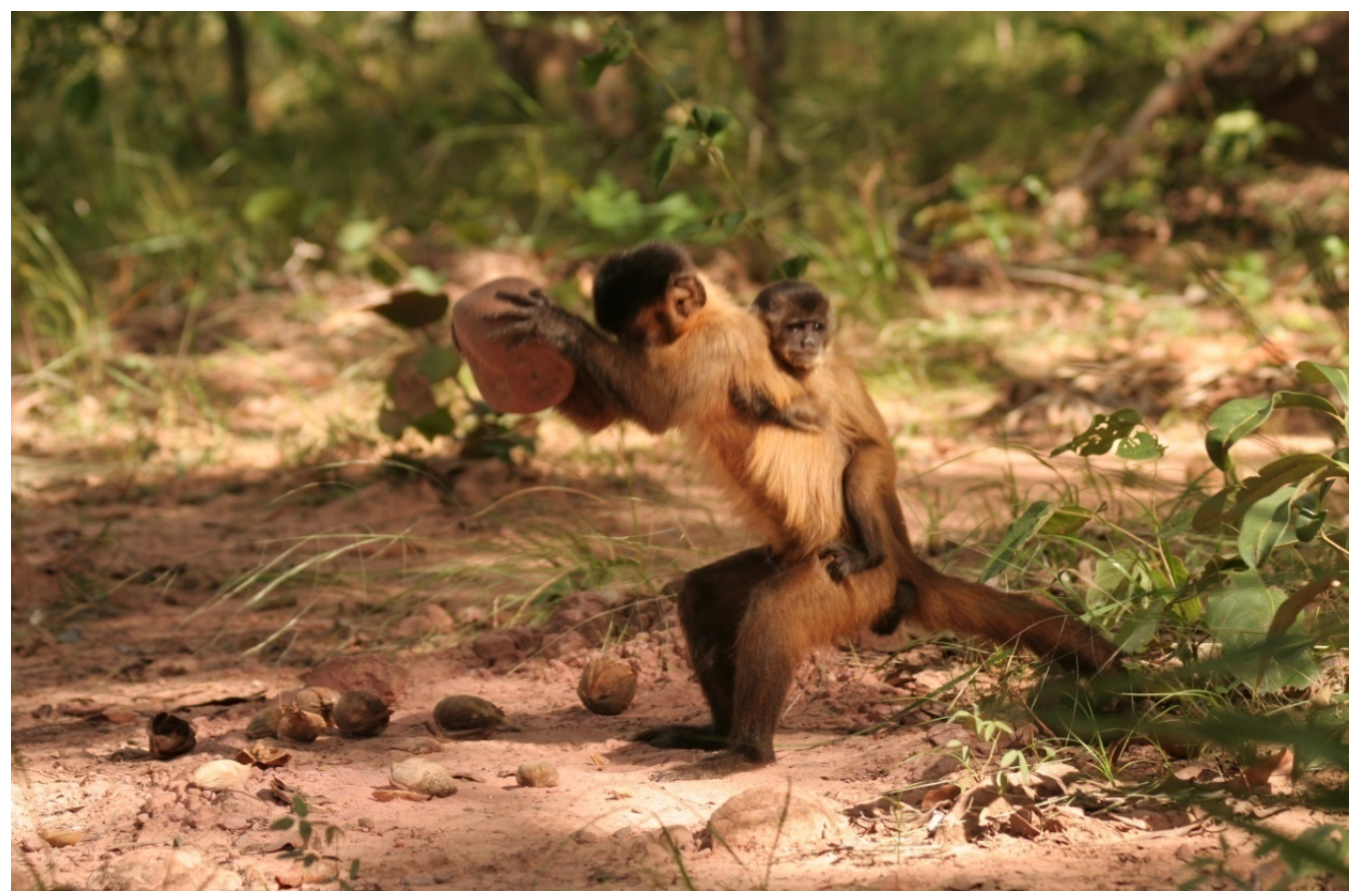

MICHELE PEREIRA VERDERANE

São Paulo

2010 
UNIVERSIDADE DE SÃO PAULO

INSTITUTO DE PSICOLOGIA

DEPARTAMENTO DE PSICOLOGIA EXPERIMENTAL

\title{
SOCIOECOLOGIA DE MACACOS-PREGO (Cebus libidinosus) EM ÁREA DE ECÓTONO CERRADO/CAATINGA
}

\author{
Tese apresentada ao Instituto de Psicologia da \\ Universidade de São Paulo, como parte dos \\ requisitos para obtenção do título de Doutor em \\ Psicologia.
}

Área de Concentração: Psicologia Experimental

MICHELE PEREIRA VERDERANE

Orientadora: Dr ${ }^{\mathrm{a}}$ Patrícia Izar

São Paulo

2010 


\section{AUTORIZO A REPRODUÇÃO E DIVULGAÇÃO TOTAL OU PARCIAL DESTE TRABALHO, POR QUALQUER MEIO CONVENCIONAL OU ELETRÔNICO, PARA FINS DE ESTUDO E PESQUISA, DESDE QUE CITADA A FONTE.}

Catalogação na publicação Biblioteca Dante Moreira Leite

Instituto de Psicologia da Universidade de São Paulo

Verderane, Michele Pereira.

Socioecologia de macacos-prego (Cebus libidinosus) em área de ecótono cerrado/caatinga / Michele Pereira Verderane; orientadora

Patrícia Izar -- São Paulo, 2010. $215 \mathrm{f}$.

Tese (Doutorado - Programa de Pós-Graduação em Psicologia. Área de Concentração: Psicologia Experimental) - Instituto de Psicologia da Universidade de São Paulo.

1. Comportamento social (animal) 2. Ecologia 3. Utilização de ferramentas 4. Cebus 5. Dietas I. Título.

QL775 


\title{
FOLHA DE APROVAÇÃO
}

\author{
MICHELE PEREIRA VERDERANE
}

SOCIOECOLOGIA DE MACACOS-PREGO (Cebus libidinosus) EM ÁREA DE ECÓTONO CERRADO/CAATINGA

Tese apresentada ao Instituto de Psicologia da Universidade de São Paulo, como parte dos requisitos para obtenção do título de Doutor em Psicologia.

Área de Concentração: Psicologia Experimental

Tese defendida e aprovada em:

\section{Banca Examinadora}

Prof.(a)Dr.(a)

Instituição:

Assinatura:

Prof.(a)Dr.(a)

Instituição:

Assinatura:

Prof.(a)Dr.(a)

Instituição:

Assinatura:

Prof.(a)Dr.(a)

Instituição:

Assinatura:

Prof.(a)Dr.(a)

Instituição:

Assinatura: 
"Quando oiei a terra ardendo Qual a fogueira de São João Eu preguntei a Deus do céu,ai Por que tamanha judiação

Que braseiro, que fornaia Nem um pé de prantação Por farta d'água perdi meu gado Morreu de sede meu alazão..."

(Asa Branca - Luíz Gonzaga) 


\section{AGRADECIMENTOS}

À minha família pelo respeito, apoio e incentivo incondicional às minhas escolhas. Em especial, agradeço à minha mãe, Jacira, pela base segura e apoio irrestrito em todas as fases desse trabalho. Agradeço, também, por todo o esforço para me enviar, no Piauí, mantimentos e outros itens de primeira necessidade. Ao meu pai, por ter topado a aventura de dirigir $2.000 \mathrm{~km}$, de São Paulo ao Piauí, e mais $2.000 \mathrm{~km}$, do Piauí a São Paulo, conduzindo um carro abarrotado com todos os meus presentes de mudança. À minha irmã, Gisele, pelo carinho, amizade, apoio e pela ajuda na revisão deste trabalho. Ao Hildebrando (o mais louco de todos, que embarcou ao meu lado para uma aventura de dois anos no Piauí), agradeço pela coragem de acreditar nas minhas escolhas, pela dedicação, companheirismo e pela valiosa ajuda em todos os aspectos envolvidos na realização desse trabalho.

À professora Patrícia Izar, pelo entusiasmo, empenho e envolvimento em todas as fases desta pesquisa, pela orientação séria e criteriosa, por ouvir, confiar e respeitar as minhas opiniões, pelo incentivo, compreensão e amizade ao longo dessa parceira duradoura.

A todas as pessoas que me ajudaram no Piauí. Em especial, agradeço à família Oliveira (família M), que foi uma família para mim durante os dois anos em que estive no Piauí. Agradeço à Maria por todo cuidado e carinho dedicado aos pesquisadores do EthoCebus (pesquisa-doídos, como costumava dizer) e pelas deliciosas refeições. Às crianças, Marcos, Junior, Marina, Mara, Marcinho e Martinha, por tornarem o meu dia a dia mais alegre, pelo carinho e amizade. Ao Mauro, pela valiosa ajuda. Agradeço, também, ao Raimundo e a Sara pela recepção e hospedagem durante os primeiros dias no Piauí. Ao Paulinho, pela amizade, prontidão, apoio e, é claro, por fornecer a cerveja mais gelada de Gilbués.

À equipe de pesquisadores do EthoCebus: às professoras Dorothy Fragaszy, Elisa Visalberghi e Patrícia Izar e ao professor Eduardo Ottoni, pela oportunidade, apoio (estrutural e intelectual) e por respeitarem e apoiarem o meu trabalho. À Noemi Spagnoletti e Eduardo Ramos da Silva (Darvin), meus companheiros de "campo", pela amizade, respeito, troca de idéias, por participarem dos momentos alegres e difíceis durante a coleta dos dados e por ajudarem a manter minha saúde mental. 
Aos meus assistentes de campo (meus fieis escudeiros), Josemar, Arizomar e Júnior, por toda a ajuda na coleta de dados, pelo trabalho bem executado, pela companhia agradável ao longo de MUITAS horas de trabalho de campo, por me ensinarem muitas coisas sobre o semi-árido e a vida fora das grandes metrópoles e, acima de tudo, pela responsabilidade e dedicação, fundamentais para execução deste trabalho.

Aos meus amigos de São Paulo, por serem, simplesmente, amigos: Andersom (Dê), Fábio, Márcia, Sandro, Elaine, Alcina e Magoo.

Aos meus colegas do Laboratório de Etologia Cognitiva e adjacências: Tiago, Olívia, Lucas, Luiz, Marina, Mari Lee, Mari Dutra, Marcos, Marcola, Zé e Altay (que agradeço, também, pela ajuda estatística) pela troca de experiência.

Às professoras Briseida Resende e Cibele Biondi, por participarem da minha banca de qualificação e pelas contribuições importantes para este trabalho. À Briseida, agradeço, também, pelo apoio desde o início da minha história com os macacos-prego, pela confiança e respeito que sempre demonstrou pelo meu trabalho.

Aos professores Fernando Leite Ribeiro, Emma Otta e Vera Silva Bussab, pelas sugestões valiosas durante a disciplina de seminários em etologia.

Às agências de fomento pelo suporte financeiro: Fapesp, CNPq e Capes.

Por fim, aos macacos-prego, por tudo que me ensinaram e por serem criaturas tão fascinantes. 


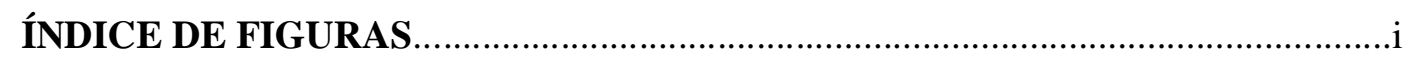

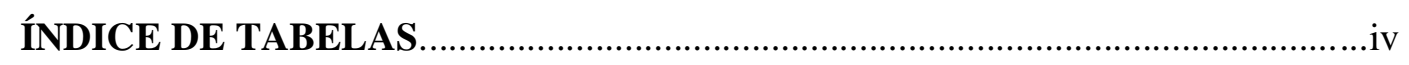

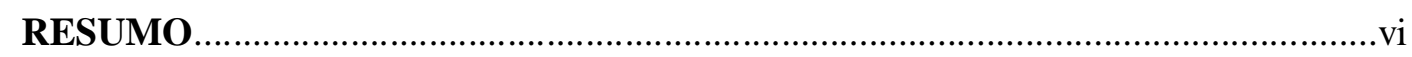

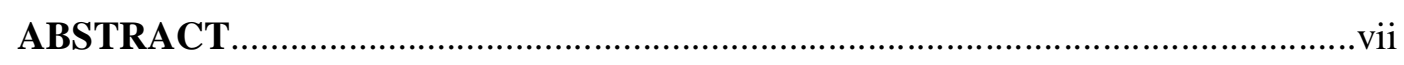

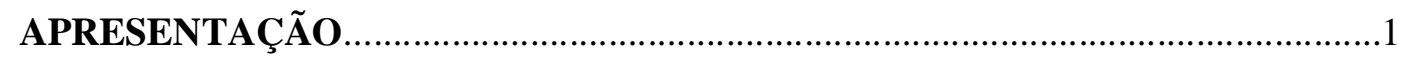

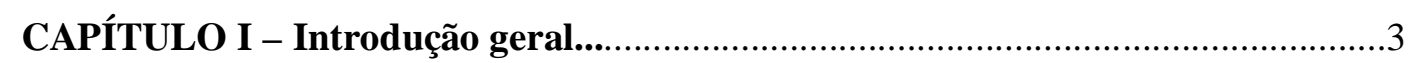

1. INTRODUÇÃ

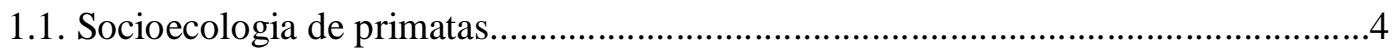

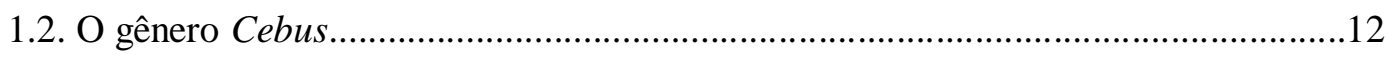

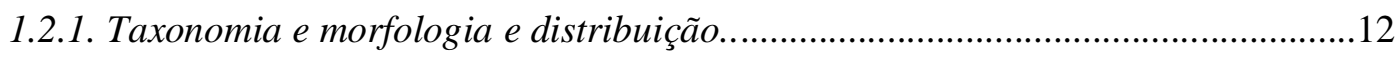

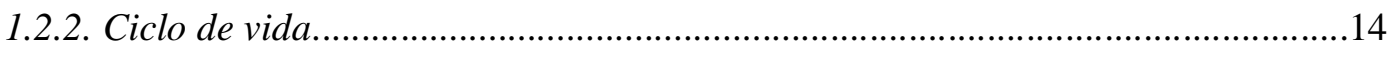

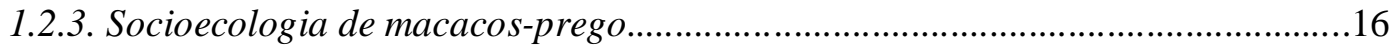

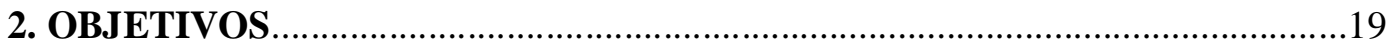

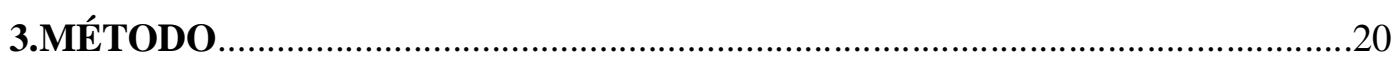

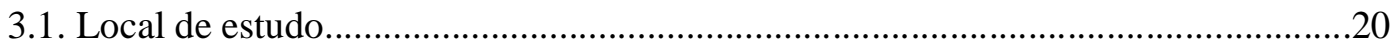

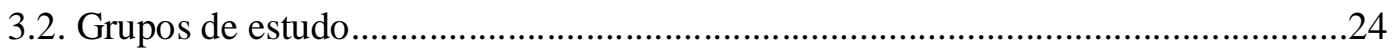

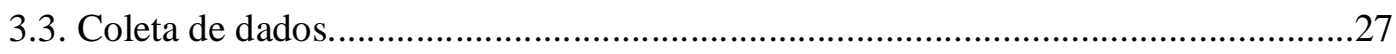

CAPÍTULO II - Padrão de atividades e dieta de uma população de macacos-prego selvagens (Cebus libidinosus), que utiliza ferramentas, em área de ecótono

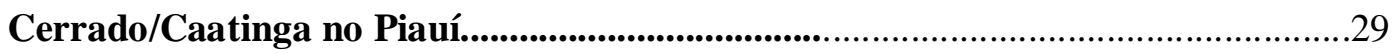

1.INTRODUÇÃ $\tilde{A}$

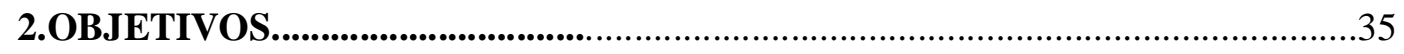

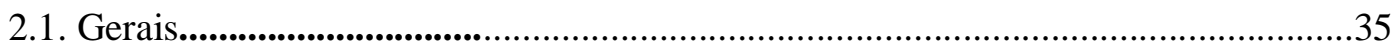

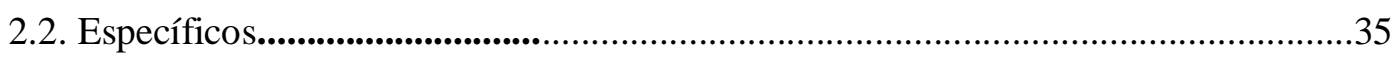

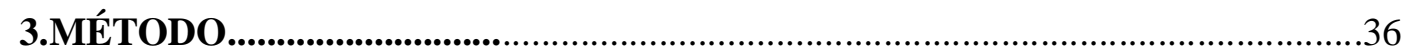




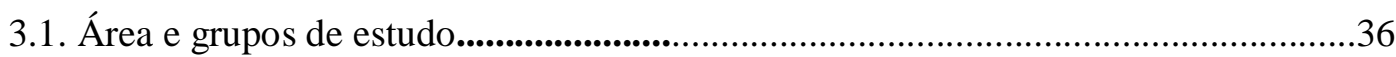

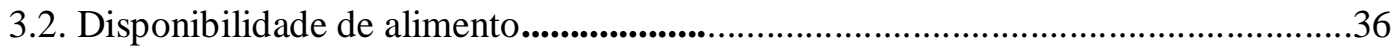

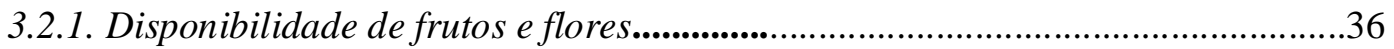

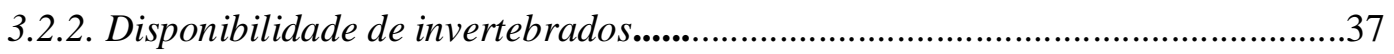

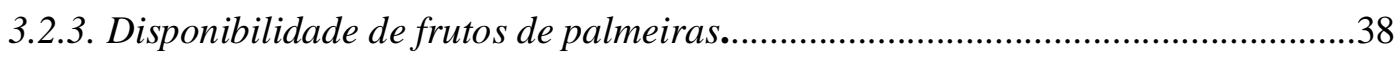

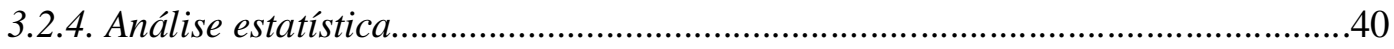

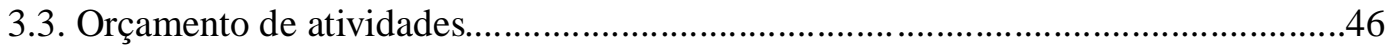

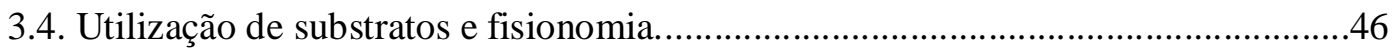

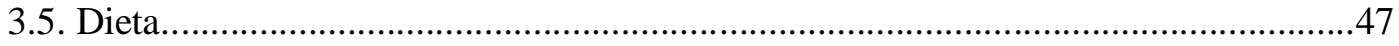

4.RESULTADOS

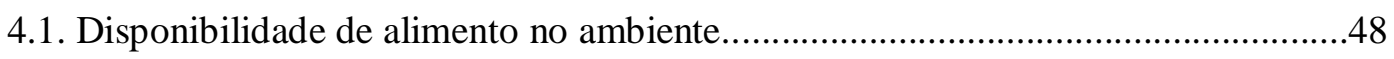

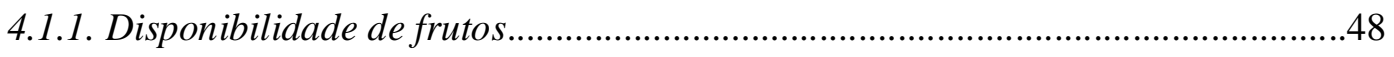

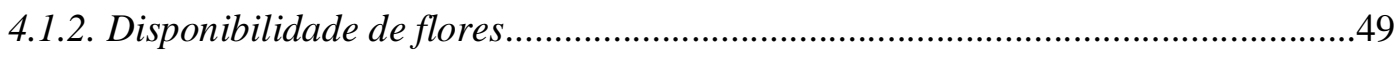

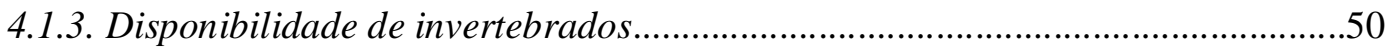

4.1.4. Disponibilidade de cocos............................................................................ 50

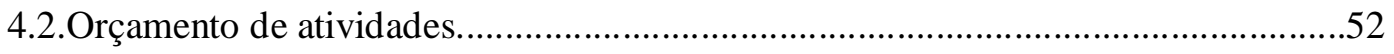

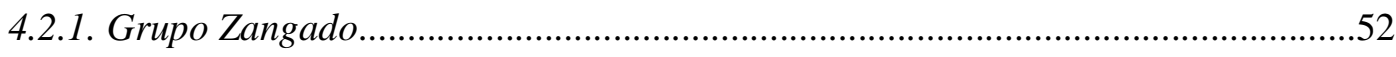

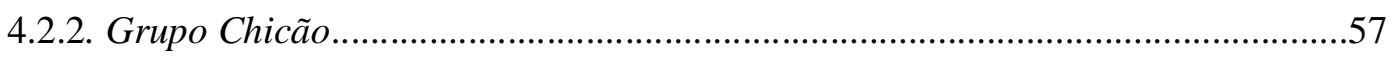

4.2.3. Orçamento de atividades: comparação entre grupos........................................61

4.3. Padrão de exploração de substratos e fisionomias..................................................64

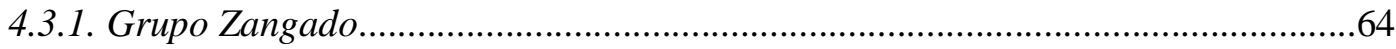

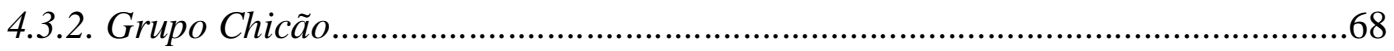

4.3.3. Padrão de uso de substrato e fisionomia: comparação entre grupos....................72

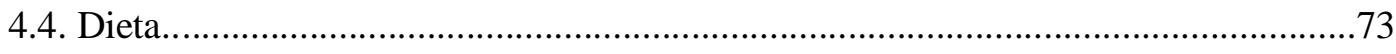

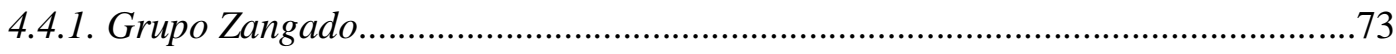




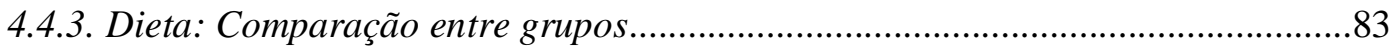

5-DISCUSSÃO

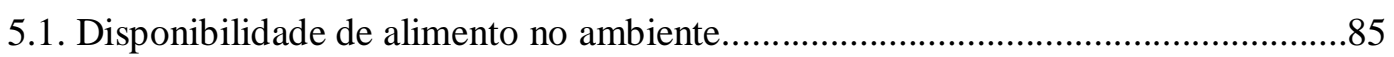

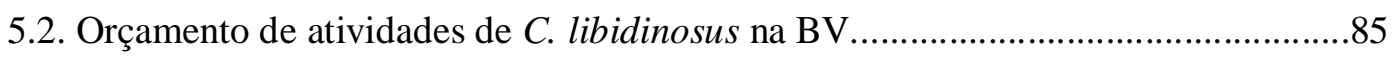

5.3. Uso de substratos e fisionomias por C. libidinosus da Boa Vista..........................93

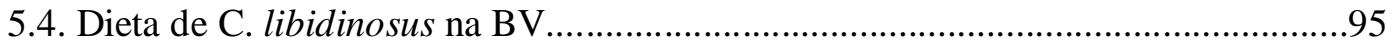

5.5. Existe diferença no padrão de atividades, dieta e escolha dos substratos em

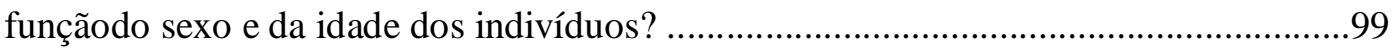

5.6. A influência do uso de ferramentas sobre orçamento de atividades, dieta e uso de

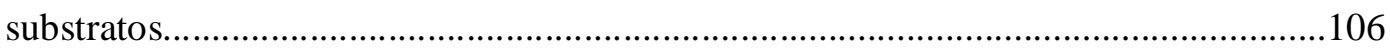

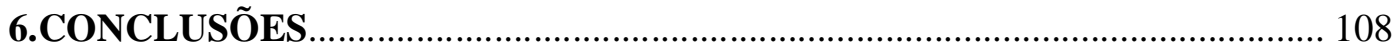

CAPÍTULO III - Socioecologia de macacos-prego selvagens (Cebus libidinosus) em área de ecótono Cerrado/Caatinga no Piauí: o efeito do uso de ferramentas nas

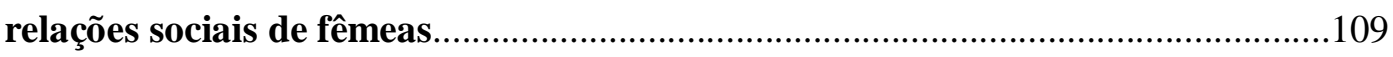

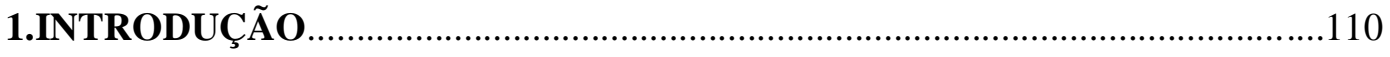

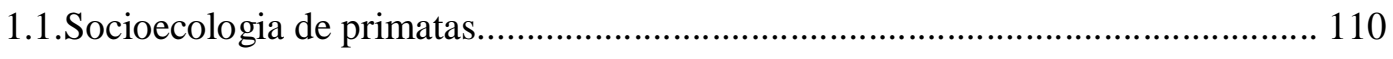

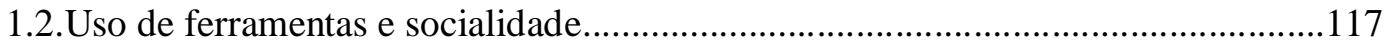

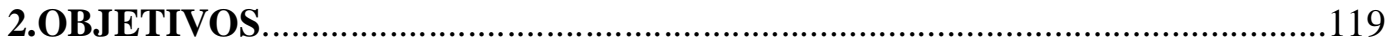

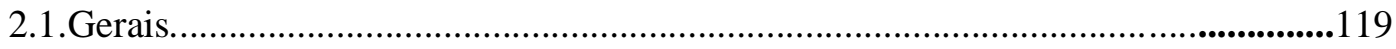

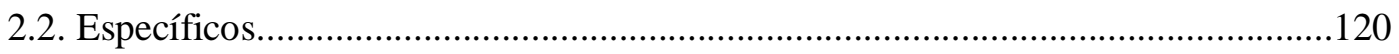

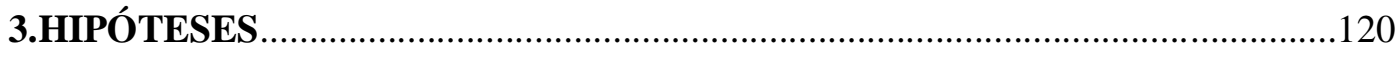

4.MÉTODO 


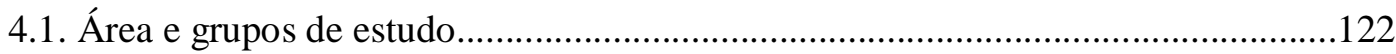

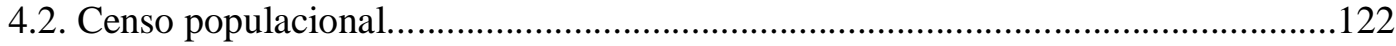

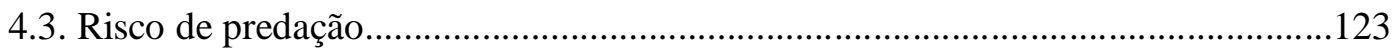

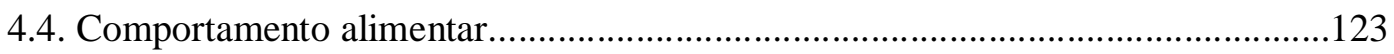

4.5. Caracterização e tamanho das fontes alimentares.................................................124

4.6. Regime de competição por alimento e padrão de relações sociais entre fêmeas....130

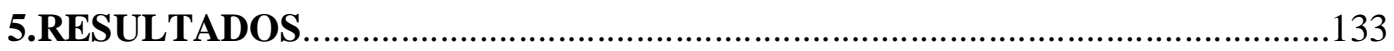

5.1.Densidade populacional de Cebus libidinosus na Boa Vista..................................133

5.2. Dinâmica de população e tamanho dos grupos de macacos-prego na Boa Vista...133

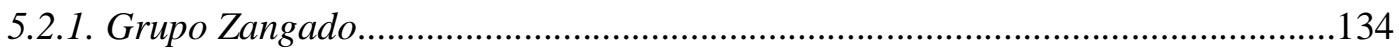

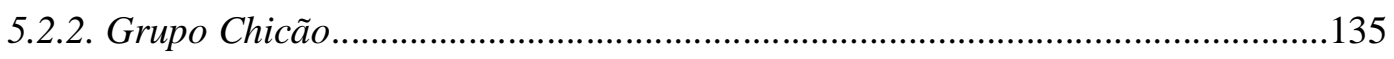

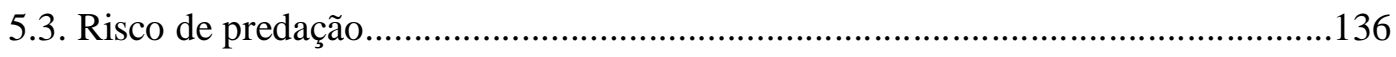

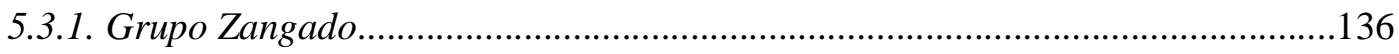

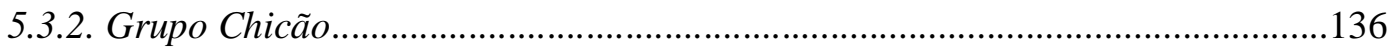

5.4. Comportamento alimentar de fêmeas adultas.....................................................137

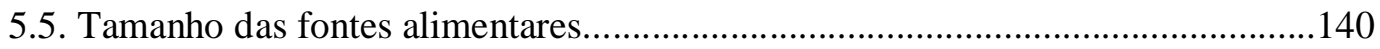

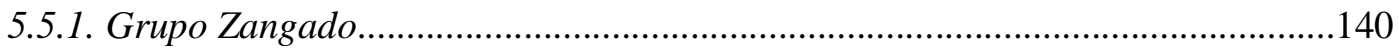

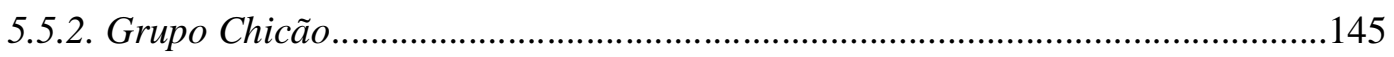

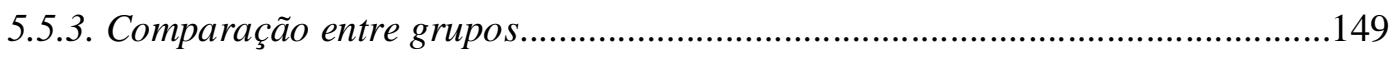

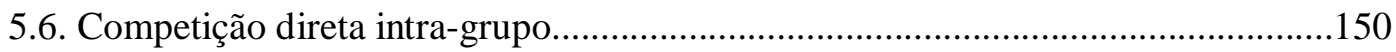

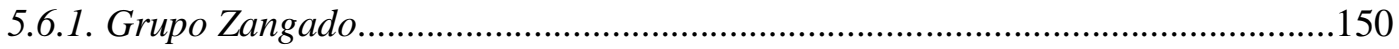

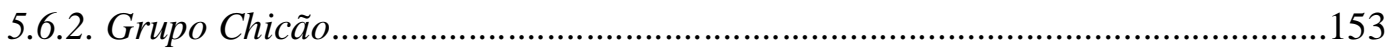

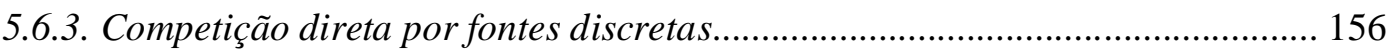

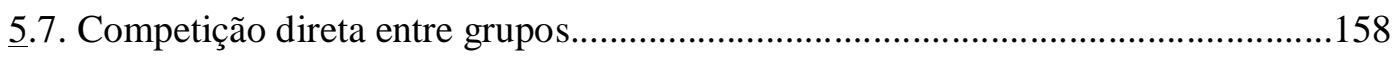

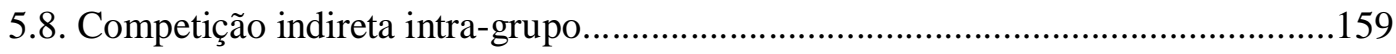




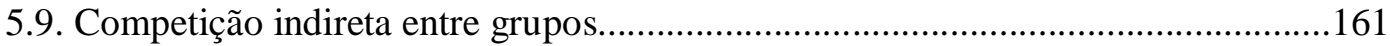

5.10. Padrão de relações sociais entre fêmeas...............................................................162

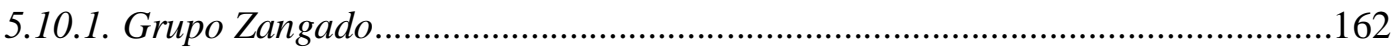

5.10.2. Grupo Chicão

6.DISCUSSÃ O

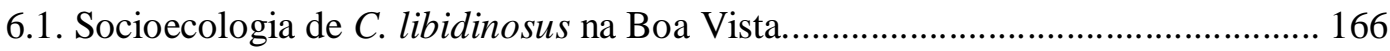

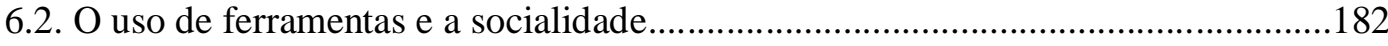

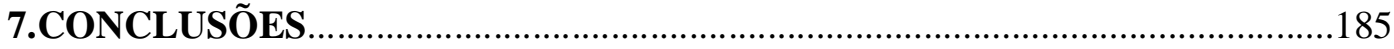

CONCLUSÃO

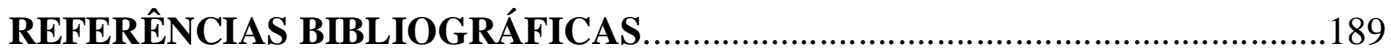




\section{ÍNDICE DE FIGURAS}

\section{CAPÍTULO I - Introdução geral}

Figura 1: Distribuição geográfica das espécies do gênero Cebus (fonte www.icb.ufmg.br/zoo/primatas/cebus_map.htm).............................................13

Figura 2: À esquerda, localização da área de estudo no município de Gilbués. À direita (acima), vista da fazenda BV, (abaixo) imagem de satélite da BV, com destaque para os morros que circundam a região no centro da Figura (as setas indicam os nomes de identificação de cada encosta).....

Figura 3: Macho subadulto (Teimoso) forrageando em um paredão rochoso (Foto:

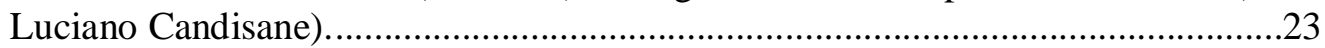

Figura 4: Área de chapada (à frente) e morros de arenito (ao fundo) na BV. .23

Figura 5: Machos subadultos (Jatobá e Mansinho) observando bípedes em topo de morro (Foto: Eduardo Darvin Ramos da Silva).

Figura 6: Temperatura média (máxima e mínima) e total de precipitação pluviométrica registrado na BV entre junho de 2006 e abril de 2008.

\section{CAPÍTULO II - Padrão de atividades e dieta de uma população de macacos-prego selvagens (Cebus libidinosus), que utiliza ferramentas, em área de ecótono Cerrado/Caatinga no Piauí}

Figura 1: Coletores de frutos e flores para amostragem de biomassa na área de estudo.

Figura 2: Armadilha "pitfall" para amostragem de invertebrados na área de

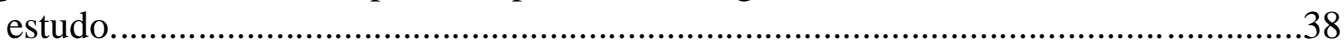

Figura 3: Palmeira "catulé" com cacho de cocos..............................................................

Figura 4: Disponibilidade (biomassa) de frutos na BV entre maio de 2006 e abril de 2008.

Figura 5: Disponibilidade (bimoassa) de flores na BV entre dezembro de 2006 e abril de 2008.

Figura 6: Disponibilidade (biomassa) de invertebrados na BV entre maio de 2006 e abril de 2008 .

Figura 7: Disponibilidade (número de palmeiras catulé e piaçava com frutos) de cocos na BV entre maio de 2006 e abril de 2008.

Figura 8: Disponibilidade de cocos da palmeira catulé e da palmeira piaçava (número de indivíduos com frutos) na BV entre maio de 2006 e abril de 2008.

Figura 9: Orçamento de atividades do grupo ZA entre maio de 2006 e abril de 2008.

Figura 10: Orçamento de atividades do grupo ZA nas estações seca e chuvosa (média e desvio padrão).

Figura 11: Orçamento de atividades do grupo ZA nos períodos da manhã, meio do dia e tarde.

Figura 12: Orçamento de atividades de machos e fêmeas do grupo

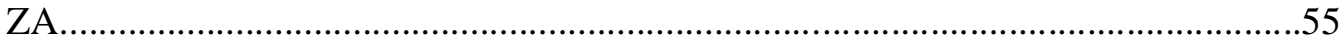

Figura 13: Orçamento de atividades de adultos e juvenis do grupo ZA..........................56

Figura 14: Orçamento de atividades do grupo ZA por classe de sexo e idade entre o período de fevereiro de 2007 e abril de 2008 
Figura 15: Orçamento de atividades do grupo $\mathrm{CH}$ entre o período de fevereiro de 2007 e

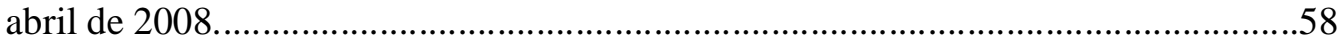

Figura 16: Orçamento de atividades do grupo $\mathrm{CH}$ nas estações seca e

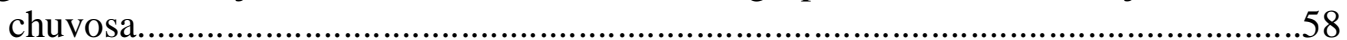

Figura 17: Orçamento de atividades do grupo $\mathrm{CH}$ nos períodos da manhã, meio do dia e tarde.

Figura 18: Orçamento de atividades de machos e fêmeas grupo $\mathrm{CH}$............................60

Figura 19: Orçamento de atividades de adultos e juvenis do grupo $\mathrm{CH}$.........................61

Figura 20: Orçamento de atividades do grupo $\mathrm{CH}$ por classe de sexo e idade entre o período de fevereiro de 2007 e abril de 2008

Figura 21: Padrão de uso de substratos pelo grupo ZA entre maio de 2006 e abril de 2008.

Figura 22: Padrão de uso de substratos pelo grupo ZA nas estações seca e

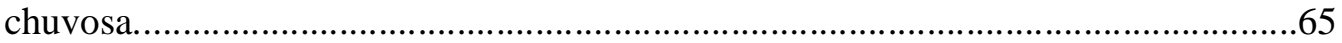

Figura 23: Padrão de uso de substratos do grupo ZA por classe de sexo e

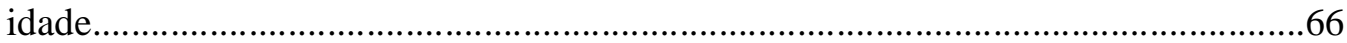

Figura 24: Proporção de tempo de exploração de diferentes fisionomias pelo grupo ZA

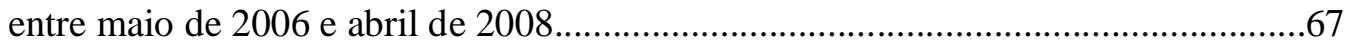

Figura 25: Proporção de tempo de exploração de diferentes fisionomias pelo grupo ZA

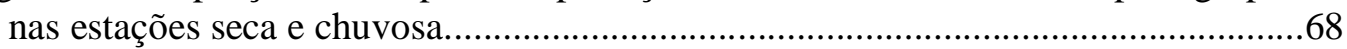

Figura 26: Padrão de uso de substratos pelo grupo $\mathrm{CH}$ entre fevereiro de 2007 e abril de 2008

Figura 27: Padrão de uso de substratos pelo grupo $\mathrm{CH}$ nas estações seca e

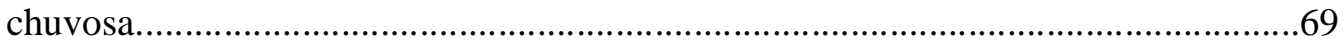

Figura 28: Padrão de uso de substratos do grupo $\mathrm{CH}$ por classe de sexo e

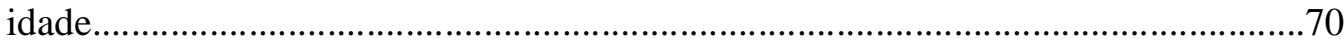

Figura 29: Proporção de tempo de exploração de diferentes fisionomias pelo grupo $\mathrm{CH}$ entre fevereiro de 2007 e abril de 2008

Figura 30: Proporção de tempo de exploração de diferentes fisionomias pelo grupo $\mathrm{CH}$

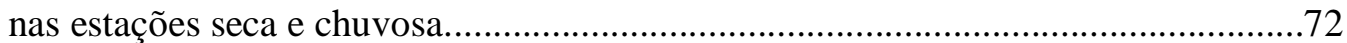

Figura 31: Dieta do grupo ZA entre maio de 2006 e abril de 2008...............................74

Figura 32: Dieta do grupo ZA nas estações seca e chuvosa............................................75

Figura 33: Proporção de itens alimentares com distribuição discreta e dispersa consumidos pelo grupo ZA entre maio de 2006 e abril de 2008.................................75

Figura 34: Dieta do grupo ZA nos períodos da manhã, meio do dia e tarde....................76

Figura 35: Dieta de machos e fêmeas do grupo ZA...........................................................

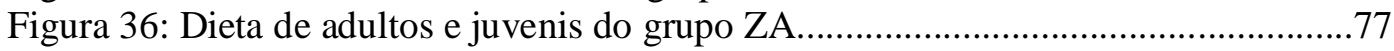

Figura 37: Dieta do grupo ZA por classe de sexo e idade...........................................78

Figura 38: Dieta do grupo CH entre fevereiro de 2007 e abril de 2008.........................79

Figura 39: Dieta do grupo $\mathrm{CH}$ nas estações seca e chuvosa..........................................80

Figura 40: Proporção de itens alimentares com distribuição discreta e dispersa consumidos pelo grupo $\mathrm{CH}$ entre fevereiro de 2007 e abril de 2008 ..........................80

Figura 41: Dieta do grupo $\mathrm{CH}$ nos períodos da manhã, meio do dia e tarde...................81

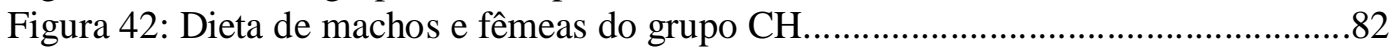

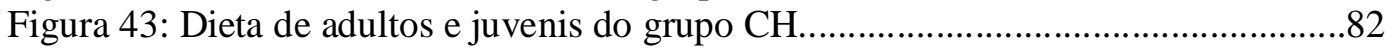

Figura 44: Dieta dos indivíduos do grupo $\mathrm{CH}$ por sexo e idade...................................83 
CAPÍTULO III - Socioecologia de macacos-prego selvagens (Cebus libidinosus) em área de ecótono Cerrado/Caatinga no Piauí: o efeito do uso de ferramentas nas relações sociais de fêmeas

Figura 1: A- Palmeira da espécie catulé. B- Cacho de cocos da palmeira tucum. CCacho de coco da palmeira catulé (Fotos: Eduardo D. R. da Silva e Noemi Spagnoletti).... 126

Figura 2: A- Sítio de quebra utilizado pelos macacos-prego da BV (bigorna de madeira e martelo de siltito). B- Sítio de quebra no chão do morro com restos de fruto de caroba. C- Coco da palmeira catulé, recurso processado com auxílio de ferramentas para extração do endosperma pelos animais da BV (Fotos: Eduardo D. R. da Silva e Noemi Spagnoletti)..... 126

Figura 3: Macho adulto (Chicão) utilizando pedras (como martelo e bigorna) para quebrar cocos. Ao lado, o juvenil, Tucum, observa a execução da tarefa (Foto: Luciano Candisani).

Figura 4: Dieta de fêmeas adultas do grupo ZA nas estações seca e chuvosa (média e desvio padrão).

Figura 5: Dieta de fêmeas adultas do grupo $\mathrm{CH}$ nas estações seca e

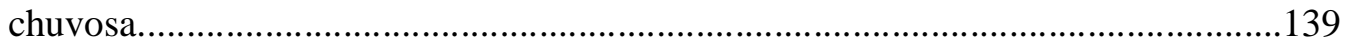

Figura 6: Comparação da dieta de fêmeas adultas do grupo ZA e CH entre o período de fevereiro de 2007 e abril de 2008. 140

Figura 7: Tempo médio de depleção (em minutos) de fontes com distribuição discreta exploradas pelo grupo ZA nas estações seca e chuvosa.

Figura 8: Tamanho médio das unidades de alimentação (número de indivíduos) em fontes com distribuição discreta exploradas pelo grupo ZA nas estações seca e chuvosa. 143

Figura 9: Tempo médio de depleção (em minutos) de fontes com distribuição discreta exploradas pelo grupo $\mathrm{CH}$ durante as estações seca e chuvosa................................147

Figura 10: Tamanho médio das unidades de alimentação (número de indivíduos) de fontes com discretas exploradas pelo grupo $\mathrm{CH}$ durante as estações seca e chuvosa.

Figura 11: Contexto (em porcentagem) das interações agressivas entre membros do grupo ZA

Figura 12: Proporção (em porcentagem) das disputas alimentares por tipo de recurso no grupo ZA.

Figura 13: Proporção (em porcentagem) das disputas por diferentes tipos de alimentos protagonizadas por fêmeas do grupo ZA.

Figura 14: Contexto (em porcentagem) das interações agressivas entre membros do grupo $\mathrm{CH}$. 155

Figura 15: Proporção (em porcentagem) das disputas alimentares por tipo de recurso no grupo $\mathrm{CH}$......

Figura 16: Proporção (em porcentagem) das disputas por diferentes tipos de alimentos protagonizadas por fêmeas do grupo $\mathrm{CH}$. 156

Figura 17: Distâncias médias (em metros) percorridas diariamente pelos grupos ZA e $\mathrm{CH}$ entre o período de janeiro de 2007 e abril de 2008 160

Figura 18: Árvore de Dominância entre as fêmeas do grupo ZA. Indivíduos dominantes originam as setas que atingem os subordinados.

Figura 19: Árvore de Dominância entre as fêmeas do grupo CH. Indivíduos dominantes originam as setas que atingem os subordinados.... 165 


\section{ÍNDICE DE TABELAS}

\section{CAPÍTULO I - Introdução geral}

Tabela 1: Relação dos indivíduos do grupo Zangado durante o período de estudo

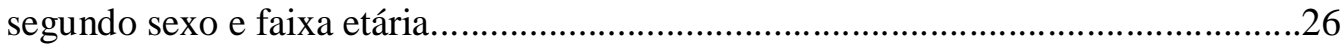

Tabela 2: Relação dos indivíduos do grupo Chicão durante o período de janeiro a março de 2008 segundo sexo, faixa etária e comentários.

CAPÍTULO II - Padrão de atividades e dieta de uma população de macacos-prego selvagens (Cebus libidinosus), que utiliza ferramentas, em área de ecótono Cerrado/Caatinga no Piauí.

Tabela 1: Abundancia de seis espécies de palmeiras na Boa Vista

Tabela 2: Horas de observação direta, número de dias e dias completos de observação e quantidade amostras de varredura coletadas para os grupos $\mathrm{ZA}$ e $\mathrm{CH}$ a cada mês de pesquisa.

Tabela 3: Comparação do orçamento de atividades (porcentagem das amostras de varredura e desvio padrão) dos grupos ZA e CH para todo período de estudo e para as estações seca e chuvosa.

Tabela 4: Comparação do orçamento de atividades (porcentagem das amostras de varredura e desvio padrão) dos grupos $\mathrm{ZA}$ e $\mathrm{CH}$ em três períodos do dia.

Tabela 5: Comparação entre os grupos ZA e $\mathrm{CH}$ quanto à proporção de tempo (porcentagem das amostras de varredura e desvio padrão) despendida nos diferentes tipos de substratos.

Tabela 6: Comparação da exploração das diferentes fisionomias (porcentagem das amostras de varredura e desvio padrão) pelos grupos ZA e $\mathrm{CH}$ durante as estações seca e chuvosa.

Tabela 7: Comparação da dieta (porcentagem das amostras de varredura de alimentação e desvio padrão) dos grupos ZA e $\mathrm{CH}$ durante as estações seca e

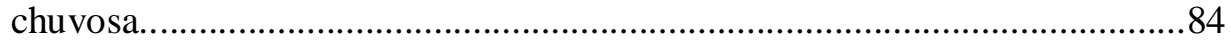

Tabela 8: Orçamento de atividades (em porcentagem) de diferentes populações e

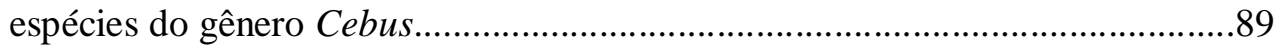

Tabela 9: Relação dos itens alimentares (em porcentagem) consumidos por diferentes populações e espécies do gênero Cebus.

\section{CAPÍTULO III - Socioecologia de macacos-prego selvagens (Cebus libidinosus) em área de ecótono Cerrado/Caatinga no Piauí: o efeito do uso de ferramentas nas relações sociais de fêmeas.}

Tabela 1: Relação das famílias botânicas exploradas pelo grupo ZA nos episódios de alimentação em fontes discretas (fruteiras e palmeiras)................................141

Tabela 2: Relação dos itens alimentares explorados durante episódios de uso de bigornas no grupo ZA 
Tabela 3: Discriminação do tempo médio de depleção e tamanho médio das unidades de alimentação no grupo ZA para sete itens alimentares com distribuição discreta no ambiente. 145

Tabela 4: Relação das famílias botânicas exploradas pelo grupo $\mathrm{CH}$ nos episódios de alimentação em fontes discretas (fruteiras e palmeiras). 146

Tabela 5: Tempo médio de depleção e tamanho médio das unidades de alimentação no grupo $\mathrm{CH}$, para sete itens alimentares com distribuição discreta no

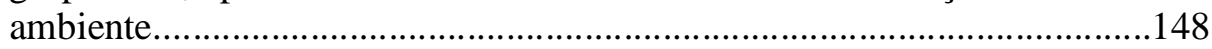

Tabela 6: Comparação entre os grupos ZA e CH quanto ao tempo médio de depleção e ao tamanho médio das unidades de alimentação em fontes discretas durante todo o período e nas estações seca e chuvosa.

Tabela 7- Proporção (em porcentagem) de conflitos agonísticos entre classes de sexo e idade no grupo ZA.

Tabela 8- Proporção (em porcentagem) de conflitos agonísticos entre classes de sexo e

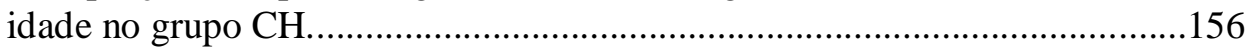

Tabela 9: IM médio e PCIM médio de fontes discretas exploradas pelos grupos ZA e $\mathrm{CH}$ durante todo o período de pesquisa e durante as estações seca e chuvosa.

Tabela 10: Tamanho médio ( \pm DP) da área explorada mensalmente (em hectares) pelos grupos ZA e CH durante as estações seca e chuvosa................................162 


\section{RESUMO}

VERDERANE, M.P. Socioecologia de macacos-prego (Cebus libidinosus) em área de ecótono Cerrado/Caatinga. São Paulo, 2010. - Tese de doutorado apresentada ao Instituto de Psicologia da Universidade de São Paulo.

Os primatas exibem uma grande diversidade de sistemas sociais e a socioecologia propõe uma abordagem para o estudo da evolução dessa diversidade, através da análise das relações entre comportamento social, ecologia e dinâmica de populações. Primatas do gênero Cebus exibem vasta distribuição geográfica e grande flexibilidade alimentar e comportamental e, portanto, são modelos ideais para o teste das previsões dos modelos. Além disso, algumas populações exibem o uso espontâneo de ferramentas para processar alimentos. Embora seja reconhecido que o uso de ferramentas pode alterar as características de recursos alimentares, o impacto dessa técnica nunca foi incorporado às previsões dos modelos socioecológicos. Os objetivos deste trabalho foram (1) estudar as relações sociais de fêmeas de uma população selvagem de Cebus libidinosus, que utiliza ferramentas, em área de ecótono Cerrado/Caatinga, à luz dos modelos socioecológicos, investigando se o uso de ferramentas afeta o padrão das relações estabelecidas entre elas, e (2) estudar o orçamento de atividades, a dieta e o uso de substratos, avaliando se fatores ecológicos afetam o tempo de atividades e a dieta desses animais. Esta pesquisa foi realizada na Fazenda Boa Vista (BV), localizada no município de Gilbués, ao Sul do estado do Piauí. Foram estudados dois grupos de macacos ( $\mathrm{ZA} \mathrm{e} \mathrm{CH})$, entre maio de 2006 e abril de 2008. Os resultados mostram que a oferta de alimento na BV não sofreu variação ao longo desta pesquisa, assim como o orçamento de atividades dos animais. Frutos e invertebrados foram os principais alimentos consumidos pelos macacos, enquanto recursos obtidos com ferramentas foram pouco representativos na dieta. Diferenças sexuais no padrão de atividades e dieta sugerem que as fêmeas possuem uma demanda energética maior e/ou que são forrageadoras menos eficientes do que os machos, enquanto as diferenças entre faixas etárias indicam que os juvenis são forrageadores menos eficientes do que os adultos. Frutos, que são recursos de alta qualidade nutricional, discretamente distribuídos no ambiente e usurpáveis, foram o principal alimento das fêmeas, e o tamanho das fontes alimentares discretas variou entre intermediário e grande. O sistema social da população de estudo correspondeu ao padrão Residente-Nepotista-Tolerante (filopatria de fêmeas, formação de hierarquia de dominância linear e estável, relações de catação e coalizão entre fêmeas), corroborando a previsão dos modelos para primatas que se alimentam de recursos de alto valor energético, com distribuição discreta e usurpáveis, e que estão submetidas a forte competição direta intra e entre grupos por alimento. O padrão de atividades, a dieta, o uso de substratos e a estrutura social de C. libidinosus da BV foram semelhantes ao padrão encontrado para algumas populações de Cebus que não utilizam ferramentas, indicando que o uso desses artefatos não alterou significativamente o tempo de atividades e a dieta dos animais da $\mathrm{BV}$, nem os regimes competitivos e a dinâmica das relações entre fêmeas. Contudo, é possível que o impacto do uso de ferramentas sobre esses aspectos comportamentais seja mais evidente em populações que dependam prioritariamente de alimentos extraídos com ferramentas.

Palavras-chave: Socioecologia, uso de ferramentas, orçamento de atividades, dieta, relações sociais de fêmeas, sistemas sociais de primatas, macaco-prego, Cebus libidinosus. 


\section{ABSTRACT}

VERDERANE, M.P. Socioecology of bearded capuchin monkeys (Cebus libidinosus) in an area of ecotone Cerrado/Caatinga. São Paulo, 2010. - Doctoral thesis presented to the Psychology Institute of the University of São Paulo.

Primates exhibit a wide diversity of social systems. Socioecology proposes an approach for studying the evolution of this diversity, by analyzing the relationship between social behavior, ecology and population dynamics. Primates of the genus Cebus exhibit a wide geographic distribution and a related diet and behavioral flexibility, thus are ideal for testing predictions from the socioecological model. In addition, some populations exhibit the spontaneous use of tools for processing food. Although it is recognized that the use of tools may change the characteristics of food resources, the impact of this technique was never incorporated into the predictions of socioecological models. Our aims were (1) to study the social relationships of females of a wild tool using population of Cebus libidinosus, in an area of ecotone Cerrado/Caatinga, in the light of socioecological models, investigating whether the use of tools affects the pattern of females social relationships, and (2) to study the activity budget, diet and substrate use, assessing whether ecological factors affect these behavioural patterns of the animals. This research was conducted at Fazenda Boa Vista (BV), located in the municipality of Gilbués, south of Piauí state. We studied two groups of monkeys (ZA and $\mathrm{CH}$ ), between May 2006 and April 2008. The results show that the amount of available food did not change in BV during the research period, as well as the activity budget of the animals. Fruits and invertebrates were the main foods eaten by the monkeys, while foods obtained with the aid of tools represented a small proportion of their diet. Sex differences in diet and activity patterns suggest that females have a higher energy demand and/or are less efficient foragers than males, while the differences between age groups indicate that juveniles are less efficient foragers than adults. Fruits, which are a high quality, patchily distributed and usurpable food resource, were the main food for females, and the size of patchy food sources ranged from intermediate to large. The social system of the study population corresponded to the standard Resident-nepotistictolerant (philopatry of females, linear dominance hierarchy and stable relations of grooming and coalition between females), supporting the models' predictions for primates that feed on high quality, patchily distributed and usurpable food resources, and are subject to strong direct competition within and between groups for food. The pattern of activities, diet, substrate use and the social structure of $C$. libidinosus at BV were similar to the pattern found in some populations of Cebus that do not use tools, indicating that the use of these artifacts did not significantly alter the activity period and the diet of animals in the BV or the competitive regimes and the dynamics of relations between females. However, it is possible that the impact of using tools on behavioral aspects is most evident in populations that depend primarily on foods extracted with the aid of tools.

Keywords: socioecology, tool use, activity budget, diet, female social relationships, primates social systems, capuchin monkeys, Cebus libidinosus. 


\section{APRESENTAÇÃO}

Minha pesquisa de doutorado é um dos frutos da parceria entre o Laboratório de Etologia Cognitiva (LEC), do Departamento de Psicologia Experimental da Universidade de São Paulo, e do projeto de colaboração internacional, EthoCebus. Sob a supervisão dos professores doutores Eduardo B. Ottoni e Patrícia Izar, o LEC desenvolve pesquisas na área de comportamento e cognição animal, com ênfase na investigação comparativa do uso de ferramentas, ecologia e comportamento social de macacos-prego (Cebus spp). O EthoCebus, iniciado em 2005 por Dorothy Fragaszy, Elisabetta Visalberghi, Patrícia Izar e Eduardo B. Ottoni, é um projeto colaborativo entre a Universidade de São Paulo, a Universidade da Geórgia (EUA) e o Instituto de Ciência e Tecnologia da Cognição (Roma, Itália). Desde 2005, a equipe de pesquisadores do EthoCebus desenvolve estudos sobre comportamento e ecologia de uma população selvagem de macacos-prego (Cebus libidinosus) no sul do Piauí, em área de ecótono Cerrado/Caatinga, com ênfase na investigação do uso espontâneo de ferramentas.

O projeto EthoCebus viabilizou a execução desta pesquisa de doutorado, que teve por objetivo analisar as relações sociais entre fêmeas da população de Cebus libidinosus à luz da perspectiva socioecológica, incorporando o impacto do uso de ferramentas às previsões dos modelos socioecológicos. Este estudo também permitiu caracterizar a área de estudo quanto à oferta de recursos alimentares, e investigar o padrão de atividades, dieta e uso de substrato.

Este é o primeiro estudo a apresentar dados sobre orçamento de atividades, dieta e socioecologia de uma população selvagem de C. libidinosus em área de ecótono Cerrado/Caatinga, bem como o primeiro a testar as previsões dos modelos 
socioecológicos usando dados de uma espécie de primata do Novo Mundo que utiliza ferramentas. Por este motivo, está também inserido no escopo das pesquisas coordenadas pela minha orientadora, junto ao LEC, cujo objetivo é investigar a relação entre flexibilidade comportamental e variabilidade de características ecológicas das áreas ocupadas por diferentes populações de Cebus spp.

Minha tese de doutorado é resultado desta pesquisa. A tese está organizada na forma de três capítulos, explicitados a seguir: I) Introdução geral e descrição da área e dos grupos de estudo; II) Padrão de atividades e dieta de uma população de macacosprego selvagens (Cebus libidinosus), que utiliza ferramentas, em área de ecótono Cerrado/Caatinga no Piauí; III) Socioecologia de macacos-prego selvagens (Cebus libidinosus) em área de ecótono Cerrado/Caatinga no Piauí: o efeito do uso de ferramentas nas relações sociais de fêmeas. Os Capítulos II e III são apresentados no formato de manuscrito, com introdução, objetivos, metodologia, resultados, discussão e conclusão. As referências bibliográficas dos três capítulos estão apresentadas no final da dissertação. 


\section{CAPÍTULO I: Introdução geral}




\section{1-INTRODUÇÃO}

\subsection{Socioecologia de primatas}

O sistema social de primatas pode ser definido como o conjunto das relações entre animais co-específicos que interagem regularmente e o fazem mais entre si do que com membros de outra sociedade. Existem três elementos distintos e inerentes ao sistema social de primatas: organização social, sistema de acasalamento e estrutura social (Kappeler \& van Schaik, 2002). A organização social diz respeito ao tamanho, composição por classe de sexo e idade e a coesão espaço-temporal de uma unidade social. O sistema de acasalamento possui um componente social, que se refere ao padrão de acasalamento da sociedade, e um componente genético, que se refere às conseqüências reprodutivas do padrão de acasalamento. A estrutura social abarca o padrão de interação social entre membros de uma sociedade e os relacionamentos resultantes dessas interações (Kappeler \& van Schaik, op cit).

Os sistemas sociais de primatas não humanos são extremamente diversificados. Quanto à organização social, há, por exemplo, um grande número de espécies em que os indivíduos de um mesmo grupo social permanecem quase o tempo todo juntos, durante todas as atividades do grupo, como é o caso dos micos-de-cheiro (Saimiri spp: Baldwin \& Baldwin, 1972) e os gorilas (Gorilla gorilla: Stewart \& Harcourt, 1987). Em outras, o grupo social pode dividir-se em subgrupos menores durante o dia ou ao longo de vários dias para, por exemplo, forragear ou patrulhar o território, como no caso dos muriquis (Brachyteles arachnoides: Nishimura et al., 1988) e dos chimpanzés (Pan paniscus: Nishida \& Hiraiwa-Hasegawa, 1987). Ainda, há espécies consideradas solitárias, em que os indivíduos reúnem-se apenas ocasionalmente para a realização de algumas atividades, por exemplo, para dormirem ou acasalarem, como no caso da maioria dos 
prossímios noturnos (família Lorisidae: Bearder, 1987; Kappeler \& van Schaik, 2002) e dos orangotangos (Pongo pygmaeus: Rodman \& Mitani, 1987).

Outra fonte de variação dos sistemas sociais de primatas é o sistema de acasalamento (Kappeler \& van Schaik, 2002). Algumas espécies são monogâmicas, ou seja, machos e fêmeas acasalam, normalmente, com apenas um indivíduo do sexo oposto, como é o caso dos gibões (Hylobates sp: Reichard, 2003) e dos macacos-danoite (Aotus sp: Garber \& Leigh, 1997). Em outras espécies, como os sagüis-de-carasuja (Saguinus fuscicollis: Terborgh \& Goldizen, 1985; Goldizen, 1987a), o sistema de acasalamento é poliândrico, isso significa que uma fêmea acasala com vários machos e cada um deles acasala apenas com essa fêmea. Existem, ainda, várias formas de poliginia: (1) poliginia espacial, em que um macho controla o acesso a várias fêmeas sexualmente receptivas através da defesa agressiva do território ocupado por elas (também conhecida como harém disperso, é considerada o principal sistema de acasalamento de primatas solitários; Bearder, 1987); (2) competição poligínica indireta, em que machos percorrem grandes distâncias à procura de fêmeas receptivas e desertam ao término da cópula, à procura de outras fêmeas receptivas (p. ex., Mirza coquereli: Kapeller, 1997b); (3) poliginia uni-macho, um único macho defende o acesso exclusivo à cópula em um grupo de fêmeas (também conhecida como harém, ocorre em espécies como o gorila; Harcourt, 1981) e (4) poliginia multi-macho, vários machos defendem um grupo de fêmeas, na maioria das espécies resulta em um pronunciado viés na taxa de sucesso reprodutivo dos machos em função da posição de dominância (p. ex., Ateles spp: Robinson \& Janson, 1987).

Além da grande diversidade de padrões de organização social e de sistemas de acasalamento, os sistemas sociais de primatas não humanos também variam quanto ao padrão de migração dos indivíduos entre grupos e quanto à estrutura social, com 
diferenças quantitativas e qualitativas nas interações estabelecidas entre os indivíduos de um grupo social. Toda essa variação ocorre não apenas entre espécies distintas, mas pode ser observada entre diferentes populações de uma mesma espécie e entre grupos de uma mesma população (Kappeler \& van Schaik, 2002).

Uma abordagem para o estudo da diversidade de sistemas sociais de primatas é a socioecologia, que analisa as relações entre comportamento social, ecologia e dinâmica de populações. Os primeiros trabalhos a analisar a evolução dos sistemas sociais dos primatas buscavam correlações entre variáveis ecológicas e características dos grupos, tais como habitat, tipo de dieta e tamanho do grupo. Essas correlações eram utilizadas para explicar as funções adaptativas da vida em grupo. Com essa perspectiva, Crook \& Gartland (1966) concluíram que o aumento no tamanho do grupo em muitas espécies de primatas era uma resposta à presença de predadores, já que grupos grandes eram freqüentemente encontrados em ambientes abertos, onde o risco de predação é maior. Contudo, o acúmulo de informações acerca do ciclo de vida de primatas selvagens revelou muitas exceções a esse tipo de correlação. Essas análises, além de considerarem machos e fêmeas conjuntamente, não forneciam explicações satisfatórias para as diferenças específicas no padrão de migração dos primatas (Wrangham, 1980). A socioecologia moderna busca elaborar modelos que permitam explicar a evolução dos diferentes sistemas sociais dos primatas (van Hoof \& van Schaik, 1992).

De uma maneira geral, a premissa central a todos os modelos socioecológicos é que as características do recurso alimentar (como, qualidade, distribuição e abundância) afetam o regime de competição por alimento ao qual fêmeas primatas estão submetidas. O regime de competição por alimento, por sua vez, afeta o padrão de relacionamento social estabelecido entre as fêmeas (Wrangham, 1980; van Schaik, 1989; Isbell, 1991; Sterck et al., 1997). Essa premissa baseia-se no conceito de investimento parental 
proposto por Trivers (1972), de que o sucesso reprodutivo do sexo que investe mais na prole é limitado pelo acesso a recursos, enquanto o sucesso reprodutivo do sexo que investe menos é limitado pelo acesso ao sexo que investe mais. Fêmeas produzem óvulos, gametas grandes e ricos em nutrientes necessários ao desenvolvimento do feto, cujo custo de produção é muito maior comparado ao de espermatozóides, gametas masculinos, que são pequenos e carregam apenas o material genético. Entre os mamíferos, além do custo diferencial associado à produção de gametas, as fêmeas também arcam com os custos da gestação e da nutrição pós-parto dos filhotes através do aleitamento. A lactação é considerada a forma mais dispendiosa de investimento materno; calcula-se que fêmeas primatas aumentam suas demandas energéticas em 20 a $50 \%$ durante esse período (Nicolson, 1987). Por fim, os primatas fazem parte de um seleto grupo de mamíferos que exibem transporte extensivo de infantes (Ross, 2001). Na maioria das espécies, os filhotes são carregados junto ao corpo durante o dia inteiro e, salvo algumas exceções em que a ajuda de alocuidadores é fundamental para a sobrevivência dos filhotes (Callithrichidae: Monteiro da Cruz, 1998; Schradin \& Anzenberger, 2001), essa tarefa é executada essencialmente pelas mães. O transporte do filhote não impõe à fêmea um custo energético tão alto quanto a lactação, mas, ainda assim, é uma forma muito custosa de investimento parental (Nicolson, 1987).

Em função dos custos associados à produção de gametas, gestação e ao cuidado pós-natal dos filhotes, na maior parte das espécies de primatas, a capacidade reprodutiva das fêmeas é limitada pela obtenção de alimento (van Schaik, 1989). Já os machos maximizam sua aptidão copulando com o maior número de fêmeas, portanto, sua capacidade reprodutiva é limitada pela disponibilidade de fêmeas. Sendo assim, os modelos socioecológicos consideram que a distribuição de fêmeas ocorre em função da disponibilidade de alimento no ambiente, enquanto a distribuição de machos ocorre em 
função da disponibilidade de fêmeas. É por essa razão que os modelos enfocam a influência da competição por alimento entre fêmeas sobre as relações sociais estabelecidas entre elas (Wrangham, 1980; van Schaik, 1989; Isbell, 1991; Sterck et al., 1997).

O primeiro modelo socioecológico foi elaborado por Wrangham (1980) e considera as vantagens de forrageamento em grupo (aumento da habilidade competitiva e partilha de informação sobre localização e qualidade de fontes alimentares) como a principal pressão seletiva para a vida social em primatas. Por essa abordagem, a qualidade e a distribuição dos recursos alimentares no ambiente determinam o tipo de sistema social dos primatas, que foi classificado dicotomicamente em female-bonded e non female-bonded. Quando o principal recurso alimentar é de alta qualidade e distribuído em manchas discretas, as fêmeas deverão ser filopátricas e estabelecer fortes relações afiliativas entre si, já que a cooperação entre fêmeas aparentadas aumenta as chances de vencer disputas alimentares com outros grupos e, conseqüentemente, a aptidão abrangente (padrão female-bonded). Por outro lado, quando o principal recurso alimentar é de baixa qualidade e uniformemente distribuído no ambiente, haverá pouca ou nenhuma competição entre grupos por alimento, levando as fêmeas a se transferirem do seu grupo natal para evitar competir com fêmeas aparentadas (padrão non femalebonded).

Com o aumento de trabalhos de campo com primatas selvagens veio, também, a constatação de que a simples dicotomia entre female-bonded e non female-bonded não era suficiente para abarcar toda a diversidade de sistemas sociais observadas entre os primatas atuais (van Schaik, 1989). A segunda geração de modelos, elaborada por dois grupos de pesquisadores trabalhando independentemente, modificou o modelo inicial 
proposto por Wrangham para incorporar mais complexidade nas relações entre competição por alimento e relacionamento social de fêmeas.

O modelo proposto por van Schaik (1989) difere essencialmente do modelo de Wrangham porque considera o risco de predação como maior pressão seletiva para socialidade de primatas. Para van Schaik, as fêmeas primatas só enfrentariam os custos da competição intra-grupo por alimento (considerado o maior custo da socialidade em primatas) se esses fossem superados pelas vantagens obtidas através da redução da pressão de predação. Esse modelo também diferencia a competição por alimento em direta e indireta, que podem ocorrer intra e entre grupos (Janson \& van Schaik, 1988), dependendo da qualidade e distribuição dos principais recursos alimentares (uma descrição detalhada dos tipos de competição por alimento encontra-se no Capítulo III). Van Schaik pontua que, num ambiente onde o risco de predação é baixo, a densidade populacional deve ser alta e a competição entre grupos deve predominar. Por outro lado, quando a pressão de predação é elevada, os grupos sociais devem ser mais coesos e a competição intra-grupo torna-se mais importante. Por esse modelo, o tipo e a intensidade de competição por alimento a que fêmeas primatas estão submetidas devem levar a quatro tipos de sistemas sociais, ou síndromes sociais. Posteriormente, em 1997, Sterck e colaboradores estenderam o modelo de van Schaik e nomearam as quatro síndromes sociais (referidas no modelo anterior como A, B, C e D) como: (1) Dispersor-Igualitário (Dispersal-Egalitarian): quando a competição direta intra e entre grupos é fraca ou inexistente. Nessa situação, as fêmeas obtêm poucas vantagens com o estabelecimento de relações de dominância fortes e decididas e com a formação de coalizões nepotistas ou mutualísticas para competir por alimento ou postos de dominância. Conseqüentemente, estabelecem relações igualitárias entre si (sem hierarquia de dominância formal) e dispersam de seu grupo natal, já que não perdem 
parceiros de coalizão, nem enfrentam resistência para imigrarem para outro grupo; (2) Residente-Igualitário (Resident-Egalitarian): quando a competição direta intra-grupo é fraca e a competição direta entre grupos é forte. Como resultado da fraca competição intra-grupo, as fêmeas não estabelecem relações de dominância e a formação de coalizões torna-se pouco importante. Contudo, como a competição entre grupos é forte, as fêmeas permanecem no seu grupo natal para ajudar os parentes em disputas com outros grupos; (3) Residente-Nepotista (Resident-Nepotistic): quando a competição direta intra-grupo é forte e a competição direta entre grupos é fraca. As fêmeas formam hierarquia de dominância linear, nepotista e despótica, com relações agonísticos bem decididas (em que um indivíduo ganha e o outro perde consistentemente), e formam alianças de longa duração entre fêmeas aparentadas e coalizões mutualísticas entre fêmeas não aparentadas. As fêmeas permanecem em seus grupos natais porque, ao tentarem se transferir, perderiam acesso a aliados importantes e, provavelmente, enfrentariam forte resistência para imigração por parte de fêmeas de outros grupos; (4) Residente-Nepotista-Tolerante (Resident-Nepotistic-Tolerant): quando a competição direta intra e entre grupos é forte. As fêmeas permanecem em seus grupos natais e formam hierarquia de dominância linear, nepotista, mantidas através de coalizões. Entretanto, como a competição entre grupos também é forte, as fêmeas dominantes devem ser tolerantes com as subordinadas (permitindo que elas tenham acesso regular a recursos alimentares importantes e a parceiros sociais - van Schaik, 1989), prevenindo, assim, a perda de apoio em disputas entre grupos.

O modelo de Sterck et al. (1997) também incorpora os efeitos do comportamento de machos (como a coerção sexual e o infanticídio), da saturação do ambiente e dos custos associados à dispersão sobre o padrão de relações sociais de fêmeas primatas. 
O modelo elaborado por Isbell (1991) difere dos modelos de van Schaik (1989) e Sterck et al. (1997) porque considera que a abundância e distribuição do principal recurso alimentar é suficiente para determinar as relações sociais entre fêmeas (a influência do risco de predação é apenas indireta) e que a competição direta e indireta por alimento co-variam intra e entre grupos. Essa abordagem prevê três tipos de sistemas sociais: (1) forte competição direta e indireta por alimento, tanto intra quanto entre grupos resulta em filopatria de fêmeas, com estabelecimento de hierarquias de dominância lineares e estáveis e formação de coalizões (corresponde ao padrão femalebonded proposto por Wrangham); (2) competição direta e indireta por alimento entre grupos e fraca competição direta e indireta intra-grupo resulta em filopatria de fêmeas, porém, com hierarquias de dominância instáveis e não-lineares e (3) fraca competição direta e indireta por alimento intra e entre grupos resulta em dispersão de fêmeas e hierarquias de dominância instáveis e não-lineares (corresponde ao padrão non-femalebonded proposto por Wrangham).

O modelo de Isbell (1991) trouxe grandes contribuições metodológicas para o estudo da socioecologia de primatas, especificamente por determinar os indicadores comportamentais de competição indireta intra e entre grupos. Não obstante, atualmente, considera-se que o modelo elaborado por Sterck et al. (1997) é o que melhor explica a relação entre variáveis ecológicas e sistemas sociais dos primatas (Snaith \& Chapman, 2007).

De acordo com Isbell e Young (2002), trabalhos que testem os modelos socioecológicos precisam analisar dados quantitativos sobre risco de predação, características dos recursos alimentares (como o padrão de distribuição e o tempo de depleção das fontes alimentares), indicadores comportamentais de competição por alimento intra e entre grupos (como taxa de interação agressiva intra e entre grupos, 
distâncias percorridas diariamente e tamanho da área de uso) e padrão de relações sociais estabelecidas entre fêmeas de uma população de primatas (como catação, hierarquia de dominância e coalizão). Para analisar as características dos recursos alimentares e os indicadores comportamentais de competição por alimento é preciso, antes de tudo, identificar os alimentos que compõem a dieta de uma população, bem como o padrão de atividades e a reação dos animais em face a flutuações sazonais que afetem as características do habitat (como disponibilidade de alimentos no tempo e espaço, temperatura e pluviosidade). Desta forma, o estudo do orçamento de atividades e da dieta dos animais é fundamental à pesquisas almejam analisar as relações sociais de primatas à luz da abordagem socioecológica.

\subsection{O gênero Cebus}

\subsubsection{Taxonomia, morfologia e distribuição.}

Os macacos do gênero Cebus pertencem à ordem dos Primatas, família Cebidae, sendo classificados junto com os micos-de-cheiro (Saimiri spp) na subfamília Cebinae (Rylands et al., 2000). O gênero Cebus é dividido em dois subgrupos, com base na presença e ausência de tufos na cabeça (Hershkovitz, 1949): (1) o grupo "sem topete" (popularmente conhecidos como caiararas), composto pelas espécies $C$. capucinus, $C$. olivaceus e C. albifrons, e (2) o grupo "com topete", constituído, até 2001, por uma única espécie (Cebus apella), popularmente chamada de macaco-prego. Devido à grande variabilidade fenotípica (p. ex., diferenças consideráveis são observadas entre os indivíduos de uma mesma região e, até mesmo, de um mesmo grupo social - Fragaszy et al., 2004a), a classificação das diversas formas representantes do gênero Cebus permanece, até hoje, como um dos maiores desafios taxonômicos em primatologia. Em uma revisão taxonômica, Groves (2001) utilizou atributos morfológicos para propor um 
novo arranjo taxonômico para o gênero Cebus, com a inclusão da espécie C. kaapori no grupo dos caiararas (sem topete), e a elevação de três sub-espécies de C. apella à categoria de espécie (C. libidinosus, $C$. nigritus e $C$. xanthosternus) no grupo dos macacos-prego (com topete).

O gênero Cebus possui a segunda maior distribuição geográfica dentre os primatas neotropicais (atrás apenas do gênero Alouatta), ocorrendo de Honduras, passando pela Venezuela, Colômbia, Equador, Peru, Bolívia, Guianas e Brasil, até o sudeste do Paraguai e nordeste da Argentina (Fragaszy et al., 2004a; Figura 1). No Brasil ocorrem quase todas as espécies do gênero, com exceção de $C$. capucinus, sendo que as espécies de macacos-prego (com topete) são as que ocupam uma maior diversidade de ambientes, como a região de Floresta Amazônica, Cerrado, Caatinga, matas semi-decíduas e Mata Atlântica, ocorrendo da região norte à região sul do país (Mittermeier \& Coimbra-Filho 1982).

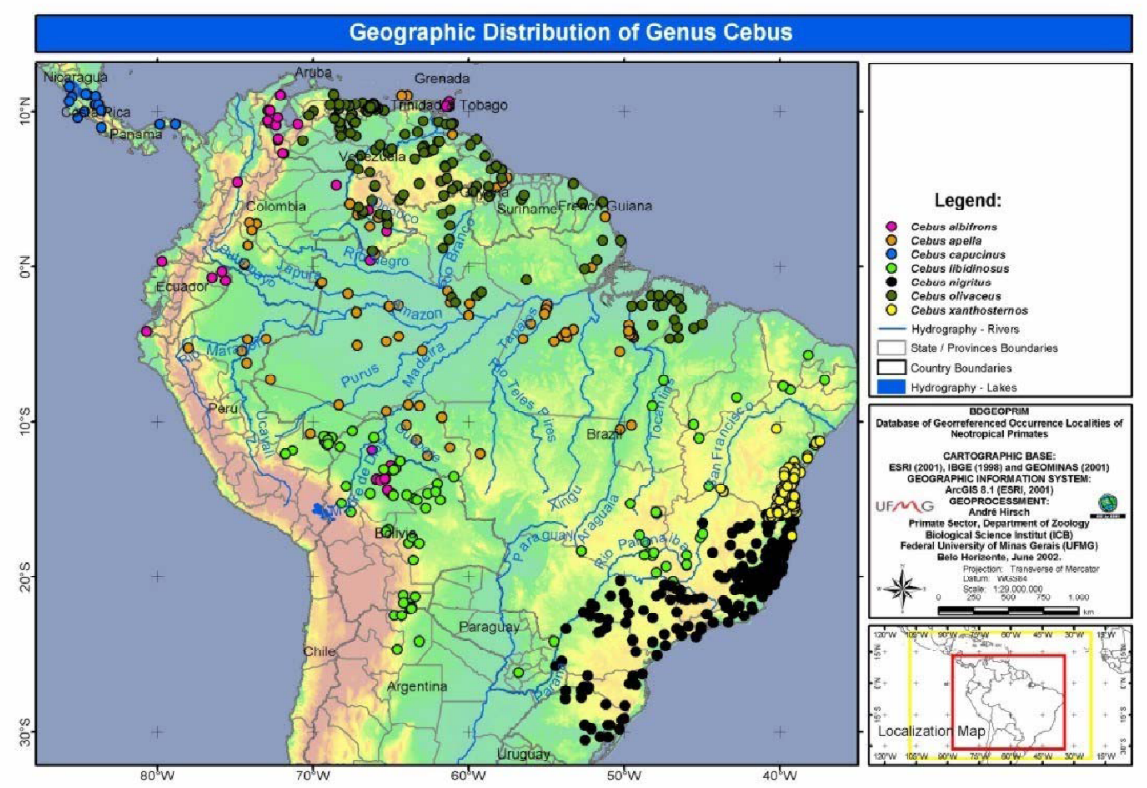

Figura 1: Distribuição geográfica das espécies do gênero Cebus (fonte www.icb.ufmg.br/zoo/primatas/cebus_map.htm). 
Os macacos Cebus são diurnos e preferencialmente arborícolas. Grande parte da sua locomoção se dá através do quadrupedalismo, por saltos e escaladas, porém, bipedalismo e terrestrialidade podem ser facultativos, de acordo com as condições ecológicas encontrados no habitat (Napier \& Napier, 1967). Esses primatas possuem tamanho intermediário (porte médio) e corpo robusto. Há um ligeiro dimorfismo sexual quanto ao tamanho corpóreo, com machos adultos pesando entre 3,6 e 3,9 kg, enquanto fêmeas variam de 2,5 a 3,0 kg (Fleagle, 1999). O comprimento do corpo, da cabeça aos pés, varia de 30 a $56 \mathrm{~cm}$, enquanto a cauda mede de 30 a $50 \mathrm{~cm}$ (Napier \& Napier, 1967). A coloração varia do marrom claro ao amarelo mostarda indo até o preto, de acordo com as diferentes regiões geográficas habitadas. Os ombros e barriga são mais claros que o resto do corpo e, nas espécies com topete, sobre o ouvido estende-se um espesso tufo de pêlos (Napier \& Napier, op cit), característica que dá nome ao grupo. As mãos são preênseis e possuem polegares pseudo-oponíveis e sua cauda é semi-prêensil, permitindo a sustentação do corpo e transporte de objetos por este membro.

\subsubsection{Ciclo de vida}

As espécies do gênero Cebus são caracterizadas por um longo período de vida, desenvolvimento lento e baixa taxa de natalidade. Em cativeiro, há registros de um animal que viveu até os 55 anos (Fragaszy et al., 2004a). Dados sobre populações selvagens ainda são escassos na literatura, mas Robinson (1988a) estimou que os indivíduos de C. olivaceus, em Hato Massaguaral, podem viver, pelo menos, até os 35 anos.

Os infantes de macacos Cebus nascem em um estágio semi-altricial de desenvolvimento, isto é, apresentam o corpo coberto por pêlos, olhos abertos, certa capacidade de locomoção e termo-regulação (Fragaszy et al., 2004a), porém, são 
totalmente dependentes de suas mães e/ou alocuidadores para alimentação, locomoção e defesa contra predadores. O peso dos infantes ao nascimento foi calculado por Fragaszy e Adams-Curtis (1998) em cerca de 9\% do peso das mães. A duração da infância é estimada em 18 meses, quanto ocorre a independência locomotora e alimentar (Di Bitetti \& Janson, 2001a), porém, em cativeiro e em semi-liberdade a independência pode ocorrer um pouco mais cedo, por volta dos 14 meses de vida (Fragaszy \& AdamsCurtis, 1997; Verderane, 2005).

A idade da primeira concepção, quando a fêmea é considerada adulta, varia de indivíduo para indivíduo. Em condições de cativeiro, foi observado que as fêmeas começaram a se reproduzir com idades que variaram de 4 anos e 7 meses até os 6 anos e 6 meses, uma média de 5,2 anos (Fragaszy \& Bard, 1996). Em grupos selvagens, entretanto, é provável que este estágio ocorra mais tarde, entre 6-7 anos de idade. Comumente, uma única fêmea do grupo social entra em estro a cada vez. As fêmeas sexualmente reprodutivas apresentam estro a cada 20-35 dias. São elas que escolhem o macho com quem vão copular, seguindo-o e emitindo vocalizações e expressões faciais especificamente utilizadas nesse contexto. O tempo de gestação é de aproximadamente 149-158 dias e o intervalo entre nascimentos varia de 18 a 22 meses (Fragszy, 1990; Recabarren et al., 2000; Carosi \& Visalberghi, 2002; Fragszy et al., 2004a; Izar et al., 2008). O comportamento materno é caracterizado por interações íntimas entre mãe e filhote (Fragaszy et al., 1991). A tolerância social, de indivíduos adultos em relação aos infantes e juvenis, e o cuidado alomaterno são características proeminentes na espécie do gênero Cebus (Izawa, 1980; Izar, 1994; Baldovino, 2005; Verderane et al., 2005). 


\subsubsection{Socioecologia de macacos-prego}

Macacos-prego (C. apella, C. libidinosus, C. nigritus e C. xanthosternus) são primatas onívoros, que incluem uma grande diversidade de itens alimentares à sua dieta, como polpa de frutos maduros, folhas, brotos, seiva, sementes, néctar, ovos, invertebrados e pequenos vertebrados, como aves e roedores (Galetti \& Pedroni, 1994; Ferreira et al., 2002; Resende et al., 2003; Izar, 2004). O forrageamento é oportunístico, com emprego de técnicas extrativas para obtenção de itens alimentares encapsulados, como larvas de insetos em galhos secos ou ninhos e meristema de palmeiras (Taira et al., 2002; Taira; 2007). Além disso, o macaco-prego exibe um vasto repertório manipulativo e o uso proficiente de ferramentas em laboratório (Visalberghi \& McGrew, 1997) e em semi-liberdade (Ottoni \& Mannu, 2001; Resende, 2004; Ottoni et al., 2005). Recentemente, muitos estudos vêm relatando o uso espontâneo e extensivo de ferramentas (principalmente a utilização de pedras para extração de alimentos encapsulados) em grupos selvagens (Fragaszy et al., 2004b; Visalberghi et al., 2007; Moura \& Lee, 2004; Waga et al., 2006; Ottoni \& Izar, 2008; Mannu \& Ottoni, 2009, Ferreira et al., 2010). Apesar da dieta diversificada, muitos estudos mostram que a maior parte da alimentação desses primatas (cerca de 50-60\%) é constituída por polpa de frutos maduros (Izawa, 1979; Terborgh, 1983; Galetti \& Pedroni, 1994; Peres, 1994; Zhang, 1995; Di Bitetti, 2001; Spironello, 2001; Izar, 2004), um recurso que apresenta uma distribuição discreta no ambiente (Janson, 1990 a e b).

Estudos sobre socioecologia de macacos-prego corroboram as previsões dos modelos socioecológicos para primatas cuja alimentação baseia-se em recursos com distribuição discreta. Os macacos-prego são caracterizados por filopatria de fêmeas, que se organizam em hierarquia de dominância rígida, formam alianças e estabelecem relações de catação, geralmente baseadas em parentesco (Robinson \& Jason, 1987; Izar, 
1994; Parr, 1997; Visalberghi \& McGrew, 1997; Ferreira, 2006). Esses primatas vivem em grupos multi-macho/multi-fêmea, via de regra, estáveis e coesos (Freese \& Oppenheimer, 1981). Em populações selvagens, a composição do grupo social varia de três a trinta indivíduos (Lynch \& Rímoli, 2000), incluindo um a quatro machos adultos, uma a quatro fêmeas adultas (para cada macho adulto) e seus filhos imaturos, ou seja, infantes e juvenis (Janson, 1990a e b; Izawa, 1980).

Embora esse padrão de organização social seja considerado típico de macacosprego, pesquisas recentes em área de Mata Atlântica sugerem que a organização social desses primatas pode ser mais flexível do que concebiam estudos anteriores (Izar, 2004; Nakai, 2007; Alfaro-Lynch, 2007). Por exemplo, Izar (2004) analisou dados sobre risco de predação, distribuição de alimento, regimes competitivos e relacionamento social de fêmeas de um grupo de macacos-prego (C. nigritus), no Parque Estadual Carlos Botelho (PECB), à luz de premissas dos modelos socioecológicos. A autora verificou que os macacos do PEBC alimentam-se em fontes de tamanho pequeno a intermediário, utilizando tanto os recursos de distribuição discreta (frutos) quanto os recursos igualmente distribuídos (bromélias e invertebrados). Ao longo do estudo, houve um período caracterizado por redução severa na oferta de frutos maduros, durante o qual os macacos passaram a utilizar predominantemente os recursos dispersos. Apesar dessa mudança na estratégia de forrageamento, houve uma redução no tamanho do grupo social. A autora concluiu que a mudança na composição da dieta (de recursos discretos para uniformemente distribuídos) não foi suficiente para reduzir os efeitos de competição intra-grupo sobre a energia ingerida per-capita. Como conseqüência do aumento da competição indireta intra-grupo, houve uma divisão permanente do grupo social, e as fêmeas começaram a forragear em pequenos subgrupos, algumas vezes acompanhadas apenas por imaturos. 
A caracterização de um padrão de coesão grupal mais fluído em macacos-prego, com transferência de fêmeas entre grupos (Izar, 2004; Nakai, 2007), é intrigante, já que a organização social multimacho/multifêmea com filopatria de fêmeas é considerada regra para esses primatas. Outros trabalhos, realizados com diferentes populações de $C$. nigritus em áreas de Mata Atlântica, verificaram que o forrageamento em pequenos subgrupos parece ser uma característica comum à espécie (Rímoli, 2001; Alfaro-Lynch, 2007). Uma possível explicação é que a modificação de grupos coesos para grupos com maior grau de fissão (Aureli et al., 2008) seria uma estratégia para lidar com ambientes que podem apresentar déficit drástico na oferta de alimento, como no caso das florestas localizadas no sudeste da área de distribuição dos macacos-prego (Izar, 2004).

Esses trabalhos sugerem que a flexibilidade comportamental de macacos do gênero Cebus, já bem documentada na literatura em relação à dieta (Brown \& Zunino, 1990; Galetti \& Pedroni, 1994) e à utilização de técnicas de forrageamento complexas (Ottoni \& Mannu, 2001; Taira et al., 2002; Fragaszy et al., 2004b; Moura \& Lee, 2004; Ottoni \& Izar, 2008; Mannu \& Ottoni, 2009; Ferreira et al., 2010), estende-se também ao padrão de organização social (Izar \& Ferreira, 2007). A habilidade dos macacosprego em explorar diversos recursos alimentares, não acessíveis a maioria dos outros primatas, é considerada uma das principais causas da ampla distribuição geográfica desses animais e da sua ocorrência em ecossistemas utilizados apenas marginalmente por outras espécies de primatas (Brown \& Zunino; 1990; Fragaszy et al., 2004a). Nesse contexto, é plausível supor que a flexibilidade social desses animais contribua para a ocupação de ambientes diversos, especialmente aqueles que apresentam condições ecológicas adversas, com escassez de água e alimento.

Apesar de apresentar uma ampla distribuição geográfica, ocorrendo em ambientes tão variados como a Floresta Amazônica, Cerrado, Caatinga, matas semi- 
decíduas e Mata Atlântica, a maior parte dos estudos sobre macacos-prego refere-se a populações que habitam florestas (p. ex., Amazônia: Terborgh, 1983; Izawa, 1980; Spironello, 2001; Mata Atlântica: Torres de Assumpção, 1983; Rímoli, 2001; Izar, 2004; Alfaro-Lynch, 2007; Nakai, 2007; e florestas semi-decíduas da América do Sul: Janson, 1985, 1988; Galetti \& Pedroni, 1994). Além disso, raros são os estudos que enfocam a flexibilidade da organização social como um elemento importante para a capacidade de ocupar ambientes distintos (Izar \& Ferreira, 2007). Estudos sobre populações que ocorrem em regiões diferentes das que já foram estudadas, como, por exemplo, em áreas de Cerrado, Caatinga e mangues, são fundamentais para a compreensão da organização social, ecologia e dinâmica dessas populações, bem como para um maior entendimento das capacidades adaptativas de macacos-prego que permitiram a ocupação de uma grande variedade de ambientes.

Este é o primeiro estudo a apresentar dados sobre orçamento de atividades, dieta e socioecologia de uma população selvagem de C. libidinosus em área de ecótono Cerrado/Caatinga, bem como o primeiro a testar as previsões dos modelos socioecológicos usando dados de uma espécie de primata do Novo Mundo que utiliza ferramentas.

\section{2- OBJETIVOS}

Os objetivos deste trabalho foram: (1) caracterizar a área de estudo quanto à oferta de alimentos (abundância de frutos, flores, frutos de palmeiras e invertebrados); (2) estudar o padrão de atividades, a escolha dos substratos e a dieta de uma população selvagem de macacos-prego (Cebus libidinosus), que utiliza ferramentas para obtenção de alimentos, em área de ecótono Cerrado/Caatinga no sul do Piauí; (3) verificar se fatores ambientais, como pluviosidade, temperatura e oferta de recursos alimentares, 
afetam o tempo de atividades e a dieta dos animais, bem como avaliar a contribuição do uso de ferramentas para o forrageamento desses primatas; (4) caracterizar os principais recursos consumidos pelos animais quanto ao tamanho, distribuição e qualidade; (5) avaliar o risco de predação na área de estudo e identificar os regimes de competição por alimento ao quais estão submetidas as fêmeas dessa população; (6) analisar as relações sociais de as fêmeas à luz dos modelos sócio-ecológicos e (7) investigar o(s) efeito(s) do uso de ferramentas sobre o padrão de atividades, dieta, regimes competitivos e padrão de relações sociais entre as fêmeas dessa população.

\section{3-MÉTODO}

\subsection{Local de estudo}

A presente pesquisa foi realizada em uma área de ecotóno Cerrado/Caatinga, localizada no município de Gilbués, ao Sul do estado do Piauí, entre as coordenadas $9^{\circ}$ 00’ Sul a 45 00' Oeste (Figura 2). O local de estudo, que inclui a Reserva Biológica Serra da Água Branca (com 250 ha) e a fazenda privada Boa Vista (com 1000 ha) (de agora em diante referida como BV), é uma planície limitada por escarpas e "mesas" de arenito que se erguem a mais de $30 \mathrm{~m}$ de altura, com abundantes blocos de arenito aos pés das escarpas (Fragaszy et al., 2004b). 


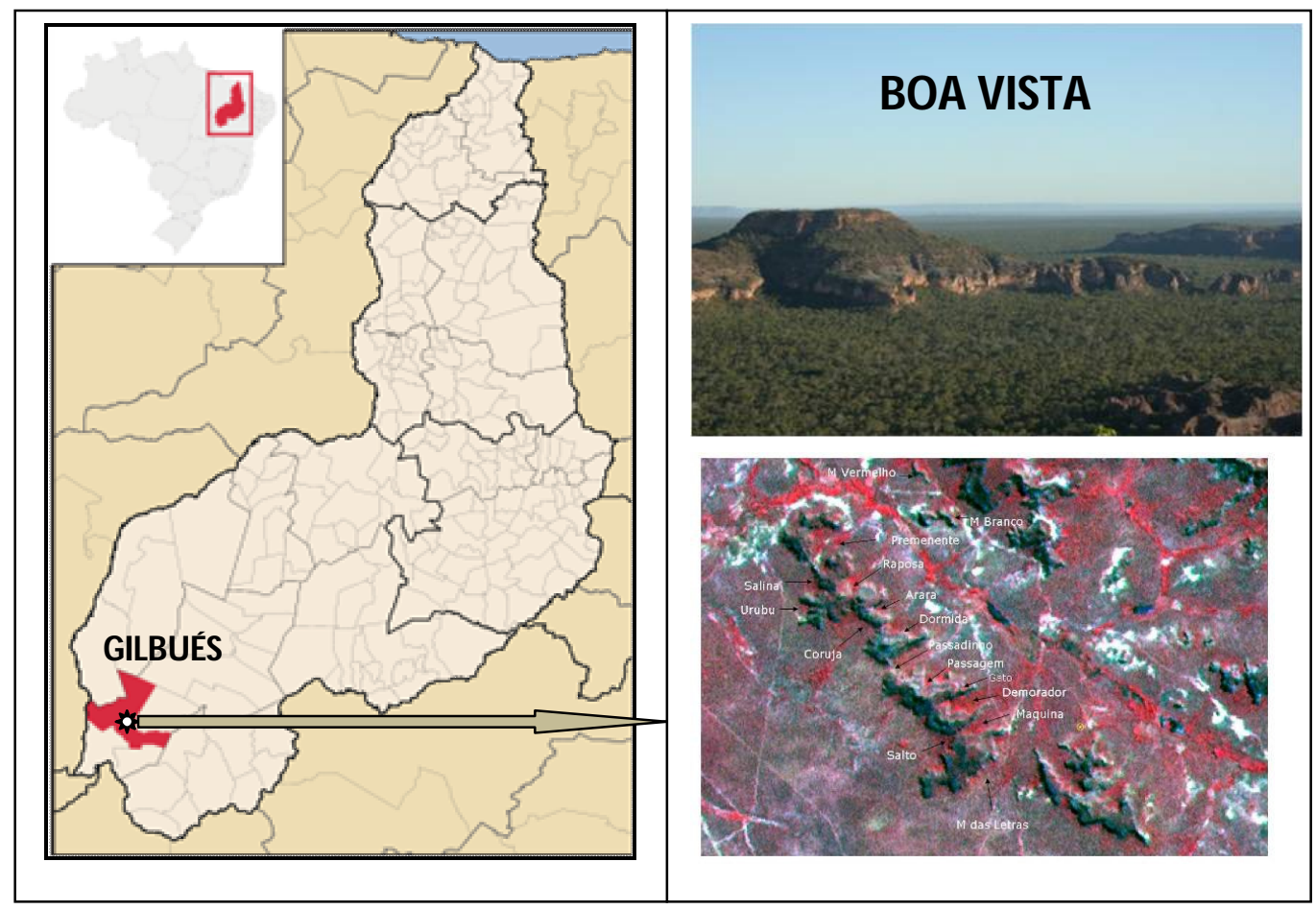

Figura 2: À esquerda, localização da área de estudo no município de Gilbués. À direita (acima), vista da fazenda BV, (abaixo) imagem de satélite da BV, com destaque para os morros que circundam a região no centro da Figura (as setas indicam os nomes de identificação de cada encosta).

A região apresenta vegetação heterogênea, constituída, principalmente por árvores e arbustos baixos, muitos dos quais apresentam adaptações xerofíticas e ao fogo. Observa-se, também, uma grande diversidade de fisionomias, tanto nas planícies como nos morros. As áreas planas são constituídas por chapadas, brejos e grotas, enquanto nos morros de arenito encontram-se áreas de encosta, paredões rochosos e topo de morros (Ramos da Silva, 2008; Spagnoletti, 2009; observação pessoal; Figuras 3, 4 e 5). As chapadas cobrem a maior parte das planícies e são caracterizadas pelo predomínio de árvores de médio porte (p. ex., sapucaia: Eschweilera nana, pequi: Caryocar brasiliense e jatobá: Hymenaea courbari) e pela abundância de palmeiras rasteiras (p. ex., catulé e tucum: Astrocaryum SP - Capítulo II). As grotas são grandes depressões no solo das planícies, esculpidas pela ação das chuvas, que se iniciam nos "pés" dos morros, estendem-se pela chapada e culminam nos brejos. Nestas áreas, há 
predomínio de árvores de médio porte (p. ex., fruta d'anta) e concentração de blocos de arenito, utilizados como ferramentas pelos macacos. Os brejos apresentam maior diversidade de árvores de médio porte (p. ex., ingá: Inga sp.), formação de buritizais (Mauritia fluxuosa) e abundância de palmeiras da espécie piaçava (Orbignya sp.), além da presença de pequenas lagoas sazonais e cursos d' água perenes. As encostas circundam os morros de arenito e são caracterizadas pelo predomínio de arbustos e árvores de médio (p. ex., faveiras: Parkia pendula) e pequeno porte (p. ex., ata: Annona sp.), baixa densidade de palmeiras e maior concentração de blocos de arenitos. Por fim, nos topos há predominância de vegetação herbácea e arbustiva e algumas espécies de bromeliáceas (p. ex., mucambira: Bromelia laciniosa e ananás) e cactáceas (p.ex., xique-xique: Pilosocereus gounellei e mandacaru: Cereus giganteus), também são encontrados "caldeirões" (erosões no solo dos morros capazes de armazenarem água da chuva durante a estiagem).

A fauna local é constituída por mamíferos de pequeno e médio porte, como a onça parda (Puma concolor), cachorro do mato (Cerdocyon thous), irara (Eyra barbara), tamanduá-mirim (Tamandua tetradactyla) e tatu-peba (Euphractus sexcinctus). Há também uma grande diversidade de aves, incluindo algumas espécies de rapina, como a águia chilena (Gernoaethus melanoleucus), carcará (Polyborus plancus) e acauã (Herpetotheres cachinnans) e de répteis, como o teiú (Tupinambis sp.), jibóia (Boa constrictor) e jararaca (Bothrops sp.) e pequenos lagartos (Verderane, Ramos da Silva, Spagnoletti, dados não publicados; observação pessoal). 


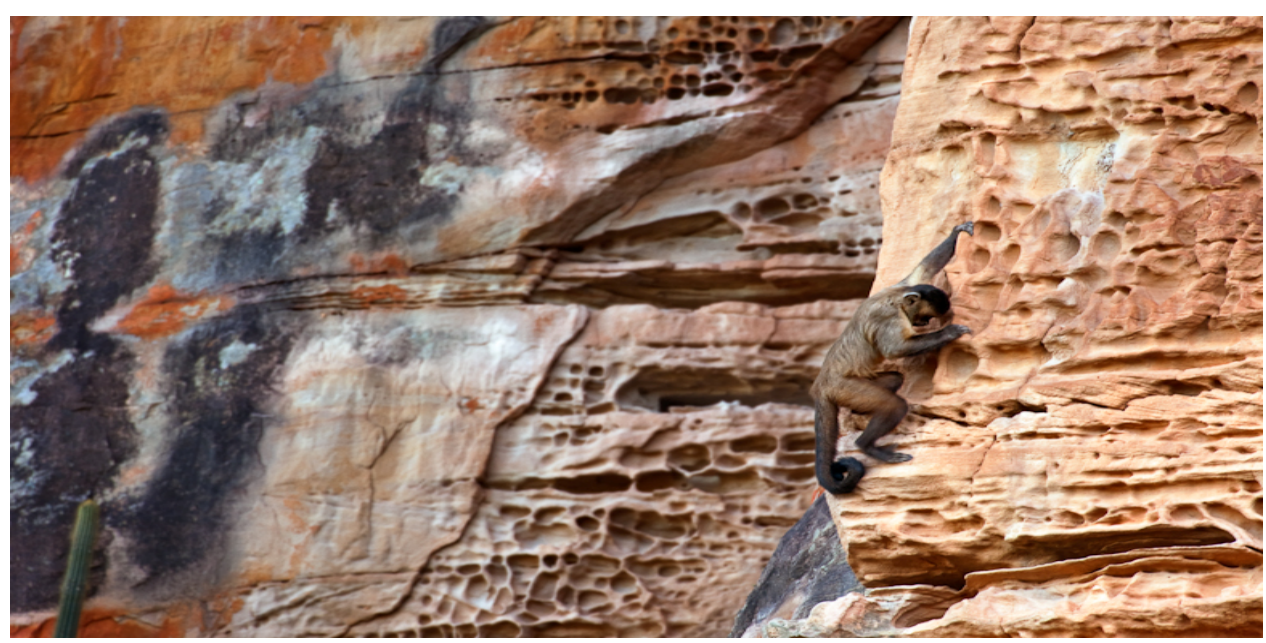

Figura 3: Macho subadulto (Teimoso) forrageando em um paredão rochoso (Foto: Luciano Candisane).

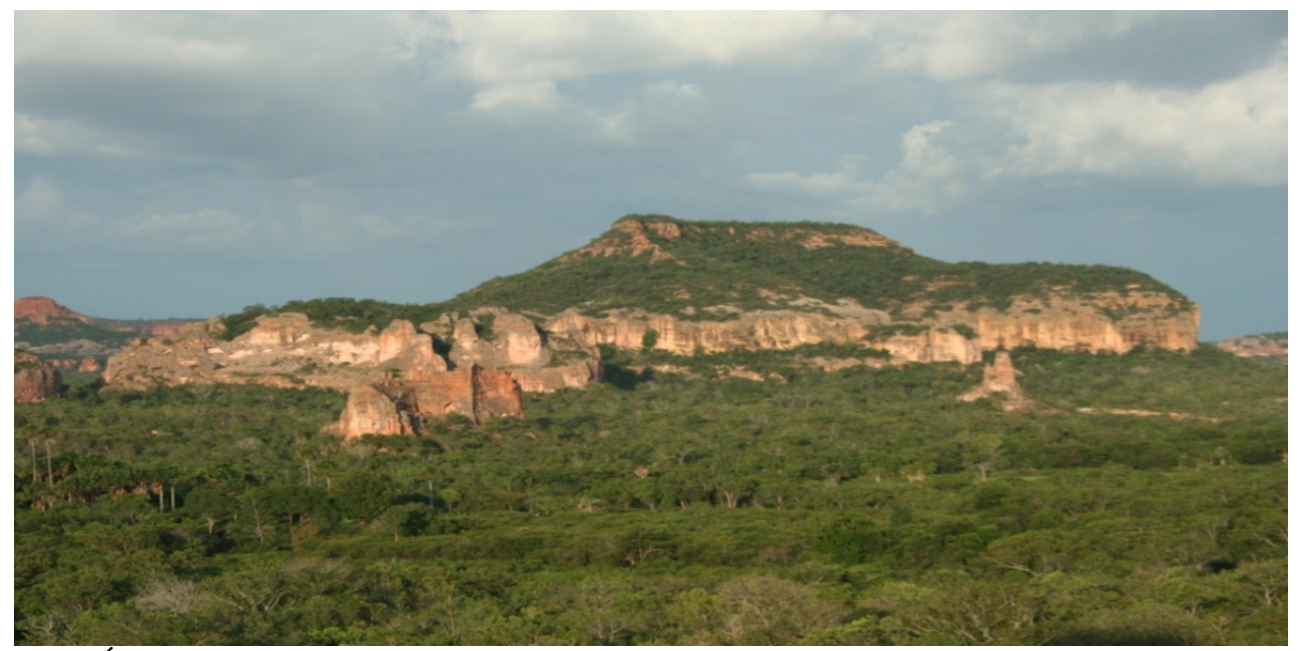

Figura 4: Área de chapada (à frente) e morros de arenito (ao fundo) na BV.

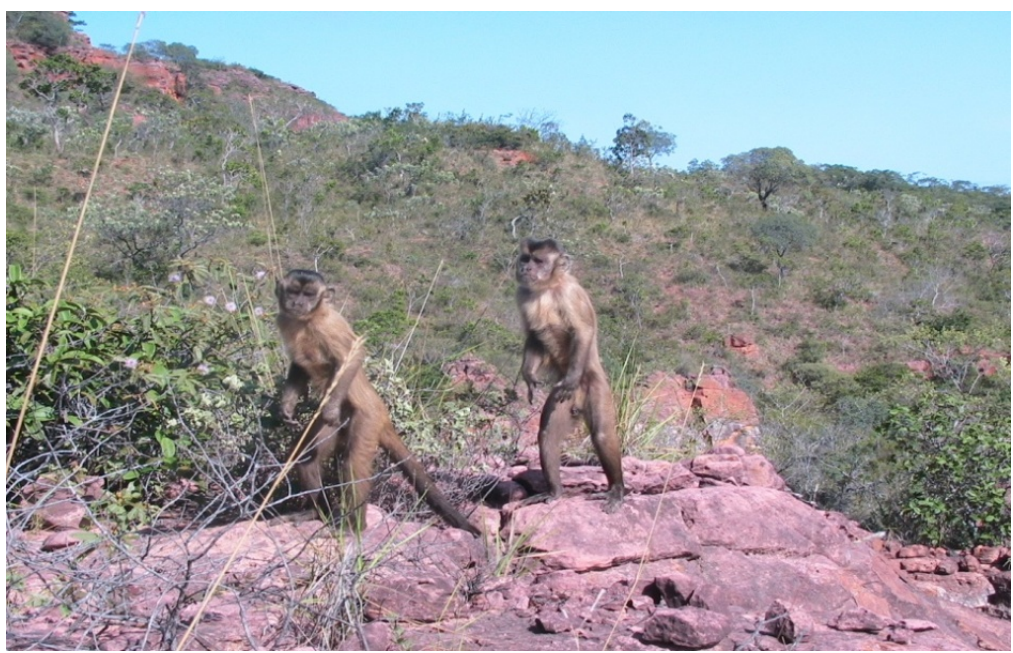

Figura 5: Machos subadultos (Jatobá e Mansinho) observando bípedes em topo de morro (Foto: Eduardo Darvin Ramos da Silva). 
A região apresenta duas estações bem definidas quanto ao regime de chuvas: uma estação seca (de maio a setembro) e uma estação chuvosa (de outubro a abril). Ao longo da coleta de dados (entre junho de 2006 e abril de 2008), a temperatura média durante a estação seca foi de $26,7 C^{\circ}$ (temperatura máxima de $33,6 C^{\circ}$ e mínima de $20,4 C^{\circ}$ ) e a umidade relativa do ar média foi de 52,2\% (umidade relativa máxima de $70,2 \%$ e mínima de $30,1 \%$ ). Na estação chuvosa, a temperatura média foi $27,5 \mathrm{C}^{\circ}$ (temperatura máxima de $32,5 \mathrm{C}^{\circ}$ e mínima de $22,4 \mathrm{C}^{\circ}$ ) e a umidade relativa do ar média foi de 70,2\% (umidade relativa máxima de 89,1\% e mínima de 49,9\%) (Figura 6).

A precipitação anual média para o mesmo período foi de $1289,0 \mathrm{~mm}$. No entanto, houve uma grande diferença nos índices pluviométricos entre as estações, sendo que a precipitação média durante o período de seca foi de $24,5 \mathrm{~mm}$, enquanto no período chuvoso foi de 1265,0 mm (Figura 6).

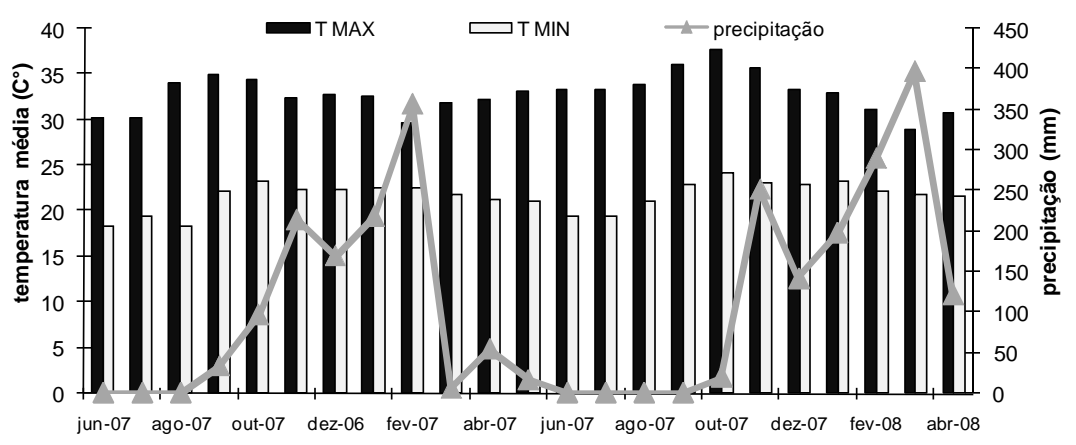

Figura 6: Temperatura média (máxima e mínima) e total de precipitação pluviométrica registrado na BV entre junho de 2006 e abril de 2008.

\subsection{Grupos de estudo}

Os sujeitos desta pesquisa foram indivíduos de dois grupos selvagens de macacos-prego, Zangado (ZA) e Chicão $(\mathrm{CH})$. A escolha do grupo ZA ocorreu durante visitas prévias à área de pesquisa (em julho de 2005 e fevereiro de 2006), quando foram realizados censos populacionais e entrevistas com moradores da região. O processo de 
habituação ocorreu entre o período de agosto de 2005 e março de 2006, de modo que, ao início deste trabalho, o grupo ZA já estava completamente habituado à presença humana. O acompanhamento do grupo $\mathrm{CH}$ iniciou-se em fevereiro de 2006, em função de uma redução drástica e inesperada no tamanho do grupo ZA (decorrente de emigrações e desaparecimentos). $\mathrm{O}$ grupo $\mathrm{CH}$ vem sendo monitorado há cerca de dez anos pelos moradores da BV e visita regularmente uma ceva construída estrategicamente em uma área já utilizada pelo grupo (chamada daqui em diante de área de aprovisionamento), onde são oferecidas provisões de cocos nativos, frutas frescas e água como parte de um programa de ecoturismo. Esse grupo é bastante habituado à presença humana e a relação de parentesco de alguns de seus membros é conhecida.

Durante a coleta de dados, a composição do grupo ZA variou entre 8 e 14 indivíduos, sendo 5 adultos (1 macho e 4 fêmeas), 4 machos subadultos, 4 juvenis (1 macho e 3 fêmeas) e 3 infantes ( 1 macho e 1 fêmea; 1 infante desapareceu antes que o sexo pudesse ser identificado) ${ }^{1}$, como mostra a Tabela 1 . A composição do grupo $\mathrm{CH}$ variou entre 17 e 19 indivíduos, sendo 8 adultos (2 machos e 6 fêmeas), 4 machos subadultos, 4 juvenis ( 3 machos e 1 fêmea) e 5 infantes ( 4 machos e 1 fêmea) (Tabela 2).

As faixas etárias foram definidas com base nos trabalhos de Izawa (1980), Torres de Assumpção (1983), Fragaszy et al. (1991) e Izar (1994). Assim, utilizou-se a seguinte classificação:

- $\quad$ Infante: desde o nascimento até 1,5 anos, o que corresponde a aproximadamente 18 quadrissemanas;

\footnotetext{
${ }^{1}$ Alguns indivíduos dos dois grupos mudaram de faixa etária ao longo da coleta. Para fins descritivos de composição de grupo, considerei a faixa etária na qual o indivíduo permaneceu por mais tempo ao longo das observações.
} 
- $\quad \underline{J u v e n i l: ~ i m a t u r o s ~ c o m ~ i d a d e s ~ e n t r e ~ 1,5 ~ e ~} 5$ anos. Essa classificação foi aplicada apenas aos machos, as fêmeas foram consideras juvenis de 1,5 anos até a idade da primeira concepção, calculada através da subtração de 160 dias (período de gestação estimado para a espécie - Recabarren et al., 2000; Fragaszy et al., 2004a) da data de nascimento ou do primeiro avistamento do filhote.

- $\quad$ Subadulto: machos com idades entre 5 e 7 anos. Esses machos apresentam tamanho de adulto, mas possuem topete pouco desenvolvido.

- $\quad$ Adultos: os machos foram considerados adultos quando tinham mais de 7 anos de idade, já as fêmeas, a partir da primeira concepção.

A faixa etária dos machos dominantes de cada grupo, fêmeas com infantes e infantes nascidos a partir de 2004 foi determinada com precisão. Para os demais indivíduos, a idade foi inferida com base no tamanho corpóreo, desenvolvimento dos tufos da cabeça (topete) e comportamento, conforme Izawa (1980).

Tabela 1: Relação dos indivíduos do grupo Zangado durante o período de estudo segundo sexo e faixa etária. O sinal / indica transição de faixa etária, $\infty$ indica nascimento, + indica óbito ou desaparecimento, $\rightarrow$ indica emigração do grupo ao longo da coleta de dados.

\begin{tabular}{l|c|c|l}
\hline \multicolumn{1}{c|}{ SUJEITO } & SEXO & IDADE & \multicolumn{1}{c}{ COMENTÁRIOS } \\
\hline Zangado & macho & adulto & macho alfa \\
\hline Moça Branca & fêmea & adulta & fêmea alfa \\
\hline Pretinha & fêmea & adulta & + entre 12 e 22 de maio/06 \\
\hline Emília & fêmea & adulta & \\
\hline Moça Chita & fêmea & adulta & \\
\hline Dengoso & macho & subadulto & $\rightarrow$ em julho/06 \\
\hline Mansinho & macho & subadulto & $\rightarrow$ em junho-06 \\
\hline Teimoso & macho & subadulto & $\rightarrow$ em julho-06 \\
\hline Jatobá & macho & subadulto & $\rightarrow$ em junho-06 \\
\hline Catuaba & fêmea & juvenil & \\
\hline Dunga & fêmea & juvenil & \\
\hline Ervilha & fêmea & infante/juvenil & filha de Emília \\
\hline Kiko & macho & infante & filho de Moça Branca, $\infty$ em 24/10/05 \\
\hline Pretinho & IND & infante & filho(a) de Pretinha, + entre 12 e 22/ 05/06 \\
\hline Café & macho & infante & filho de Moça Chita, $\infty$ entre 10/12/06 \\
& & e 03/01/07 \\
\hline Elisa & fêmea & infante & filha de Emília, $\infty$ em março/07 \\
\hline
\end{tabular}


Tabela 2: Relação dos indivíduos do grupo Chicão durante o período de janeiro a março de 2008 segundo sexo, faixa etária e comentários. O sinal $\infty$ indica nascimento, + indica óbito ou desaparecimento, $\rightarrow$ indica imigração para o grupo.

\begin{tabular}{l|c|c|l}
\hline \multicolumn{1}{c|}{ SUJEITO } & SEXO & IDADE & \multicolumn{1}{c}{ COMENTÁRIOS } \\
\hline Chicão & macho & adulto & macho alfa \\
\hline Segundo Chefe & macho & adulto & + em julho de 2007 \\
\hline Piaçava & fêmea & adulta & fêmea alfa \\
\hline Dendê de Coco & fêmea & adulta & + em novembro de 2007 \\
\hline Teninha & fêmea & adulta & \\
\hline Chiquinha & fêmea & adulta & \\
\hline Chuchu & fêmea & adulta & \\
\hline Dita & fêmea & adulta & \\
\hline Dengoso & macho & subadulto & $\rightarrow$ em julho/06 \\
\hline Mansinho & macho & subadulto & $\rightarrow$ em junho-06 \\
\hline Teimoso & macho & subadulto & $\rightarrow$ em julho-06 \\
\hline Jatobá & macho & subadulto & $\rightarrow$ em junho-06 \\
\hline Tucum & macho & juvenil & filho de Teninha \\
\hline Caboclo & macho & juvenil & filho de Chiquinha \\
\hline Amarelinha & fêmea & juvenil & \\
\hline Pico & macho & infante & filho de Piaçava, + entre $01 \mathrm{e} 10 / 02 / 08$ \\
\hline Tomate & macho & infante & filho de Teninha, $\infty$ em dezembro/06 \\
\hline Catú & macho & infante & filho de Chuchu, $\infty$ em 5/2/07 \\
\hline Cangaceiro & macho & infante & filho de Chiquinha, $\infty$ em $29 / 09 / 07$ \\
\hline Pati & macho & infante & filho de Piaçava, $\infty$ em $2 / 11 / 07$ \\
\hline Doree & fêmea & infante & filha de Dita, $\infty$ em 9/11/07 \\
\hline
\end{tabular}

\subsection{Coleta de dados}

Os dados do grupo ZA foram coletados ao longo de 25 meses, entre abril de 2006 e abril de 2008, e os do grupo $\mathrm{CH}$ ao longo de 15 meses, entre fevereiro de 2007 e março de 2008. O primeiro mês de observação foi dedicado ao reconhecimento dos indivíduos do grupo e da área de estudo e ao teste e ajuste de metodologia. Por esta razão, os dados coletados neste período foram excluídos das análises. Ao final do período de testes foi possível reconhecer todos os indivíduos do grupo, inclusive diferenciando-os por sexo e idade.

As observações comportamentais foram conduzidas pelo método de amostragens de "varredura instantânea" (scan-sampling - Atmann, 1974), com registros de 10 minutos a intervalos de 10 minutos. Foi realizado um total de 7279 varreduras, sendo 5139 para o grupo ZA e 2140 para o grupo $\mathrm{CH}$. Esses dados foram utilizados para 
calcular o orçamento de atividades, quantificar a freqüência de diferentes itens alimentares incluídos na dieta e o padrão orçamentário de uso de substrato e fisionomia (conforme detalhado no Capítulo II). Utilizou-se, também, o método de amostragem de “todas as ocorrências" (Altmann, op cit) para registros de interação agonística, catação, formação de coalizões, vocalizações de alarme e encontros intra e inter específicos (conforme detalhado no Capítulo III).

Ao todo, foram totalizadas 2707 horas de observação dos grupos, sendo 1932 horas para o grupo ZA e 775 horas para o grupo $\mathrm{CH}$. Entre junho de 2007 e março de 2008, dois assistentes de campo (Jozimar de Oliveira e Arizomar de Oliveira) auxiliaram na coleta de dados e foram responsáveis por 750 das 2707 horas de observação dos grupos (480 horas de observação para o grupo ZA e 270 horas para o grupo $\mathrm{CH}$ ). Os dois assistentes acompanharam os trabalhos de campo desde o início da pesquisa e foram treinados ao longo de um ano para coleta de dados. Seus dados só foram incluídos nesta pesquisa após a constatação de mais de $85 \%$ de concordância entre observadores. Esses testes foram realizados durante a coleta de dados, da seguinte maneira: (1) a cada dia um assistente acompanhava a pesquisadora em campo; (2) o assistente permanecia próximo à pesquisadora ao início de cada varredura, registrando simultaneamente e na mesma seqüência que a pesquisadora, as informações estipuladas no protocolo de coleta; (3) ao término de cada varredura os dados eram confrontados eventuais discordâncias discutidas. 
CAPÍTULO II: Padrão de atividades e dieta de uma população de macacos-prego selvagens (Cebus libidinosus), que utiliza ferramentas, em área de ecótono Cerrado/Caatinga no Piauí. 


\section{1-INTRODUÇÃ̃o}

O estudo do orçamento de atividades de primatas, isto é, a alocação de tempo em diferentes comportamentos, como alimentação, descanso, locomoção e interação social, permite investigar como esses animais interagem com o seu habitat e investem tempo e energia em sobrevivência e reprodução (Defler, 1995). O orçamento de atividades pode ser bastante variável entre espécies distintas, populações de mesma espécie vivendo em ambientes diferentes e, até mesmo, entre membros de um mesmo grupo (p. ex., em Cebus spp: Fragaszy, 1986, 1990a; Robinson, 1986; Rose, 1994 Fragaszy \& Boinski, 1995; Ferreira et al., 2008).

A maior parte das variações inter-específicas no orçamento de atividades dos primatas tem sido explicada com base em características intrínsecas das espécies, como dieta, tamanho corpóreo, capacidade digestiva e demanda energética (Milton, 1980; Strier, 2007). Assim como na maioria dos vertebrados, entre os primatas o tipo de dieta e o tamanho corpóreo estão intimamente relacionados (Fleagle, 1999). O tipo de dieta, por sua vez, restringe o modo como uma espécie utiliza seu tempo e espaço (Fragaszy et al., 2004a). Por exemplo, espécies de grande porte tendem a apresentar uma dieta baseada em folhas, que são recursos abundantes no ambiente (Wrangham, 1980; van Schaik, 1989; Sterck \& Steenbeek, 1997), porém, de baixo valor energético e que requerem tempo e especializações anatômicas para serem digeridos (Strier, 2007). Já os primatas de pequeno porte costumam incluir grandes porções de frutos em suas dietas, que são recursos de alto valor energético e facilmente digeridos, porém, com distribuição discreta no ambiente (Wrangham, 1980; van Schaik, 1989; Sterck \& Steenbeek, 1997; Strier, 2007), que demandam tempo e energia para serem localizados. Os primeiros são chamados de "minimizadores de energia", porque dedicam uma proporção substancial de seu tempo de atividades ao descanso e pouco tempo à 
locomoção (p. ex., Alouatta palliata: Milton, 1980; Colobus guereza: Oates, 1977a; Trachypithecus pileatus: Stanford, 1991). Os últimos, por outro lado, são conhecidos como "maximizadores de energia", porque descansam pouco e passam uma grande proporção do seu tempo de atividades procurando fontes alimentares e deslocando-se entre elas (p. ex., Cercopithecus ascanius: Cords, 1987; Lagothrix lagotricha: Defler, 1996; Pan troglodytes: Wrangham, 1977; Cebus spp: Terborgh, 1983; Galetti \& Pedroni, 1994; Zhang, 1995; Di Bitetti, 2001; Spironello, 2001).

O orçamento de atividades e a dieta de primatas podem variar diária e sazonalmente, de acordo com fatores ambientais, como pluviosidade, temperatura, risco de predação e variação na abundância e distribuição dos recursos limitantes (Milton, 1980; Rylands, 1982; Oates, 1987; Mendes, 1989; Isbell \& Young, 1993; Peres, 1993; Bronikowski \& Altmann, 1996; Gursky, 2000; Hanya, 2004; Kosheleff1 \& Anderson, 2009; Masi et al., 2009; Van Doorn et al., 2010). Por exemplo, primatas que vivem em ambientes sazonais precisam ajustar suas dietas para lidar com flutuações na disponibilidade de recursos alimentares (Gursky, 2000). Assim, durante períodos de escassez dos alimentos preferidos (que geralmente possuem alto valor nutricional, como os frutos), algumas espécies adotam uma dieta de subsistência (Strier, 2007). Isso significa que esses primatas aumentam o consumo dos chamados alimentos de reserva (fallback foods - Marshall \& Wrangham, 2007; Altmman, 2009; Wright et al., 2009), que, normalmente, são recursos de baixa qualidade nutricional, porém, abundantes no ambiente (como folhas e invertebrados - Izar, 2004; Snaith \& Chapman, 2007). Da mesma maneira, os primatas podem alterar seu tempo de atividades para lidar com a sazonalidade na oferta de alimentos, por exemplo, aumentando o tempo de deslocamento e as distâncias percorridas diariamente para localizar um maior número de fontes alimentares (Isbell, 1991), aumentando o tempo dedicado à alimentação para 
compensar uma dieta mais pobre (Janson, 1987; Pazol \& Cords, 2005; Teichroeb \& Sicotte, 2009) ou, ainda, reduzindo o tempo de deslocamento e aumentando o de descanso para conservar energia (Milton, 1980, 1998). Diversos estudos com macacos do gênero Cebus relatam mudanças significativas no orçamento de atividades em função do regime de chuvas e da oferta de alimentos. No geral, durante os meses de seca, os animais investem mais tempo em forrageamento, locomoção e descanso e menos tempo em interação social (Cebus apella: Terborgh, 1983; C. olivaceus: Robinson, 1986; C. nigritus: Rímoli, 2001; C. libidinosus: Moura, 2004; Cebus spp: Ferreira et al., 2008).

Variações intra-específicas no orçamento de atividades e dieta de primatas podem correr como o resultado de diferenças no tamanho e composição, por classe de sexo e idade, dos grupos sociais (Isbell, 1991; Janson \& Goldsmith, 1995), de preferências ligadas a tradições alimentares (Panger et al., 2002), além, é claro, de diferenças ambientais. Variações no orçamento de atividades e na dieta de primatas são observadas até entre indivíduos de um mesmo grupo social, em função de demandas energéticas diferenciadas (devido aos custos reprodutivos e dimorfismo no tamanho corpóreo - Rose, 1994; McCabe \& Fedigan, 2007), diferenças nas competências alimentares (Fragaszy \& Boinski, 1995; Santos, 2010), competição alimentar mediada por hierarquia de dominância (Ferreira et al., 2008), além de preferências alimentares individuais. Por exemplo, diferenças sexuais no orçamento de atividades foram encontradas em populações de C. capucinus selvagens, em que fêmeas dedicam mais tempo às atividades de forrageamento e interação social, e machos à vigilância e ao descanso (Rose, 1994), e de C. olivaceus, em que fêmeas despendem mais tempo em interação social e machos mais tempo em descanso (Robinson, 1986). Já Ferreira et al. (2008), estudando um grupo semi-livre de macacos-prego (Cebus spp), observaram 
diferenças no padrão de atividades em função do posto de dominância dos indivíduos: indivíduos dominantes forragearam mais e locomoveram-se menos do que os subordinados.

A escolha de micro-habitats e substratos é, também, um aspecto importante da vida dos primatas, já que está diretamente relacionada a fatores que afetam a sobrevivência e reprodução dos indivíduos, como a busca por alimentos e a evitação de predadores (Enstam \& Isbell, 2003). Diversos estudos mostram que os primatas não utilizam seu ambiente de maneira aleatória, ao contrário, selecionam micro-habitats e substratos de acordo com características ambientais (p. ex., estrutura da vegetação, a disponibilidade dos recursos alimentares no tempo e no espaço e distribuição do risco de predação - Boinski, 1989; Enstam \& Isbell, 2004) e individuais (p. ex., tamanho corpóreo - Bezanson, 2009). Assim como o orçamento de atividades e a dieta, o padrão de utilização de micro-habitats e substratos pode variações em função de flutuações na estrutura da vegetação, distribuição dos recursos e risco de predação (Youlatos, 1998).

Com base na literatura apresentada, fica evidente que o estudo do orçamento de atividades, dieta e escolha de substratos, ao longo de ciclos anuais e sazonais, permite compreender muitos aspectos do ciclo de vida e da organização social dos primatas não humanos, bem como para entender as estratégias comportamentais que lhes permitem lidar com flutuações na oferta de recursos limitantes. Além disso, o estudo do orçamento de atividades e da dieta é uma ferramenta importante para avaliar se uma população está submetida aos efeitos da competição por alimento (Isbell, 1991; Fashing et al., 2007).

Os macacos do gênero Cebus são primatas de médio porte que possuem uma dieta onívora. Embora sejam formalmente classificados como frugívoros/insetívoros, esses animais possuem uma dieta extremamente diversificada, que varia entre 
populações dependendo das condições ambientais. De fato, a lista de recursos alimentares alternativos, consumidos por esses primatas em períodos de escassez de alimentos, é extensa e inclui frutos de palmeiras (Terborgh, 1983; Spironello, 1991; 2001; Peres, 1994; Zhang, 1995; Di Bitteti, 2001), néctar/seiva (Terborgh, 1983; Spironello, 1991, 2001; Peres, 1994; Rímoli, 2001; Moura, 2004; Rímoli et al., 2008; Sabbatini et al.; 2008; Gouveia, 2009), sementes (Galetti \& Pedroni, 1994; Peres, 1994), folhas e base foliar de bromélias (Brown \& Zunino, 1990; Peres, 1994; Zhang, 1995; Izar, 2004), pequenos vertebrados (Rose \& Fedigan, 1995; Rose, 1997) e alimentos antrópicos (Rímoli, 2001; Moura, 2004; Sabbatini et al., 2008; Spagnoletti, 2009).

Essa dieta tão generalista é apontada por muitos pesquisadores como uma das principais causas da ampla distribuição geográfica desses animais (Brown \& Zunino; 1990; Fragaszy et al., 2004a). Apesar do crescente número de estudos com populações de macacos-prego selvagens (Izawa, 1980; Terborgh, 1983; Torres de Assumpção, 1983; Janson, 1985, 1988; Galetti \& Pedroni, 1994; Spironello, 2001; Rímoli, 2001; 2007; Izar, 2004; Alfaro-Lynch, 2007), pouco se sabe sobre as populações que vivem em regiões semi-áridas. Pesquisas recentes com $C$. libidinosus em áreas de Cerrado e Caatinga revelaram que o uso de ferramentas para a obtenção de alimentos é um comportamento difundido nessas regiões (Fragaszy et al., 2004b; Visalberghi et al., 2007; Moura \& Lee, 2004; Waga et al., 2006; Ottoni \& Izar, 2008; Mannu \& Ottoni, 2009; Ferreira et al., 2010). Tendo em vista a escassez de informações sobre a ecologia dessas populações, os estudos enfocando o padrão de atividades, escolha de substratos e a dieta, bem como a contribuição do uso de ferramentas para o forrageamento, são importantes para a compreensão das estratégias comportamentais que permitem a esses animais ocuparem ambientes tão sazonais. 


\section{2-OBJETIVOS}

\subsection{Gerais}

Caracterizar a área de estudo quanto à oferta de recursos alimentares. Investigar o padrão de atividade, a escolha dos substratos e a dieta de uma população selvagem de macacos-prego (Cebus libidinosus), que utiliza ferramentas para obtenção de alimentos, em área de ecótono Cerrado/Caatinga no Piauí. Avaliar se fatores ambientais, como pluviosidade, temperatura e oferta de recursos alimentares, afetam o tempo de atividades e a dieta dos animais, bem como avaliar a contribuição do uso de ferramentas para o forrageamento desses animais.

\subsection{Específicos}

1) Avaliar a oferta temporal de frutos, flores, cocos de palmeiras e invertebrados na região da Boa Vista;

2) Descrever o padrão de atividades de C. libidinosus na Boa Vista (incluindo o tempo despendido em atividade de uso de ferramentas) e compará-lo ao de populações de Cebus que não utilizam ferramentas. Verificar se as variáveis ambientais afetam o tempo de atividades desses animais;

3) Verificar se o ciclo de atividades diárias varia em função do período do dia (manhã, meio do dia e tarde);

4) Descrever o padrão de utilização dos diferentes substratos e fisionomias pelos macacos-prego da BV e verificar se existem variações sazonais;

5) Identificar os itens alimentares consumidos pelos macacos da Boa Vista e avaliar a importância dos alimentos obtidos com auxílio de ferramentas para a composição da dieta. Verificar se variáveis ambientais afetam a proporção de itens alimentares incluídos na dieta; 
6) Verificar se a proporção de itens alimentares consumidos diariamente varia em função do período do dia (manhã, meio do dia e tarde);

7) Verificar se o orçamento de atividades, a utilização dos substratos e a dieta desses animais são afetados pelo sexo e/ou idade dos indivíduos do grupo.

\section{3-MÉTODO}

\section{1. Área e grupos de estudo}

A pesquisa foi realizada na Fazenda Boa Vista (BV), localizada numa área de ecotóno Cerrado/Caatinga, no município de Gilbués, ao Sul do estado do Piauí. Os sujeitos desse estudo foram os membros de dois grupos selvagens de macacos-prego (Cebus libidinosus): grupo Zangado (ZA) e grupo Chicão $(\mathrm{CH})$. Uma descrição mais detalhada da área e dos grupos de estudo encontra-se no Capítulo I.

\subsection{Disponibilidade de alimento}

\subsubsection{Disponibilidade de frutos e flores}

A oferta mensal de frutos e flores na área foi amostrada seguindo a metodologia utilizada por Izar (2004), distribuindo coletores para amostrar a quantidade de frutos e flores que caem das copas. Esse método permitiu estimar a massa de frutos e flores $(\mathrm{kg})$

por unidade de área do habitat $\left(\mathrm{km}^{2}\right)$. Os coletores consistiram de cestos redondos confeccionados com tela e arame, com área de $47,12 \mathrm{~cm}^{2}$, fixados aos troncos das árvores (à altura do peito) no local de coleta (Figura 1). Foram distribuídos 100 coletores ao longo de uma trilha de $3 \mathrm{~km}$ de extensão (a um metro de distância lateral) dentro da área de uso do grupo estudado, a uma distância mínima de 30 m entre cada coletor. Os coletores foram esvaziados a cada quinze dias e a biomassa de frutos e de flores coletados foi separada e pesada. 


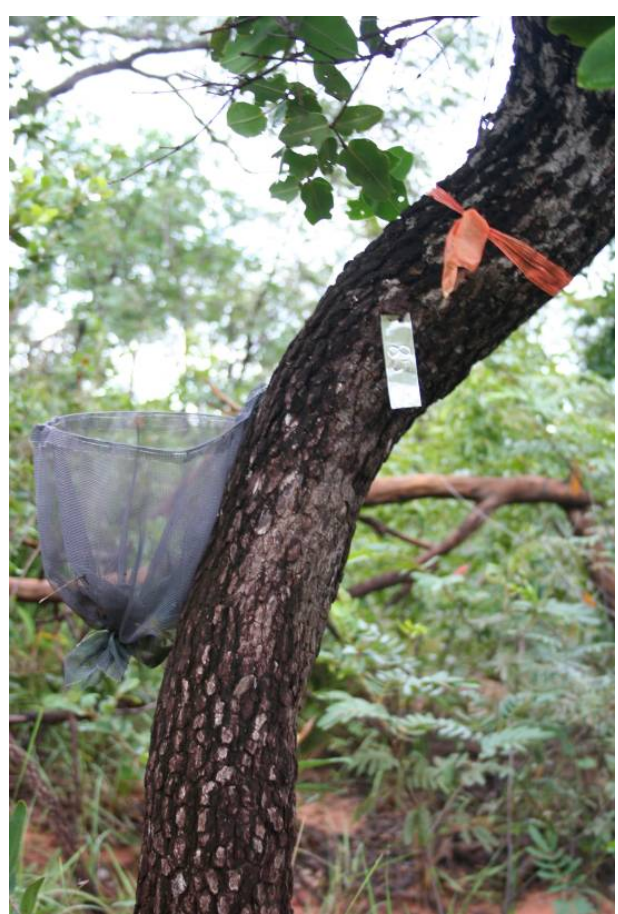

Figura 1: Coletores de frutos e flores para amostragem de biomassa na área de estudo.

\subsubsection{Disponibilidade de invertebrados}

Ainda seguindo a metodologia de Izar (2004), foi feita uma avaliação da variação mensal da abundância (biomassa) de invertebrados no habitat, utilizando o método de armadilhas "pitfall". Esse método é mais indicado para avaliar a abundância de invertebrados ativos que vivem na superfície, em vegetação baixa ou solo nu. Embora os animais estudados nesta pesquisa possam alimentar-se de uma grande variedade de invertebrados, com diferentes hábitos, considera-se que esse método fornece um índice confiável da variação mensal na oferta desses recursos no habitat.

As armadilhas "pitfall" consistiram de recipientes enterrados no solo de modo a capturar os invertebrados que caiam na sua superfície. Na presente pesquisa, foram utilizadas garrafas PET como recipientes. Para evitar que os invertebrados saíssem das armadilhas após a captura, a parte superior das garrafas foi cortada, invertida, e encaixada na abertura, formando um funil que impedia a fuga dos animais (Figura 2). As armadilhas foram distribuídas seguindo o mesmo critério de distribuição dos 
coletores de frutos. As armadilhas foram esvaziadas a cada quinze dias, e a biomassa de invertebrados capturados foi separada e pesada.

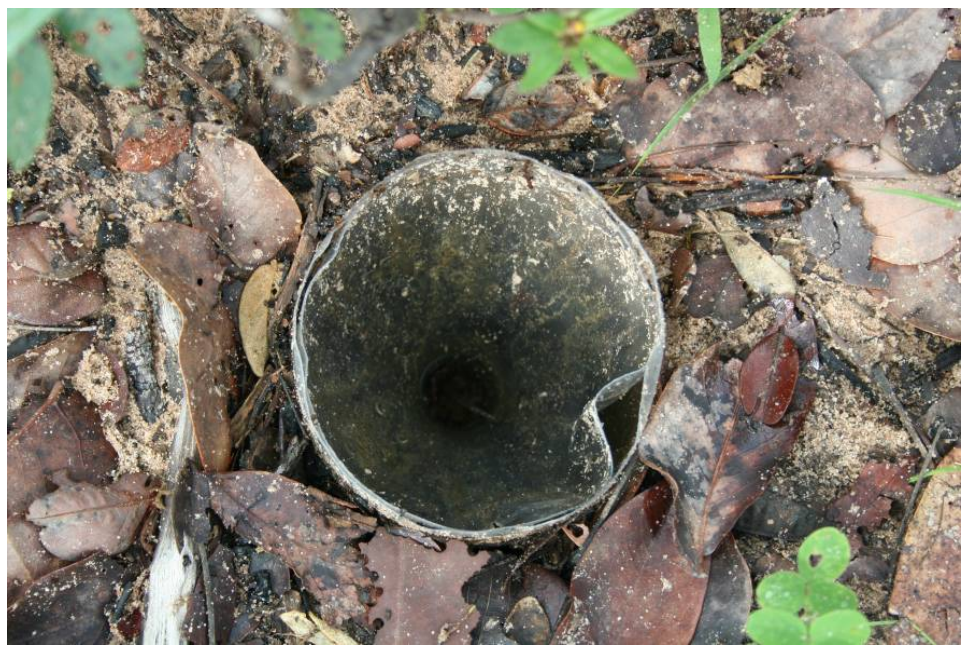

Figura 2: Armadilha "pitfall" para amostragem de invertebrados na área de estudo.

\subsubsection{Disponibilidade de frutos de palmeiras}

$\mathrm{Na}$ área de estudo ocorrem mais de sete espécies de palmeiras, dentre elas, as mais consumidas pelos macacos-prego estudados são: catulé (Attalea barreirensis), tucum (Astrocaryum campestre), piaçava (Orbignya sp) e catulí (Attalea sp). Os frutos dessas palmeiras são um recurso alimentar importante para os macacos-prego, tanto pela polpa que apresentam, como pelo nutritivo endosperma, que é acessado com o auxílio de ferramentas. A maior parte dessas palmeiras apresenta caules subterrâneos curtos e as frondes e os cachos de frutos emergem do solo (Figura 3), do modo que o método de coletores, utilizado para avaliar a oferta de frutos, não é apropriado para estimar a produção de cocos dessas palmeiras.

Por essa razão, a disponibilidade de frutos de palmeiras foi avaliada através de dados obtidos em um estudo fenológico das palmeiras. A escolha dos indivíduos monitorados durante o estudo foi feita ao longo da trilha onde estão localizados os coletores de frutos e invertebrados. Em cada um dos 100 pontos que apresentam 
coletores, foram marcadas quatro palmeiras (nas direções Norte, Sul, Leste e Oeste), dentro de uma distância lateral mínima de três metros, e uma máxima de 10 metros, do ponto do coletor. As palmeiras foram identificadas com fitas plásticas e placas de metais, contendo o nome da espécie e a sua localização. Apenas palmeiras adultas foram marcadas. Quando não houve palmeiras adultas dentro dos limites de distância e direção estabelecidos, registrou-se ausência de palmeiras. As palmeiras marcadas foram monitoradas uma vez por mês, e dados sobre ausência ou presença de flor, fruto maduro e fruto seco foram coletados.

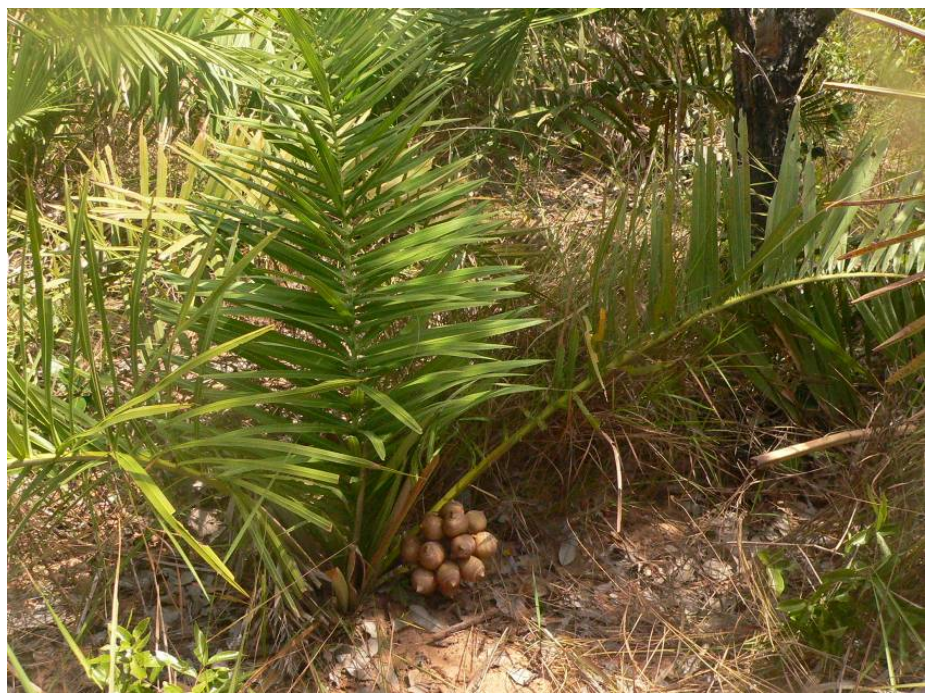

Figura 3: Palmeira "catulé" com cacho de cocos.

Os dados obtidos no estudo fenológico, para proporção de indivíduos amostrados contendo frutos, foram extrapolados para a área de estudo considerando-se a abundância populacional de cada espécie de palmeira e do total de palmeiras. Seguindo a metodologia de Taira (2007), a abundância de palmeiras na BV foi estimada a partir de quatro parcelas $(100 \times 100 \mathrm{~m})$ montadas em pontos diferentes ao longo do transecto de $3 \mathrm{~km}$ usado para escolher as palmeiras da fenologia, cuja localização foi determinada de forma a amostrar as diferentes fisionomias de vegetação, topografia e hidrografia da 
área de estudo. Em cada parcela foram contados todos os indivíduos das espécies de palmeiras (1) catulé, (2) catulí, (3) piaçava, (4) tucum, (5) tucum-anão e (6) pati, o que permitiu estimar a abundância de cada espécie de palmeira e do total de palmeiras (Tabela 1).

Tabela 1: Abundancia de seis espécies de palmeiras na Boa Vista.

\begin{tabular}{|c|c|c|c|c|c|c|}
\hline $\begin{array}{l}\text { ponto da trilha } \\
\text { fisionomia }\end{array}$ & $\begin{array}{c}5 \\
\text { lagoa }\end{array}$ & $\begin{array}{c}43 \\
\text { chapada }\end{array}$ & $\begin{array}{c}63 \\
\text { morro }\end{array}$ & $\begin{array}{c}89 \\
\text { chapada }\end{array}$ & TOTAL & N/ha \\
\hline Catule & 15 & 390 & 1 & 899 & 1305 & 326,25 \\
\hline Catuli & 7 & 55 & 0 & 5 & 67 & 16,75 \\
\hline Pati & 0 & 0 & 0 & 24 & 24 & 6 \\
\hline Piassava & 366 & 215 & 0 & 0 & 581 & 145,25 \\
\hline Tucum & 0 & 0 & 3 & 0 & 3 & 0,75 \\
\hline Tucum-anão & 0 & 0 & 0 & 155 & 155 & 38,75 \\
\hline TOTAL & 388 & 660 & 4 & 1083 & 2135 & 533,75 \\
\hline
\end{tabular}

\subsubsection{Análise estatística}

Para verificar se a oferta de alimento na mata apresentou sazonalidade, a biomassa de frutos, flores, invertebrados e o número de palmeiras com frutos amostrados a cada mês foi comparada entre os meses chuvosos e secos através do teste ANOVA, com o programa SPSS 13 para Windows.

\subsection{Orcamento de atividades}

Os dados do grupo ZA foram coletados entre abril de 2006 e abril de 2008, totalizando 25 meses de observações, e os do grupo $\mathrm{CH}$ entre fevereiro de 2007 e abril de 2008, somando 15 meses de observação. As observações do grupo ZA foram realizadas entre 6 a 10 dias completos por mês e as do grupo $\mathrm{CH}$ entre 4 e 8 dias por 
mês, das 05:30 às 18:30 horas. Ao todo, foram 267 dias de observação, totalizando 2707 horas de contato direto com os grupos, sendo 192 dias e 1932 horas de observação do grupo ZA e 75 dias e 775 horas do grupo $\mathrm{CH}$ (Tabela 2). As variações na quantidade de dias dedicados à observação dos grupos refletem períodos distintos da coleta de dados: (1) entre maio/06 e jan/07 todo o esforço de campo foi dedicado ao estudo do grupo ZA, portanto, nesse período houve uma maior concentração de dias de observação desse grupo; (2) em fev/07 iniciou-se o acompanhamento do grupo $\mathrm{CH}$; os dados utilizados na presente pesquisa, referentes ao período de fev/07 a maio/07 foram coletados exclusivamente pela presente pesquisadora, assim, para que os dois grupos pudessem ser acompanhados a cada mês foi preciso reduzir os dias de observação do grupo ZA; (3) entre junho/07 e abril/08 três assistentes de campo se revezaram com a presente pesquisadora na coletada de dados, o que resultou no aumento dos dias de observação de ambos os grupos. As variações ocorridas em cada um desses períodos foram decorrentes de dias em que não foi possível encontrar os animais e, principalmente, de dias em que os grupos foram perdidos de vista. 
Tabela 2: Horas de observação direta, número de dias e dias completos de observação e quantidade amostras de varredura coletadas para os grupos $\mathrm{ZA}$ e $\mathrm{CH}$ a cada mês de pesquisa.

\begin{tabular}{|c|c|c|c|c|c|c|c|c|}
\hline \multirow[b]{2}{*}{ Mês } & \multicolumn{4}{|c|}{ Grupo Zangado } & \multicolumn{4}{|c|}{ Grupo Chicão } \\
\hline & $\begin{array}{c}\text { horas } \\
\text { obs. }\end{array}$ & $\begin{array}{l}\text { dias } \\
\text { obs. }\end{array}$ & $\begin{array}{c}\text { dias } \\
\text { compl. }\end{array}$ & $\begin{array}{c}\mathrm{N} \\
\text { scans }\end{array}$ & $\begin{array}{c}\text { horas } \\
\text { obs. }\end{array}$ & $\begin{array}{l}\text { dias } \\
\text { obs. }\end{array}$ & $\begin{array}{c}\text { dias } \\
\text { compl. }\end{array}$ & $\begin{array}{c}\mathrm{N} \\
\text { scans }\end{array}$ \\
\hline mai/06 & 79,4 & 10 & 7 & 208 & & & & \\
\hline jun/06 & 113 & 12 & 10 & 288 & & & & \\
\hline jul/06 & 102 & 10 & 7 & 275 & & & & \\
\hline ago/06 & 114,3 & 10 & 10 & 326 & & & & \\
\hline set/06 & 75 & 7 & 8 & 186 & & & & \\
\hline out/06 & 51,1 & 5 & 8 & 138 & & & & \\
\hline nov/06 & 45,3 & 5 & 7 & 128 & & & & \\
\hline dez/06 & 53,3 & 6 & 4 & 135 & & & & \\
\hline jan/07 & 95 & 10 & 6 & 257 & & & & \\
\hline fev/07 & 56 & 5 & 9 & 153 & 43 & 4 & 7 & 126 \\
\hline $\mathrm{mar} / 07$ & 48,2 & 5 & 7 & 135 & 41,1 & 4 & 9 & 122 \\
\hline $\mathrm{abr} / 07$ & 51 & 5 & 7 & 138 & 36,1 & 4 & 4 & 88 \\
\hline mai/07 & 38,4 & 4 & 6 & 100 & 28 & 4 & 6 & 76 \\
\hline jun/07 & 72,5 & 8 & 6 & 185 & 62,5 & 6 & 6 & 179 \\
\hline jul/07 & 75 & 8 & 6 & 209 & 56 & 6 & 4 & 168 \\
\hline ago/07 & 86,2 & 8 & 8 & 239 & 56 & 5 & 5 & 165 \\
\hline set/07 & 86,1 & 8 & 7 & 256 & 70 & 6 & 6 & 210 \\
\hline out $/ 07$ & 100 & 10 & 8 & 297 & 83 & 8 & 6 & 230 \\
\hline nov/07 & 109,5 & 10 & 10 & 311 & 45 & 4 & 4 & 129 \\
\hline dez/07 & 108,3 & 10 & 8 & 298 & 64,1 & 6 & 6 & 156 \\
\hline $\mathrm{jan} / 08$ & 98,3 & 10 & 7 & 205 & 47,3 & 4 & 4 & 131 \\
\hline fev/07 & 85 & 8 & 8 & 227 & 43 & 4 & 4 & 100 \\
\hline $\mathrm{mar} / 07$ & 97,2 & 9 & 9 & 273 & 61,2 & 6 & 6 & 158 \\
\hline abr/07 & 57,2 & 6 & 5 & 172 & 37,4 & 4 & 3 & 92 \\
\hline TOTAL & 1901 & 189 & 178 & 5139 & 775 & 75 & 80 & 2140 \\
\hline
\end{tabular}

As atividades diárias dos grupos foram amostradas utilizando-se o método de varredura instantânea (scan-sampling; Altmann, 1974), com registros de 10 minutos a intervalos de 10 minutos. Assim, a cada hora, foram realizadas três amostras de varredura. Foi coletado um total de 7279 varreduras, sendo 5139 para o grupo ZA e 2140 para o grupo $\mathrm{CH}$ (Tabela 2). Em cada amostra de varredura registrei a identidade dos indivíduos avistados e seus respectivos comportamentos, de acordo com o seguinte etograma: 
1) alimentação: inclui as atividades de (a) forrageamento (busca ou manipulação de itens alimentares) e (b) comer (ingestão de itens alimentares);

2) locomoção: deslocamento horizontal ou vertical, pelo o chão ou pelas árvores, em postura quadrúpede, bípede, ou por saltos;

3) observação/vigilância: olhar fixamente para outro(s) membro(s) do grupo, observador(es) ou local, monitorar o ambiente visualmente para procurar ou acompanhar outro(s) membro(s) do grupo ou de grupos vizinhos ou indivíduos de outras espécies (incluindo possíveis predadores), monitorar o ambiente visualmente após emissão de vocalização de alarme;

4) descanso: inatividade, sentado ou deitado, dormindo ou acordado;

5) uso de ferramenta: utilização de pedras como martelos e bigornas para abrir alimentos encapsulados. Essa categoria engloba as atividades de posicionar o recurso na bigorna e golpeá-lo com um martelo para a extração do alimento; a busca e o consumo dos itens quebrados foram contabilizados na categoria alimentação por endosperma;

6) interação social: dirigir ou receber, de outros membros do grupo, comportamentos como catação, brincadeira, amamentação, lip-smaking, interações agonísticas e cópula. Para infantes, ser transportado pela mãe ou por alocuidadores foi considerado interação social;

7) outros: todas as atividades que não se enquadram nas descritas acima, como vocalizar, coçar e auto-catação.

Todos os membros dos grupos de estudo eram reconhecidos individualmente, inclusive por classe de sexo e idade. Não obstante, o número de indivíduo observado a 
cada amostra de varredura variou consideravelmente, especialmente em função da reduzida visibilidade em alguns tipos de fisionomias (encostas e morros, principalmente) e pela diminuição da coesão do grupo durante o forrageamento. Por esse motivo, as amostras de varredura foram normalizadas pelo número de animais visualizados em cada registro. Por exemplo, se em uma varredura foram observados três indivíduos forrageando e um descansando, a proporção das atividades nessa amostra foi 0,75 para forrageamento e 0,25 para descanso (conforme Izar \& Resende, 2007). A proporção normalizada de amostras de varredura dedicada às atividades descritas no etograma foi calculada mensalmente e para todo o período de estudo, bem como para as estações seca e chuvosa.

Para cada grupo foram realizadas as seguintes análises:

1) orçamento de atividades do grupo: para verificar se o orçamento de atividades do grupo apresentou sazonalidade, a proporção de tempo dedicada às diferentes atividades foi comparada entre os meses chuvosos e secos através do teste Anova. O teste de correlação de Person foi utilizado para verificar se houve associações positivas ou negativas entre a proporção de tempo dedicada às diferentes atividades;

2) orçamento de atividades do grupo por período do dia: o dia de observação foi dividido em três períodos: (a) manhã: 6:00 às 10:00 h, (b) meio do dia: 10:01 às 14:00 h e (c) tarde: 14:01 às 18:00 h. Esses períodos foram escolhidos por refletirem variações diárias de claridade, temperatura e umidade relativa do ar. Para verificar se houve variação nas atividades do grupo em função do período do dia e em função do período do dia nas 
estações seca e chuvosa, a proporção de tempo alocada em cada atividade foi comparada entre os períodos do dia e estações através do teste GLM.

3) orçamento de atividades por classe de sexo e idade: o teste GLM foi utilizado para verificar se indivíduos de classes de sexo e idade distintas diferiram quanto à proporção de tempo despendida nas atividades diárias.

Por fim, foram feitas comparações entre grupos quanto ao orçamento de atividades utilizando-se o teste GLM, com o programa SPSS 13 para Windows.

Os indivíduos do grupo ZA distribuíram-se em seis classes de sexo e idade: a) macho adulto $(n=1)$, b) fêmea adulta $(n=4-3), c)$ macho juvenil $(n=1)$, d) fêmea juvenil $(n=3-2)$, e) macho infante $(n=2-1)$ e f) fêmea infante $(n=2-1)$, conforme a classificação apresentada no Capítulo I. Machos subadultos $(\mathrm{n}=4)$ estiveram presentes apenas nos três primeiros meses de observação (quando emigraram para o grupo $\mathrm{CH}$ ), e por essa razão foram excluídos das análises. Os indivíduos do grupo $\mathrm{CH}$ distribuíram-se em sete classes de sexo e idade: a) macho adulto $(n=2-1)$, b) fêmea adulta $(n=6-5)$, c) macho subadulto $(n=4)$, d) macho juvenil $(n=3-2)$, d) fêmea juvenil $(n=1)$, e) macho infante (n=4-3) e f) fêmea infante $(n=1)$.

Para que juvenis machos do grupo ZA pudessem ser incluídos na análise comparativa entre classes de sexo e idade, foram utilizados apenas os dados referentes ao período de fevereiro de 07 a abril de 2008, já que em períodos anteriores não havia no grupo nenhum indivíduo dessa faixa etária. Dados referentes a esse mesmo período também foram utilizados nas comparações entre os grupos. Os dados de orçamento de atividades de machos subadultos do grupo $\mathrm{CH}$ foram agrupados aos dados de machos adultos para fins comparativos, já que a proporção de tempo alocada nas diferentes atividades não variou entre as duas classes de idade. Para evitar vieses nos resultados, 
os infantes foram excluídos das análises comparativas entre classes de sexo e idade de ambos os grupos devido à quantidade limitada de meses amostrados para fêmeas e a grande concentração de observação de machos apenas nos primeiros meses de vida.

\subsection{Utilização de substratos e fisionomias}

O padrão de escolha de substratos pelos macacos da BV foi analisado considerando a proporção de amostras de varredura dedicada à utilização de 1) substratos arbóreos (dividido de acordo com as seguintes alturas ocupadas pelos indivíduos: (1a) de 0,5 a 3,0 metros, (2a) de 3,1 a 6,0 metros e (3a) mais de 6,0 metros), 2) chão (substratos planos compreendendo tanto o solo das chapada, brejos e grotas, como solo rochoso das encostas e topos) e 3) cavernas.

O teste GLM foi utilizado para verificar se o tempo de permanência nos diferentes substratos variou em função do tipo de superfície e da estação do ano. Esse mesmo teste foi utilizado para verificar se houve diferença no padrão de utilização dos substratos em função do sexo e idade dos indivíduos do grupo, bem como para comparar os dois grupos de estudo. O teste de correlação de Person foi utilizado para verificar se houve associações positivas ou negativas entre a proporção de tempo de permanência dos diferentes substratos e o orçamento de atividades.

Para analisar o padrão de exploração das diferentes fisionomias considerou-se a proporção de amostras de varredura em que o grupo se encontrava em área de (1) chapada, (2) encosta, (3) topo, (4) grota e (5) brejo (conforme a descrição apresentada no Capítulo I). Para o grupo $\mathrm{CH}$ houve a adição de mais uma fisionomia, designada "área de aprovisionamento". As amostras de varreduras em que os membros do grupo encontravam-se distribuídos em dois tipos de fisionomias (p. ex., uma parte em área de chapada e outra em área de encosta) foram agrupadas em uma categoria designada de 
“área de transição”. Essa categoria foi excluída das análises estatísticas, pois representou apenas uma pequena parcela das amostras de varredura.

Para verificar se o tempo de permanência nas diferentes fisionomias foi afetado pelo tipo de paisagem e pela estação do ano utilizou-se o teste GLM. Esse mesmo teste foi utilizado para verificar se houve variação na exploração das fisionomias entre os grupos de estudo. O teste de correlação de Person foi utilizado para verificar se houve associações positivas ou negativas entre a proporção de tempo de permanência em diferentes fisionomias e o orçamento de atividades. As mesmas análises foram repetidas para os dados sobre padrão de exploração das fisionomias.

\subsection{Dieta}

A dieta dos grupos de estudo foi calculada considerando a proporção de amostras de varredura de alimentação (comer + forragear) dedicada ao consumo dos itens alimentares categorizados como: (1) fruto (incluindo o mesocarpo de frutos de palmeiras), (2) flor, (3) néctar, (4) semente, (5) folha (6) raiz, (7) endosperma (alimentos acessados com ferramentas), (8) invertebrado, (9) vertebrado e (10) alimento aprovisionado. As amostras de varredura de alimentação em que não foi possível identificar o item alimentar explorado foram categorizadas com "indeterminado". Apenas o grupo $\mathrm{CH}$ recebeu alimento aprovisionado, que foram frutas (como bananas e mangas), milho, cocos de palmeiras nativas e água. Os itens e quantidade de alimento ofertada foram registrados todas as vezes em que houve o aprovisionamento e representaram, em média, $3082 \pm 908 \mathrm{Kcal} /$ dia de aprovisionamento (cerca de $197 \pm 56$ Kcal/dia de aprovisionamento por indivíduo; Spagnoletti, 2009).

Frutos, sementes, flores, néctar, endosperma e alimentos aprovisionados foram considerados recursos com distribuição discreta (clumped) no ambiente, enquanto 
folhas, raízes, invertebrados e vertebrados foram considerados recursos uniformemente distribuídos (ver Capítulo III). Para a análise da dieta dos grupos foram utilizados os mesmos critérios e procedimentos estatísticos adotados na análise do orçamento de atividades. Assim, para cada grupo, a proporção de amostras de varredura de alimentação dedicada à exploração dos diferentes itens alimentares foi comparada entre os meses chuvosos e secos, através do teste ANOVA. Para verificar se houve variação na proporção de itens consumidos diariamente no período do dia (manhã, meio do dia e tarde) e nas estações seca e chuvosa, a proporção de tempo alocada em cada tipo de alimento foi comparada entre os três períodos do dia e as estações através do teste GLM. A dieta também foi analisada em função da idade e do sexo dos indivíduos do grupo utilizando-se o teste GLM. A comparação da dieta entre os grupos ZA e CH foi feita através do teste GLM. Os infantes de ambos os grupos foram excluídos das análises da dieta por classe de sexo e idade pelos mesmos motivos apresentados no orçamento de atividades.

\section{RESULTADOS}

\subsection{Disponibilidade de alimento no ambiente}

\subsubsection{Disponibilidade de frutos}

A biomassa de frutos no ambiente foi bastante variável ao longo de todo período de estudo (Figura 4), assim como o número de espécies com frutos a cada mês. Durante o período chuvoso, a oferta média de frutos disponível na mata foi de (média \pm DP) $227,0 \pm 191,0 \mathrm{~kg} / \mathrm{ha}$, enquanto no período seco foi de $284,0 \pm 188,0 \mathrm{~kg} / \mathrm{ha}$. Não houve diferença significativa na biomassa média de frutos disponível a cada mês entre as estações seca e chuvosa $(\mathrm{F}=0,153 ; \mathrm{gl}=22 ; \mathrm{p}=0,700)$. 


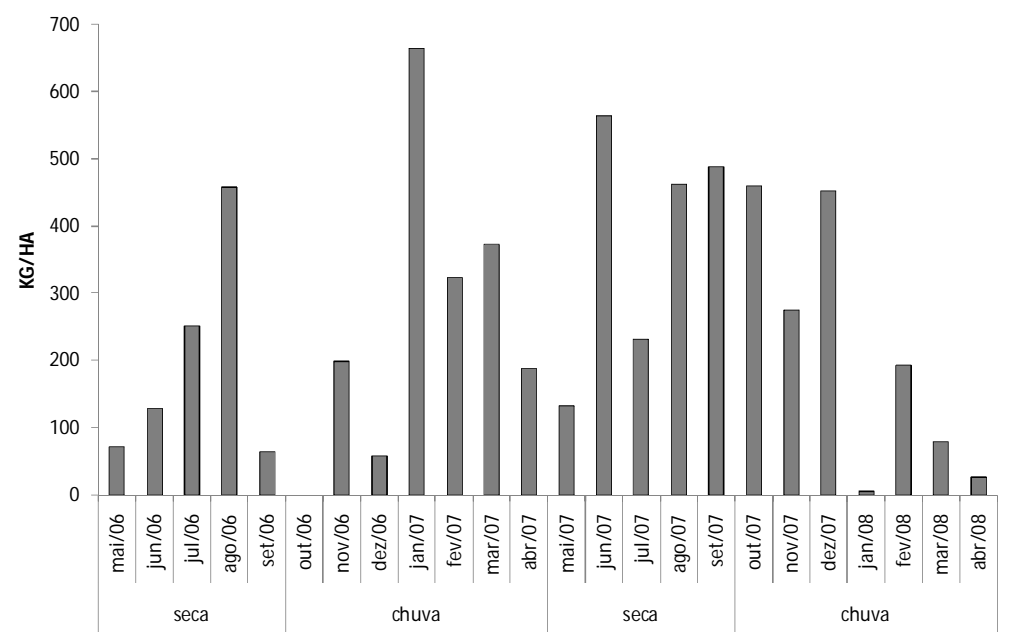

Figura 4: Disponibilidade (biomassa) de frutos na BV entre maio de 2006 e abril de 2008.

\subsubsection{Disponibilidade de flores}

Em dezembro de 2006, após constatar a importância de flores e néctar na dieta da população estudada, iniciei a amostragem destes recursos.

Houve grande variação na oferta de flores na mata a cada mês (Figura 5). Durante a estação chuvosa, a biomassa média de flores foi de $355,0 \pm 168,0 \mathrm{~kg} / \mathrm{ha}$, enquanto na estação seca foi de $229,0 \pm 148,0 \mathrm{~kg} / \mathrm{ha}$, mas a variação entre as estações não foi significativa $(\mathrm{F}=2,768 ; \mathrm{gl}=15 ; \mathrm{p}=0,118)$.

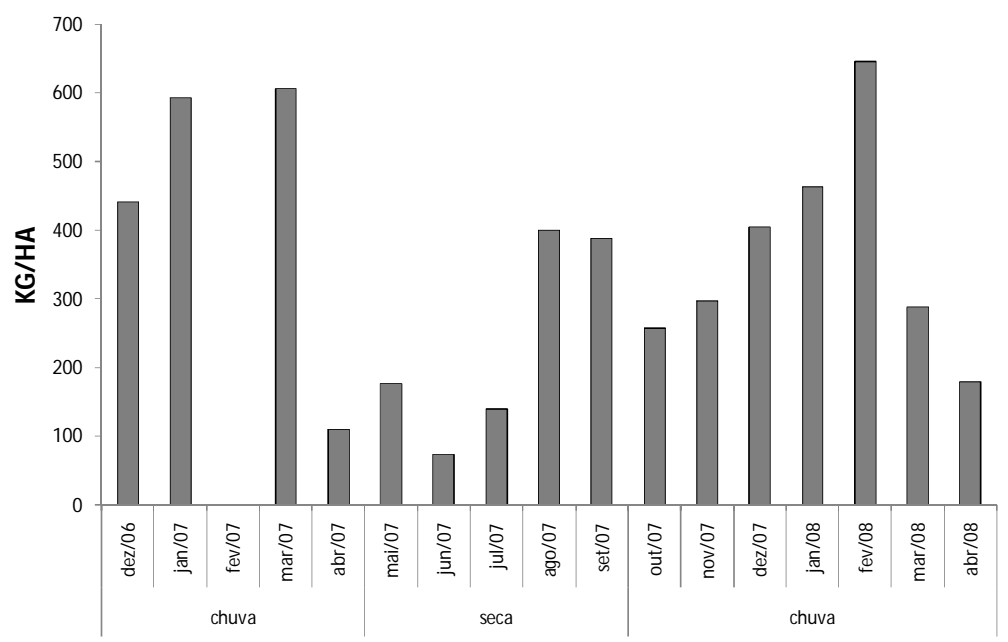

Figura 5: Disponibilidade (bimoassa) de flores na BV entre dezembro de 2006 e abril de 2008. 


\subsubsection{Disponibilidade de invertebrados}

A oferta de invertebrados no ambiente esteve fortemente associada ao regime de chuvas (Figura 6). Durante a estação chuvosa, a biomassa média de invertebrados na BV foi de 39435,0 $\pm 41088,0 \mathrm{~kg} / \mathrm{ha}$, enquanto na estação seca foi de 10744,0 \pm 3911,0 $\mathrm{kg} / \mathrm{ha}$, sendo significativa a diferença entre as estações $(\mathrm{F}=4,811 ; \mathrm{gl}=23 ; \mathrm{p}<0,05)$.

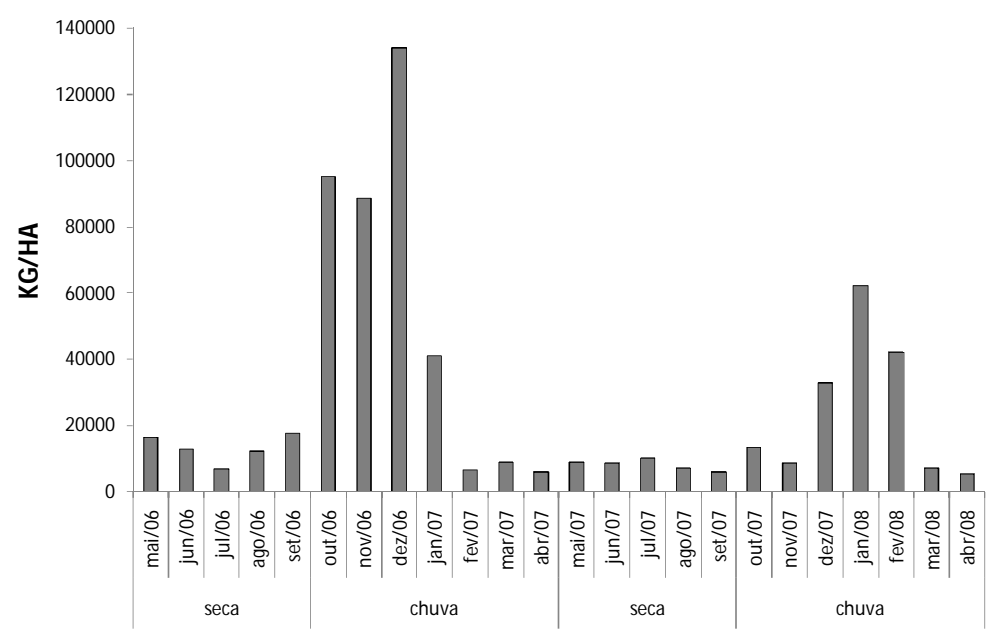

Figura 6: Disponibilidade (biomassa) de invertebrados na BV entre maio de 2006 e abril de 2008.

\subsubsection{Disponibilidade de cocos}

O estudo fenológico das palmeiras piaçava (Orbignya sp) e catulé (Attalea barreirensis) revelou que os cocos estiveram disponíveis no ambiente ao longo de todo o período de estudo, considerando a produtividade das duas espécies conjuntamente (Figura 7). Houve, entretanto, uma oferta total de cocos (catulé + piaçava) significativamente maior na estação seca $(30,7 \pm 6,1$ palmeiras com frutos/ha) do que na estação chuvosa $(15,3 \pm 6,2$ palmeiras com frutos/ha; $\mathrm{F}=35,877 ; \mathrm{gl}=23 ; \mathrm{p}<0,001)$. 


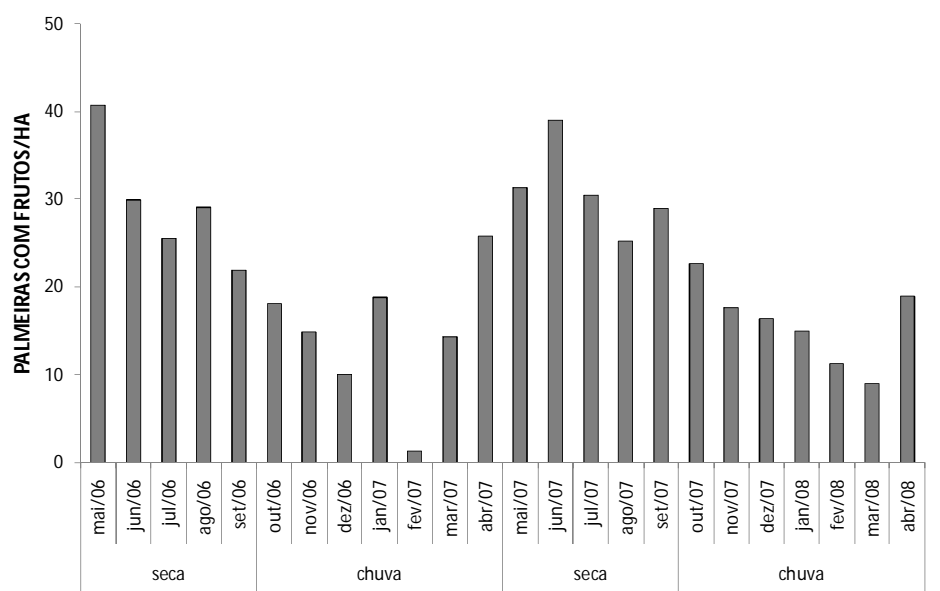

Figura 7: Disponibilidade (número de palmeiras catulé e piaçava com frutos) de cocos na BV entre maio de 2006 e abril de 2008.

As duas espécies de palmeiras diferiram quanto ao período de frutificação (Figura 8) e densidade populacional. O número de palmeiras piaçava frutificando a cada mês não variou entre as estações seca $(4,3 \pm 2,6$ palmeiras com frutos/ha) e chuvosa $(5,1$ \pm 3,5 palmeiras com frutos/ha; $\mathrm{F}=0,084 ; \mathrm{gl}=23 ; \mathrm{p}=0,775)$. Já a palmeira catulé apresentou um pico de frutificação na estação seca $(26,5 \pm 6,8$ palmeiras com frutos/ha; chuvosa: $10,2 \pm 6,0$ palmeiras com frutos/ha; $F=35,870 ; \mathrm{gl}=23 ; \mathrm{p}<0,001)$. Palmeiras da espécie catulé (343 palmeiras/ha) também foram mais abundantes no ambiente do que da espécie piaçava (145 palmeiras/ha, Tabela 1).

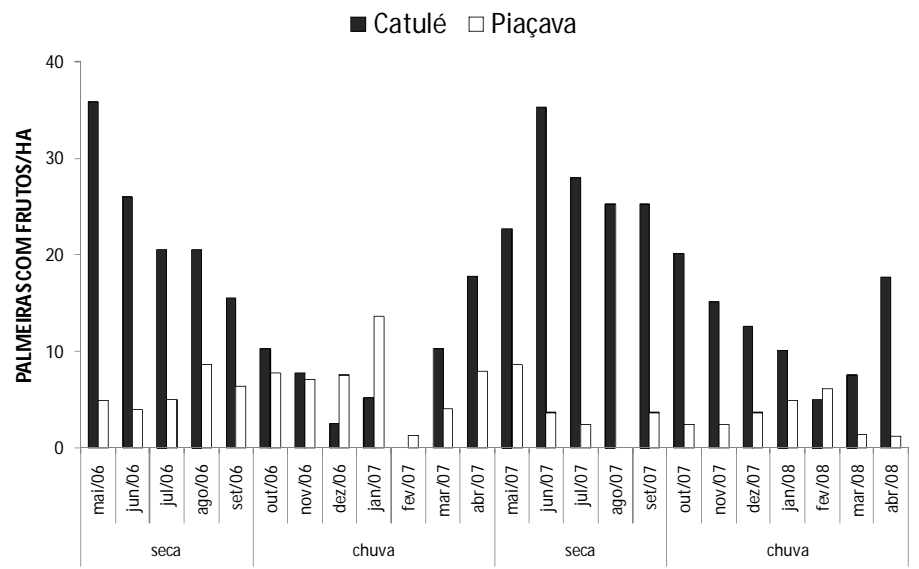

Figura 8: Disponibilidade de cocos da palmeira catulé e da palmeira piaçava (número de indivíduos com frutos) na BV entre maio de 2006 e abril de 2008. 


\subsection{Orcamento de atividades}

\subsubsection{Grupo Zangado}

Os membros do grupo ZA dedicaram a maior parte de seu tempo à atividade de alimentação (comer + forragear), em média, 46,0 \pm 6,9\% (média \pm DP) das amostras de varredura (comer: $26,0 \pm 5,8 \%$ e forragear: $20,0 \pm 5,0 \%$ ). Não houve diferença significativa no tempo dedicado à alimentação entre as estações seca e chuvosa, nem no tempo dedicado às atividades de comer e forragear (Figura 9). Locomoção foi a segunda atividade mais freqüente no grupo, representando, em média, 25,0 $\pm 4,4 \%$ das amostras de varredura. Por outro lado, o tempo dedicado ao uso de ferramentas correspondeu à menor proporção do orçamento de atividades do grupo (em média, 1,2 \pm 1,1\% das amostras de varredura). Não houve variação significativa no tempo de locomoção entre as estações seca e chuvosa, assim como no tempo dedicado ao descanso, utilização de ferramenta e comportamentos incluídos na categoria outros.

Já o tempo dedicado à observação/vigilância $(8,3 \pm 3,1 \%)$ e à interação social $(7,6 \pm 3,6 \%)$ variou significativamente entre as estações. A observação/vigilância foi mais freqüente na estação seca $(F=7,050 ; g l=23 ; p<0,05)$, enquanto as interações sociais foram mais freqüentes na chuvosa $(\mathrm{F}=6,863 ; \mathrm{gl}=23 ; \mathrm{p}<0,05$; Figura 10). Houve diferença no tempo alocado para as diferentes interações sociais $(\mathrm{F}=23,963 ; \mathrm{gl}=95$; $\mathrm{p}<0,001)$, sendo que o tempo dedicado ao cuidado de filhotes $(37,5 \pm 30,5 \%$ das amostras de varredura de interação social) foi significativamente maior que o tempo dedicado à catação $(7,2 \pm 7,6 \% ; \mathrm{p}<0,001)$ e ao agonismo $(6,0 \pm 5,3 \% ; \mathrm{p}<0,001)$, e tempo dedicado à brincadeira social $(49,3 \pm 29,8 \%)$ maior que o dedicado à catação $(\mathrm{p}<0,001)$ e ao agonismo $(\mathrm{p}<0,001)$. O tempo dedicado às diferentes interações sociais variou entre as estações, de modo que o tempo despendido em cuidado de filhotes e em catação foi maior na estação seca (cuidado: $52,7 \pm 29,4 \%$; catação: $11,5 \pm 9,8 \%$ ) do que 
na chuvosa (cuidado: $26,6 \pm 27,2 \% ; \mathrm{F}=5,032 ; \mathrm{gl}=23$; $\mathrm{p}<0,05$; catação: $4,2 \pm 3,2 \%$; $\mathrm{F}=6,997 ; \mathrm{gl}=23 ; \mathrm{p}<0,05)$, enquanto o tempo dedicado à brincadeira social foi maior na estação chuvosa $(63,0 \pm 26,0 \%)$ do que na seca $(30,1 \pm 24,2 \% ; \mathrm{F}=9,885 ; \mathrm{gl}=23$; $\mathrm{p}<0,01)$.

O tempo despendido em alimentação foi negativamente correlacionado ao de descanso $(r=-0,669 ; \mathrm{p}<0,001)$, assim como o de forrageamento ao de uso de ferramenta $(r=-0,436 ; \mathrm{p}<0,05)$. Houve tendência para correlação positiva entre o tempo dedicado à observação e à quebra $(r=0,394 ; \mathrm{p}=0,057)$.

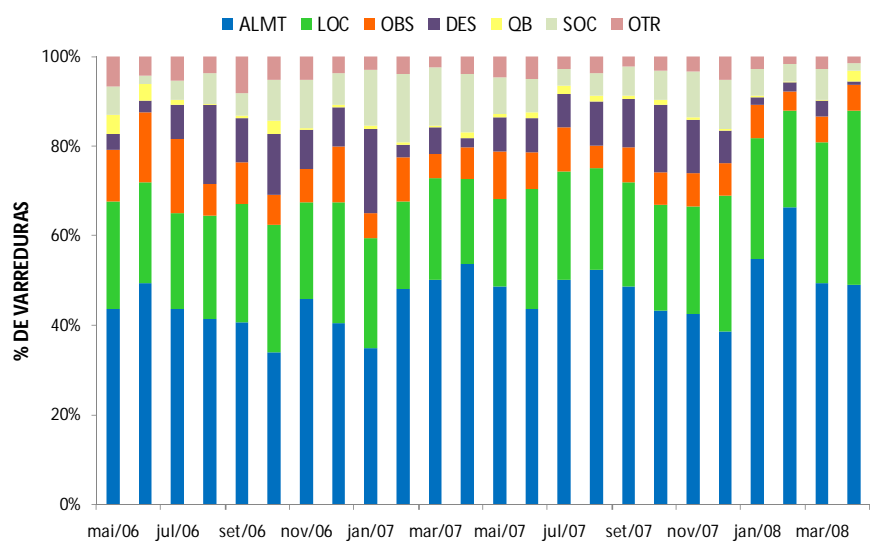

Figura 9: Orçamento de atividades do grupo ZA entre maio de 2006 e abril de 2008. Almt=alimentação (comer + forragear); Loc=locomoção; Obs=observação; Des=descanso; $\mathrm{Qb}=$ quebra de alimento com utilização de ferramenta; Soc=interação social; Otr=outros.

Houve efeito do período do dia sobre padrão de atividades do grupo ( $\mathrm{F}=3,404$; $\mathrm{gl}=116 ; \mathrm{p}<0,001)$, sendo que três atividades variaram significativamente: 1) comer $(\mathrm{F}=9,305 ; \mathrm{p} \leq 0,001) ; 2)$ locomover $(\mathrm{F}=9,305 ; \mathrm{p}<0,001)$ e 3$)$ descansar $(\mathrm{F}=15,198$; p<0,001), como indica a Figura 11. O tempo despendido na atividade de comer foi maior durante a manhã do que à tarde $(\mathrm{p}<0,001)$. O tempo de locomoção foi maior nos períodos da manhã $(\mathrm{p} \leq 0,001)$ e da tarde $(\mathrm{p}<0,001)$ do que no meio do dia, enquanto o tempo de descanso foi maior no meio do dia do que de manhã $(\mathrm{p}<0,001)$ e de tarde 
$(\mathrm{p}<0,001)$. Não foi encontrado efeito significativo da interação entre período do dia e estação $(\mathrm{F}=0,609 ; \mathrm{gl}=116 ; \mathrm{p}=0,886)$.

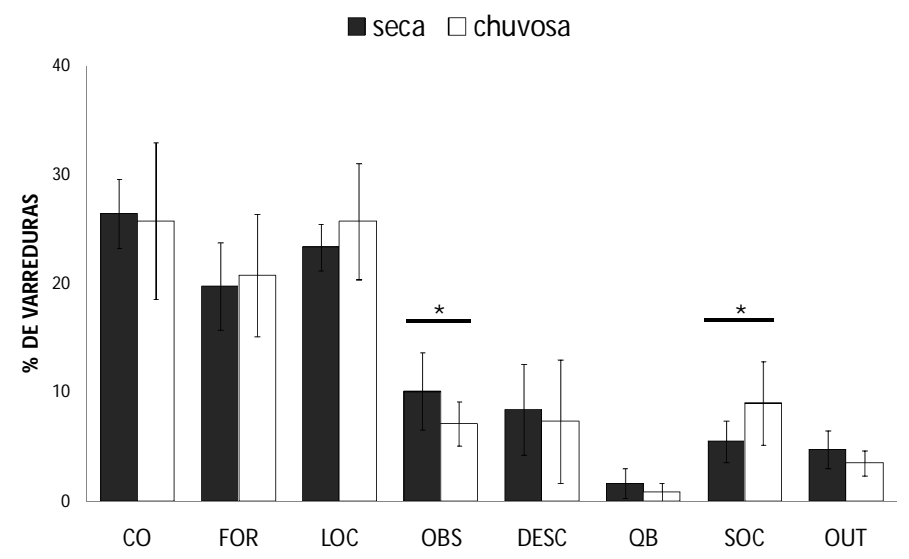

Figura 10: Orçamento de atividades do grupo ZA nas estações seca e chuvosa (média e desvio padrão). $\quad$ Co=comer; $\quad$ For=forragear; Loc=locomoção; Obs=observação; Des=descanso; $\mathrm{Qb}=$ quebra de alimento com utilização de ferramenta; Soc=interação social; Otr=outros; * $\mathrm{p}<0,05$.

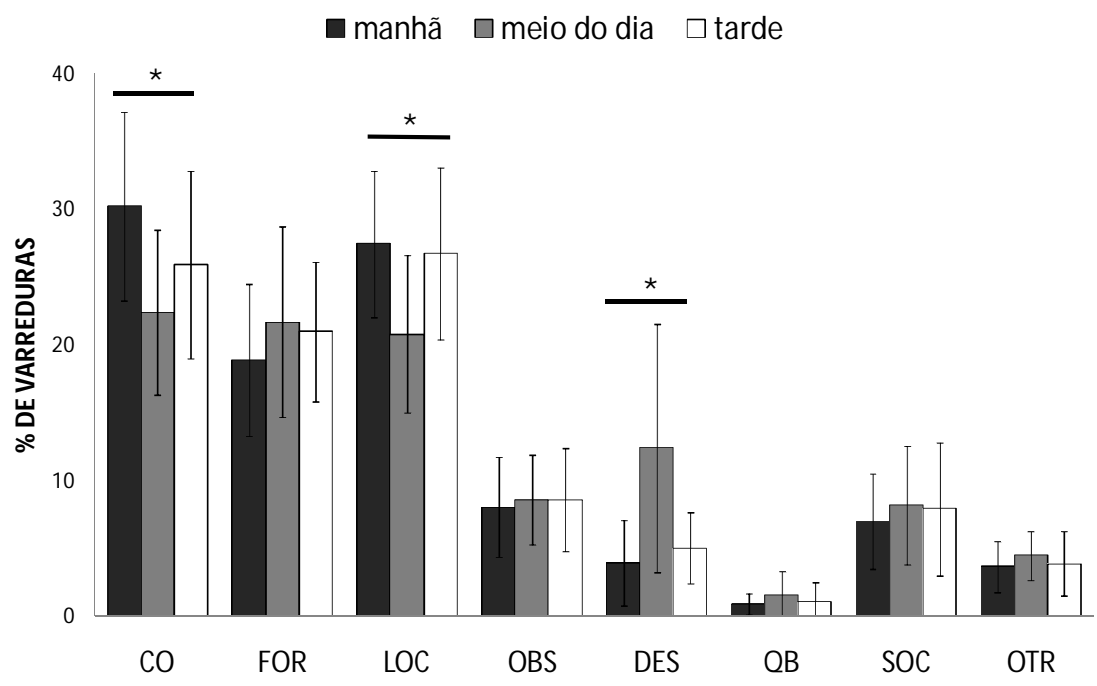

Figura 11: Orçamento de atividades do grupo ZA nos períodos da manhã, meio do dia e tarde. $\mathrm{Co}=$ comer; For=forragear; Loc=locomoção; Obs=observação; Des=descanso; $\mathrm{Qb}=$ quebra de alimento com utilização de ferramenta; Soc=interação social; Otr=outros; $\mathrm{p} \leq 0,001$.

O orçamento de atividades variou em função do sexo dos membros do grupo $(\mathrm{F}=7,717 ; \mathrm{gl}=48 ; \mathrm{p}<0,001)$. Machos e fêmeas diferiram quanto ao tempo dedicado às 
atividades de alimentação ( $\mathrm{F}=23,202 ; \mathrm{p}<0,001)$, observação $(\mathrm{F}=34,799 ; \mathrm{p}<0,001)$ e interação social $(\mathrm{F}=8,552 ; \mathrm{p}<0,01)$, sendo que fêmeas se alimentaram mais do que machos e machos observaram e interagiram socialmente mais do que fêmeas, como indica a Figura 12).

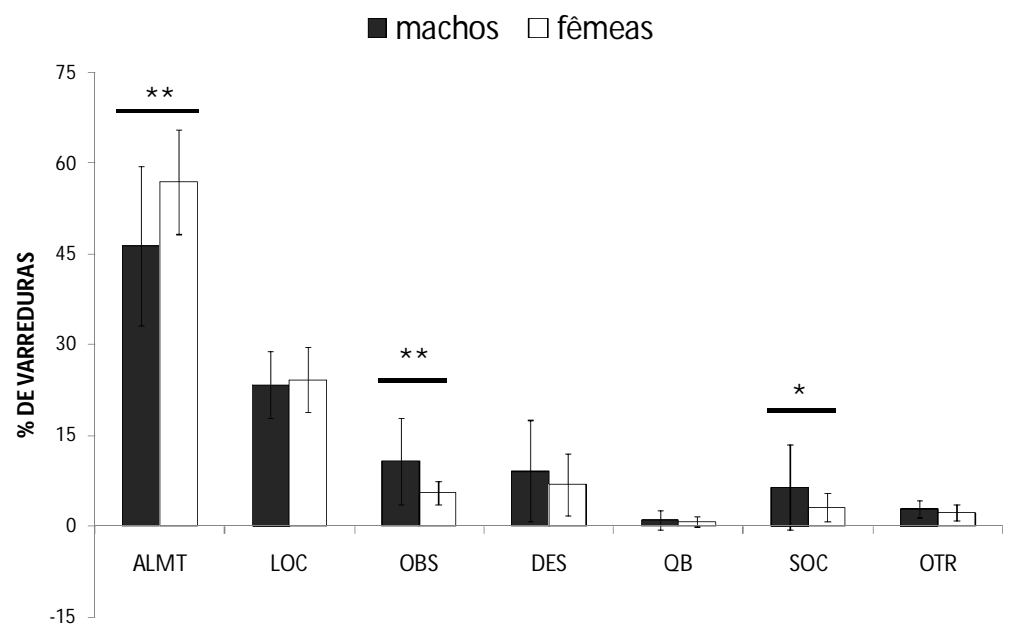

Figura 12: Orçamento de atividades de machos e fêmeas do grupo ZA. Almt=alimentação (comer + forragear); Loc=locomoção; Obs=observação; Des=descanso; $Q b=q u e b r a$ de alimento com utilização de ferramenta; Soc=interação social; Otr=outros; $* \mathrm{p}<0,01 ; * * \mathrm{p}<0,001^{2}$.

Houve, também, efeito da idade dos indivíduos sobre o padrão de atividades $(\mathrm{F}=9,765 ; \mathrm{gl}=48 ; \mathrm{p}<0,001)$, de modo que todas as atividades foram afetadas (alimentação: $\mathrm{F}=36,976 ; \mathrm{p}<0,001 ;$ locomoção: $\mathrm{F}=12,298 ; \mathrm{p} \leq 0,001$; observação: $\mathrm{F}=54,854 ; \mathrm{p}<0,001$; descanso: $\mathrm{F}=17,061 ; \mathrm{p}<0,001 ;$ uso de ferramenta: $\mathrm{F}=14,497$; $\mathrm{p}<0,001$; interação social: $\mathrm{F}=14,947 ; \mathrm{p}<0,001)$. Juvenis dedicaram significativamente mais tempo do que adultos às atividades de alimentação e interação social. Já o tempo dedicado à locomoção, observação, descanso e utilização de ferramentas foi maior entre os adultos do que entre os juvenis (Figura 13).

\footnotetext{
2. Os gráficos referentes às comparações entre machos e fêmeas e entre adultos e juvenis exibem a categoria "alimentação" quando há diferença estatística apenas se agrupadas as amostras de varredura de comer e forragear, sendo que, separadamente, essas categorias não diferem estatisticamente.
} 
A análise GLM também revelou um efeito significativo da interação entre sexo e idade sobre o orçamento de atividades $(\mathrm{F}=3,143 ; \mathrm{gl}=48 ; \mathrm{p}<0,01)$. Fêmeas adultas e fêmeas juvenis dedicaram mais tempo à alimentação do que o macho adulto e machos juvenis $(\mathrm{F}=5,534 ; \mathrm{p}<0,05)$. Machos adultos e machos juvenis dedicaram mais tempo à observação do que fêmeas adultas e fêmeas juvenis $(F=28,195 ; \mathrm{p}<0,001)$. O tempo despendido em descanso foi maior para o macho adulto do que entre as fêmeas adultas, e maior entre fêmeas juvenis do que entre machos juvenis $(F=4,992 ; p<0,05)$. Já o tempo despendido em interação social foi maior entre os machos juvenis do que entre as fêmeas juvenis $(F=9,494 ; p<0,01)$, como indica a Figura 14.

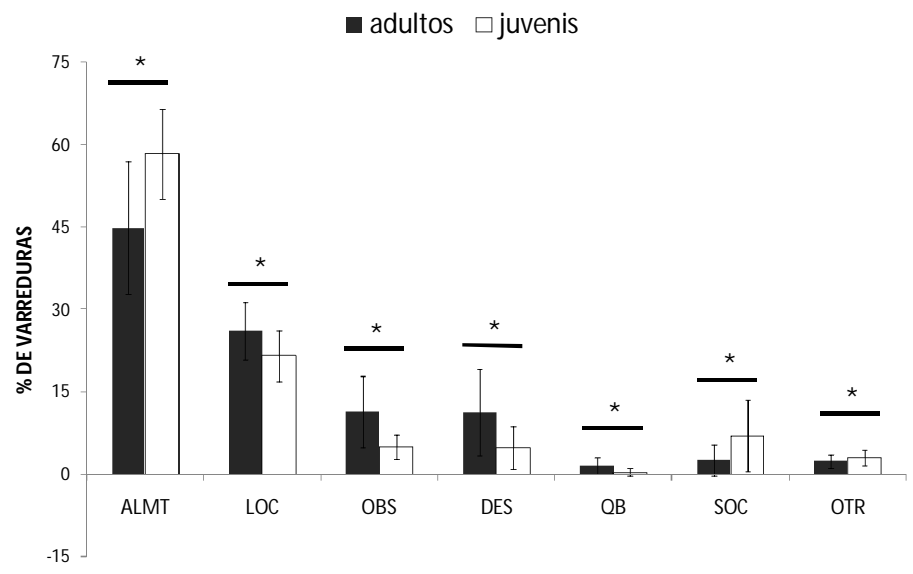

Figura 13: Orçamento de atividades de adultos e juvenis do grupo ZA. Almt=alimentação (comer + forragear); Loc=locomoção; Obs=observação; Des=descanso; Qb=quebra de alimento com utilização de ferramenta; Soc=interação social; Otr=outros; $\mathrm{p} \leq 0,001$. 


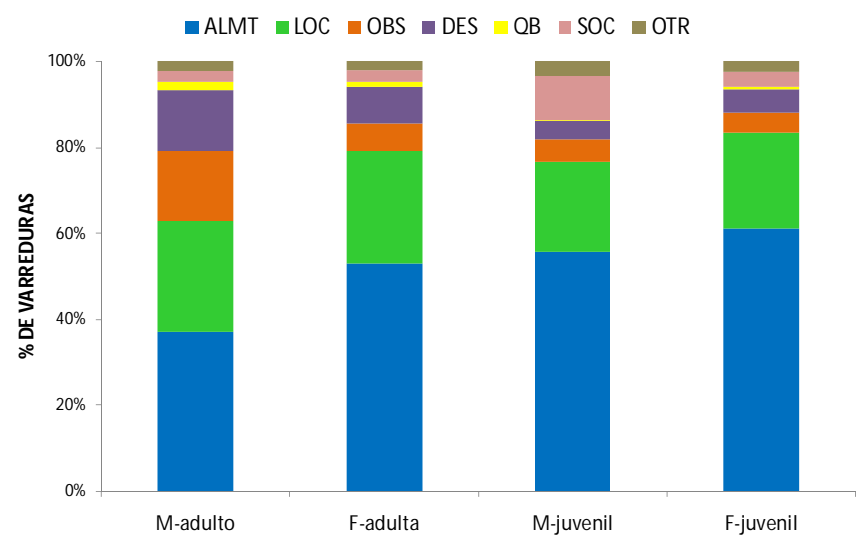

Figura 14: Orçamento de atividades do grupo ZA por classe de sexo e idade entre o período de fevereiro de 2007 e abril de 2008. Almt=alimentação (comer + forragear);

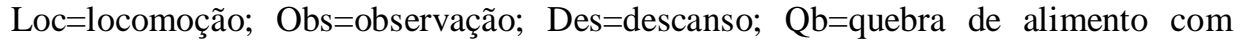
utilização de ferramenta; Soc=interação social; Otr=outros; $M=$ macho; $F=$ fêmea.

\subsubsection{Grupo Chicão}

$\mathrm{O}$ grupo $\mathrm{CH}$ também dedicou a maior parte do seu tempo de atividades à alimentação (em média, 46,0 $\pm 5,4 \%$ das amostras de varredura, sendo $26,5 \pm 3,7 \%$ para comer e 19,5 $\pm 3,6 \%$ para forragear), como mostra a Figura 15. Assim como verificado para o grupo ZA, o tempo dedicado à utilização de ferramentas representou a menor proporção do orçamento de atividades do grupo $\mathrm{CH}$ (em média, 2,3 \pm 1,6\% das amostras de varredura). Não foram observadas diferenças significativas nas atividades do grupo entre as estações seca e chuva (Figura 16). Contudo, houve diferença no tempo alocado para as diferentes atividades sociais $(\mathrm{F}=25,712 ; \mathrm{gl}=59 ; \mathrm{p}<0,001)$, sendo que $\mathrm{o}$ tempo dedicado ao cuidado de filhotes $(47,9 \pm 23,3 \%$ das amostras de varredura de interação social) foi maior do que o tempo dedicado à catação $(7,5 \pm 4,7 \% ; \mathrm{p}<0,001)$ e ao agonismo $(6,9 \pm 6,9 \% ; \mathrm{p}<0,001)$, e o tempo dedicado à brincadeira social $(37,6 \pm$ 20,3\%) maior que o dedicado à catação $(\mathrm{p}<0,001)$ e ao $(\mathrm{p}<0,001)$ agonismo. O tempo alocado as diferentes interações sociais variou entre as estações, de modo que o cuidado de filhotes foi maior na estação chuvosa $(60,6 \pm 16,6 \%)$ do que na seca $(22,7 \pm 8,9 \%$; $\mathrm{F}=22,220 ; \mathrm{gl}=14 ; \mathrm{p}<0,001)$, enquanto o tempo dedicado à catação $(11,9 \pm 2,8 \%)$ e a 
brincadeira social $(55,1 \pm 19,7 \%)$ foi maior na estação seca do que na chuvosa (catação: $5,4 \pm 3,9 \% ; \mathrm{F}=10,906 ; \mathrm{gl}=14 ; \mathrm{p}<0,01 ;$ brincadeira social: $28,9 \pm 14,6 \% ; \mathrm{F}=8,576$ $\mathrm{gl}=14 ; \mathrm{p}<0,05)$.

O tempo dedicado à locomoção foi negativamente correlacionado ao tempo de forrageamento $(r=-0,537, \mathrm{p}<0,05)$ e ao de quebra de $\operatorname{cocos}(\mathrm{P}=-0,594, \mathrm{p}<0,05)$. Houve tendência para correlação negativa entre o tempo dedicado à alimentação e ao descanso $(r=-0,489, \mathrm{p}=0,065)$.

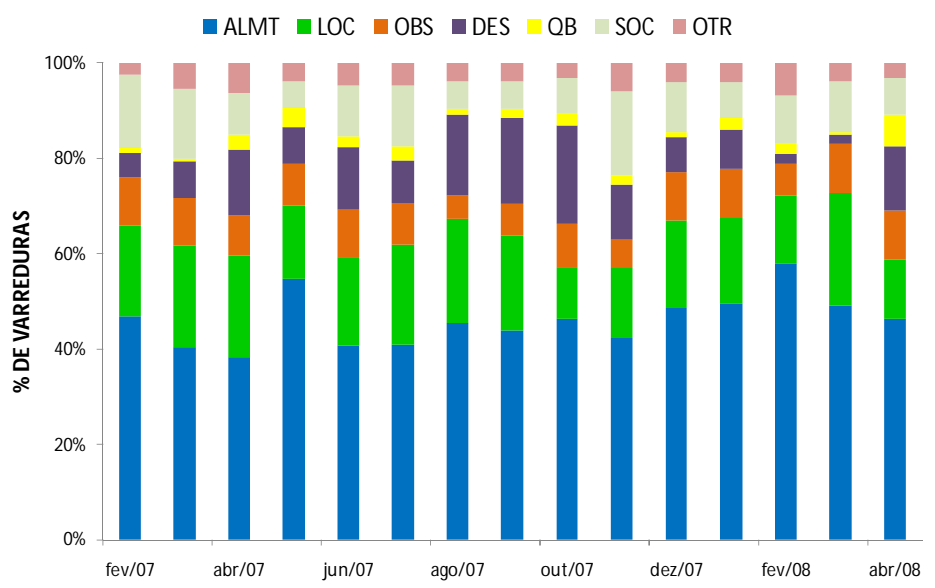

Figura 15: Orçamento de atividades do grupo $\mathrm{CH}$ entre o período de fevereiro de 2007 e abril de 2008. Almt=alimentação (comer + forragear); Loc=locomoção; Obs=observação; Des=descanso; $\mathrm{Qb}=$ quebra de alimento com utilização de ferramenta; Soc=interação social; Otr=outros.

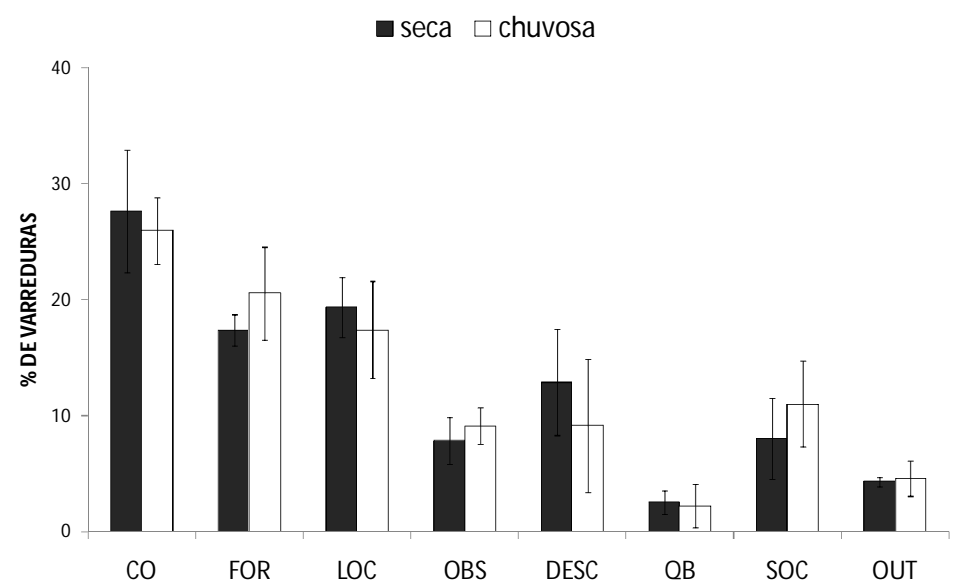

Figura 16: Orçamento de atividades do grupo $\mathrm{CH}$ nas estações seca e chuvosa. $\mathrm{Co}=$ comer; For=forragear; Loc=locomoção; Obs=observação; Des=descanso; Qb=quebra de alimento com utilização de ferramenta; Soc=interação social; Otr=outros. 
O padrão de atividades do grupo variou em função do período do dia $(\mathrm{F}=1,851$; $\mathrm{gl}=62 ; \mathrm{p}<0,05)$, de modo que as atividades afetadas foram: 1$)$ comer $(\mathrm{F}=6,316 ; \mathrm{p}<0,01)$, 2) locomoção $(F=4,545 ; p<0,05)$ e 3$)$ descanso $(F=8,917 ; p \leq 0,001)$ (Figura 17). $O$ tempo dedicado à atividade de comer foi maior no período da manhã do que no meio do dia $(\mathrm{p}<0,05)$, enquanto o tempo despendido em locomoção foi maior à tarde do que no meio do dia $(\mathrm{p}<0,05)$. A atividade de descanso, por outro lado, foi mais freqüente no meio do dia do que nos períodos da manhã $(\mathrm{p}<0,01)$ e tarde $(\mathrm{p}<0,05)$.

Não houve efeito significativo da interação entre estação e período do dia $(\mathrm{F}=0,839 ; \mathrm{gl}=62 ; \mathrm{p}=0,649)$.

A análise GLM revelou efeito significativo de sexo $(F=7,620 ; g l=48 ; p<0,001)$, idade $(\mathrm{F}=9,593 ; \mathrm{gl}=48 ; \mathrm{p}<0,001)$ e sexo/idade $(\mathrm{F}=5,357 ; \mathrm{gl}=48 ; \mathrm{p}<0,001)$ sobre o orçamento de atividades do grupo $\mathrm{CH}$. Fêmeas dedicaram mais tempo ao forrageamento $(\mathrm{F}=10,877 ; \mathrm{p}<0,01)$ e à locomoção $(\mathrm{F}=8,175 ; \mathrm{p}<0,01)$ do que machos, enquanto machos despenderam mais tempo em observação $(\mathrm{F}=24,161 ; \mathrm{p}<0,001)$, uso de ferramentas $(\mathrm{F}=25,555 ; \mathrm{p}<0,001)$ e interação social $(\mathrm{F}=14,425 ; \mathrm{p}<0,001)$ do que fêmeas (Figura 18).

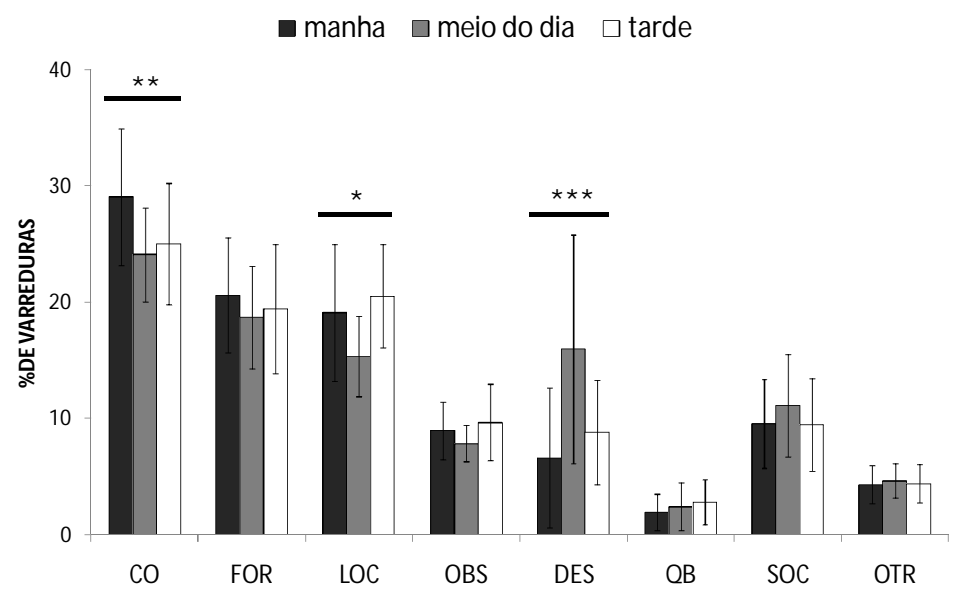

Figura 17: Orçamento de atividades do grupo $\mathrm{CH}$ nos períodos da manhã, meio do dia e tarde. $\mathrm{Co}=$ comer; For=forragear; Loc=locomoção; Obs=observação; Des=descanso; $\mathrm{Qb}=$ quebra de alimento com utilização de ferramenta; Soc=interação social; Otr=outros; ${ }^{*} \mathrm{p}<0,05 ; * * \mathrm{p}<0,01 ; * * * \mathrm{p} \leq 0,001$. 


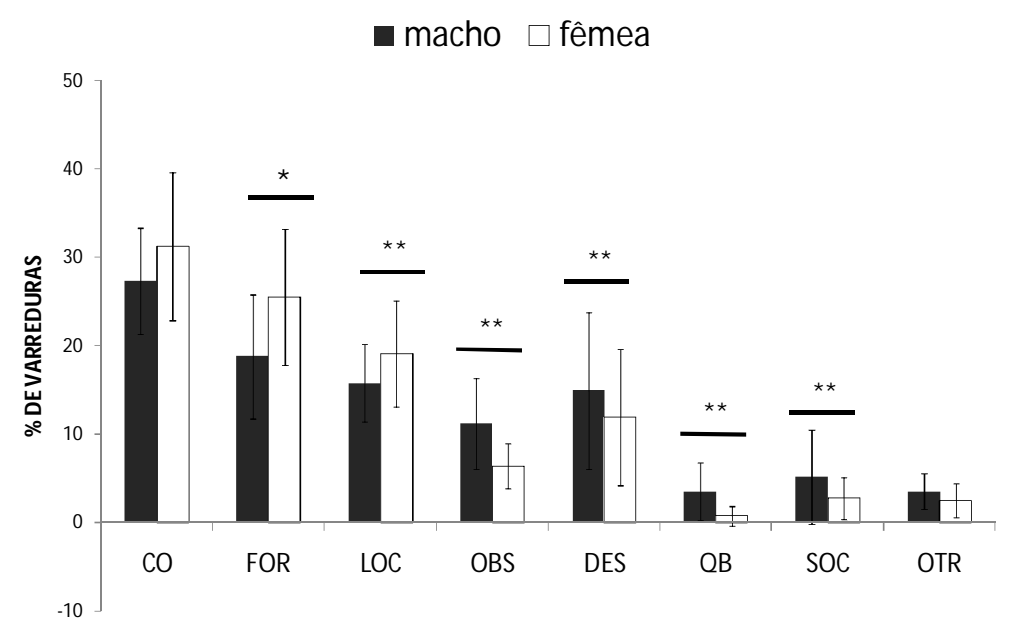

Figura 18: Orçamento de atividades de machos e fêmeas grupo $\mathrm{CH} . \mathrm{Co}=$ comer; For=forragear; Loc=locomoção; Obs=observação; Des=descanso; $Q b=q u e b r a$ de alimento com utilização de ferramenta; Soc=interação social; Otr=outros; * $\mathrm{p}<0,01 ;{ }^{*} \mathrm{p}<0,001$.

A idade dos indivíduos do grupo afetou as atividades de alimentação ( $\mathrm{F}=27,784$; p<0,001), observação $(F=29,753 ; p<0,001)$, descanso $(F=11,346 ; p<0,001)$ e quebra $(\mathrm{F}=21,980 ; \mathrm{p}<0,001)$. Juvenis dedicaram mais tempo à atividade de alimentação do que adultos, enquanto adultos despenderam mais tempo em observação, descanso e uso de ferramentas do que juvenis (Figura 19).

A interação entre sexo e idade afetou os comportamentos de observação $(\mathrm{F}=8,771 ; \mathrm{p}<0,001)$, descanso $(\mathrm{F}=6,484 ; \mathrm{p}<0,05)$ e interação social $(\mathrm{F}=32,232$; $\mathrm{p}<0,001)$. Machos adultos e machos juvenis dedicaram mais tempo à atividade de observação do que fêmeas adultas e fêmeas juvenis. O tempo despendido em descanso foi maior entre machos adultos do que entre fêmeas adultas, e maior entre fêmeas juvenis do que entre machos juvenis. Já o tempo dedicado à interação social foi maior entre fêmeas adultas do que entre machos adultos, e maior entre machos juvenis do que entre fêmeas juvenis (Figura 20). 


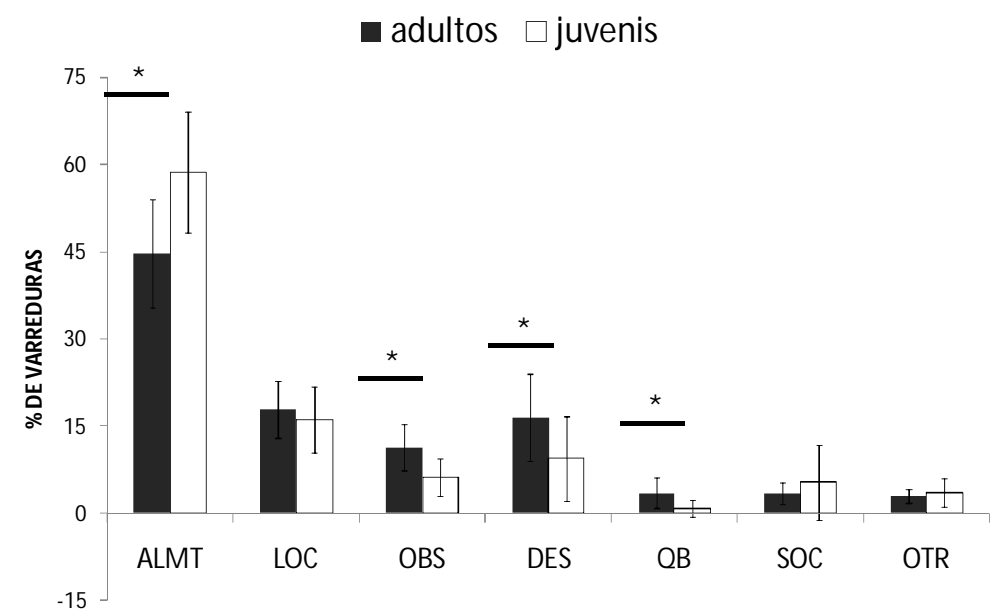

Figura 19: Orçamento de atividades de adultos e juvenis do grupo $\mathrm{CH}$. Almt=alimentação (comer + forragear); Loc=locomoção; Obs=observação; Des=descanso; $\mathrm{Qb}=q u e b r a$ de alimento com utilização de ferramenta; Soc=interação social; Otr=outros; $* \mathrm{p}<0,001$.

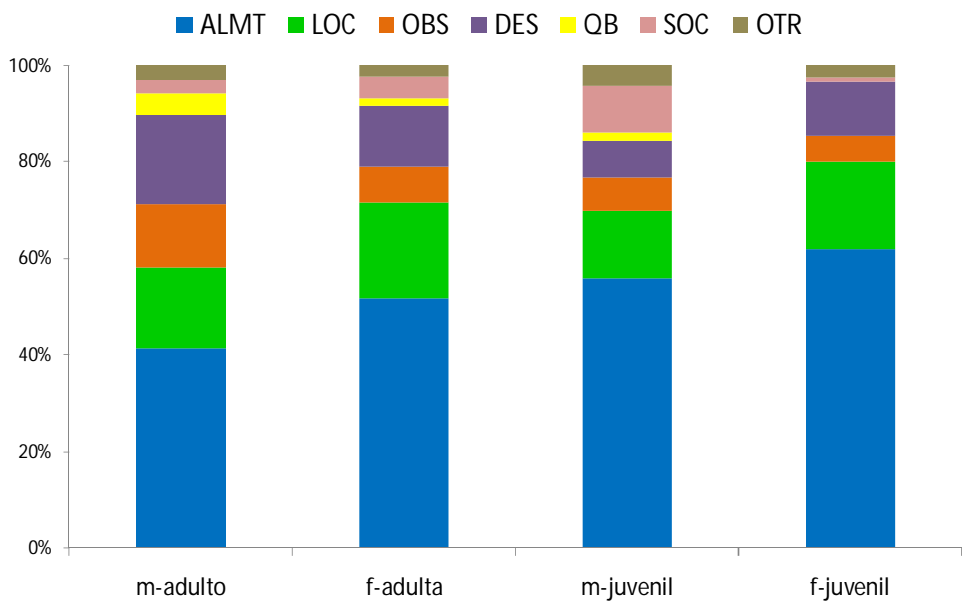

Figura 20: Orçamento de atividades do grupo $\mathrm{CH}$ por classe de sexo e idade entre o período de fevereiro de 2007 e abril de 2008. Almt=alimentação (comer + forragear);

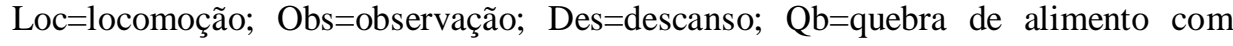
utilização de ferramenta; Soc=interação social; Otr=outros.

\subsubsection{Orçamento de atividades: comparação entre grupos}

Apesar do aprovisionamento do grupo $\mathrm{CH}$, foram observadas poucas variações entre os grupos de estudo quanto ao orçamento de atividades. A análise GLM mostrou uma tendência de efeito de grupo sobre o orçamento de atividades $(\mathrm{F}=2,193$; $\mathrm{gl}=18$; $\mathrm{p}=0,075)$, sendo que as atividades afetadas foram a locomoção $(\mathrm{F}=11,598 ; \mathrm{p}<0,01)$, o 
uso de ferramenta $(F=7,650 ; p<0,05)$ e o descanso $(F=4,756 ; p<0,05)$. O grupo ZA despendeu mais tempo em locomoção, enquanto o grupo $\mathrm{CH}$ dedicou mais tempo às atividades de uso de ferramenta e descanso (Tabela 3).

Embora o efeito da interação entre estação e grupo sobre o orçamento de atividades não tenha sido significativa $(\mathrm{F}=0,946 ; \mathrm{gl}=18 ; \mathrm{p}=0,512)$, o tempo de observação do grupo $\mathrm{CH}$ foi superior ao do grupo ZA na estação chuvosa, enquanto na estação seca, a observação foi maior no grupo ZA $(\mathrm{F}=4,615$; $\mathrm{gl}=1 ; \mathrm{p}<0,05)$, como indica a Tabela 3.

Tabela 3: Comparação do orçamento de atividades (porcentagem das amostras de varredura e desvio padrão) dos grupos ZA e CH para todo período de estudo e para as estações seca e chuvosa.

\begin{tabular}{c|l|ccccccccc}
\hline ESTAÇÃO & GRUPO & CM & FR & CF & LC & OB & DE & QB & SC & OT \\
\hline \multirow{2}{*}{ Geral } & Zangado & 26 & 20,3 & 46,4 & $24,7^{* *}$ & 8,3 & $7,8^{*}$ & $1,2^{*}$ & 7,6 & 4,0 \\
& Chicão & 26,3 & 19,5 & 46 & $18,1^{* *}$ & 8,7 & $10,4^{*}$ & $2,3^{*}$ & 10 & 4,5 \\
\hline \multirow{2}{*}{ Seca } & Zangado & 26,5 & 19,8 & 46,2 & 23,4 & $10,1^{*}$ & 8,4 & 1,6 & 5,5 & 4,8 \\
& Chicão & 27,6 & 14,4 & 45 & 19,4 & $7,8^{*}$ & 12,9 & 2,5 & 8,0 & 4,3 \\
\hline \multirow{2}{*}{ Chuvosa } & Zangado & 25,7 & 20,8 & 46,5 & 25,7 & $7,1^{*}$ & 7,4 & 0,8 & 9,0 & 3,5 \\
& Chicão & 26 & 20,6 & 46,5 & 17,4 & $9,1^{*}$ & 9 & 2,2 & 11 & 4,6 \\
\hline
\end{tabular}

$\mathrm{CM}=$ comer; $\quad \mathrm{FR}=$ forragear; $\quad \mathrm{CF}=$ alimentação $\quad$ (comer + forragear); $\quad \mathrm{LC}=$ locomoção; $\mathrm{OB}=$ observação; $\mathrm{DE}=$ descanso; $\mathrm{QB}=$ quebra de alimento com utilização de ferramenta; $\mathrm{SC}=$ interação social; OT=outros; ${ }^{*} \mathrm{p} \leq 0,05 ; * * \mathrm{p} \leq 0,01$.

Não houve interação entre período do dia e grupo sobre o orçamento de atividades $(\mathrm{F}=0,640 ; \mathrm{gl}=18 ; \mathrm{p}=0,864)$, indicando que a proporção de tempo alocado nas diferentes atividades ao longo do dia foram muito similares entre os grupos $\mathrm{ZA} \mathrm{e} \mathrm{CH}$ (Tabela 4). 
Tabela 4: Comparação do orçamento de atividades (porcentagem das amostras de varredura e desvio padrão) dos grupos ZA e $\mathrm{CH}$ em três períodos do dia.

\begin{tabular}{c|l|lllllllll}
\hline ESTAÇÃO & GRUPO & CM & FR & CF & LC & OB & DE & QB & SC & OT \\
\hline \multirow{2}{*}{ Manhã } & Zangado & 30,2 & 18,9 & 49,1 & 27,4 & 8,0 & 3,9 & 0,9 & 7,0 & 3,6 \\
& Chicão & 29,1 & 20,6 & 49,6 & 19,1 & 8,9 & 6,6 & 1,9 & 9,5 & 4,3 \\
\hline \multirow{2}{*}{ Meio do dia } & Zangado & 22,4 & 21,7 & 44,1 & 20,8 & 8,6 & 12,4 & 1,5 & 8,2 & 4,5 \\
& Chicão & 24,1 & 18,7 & 42,8 & 15,3 & 7,8 & 15,9 & 2,4 & 11,1 & 4,6 \\
\hline \multirow{2}{*}{ Tarde } & Zangado & 25,9 & 21,0 & 46,7 & 26,7 & 8,6 & 5,0 & 1,1 & 7,9 & 3,9 \\
& Chicão & 25,0 & 19,4 & 44,4 & 20,5 & 9,6 & 8,8 & 2,8 & 9,5 & 4,4 \\
\hline
\end{tabular}

$\mathrm{CM}=$ comer; $\quad \mathrm{FR}=$ forragear; $\quad \mathrm{CF}=$ alimentação $\quad$ (comer + forragear); $\quad \mathrm{LC}=$ locomoção; $\mathrm{OB}=$ observação; $\mathrm{DE}=$ descanso; $\mathrm{QB}=$ quebra de alimento com utilização de ferramenta; $\mathrm{SC}=$ interação social; OT=outros.

A comparação entre grupos por classe de sexo e idade revelou que o orçamento de atividades foi afetado pelo sexo $(\mathrm{F}=14,527 ; \mathrm{gl}=104 ; \mathrm{p}<0,001)$ e idade $(\mathrm{F}=19,959$; $\mathrm{gl}=104 ; \mathrm{p}<0,001)$ dos indivíduos e pela interação entre sexo e idade $(\mathrm{F}=7,211 ; \mathrm{gl}=104$; $\mathrm{p}<0,001)$ e grupo e sexo $(\mathrm{F}=2,016 ; \mathrm{gl}=104 ; \mathrm{p}<0,05)$.

Fêmeas dedicaram mais tempo do que machos às atividades de alimentação $(\mathrm{F}=34,616 ; \mathrm{p}<0,001)$ e locomoção $(\mathrm{F}=6,313 ; \mathrm{p}<0,05)$, enquanto machos dedicaram mais tempo do que fêmeas às atividades de observação $(\mathrm{F}=58,939 ; \mathrm{p}<0,001)$, utilização de ferramentas $(F=23,018 ; p<0,001)$ e interação social $(F=21,727 ; p<0,001)$.

A idade dos indivíduos afetou todas as atividades, sendo que adultos dedicaram significativamente mais tempo do que juvenis às atividades de locomoção $(\mathrm{F}=13,623$; $\mathrm{p}<0,001)$, observação $(\mathrm{F}=84,086 ; \mathrm{p}<0,001)$, descanso $(\mathrm{F}=27,440 ; \mathrm{p}<0,001)$ e utilização de ferramentas $(\mathrm{F}=36,058 ; \mathrm{p}<0,001)$. Juvenis, por outro lado, dedicaram mais tempo que adultos às atividades de alimentação $(\mathrm{F}=64,117 ; \mathrm{p}<0,001)$ e interação social $(\mathrm{F}=16,739 ; \mathrm{p}<0,001)$.

A interação entre sexo e idade dos indivíduos afetou as atividades de alimentação $(F=5,271 ; p<0,05)$; observação $(F=35,440 ; p<0,001)$, descanso $(F=11,472$; $\mathrm{p} \leq 0,001)$ e interação social $(\mathrm{F}=35,569 ; \mathrm{p}<0,001)$. Fêmeas adultas e fêmeas juvenis despenderam mais tempo em alimentação do que machos adultos e machos juvenis. Já 
machos adultos e machos juvenis dedicaram mais tempo à observação do que fêmeas adultas e fêmeas juvenis. Machos adultos descansaram mais do que fêmeas adultas, enquanto fêmeas juvenis descansaram mais do que machos juvenis. O tempo dedicado à interação social foi maior entre fêmeas adultas do que entre machos adultos, e maior entre machos juvenis do que entre fêmeas juvenis. Houve tendência para maior tempo despendido em utilização de ferramentas entre machos adultos e machos juvenis do que entre fêmeas adultas e fêmeas juvenis.

A interação entre sexo e grupo afetou a atividade de uso de ferramentas, sendo que os machos do grupo $\mathrm{CH}$ dedicaram mais tempo a essa atividade do que os machos do grupo ZA.

Não foi verificado efeito significativo das interações entre idade e grupo $(\mathrm{F}=1,318 ; \mathrm{gl}=104 ; \mathrm{p}=0,237)$ e sexo, idade e grupo $(\mathrm{F}=0,927 ; \mathrm{p}=0,515)$ sobre o orçamento de atividades dos grupos.

\subsection{Padrão de exploracão de substratos e fisionomias}

\subsubsection{Grupo Zangado}

Houve variação significativa na proporção de tempo que os animais passaram em cada tipo de substrato $(\mathrm{F}=155,105 ; \mathrm{gl}=7 ; \mathrm{p}<0,001)$. O tempo de permanência em substratos arbóreos $(65,0 \pm 10,0 \%)$ foi significativamente superior ao de substratos planos $(32,5 \pm 10,0 \% ; \mathrm{p}<0,001)$ e de cavernas $(2,5 \pm 2,2 \% ; \mathrm{p}<0,001)$, e o de substrato plano foi significativamente maior que o de cavernas ( $\mathrm{p}<0,001$; Figura 21). O tempo de permanência em substratos arbóreos também variou em função da altura $(\mathrm{F}=7,634$; $\mathrm{gl}=71 ; \mathrm{p}<0,001)$, sendo que o uso de estratos de altura $\mathrm{A}(25,8 \pm 6,2 \%)$ foi maior do que o de altura $C(17,3 \pm 10,0 \% ; \mathrm{p}<0,001)$. Não houve diferença entre A e B $(22,0 \pm 4,6 \%)$, 
nem entre B e C. O tempo despendido em cada tipo de substrato não variou entre as estações seca e chuvosa $(\mathrm{F}=1,443 ; \mathrm{gl}=7 ; \mathrm{p}=0,191)$, como mostra a Figura 22.

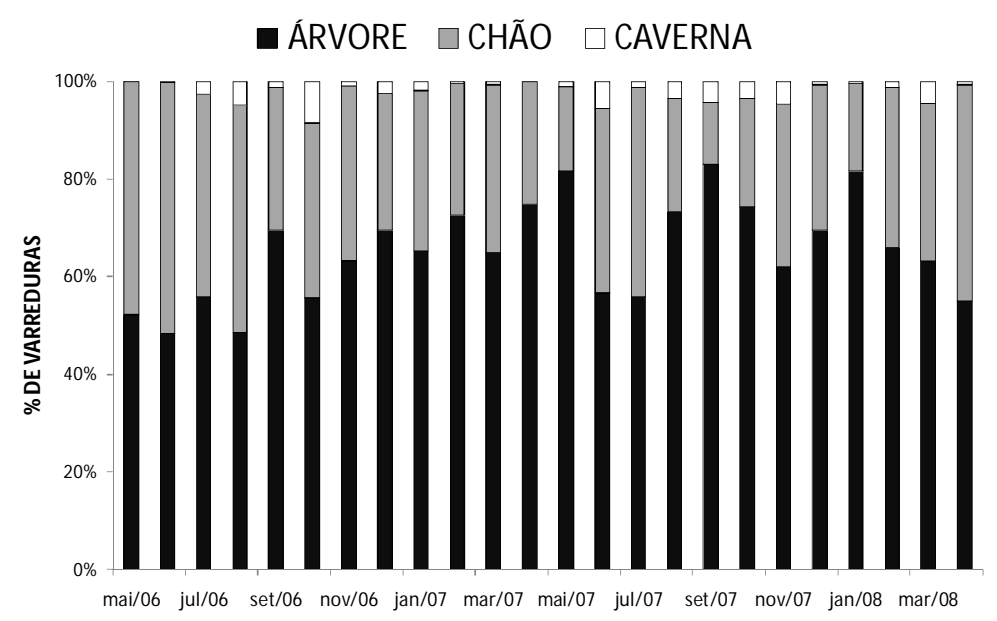

Figura 21: Padrão de uso de substratos pelo grupo ZA entre maio de 2006 e abril de 2008.

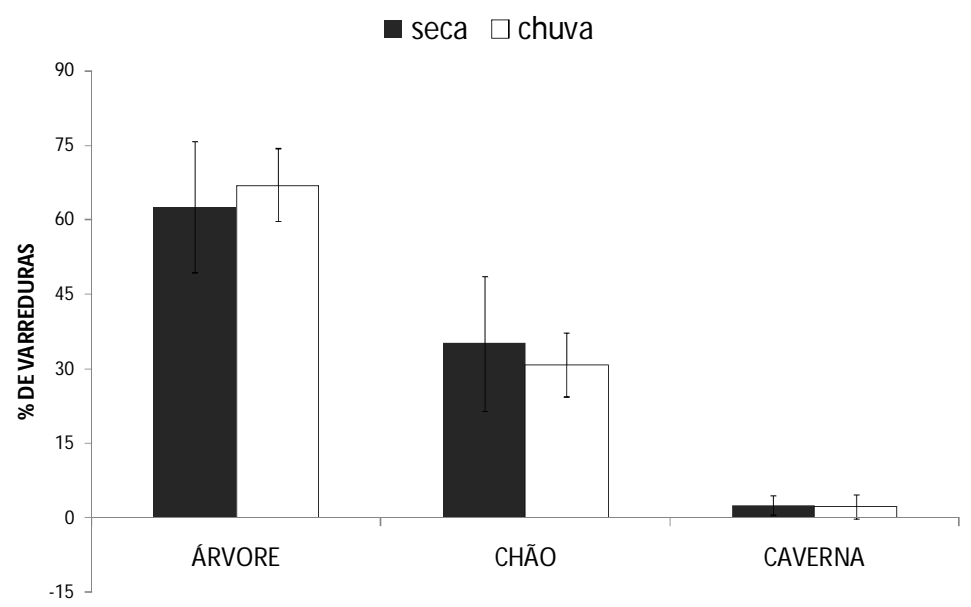

Figura 22: Padrão de uso de substratos pelo grupo ZA nas estações seca e chuvosa.

O tempo de utilização de substratos arbóreos foi negativamente correlacionado ao tempo despendido em locomoção $(r=-0,591 ; \mathrm{p}<0,01)$ e em uso de ferramenta $(r=0,485 ; \mathrm{p}<0,05)$ e positivamente correlacionado ao de interação social $(r=0,421$; $\mathrm{p}<0,05)$. O tempo de permanência em substratos planos foi positivamente correlacionado ao tempo dedicado ao uso de ferramenta $(r=0,538 ; \mathrm{p}<0,01)$ e em 
cavernas positivamente correlacionado a descanso $(r=0,539 ; \mathrm{p}<0,001)$ e negativamente a alimentação $(r=-0,405 ; \mathrm{p}<0,05)$.

Houve diferença na proporção de tempo em cada tipo de substrato em função da idade dos indivíduos $(\mathrm{F}=2,403 ; \mathrm{gl}=49, \mathrm{p}<0,05)$, sendo que adultos passaram significativamente mais tempo que juvenis em substratos planos $(F=5,155 ; \mathrm{p}<0,05)$, enquanto juvenis passaram mais tempo que adultos em substrato arbóreo $(\mathrm{F}=5,324$; p<0,05; Figura 23). Não foi observado efeito significativo de sexo, nem da interação entre sexo e idade.

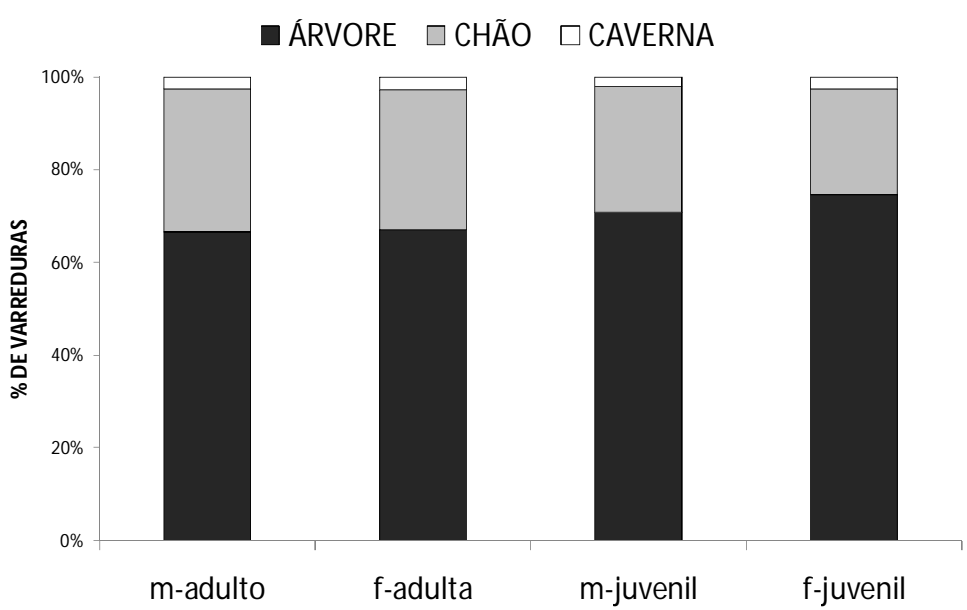

Figura 23: Padrão de uso de substratos do grupo ZA por classe de sexo e idade. M=macho; $\mathrm{F}=$ fêmea.

O tempo de permanência do grupo em área de encosta $(38,0 \pm 18,5 \%)$ foi significativamente maior do que em todas as outras fisionomias $(\mathrm{F}=18,897 ; \mathrm{gl}=119$; $\mathrm{p}<0,001:$ chapada $=11,4 \pm 7,4 \% ; \mathrm{p}<0,001 ;$ brejo $=18,0 \pm 22,0 \% ; \mathrm{p}<0,001 ; \operatorname{grota}=8,6 \pm$ $6,1 \% ; \mathrm{p}<0,001$ e topo $=9,7 \pm 3,8 \% ; \mathrm{p}<0,001$; Figura 24$)$. Não houve variação no tempo de exploração das fisionomias em função do tipo de paisagem e da estação $(\mathrm{F}=0,979$; $\mathrm{gl}=4 ; \mathrm{p}=0,422)$ (Figura 25). 
O tempo de permanência do grupo em área de chapada foi positivamente correlacionado ao de uso de ferramenta $(r=0,406 ; \mathrm{p}<0,05)$, à observação $(r=0,536$; $\mathrm{p}<0,01)$ e tendeu a correlacionar-se negativamente ao forrageamento $(r=-0,364$; $\mathrm{p}=0,081$ ). O tempo de permanência em brejo correlacionou-se positivamente ao de alimentação $(r=0,435 ; \mathrm{p}<0,05)$, assim como o tempo em grotas ao de locomoção $(r=0,452 ; \mathrm{p}<0,05)$. O tempo de permanência em áreas de topo foi positivamente correlacionado ao de locomoção $(r=0,463 ; \mathrm{p}<0,05)$ e negativamente ao de interações sociais $(r=-0,553 ; \mathrm{p}<0,01)$. Houve tendência para correlação positiva entre tempo de permanência nas encostas e tempo de interação social $(r=0,398 ; \mathrm{p}=0,054)$, assim como de tempo em topo e uso de ferramenta $(r=0,380 ; \mathrm{p}=0,067)$.

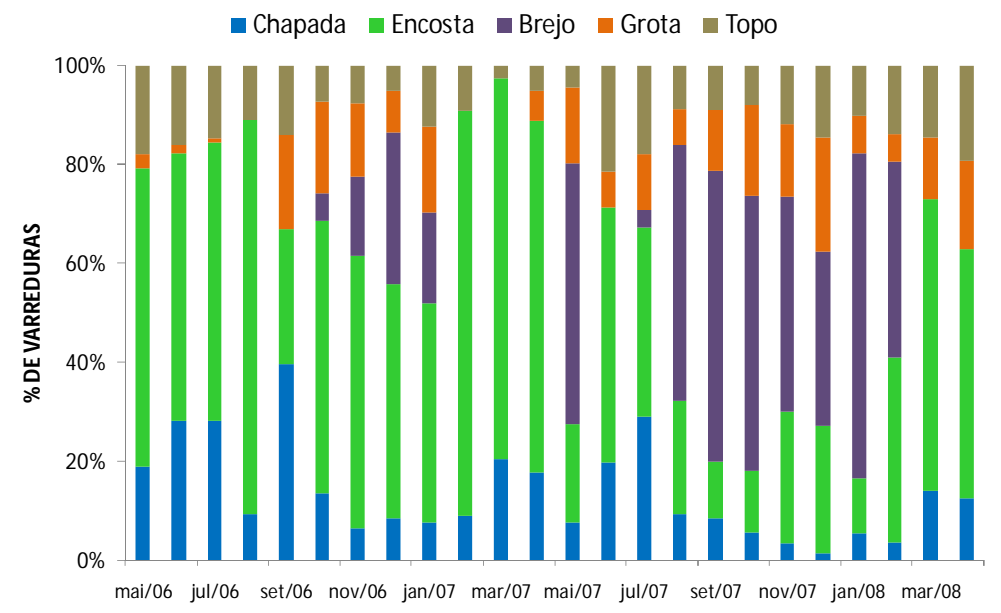

Figura 24: Proporção de tempo de exploração de diferentes fisionomias pelo grupo ZA entre maio de 2006 e abril de 2008. 


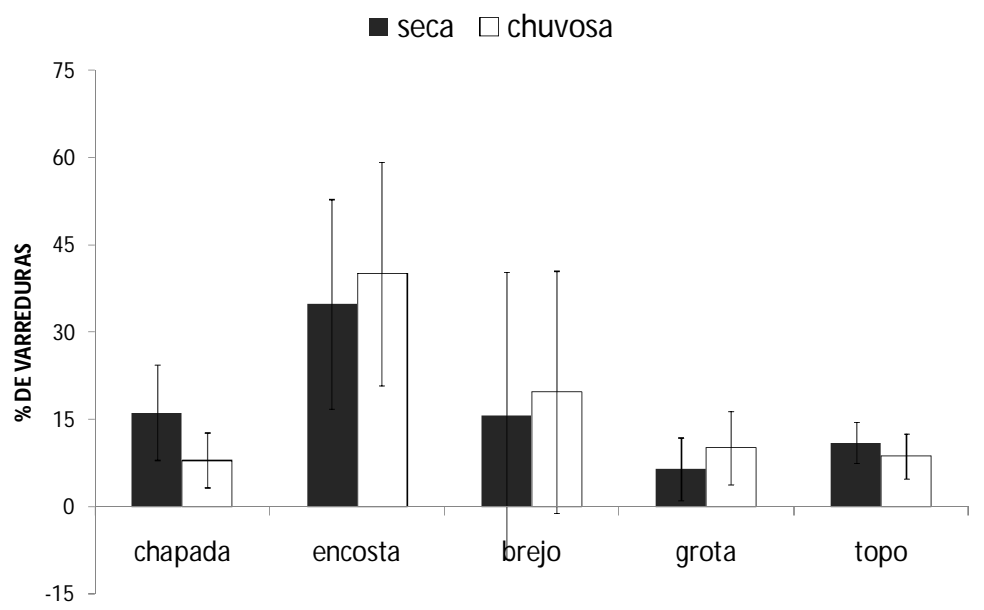

Figura 25: Proporção de tempo de exploração de diferentes fisionomias pelo grupo ZA nas estações seca e chuvosa.

\subsubsection{Grupo Chicão}

O tempo de permanência em cada substrato variou significativamente em função do tipo de substrato $(\mathrm{F}=92,167 ; \mathrm{gl}=7 ; \mathrm{p}<0,001)$. Os animais do grupo $\mathrm{CH}$ passam mais tempo em substratos arbóreos $(61,0 \pm 9,5 \%)$ do que em substratos planos $(35,0 \pm 8,0 \%$; $\mathrm{p}<0,001)$ e em cavernas $(3,5 \pm 4,3 ; \mathrm{p}<0,001)$ e mais tempo em substratos planos do que em cavernas ( $p<0,001$; Figura 26). Dentre os substratos arbóreos, houve variação em função da altura, de modo que o tempo de permanência em estratos de altura A (24 \pm $4 \%)$ foi superior ao de altura B $(15,6 \pm 7,0 \% ; \mathrm{p}<0,01)$. Não foram observadas variações entre o tempo de permanência em alturas A e C, nem entre B e C. Houve tendência para variação em função do tipo de substrato e da estação $(F=1,995 ; \mathrm{gl}=7 ; \mathrm{p}=0,063)$. $\mathrm{O}$ tempo de permanência em substratos arbóreos foi maior na estação chuvosa $(63,6 \pm$ $10,5 \%)$ do que na seca $(55,4 \pm 3,5 \%)$, enquanto o tempo de utilização de cavernas foi maior na estação seca $(7,1 \pm 5,1 \%)$ do que na chuvosa $(1,5 \pm 2,3 \%)$. Já o tempo de permanência em substratos planos não variou entre as estações seca $(37,2 \pm 5,4 \%)$ e chuvosa $(34,9 \pm 9,4$; Figura 27). 


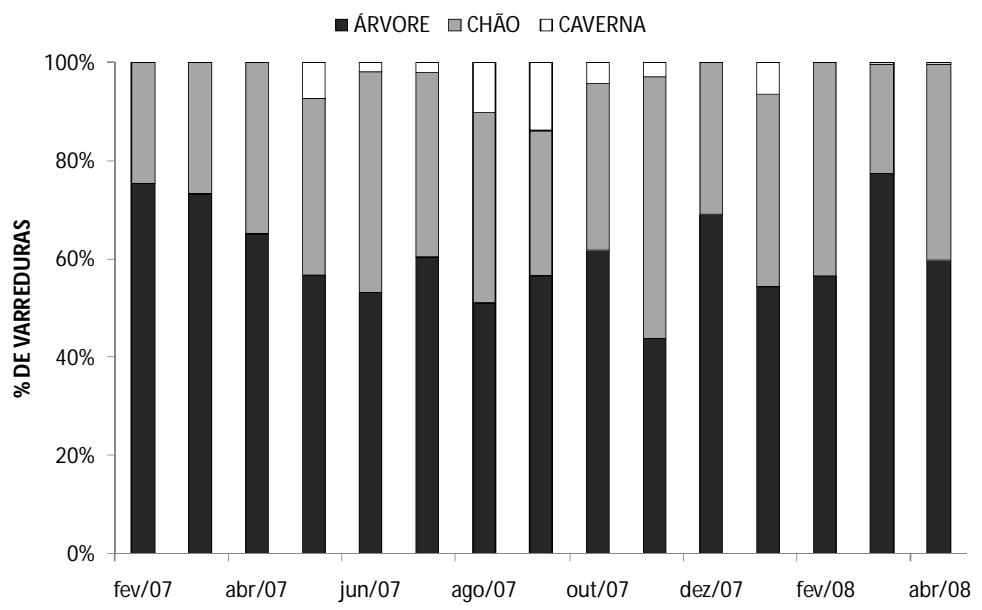

Figura 26: Padrão de uso de substratos pelo grupo $\mathrm{CH}$ entre fevereiro de 2007 e abril de 2008.

Não foram observadas variações significativas no tempo de permanência em cada tipo de substrato em função do sexo, da idade e da interação entre sexo e idade dos membros do grupo (Figura 28).

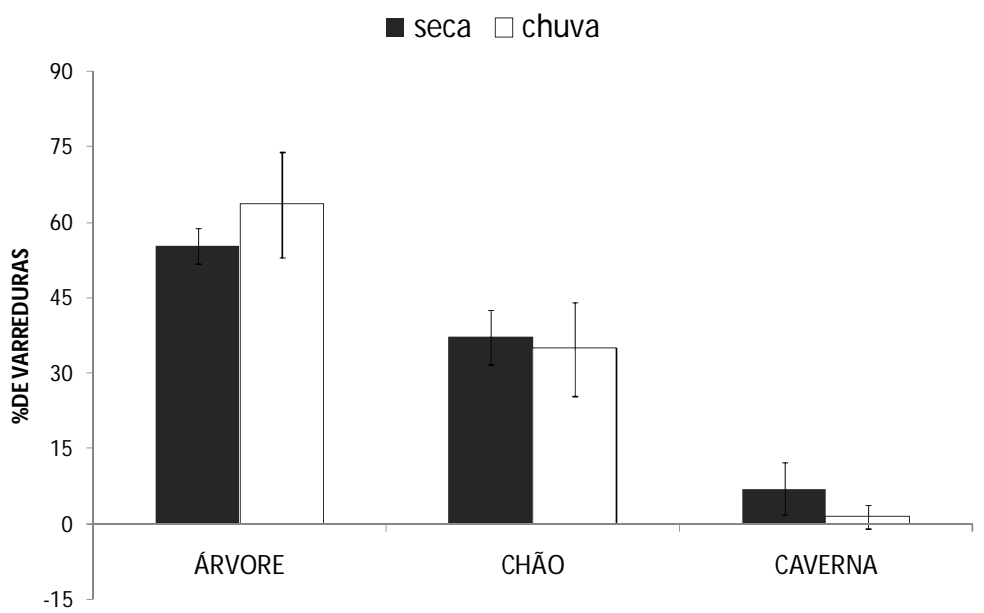

Figura 27: Padrão de uso de substratos pelo grupo $\mathrm{CH}$ nas estações seca e chuvosa. 


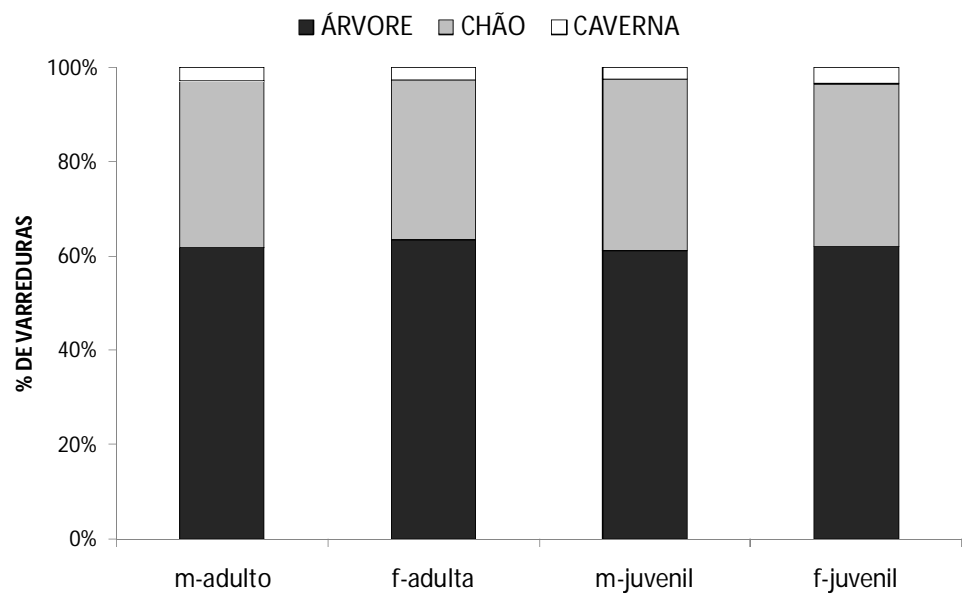

Figura 28: Padrão de uso de substratos do grupo $\mathrm{CH}$ por classe de sexo e idade. $\mathrm{M}=$ macho; $\mathrm{F}=$ fêmea.

O tempo de permanência do grupo em substratos arbóreos foi positivamente correlacionado ao de observação $(r=0,644 ; \mathrm{p}<0,05)$, assim como o uso caverna e descanso $(r=0,547 ; \mathrm{p}<0,05)$. O uso de cavernas também foi negativamente correlacionado ao tempo de observação $(r=-0,528 ; \mathrm{p}<0,05)$ e de interação social do grupo $(r=-0,601 ; \mathrm{p}<0,05)$. Houve tendência para correlação negativa entre o tempo de uso de substratos planos e o tempo de locomoção $(r=-0,483 ; \mathrm{p}=0,068)$ e de observação $(r=-0,467 ; \mathrm{p}=0,079)$.

Houve variação significativa no padrão de exploração das diferentes fisionomias $(\mathrm{F}=14,872 ; \mathrm{gl}=5 ; \mathrm{p}<0,001)$, de modo que o tempo de permanência em áreas de encosta $(27,5 \pm 9,5 \%)$ foi significativamente maior do que em áreas de brejo $(6,8 \pm 14,0 \%$; $\mathrm{p}<0,001)$, grota $(3,0 \pm 2,5 \% ; \mathrm{p}<0,001)$ e topo $(6,0 \pm 6,0 \% ; \mathrm{p}<0,001)$. Da mesma maneira, o tempo de permanência em áreas de chapada $(21,2 \pm 11,0 \%)$ foi significativamente maior do que em áreas de brejo $(\mathrm{p}<0,01)$, grota $(\mathrm{p}<0,001)$ e topo $(\mathrm{p}<0,01)$. O grupo também passou significativamente mais tempo na área de aprovisionamento $(22,7 \pm 19,0 \%)$ do que em áreas de brejo $(\mathrm{p}<0,01)$, grota $(\mathrm{p}<0,001)$ e topo ( $\mathrm{p}<0,01$; Figura 29). Houve efeito significativo da interação entre tipo de 
fisionomia e estação sobre o tempo de permanência nas diferentes fisionomias $(\mathrm{F}=3,652 ; \mathrm{gl}=5 ; \mathrm{p}<0,01)$, sendo que o tempo de permanência do grupo em áreas de chapada, brejo, grota e topo foi maior na estação chuvosa, enquanto as áreas de encosta e de aprovisionamento foram mais utilizadas na estação seca (Figura 30).

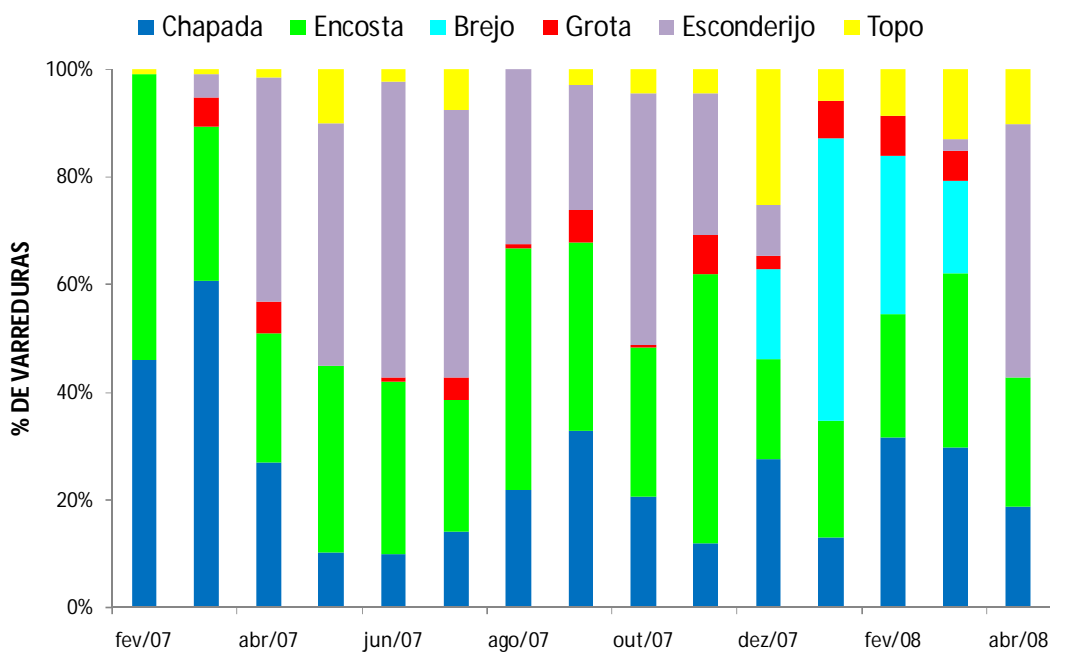

Figura 29: Proporção de tempo de exploração de diferentes fisionomias pelo grupo $\mathrm{CH}$ entre fevereiro de 2007 e abril de 2008.

O tempo de permanência do grupo no esconderijo foi positivamente correlacionado ao tempo dedicado à quebra de $\operatorname{cocos}(r=0,633 ; \mathrm{p}<0,05)$ e ao descanso $(r=0,644 ; \mathrm{p} \leq 0,01)$. Houve tendência de correlação negativa entre tempo de permanência em área de chapada e uso de ferramenta $(r=-0,494 ; \mathrm{p}=0,061)$ e de correlação positiva entre tempo de permanência em brejo e alimentação $(r=0,479 ; \mathrm{p}=0,071)$. 


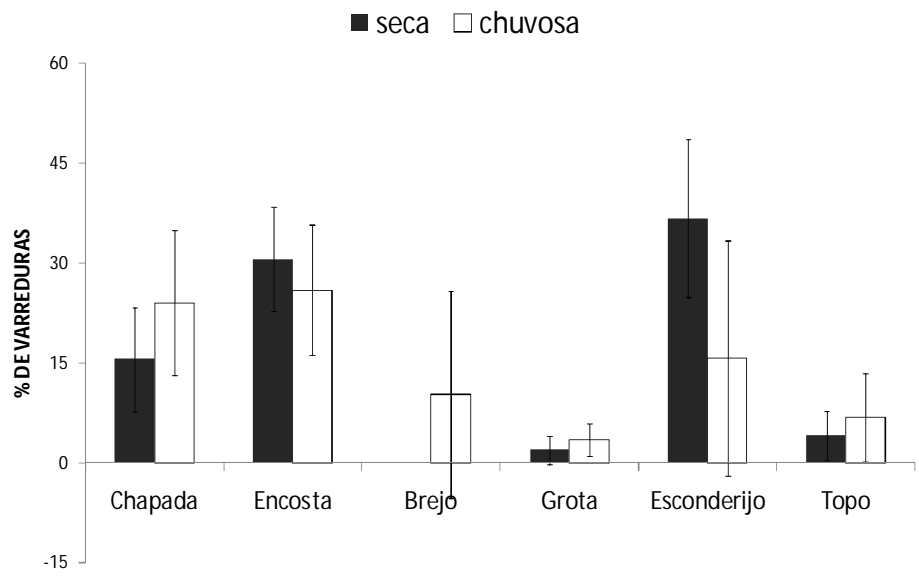

Figura 30: Proporção de tempo de exploração de diferentes fisionomias pelo grupo $\mathrm{CH}$ nas estações seca e chuvosa.

\subsubsection{Padrão de uso de substrato e fisionomia: comparação entre grupos}

A análise GLM multivariada revelou que o tempo de permanência em cada tipo de substrato variou em função do grupo $(\mathrm{F}=4,468 ; \mathrm{gl}=19 ; \mathrm{p}<0,01)$, sendo o grupo ZA passou mais tempo em substratos arbóreos $(\mathrm{F}=7,207 ; \mathrm{p}<0,01)$, enquanto o grupo $\mathrm{CH}$ passou mais tempo em substratos planos $(\mathrm{F}=4,949 ; \mathrm{p}<0,05)$. $\mathrm{O}$ grupo $\mathrm{CH}$ tendeu a passar mais tempo em caverna do que o grupo $\mathrm{ZA}(\mathrm{F}=3,146 ; \mathrm{p}=0,088)$. Dentre os substratos arbóreos, o tempo despendido em estratos de altura B foi significativamente maior para o grupo ZA $(\mathrm{F}=9,121 ; \mathrm{p}<0,01)$, como mostra a Tabela 5. Não houve efeito significativo da interação entre grupo e estação sobre o tempo de permanência nos diferentes substratos $(\mathrm{F}=1,512 ; \mathrm{gl}=19 ; \mathrm{p}=0,218)$.

Tabela 5: Comparação entre os grupos ZA e CH quanto à proporção de tempo (porcentagem das amostras de varredura e desvio padrão) despendida nos diferentes tipos de substratos.

\begin{tabular}{|c|c|c|c|c|c|c|c|}
\hline Período & Grupo & $\overline{\text { ARV }}$ & ARV-A & ARV-B & ARV-C & $\mathrm{CH}$ & $\overline{\mathrm{CAV}}$ \\
\hline \multirow{2}{*}{ Geral } & $\mathrm{ZA}$ & $65,1 \pm 10,2 * *$ & $25,8 \pm 6,2$ & $22,0 \pm 4,6 * *$ & $17,3 \pm 10,5$ & $32,6 \pm 10 *$ & $2,3 \pm 2,2$ \\
\hline & $\mathrm{CH}$ & $60,9 \pm 9,5 * *$ & $24,1 \pm 4$ & $21,2 \pm 6,9 * *$ & $60,9 \pm 8,1$ & $35,3 \pm 8,1 *$ & $3,3 \pm 4,3$ \\
\hline \multirow{2}{*}{ Seca } & ZA & $62,5 \pm 13,1$ & $27,3 \pm 7,4$ & $21,5 \pm 4,5$ & $13,7 \pm 13,1$ & $35 \pm 13,6$ & $2,4 \pm 2$ \\
\hline & $\mathrm{CH}$ & $55,4 \pm 3,5$ & $20,9 \pm 2,4$ & $17,4 \pm 6,7$ & $17,2 \pm 7,2$ & $37,2 \pm 5,4$ & $7,1 \pm 5,2$ \\
\hline \multirow{2}{*}{ Chuvosa } & ZA & $67,0 \pm 7,3$ & $24,7 \pm 5,3$ & $22,4 \pm 4,8$ & $19,9 \pm 7,6$ & $30,8 \pm 6,5$ & $2,1 \pm 2,4$ \\
\hline & $\mathrm{CH}$ & $63,6 \pm 10,5$ & $25,7 \pm 3,6$ & $14,6 \pm 7,2$ & $23, \pm 8,12$ & $34,9 \pm 9,4$ & $1,5 \pm 2,3$ \\
\hline
\end{tabular}

Arv=substrato arbóreo; Arv-A=árvore de 0,5 a 3 metros; Arv-B=árvore de 3,1 a 6 metros; Arv$\mathrm{C}=$ árvores de mais de 6 metros; $\mathrm{CH}=$ chão; $\mathrm{CV}=$ caverna; ${ }^{*} \mathrm{p}<0,05 ;{ }^{* *} \mathrm{p}<0,01$. 
O tempo de permanência nas diferentes paisagens diferiu em função do grupo $(\mathrm{F}=11,603 ; \mathrm{gl}=6 ; \mathrm{p}<0,001)$. No geral, o grupo ZA passou mais tempo em áreas de encostas, brejos, grotas e topos, enquanto o grupo $\mathrm{CH}$ permaneceu mais em áreas de chapada e na área de aprovisionamento (Tabela 6). Não houve efeito significativo da interação entre grupo e estação sobre o tempo de permanência nas diferentes fisionomias $(\mathrm{F}=1,751 ; \mathrm{gl}=6 ; \mathrm{p}=0,158)$.

Tabela 6: Comparação da exploração das diferentes fisionomias (porcentagem das amostras de varredura e desvio padrão) pelos grupos $\mathrm{ZA}$ e $\mathrm{CH}$ durante as estações seca e chuvosa.

\begin{tabular}{l|l|cccccc}
\hline Estação & Grupo & CHA & ENC & BRJ & GRT & TOP & ESC \\
\hline \multirow{2}{*}{ Geral } & Zangado & $11,4^{*}$ & $37,9^{*}$ & $18^{*}$ & $8,6^{*}$ & $9,7^{*}$ & \\
& Chicão & $21,2^{*}$ & $27,5^{*}$ & $6,8^{*}$ & $2,9^{*}$ & $5,9^{*}$ & $22,7^{*}$ \\
\hline \multirow{2}{*}{ Seca } & Zangado & 16,2 & 34,9 & 15,7 & 6,6 & 11 & \\
& Chicão & 15,5 & 30,6 & 0 & 1,9 & 4,1 & 36,7 \\
\hline \multirow{2}{*}{ Chuvosa } & Zangado & 8 & 40 & 19,7 & 10,1 & 8,7 & \\
& Chicão & 24 & 26 & 10,2 & 3,4 & 6,7 & 15,7 \\
\hline
\end{tabular}

Cha=chapada; Enc=encosta; Brj=brejo; Grt=grota; Top=topo; Esc=esconderijo. *Diferença estatística.

\subsection{Dieta}

\subsubsection{Grupo Zangado}

Dentre os recursos alimentares identificados, os invertebrados foram os mais explorados pelo grupo $(37,0 \pm 9,6 \%$ das amostras de varredura de alimentação), seguido de polpa de frutos $(34,4 \pm 15,0 \%)$ e sementes $(15,0 \pm 14,0 \%$; Figura 31$)$. Por outro lado, vertebrados $(0,7 \pm 0,8 \%)$ e alimentos obtidos com auxílio de ferramentas $(1,1 \pm 1,3 \%)$ corresponderam à menor proporção das varreduras de alimentação. Considerando apenas a proporção de varreduras de alimentação em que houve a ingestão de alimento, observamos que a polpa de frutos foi o recurso mais consumido $(43,0 \pm 21,0 \%)$. 


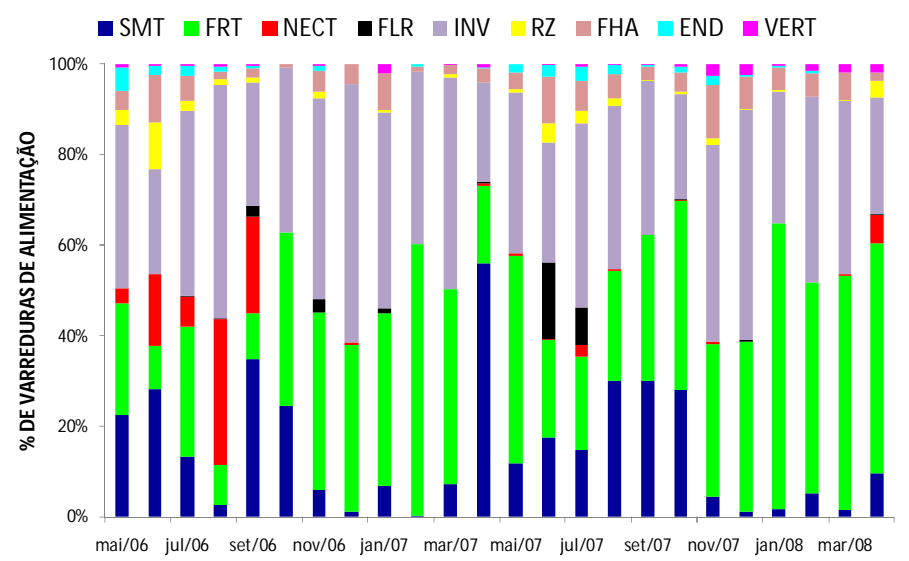

Figura 31: Dieta do grupo ZA entre maio de 2006 e abril de 2008. Smt=semente; Frt=fruto; Nect=néctar; Flr=flor; Inv=invertebrado; Rz=raiz; Fha=folha; End=endosperma de fruto de palmeira; Vert=vertebrado.

A proporção do tempo de alimentação dedicada aos diferentes recursos variou ao longo das estações (Figura 32). O tempo de alimentação por frutos foi significativamente maior durante o período chuvoso $(\mathrm{F}=17,589 ; \mathrm{gl}=23 ; \mathrm{p}<0,001)$, enquanto o de alimentação por raízes foi maior durante o período de seca $(\mathrm{F}=6,550$, $\mathrm{gl}=23 ; \mathrm{p}<0,05)$, assim como o tempo de alimentação por néctar $(\mathrm{F}=6,579 ; \mathrm{gl}=23$; $\mathrm{p}<0,05)$ e endosperma $(\mathrm{F}=15,390 ; \mathrm{gl}=23 ; \mathrm{p}<0,001)$. Houve tendência para maior tempo de alimentação por vertebrados na estação chuvosa $(\mathrm{F}=2,242 ; \mathrm{gl}=23 ; \mathrm{p}=0,053)$. A proporção de tempo dedicada à alimentação por invertebrados e frutos foi negativamente correlacionada a de sementes (respectivamente, $r=-0,672$; $\mathrm{p}<0,001$ e $r=-$ 0,568; $\mathrm{p}<0,01)$. A proporção de tempo de alimentação por frutos também foi negativamente correlacionado a de néctar $(r=-0,615 \mathrm{p}<0,001)$ e raízes $(r=-0,462$; $\mathrm{p}<0,05)$, indicando que esses recursos são alternativos a frutos, enquanto sementes são alternativos a frutos e invertebrados. Houve tendência de correlação negativa entre o tempo de alimentação por frutos e por endosperma $(r=-0,392 ; \mathrm{p}=0,058)$.

A exploração de recursos com distribuição discreta no ambiente (frutos, sementes, néctar, flores e endosperma) representou em média 55,6 \pm 10,0\% das 
amostras de varredura de alimentação, e foi superior à exploração de itens uniformemente distribuídos $(44,4 \pm 10,0 \% ; \mathrm{F}=15,106 ; \mathrm{gl}=47 ; \mathrm{p}<0,001)$. Não houve variação na proporção de amostras de varreduras dedicadas à alimentação por recursos discretos $(\mathrm{F}=0,093 ; \mathrm{gl}=23 ; \mathrm{p}=0,763)$ e uniformemente distribuídos $(\mathrm{F}=0,095 ; \mathrm{gl}=23$; $\mathrm{p}=0,760$ entre as estações seca e chuvosa (Figura 33).

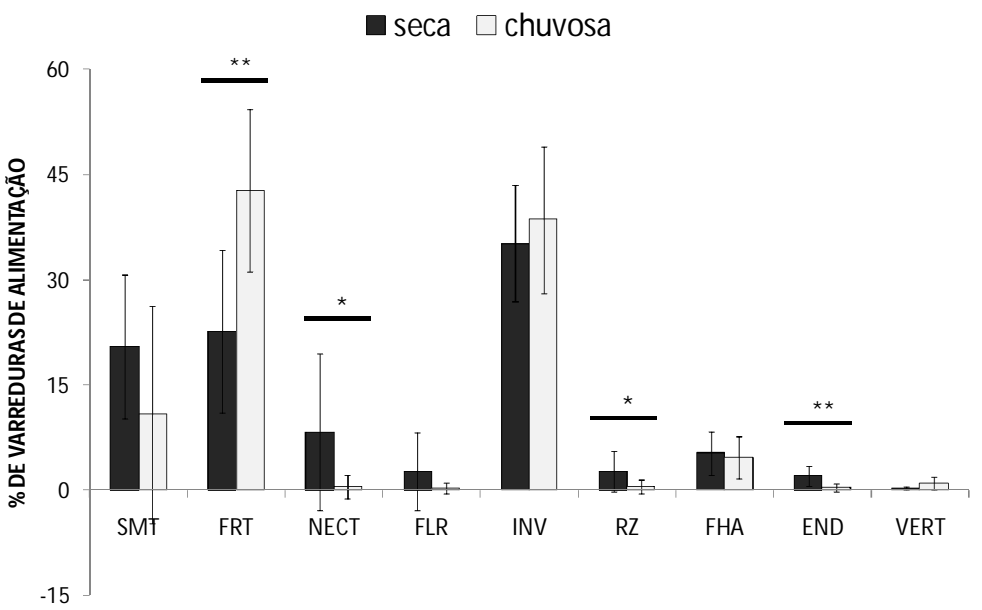

Figura 32: Dieta do grupo ZA nas estações seca e chuvosa. Smt=semente; Frt=fruto; Nect=néctar; Flr=flor; Inv=invertebrado; Rz=raiz; Fha=folha; End=endosperma de fruto de palmeira; Vert=vertebrado; ${ }^{*} \mathrm{p}<0,05 ;{ }^{* *} \mathrm{p}<0,001$.

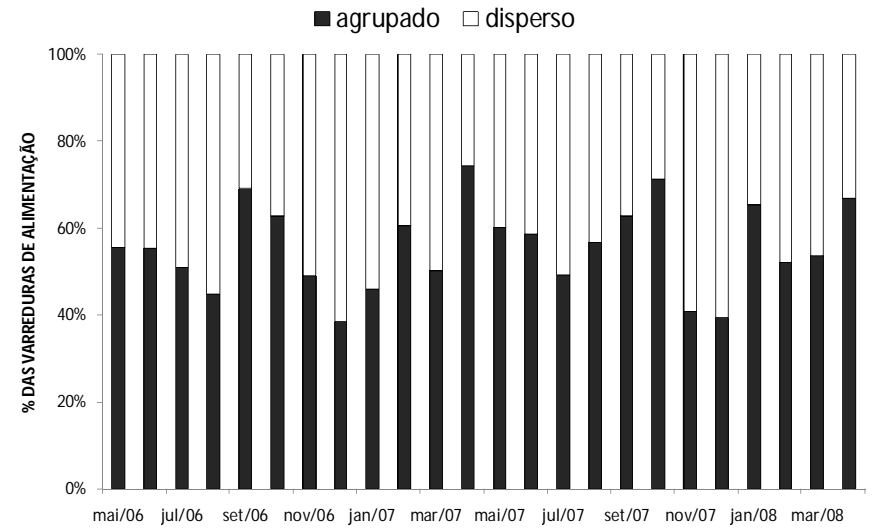

Figura 33: Proporção de itens alimentares com distribuição discreta e dispersa consumidos pelo grupo ZA entre maio de 2006 e abril de 2008.

A proporção das amostras de varredura de alimentação dedicada à exploração dos diferentes itens alimentares variou em função do período do dia $(\mathrm{F}=2,112 ; \mathrm{gl}=116$; 
p<0,01; Figura 34). O tempo dedicado à alimentação por invertebrado foi maior no período do meio do dia $(42,3 \pm 12,5 \%)$ do que na manhã $(32,2 \pm 10,9 \%$; $<<0,05)$. Houve tendência para maior tempo de alimentação por endosperma no período da tarde $(0,7 \pm$ $0,9 \%)$ do que na manhã $(1,4 \pm 2,1 \%)$. Não foi verificado efeito significativo da interação entre período do dia e estação sobre a proporção das amostras de varredura de alimentação dedicada à exploração dos diferentes itens alimentares $(\mathrm{F}=1,384 ; \mathrm{gl}=116$; $\mathrm{p}=0,152)$.

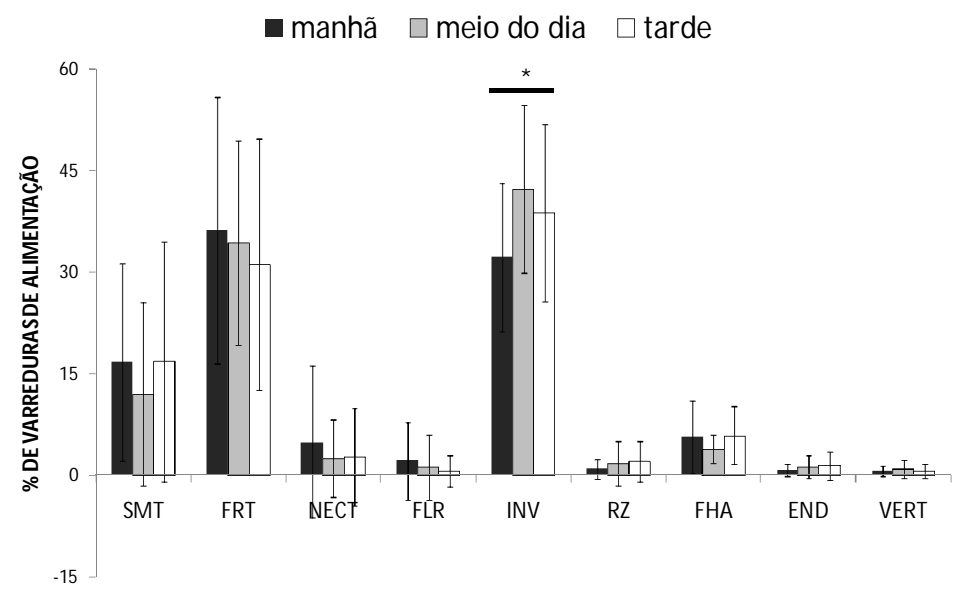

Figura 34: Dieta do grupo ZA nos períodos da manhã, meio do dia e tarde. Smt=semente; Frt=fruto; Nect=néctar; Flr=flor; Inv=invertebrado; $\mathrm{Rz}=$ raiz; $\quad \mathrm{Fha}=$ folha; End=endosperma de fruto de palmeira; Vert=vertebrado; ${ }^{*} \mathrm{p}<0,05$.

A dieta dos membros do grupo variou em função do sexo $(\mathrm{F}=2,161 ; \mathrm{gl}=47$; $\mathrm{p}<0,05)$, sendo que machos dedicaram mais tempo ao consumo de endosperma do que fêmeas $(F=14,540 ; p<0,001 ;$ Figura 35).

Houve também efeito da idade dos indivíduos $(\mathrm{F}=4,175 ; \mathrm{gl}=47 ; \mathrm{p}<0,001)$ sobre a dieta (Figuras 36). Adultos alimentaram-se mais de frutos e endosperma (frutos: $\mathrm{F}=4,949 ; \mathrm{p}<0,05$; endosperma: $\mathrm{F}=8,380 ; \mathrm{p}<0,01)$, enquanto jovens alimentaram-se mais de invertebrados $(\mathrm{F}=10,999 ; \mathrm{p}<0,01)$. Houve tendência para maior tempo de alimentação por folhas entre os juvenis do que entre os adultos $(\mathrm{F}=3,088 ; \mathrm{p}=0,084)$. 
Embora o efeito da interação entre sexo e idade sobre a dieta não tenha sido estatisticamente significativo, a proporção de tempo dedicada à alimentação por endosperma foi significativamente maior entre machos adultos e machos juvenis do que entre fêmeas adultas e fêmeas juvenis $(\mathrm{F}=4,415 ; \mathrm{p}<0,05)$ (Figura 37).

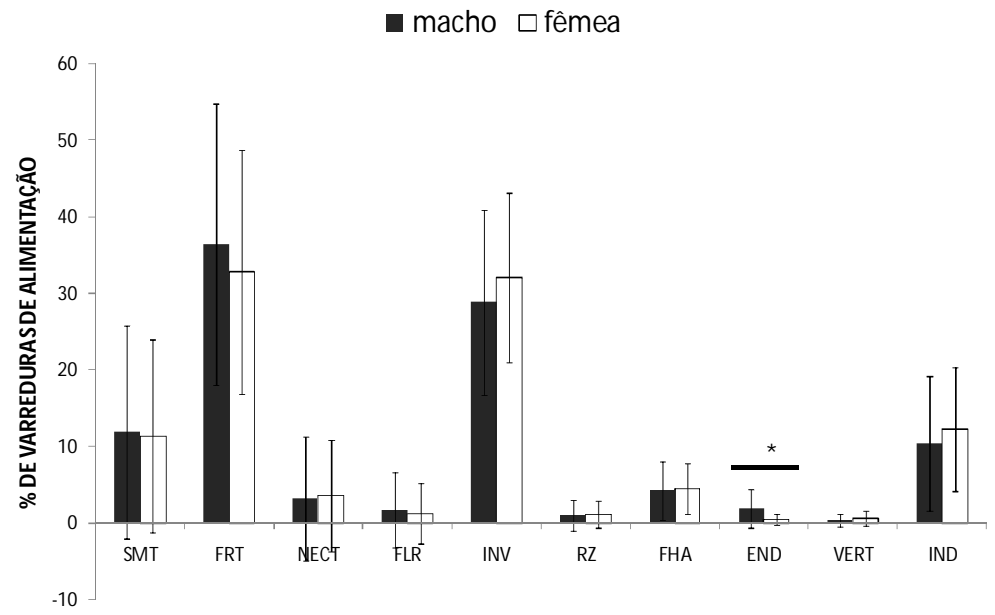

Figura 35: Dieta de machos e fêmeas do grupo ZA. Smt=semente; Frt=fruto; Nect=néctar; Flr=flor; Inv=invertebrado; Rz=raiz; Fha=folha; End=endosperma de fruto de palmeira; Vert=vertebrado; Ind=indeterminado; *p<0,001.

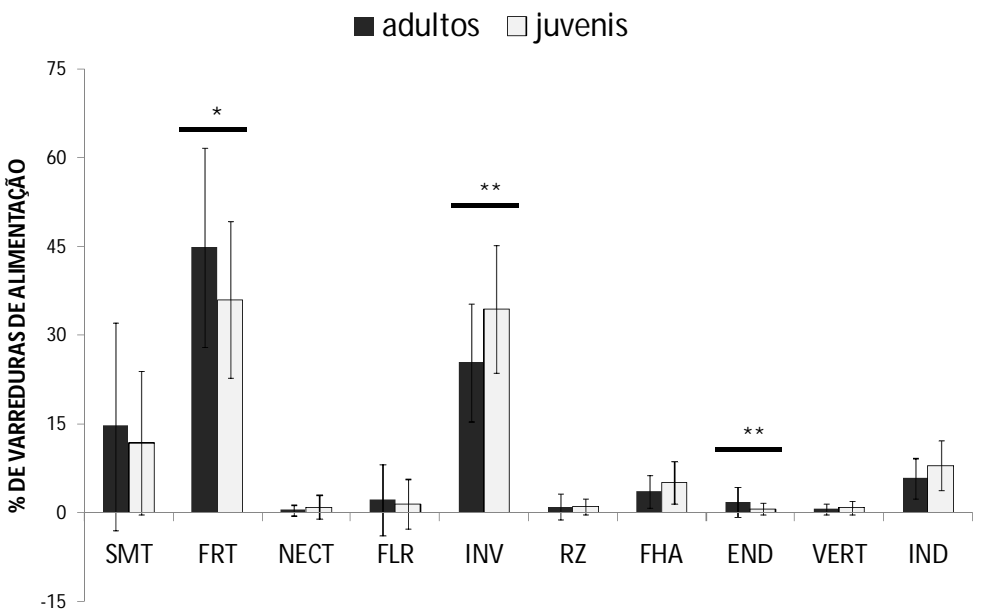

Figura 36: Dieta de adultos e juvenis do grupo ZA. Smt=semente; Frt=fruto; Nect=néctar; Flr=flor; Inv=invertebrado; $\mathrm{Rz}=$ raiz; Fha=folha; End=endosperma de fruto de palmeira; Vert=vertebrado; Ind=indeterminado; ${ }^{*} \mathrm{p}<0,05 ; * * \mathrm{p}<0,01$. 


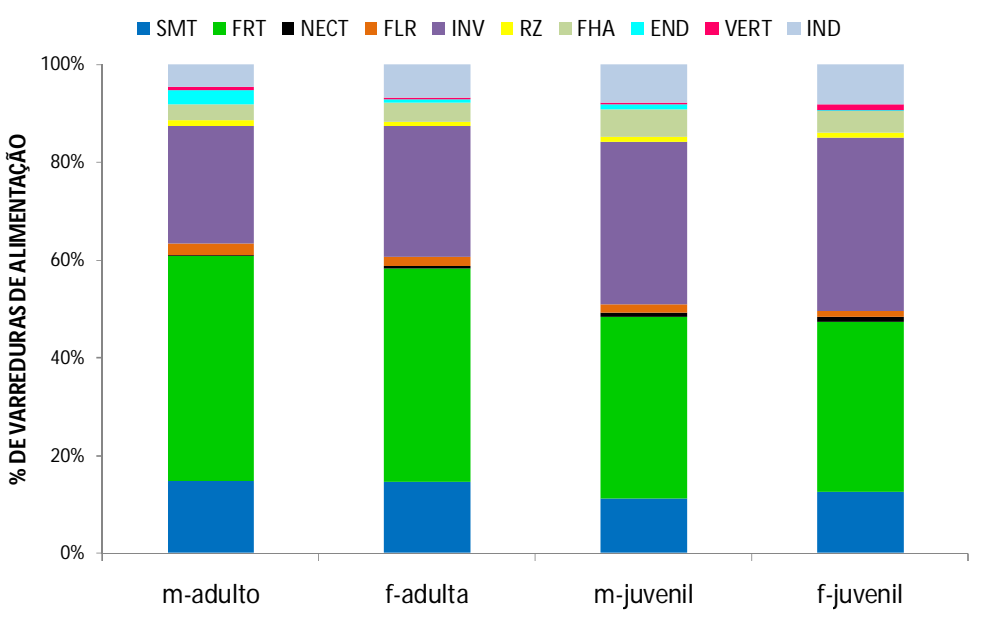

Figura 37: Dieta do grupo ZA por classe de sexo e idade. Smt=semente; Frt=fruto; Nect=néctar; Flr=flor; Inv=invertebrado; Rz=raiz; Fha=folha; End=endosperma de fruto de palmeira; Vert=vertebrado; Ind= indeterminado; $\mathrm{M}=$ macho; F=fêmea.

\subsubsection{Grupo Chicão}

Para o grupo $\mathrm{CH}$ foi possível identificar o recurso alimentar explorado em $89 \%$ das amostras de varredura de alimentação. Dentre os itens identificados, polpa de frutos $(29,8 \pm 18,5 \%$ das amostras de alimentação), invertebrados $(27,6 \pm 7,8 \%)$ e alimentos oferecidos na área de aprovisionamento $(13,0 \pm 13,6 \%)$ foram os mais consumidos pelos membros do grupo (Figura 38). Por outro lado, a alimentação por vertebrados $(0,4$ $\pm 0,4 \%)$, raízes $(2,5 \pm 2,8 \%)$ e alimentos obtidos com auxílio de ferramentas $(3,0 \pm$ 2,1\%) correspondeu à menor proporção das varreduras de alimentação. Considerando apenas a proporção de varreduras de alimentação em que houve a ingestão (consumo) de alimento, observamos que a polpa de frutos foi recurso mais consumido $(37,6 \pm$ $23,9 \%)$

A proporção de tempo dedicada à alimentação pelos diferentes recursos variou em função das estações (Figura 39). A proporção de tempo dedicada à alimentação por sementes foi maior na estação seca do que na chuvosa $(\mathrm{F}=6,254 ; \mathrm{gl}=14 ; \mathrm{p}<0,05)$, enquanto a dedicada à alimentação por polpa de frutos foi maior durante o período de chuvas $(\mathrm{F}=8,000 ; \mathrm{gl}=14 ; \mathrm{p}<0,05)$, como indica a Figura 39. Na estação seca, houve 
tendência para maior tempo de alimentação por flores $(\mathrm{F}=4,286 ; \mathrm{gl}=14 ; \mathrm{p}=0,059)$, raízes $(\mathrm{F}=4,328 ; \mathrm{gl}=14 ; \mathrm{p}=0,058)$ e alimento aprovisionado $(\mathrm{F}=3,607 ; \mathrm{gl}=14 ; \mathrm{p}=0,08) . \mathrm{O}$ tempo de alimentação por frutos foi negativamente correlacionado ao de raízes ( $r=-$ 0,792; $\mathrm{p}<0,001)$ e alimentos aprovisionados $(r=-0,792 ; \mathrm{p}<0,001)$, enquanto o tempo de alimentação por invertebrados foi negativamente correlacionado ao de sementes ( $r=-$ 0,546; $\mathrm{p}<0,05)$ e alimento aprovisionado $(r=-0,619 ; \mathrm{p}<0,05)$. Esses resultados indicam que raízes e alimento aprovisionados são recursos alternativos a frutos e sementes alternativos a invertebrados. Houve tendência para correlação negativa entre o tempo de alimentação por frutos e o tempo de alimentação por néctar $(r=-0,477 ; \mathrm{p}=0,072)$, flores $(r=-0,491 ; \mathrm{p}=0,063)$ e endosperma de $\operatorname{cocos}(r=-0,469 ; \mathrm{p}=0,078)$.

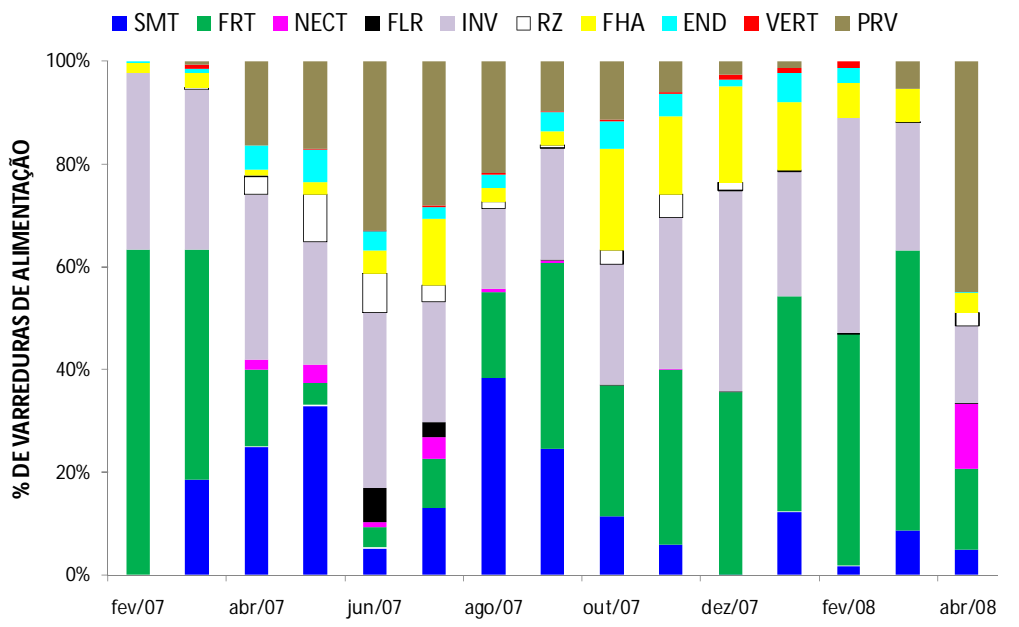

Figura 38: Dieta do grupo CH entre fevereiro de 2007 e abril de 2008. Smt=semente; Frt=fruto; Nect=néctar; Flr=flor; Inv=invertebrado; Rz=raiz; Fha=folha; End=endosperma de fruto de palmeira; Vert=vertebrado; Prv=alimento aprovisionado.

Recursos com distribuição discreta no ambiente constituíram, em média, 62,0 \pm $11,0 \%$ das amostras de varredura de alimentação do grupo, e foram superiores às amostras de varredura de alimentação por itens uniformemente distribuídos $(\mathrm{F}=33,085$; 
$\mathrm{gl}=29 ; \mathrm{p}<0,001$; Figura 40). Essas proporções não variaram significativamente entre as estações (discreto: $\mathrm{F}=1,392 ; \mathrm{gl}=14 ; \mathrm{p}=0,259$; uniforme: $\mathrm{F}=1,392, \mathrm{gl}=14 ; \mathrm{p}=0,259$ ).

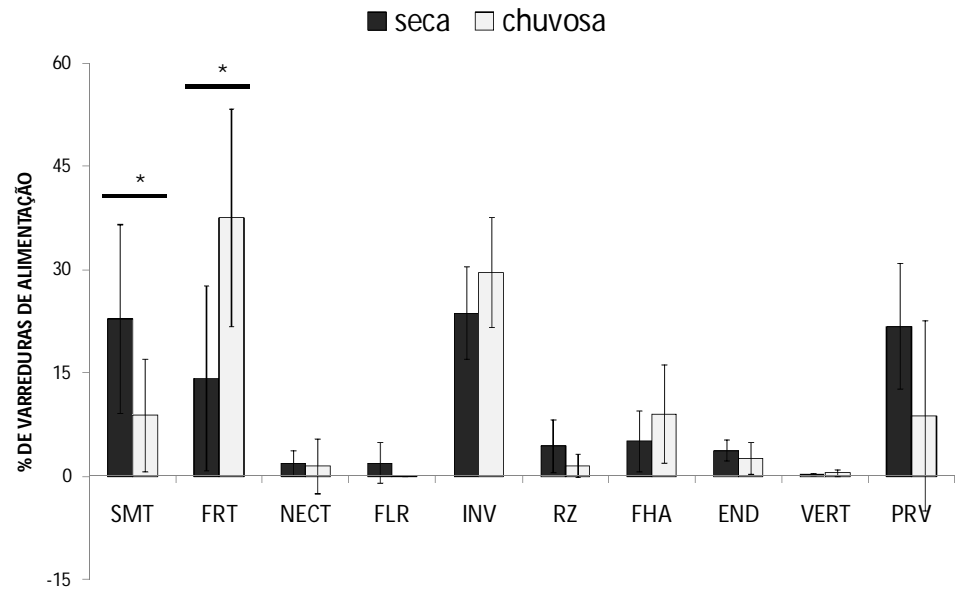

Figura 39: Dieta do grupo $\mathrm{CH}$ nas estações seca e chuvosa. Smt=semente; Frt=fruto; Nect=néctar; Flr=flor; Inv=invertebrado; Rz=raiz; Fha=folha; End=endosperma de fruto de palmeira; Vert=vertebrado; Prv=alimento aprovisionado; ${ }^{*} \mathrm{p}<0,05$.

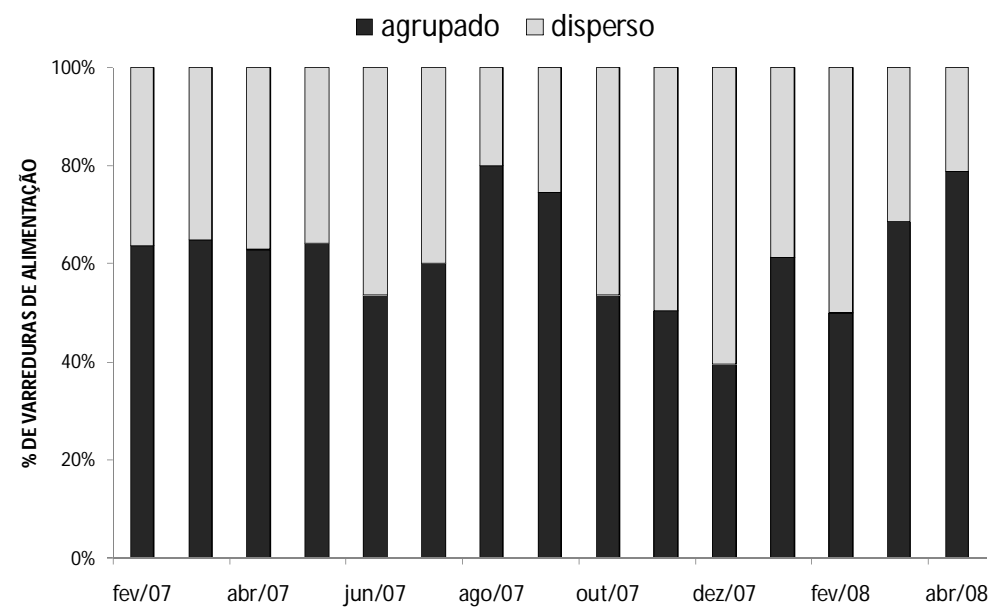

Figura 40: Proporção de itens alimentares com distribuição discreta e dispersa consumidos pelo grupo CH entre fevereiro de 2007 e abril de 2008.

A proporção das amostras de varredura de alimentação dedicada à exploração dos diferentes itens alimentares não variou em função do período do dia $(F=1,260$; 
$\mathrm{gl}=60 ; \mathrm{p}=0,241)$ nem em função do período do dia e da estação $(\mathrm{F}=0,989 ; \mathrm{gl}=60$; $\mathrm{p}=0,487$; Figura 41).

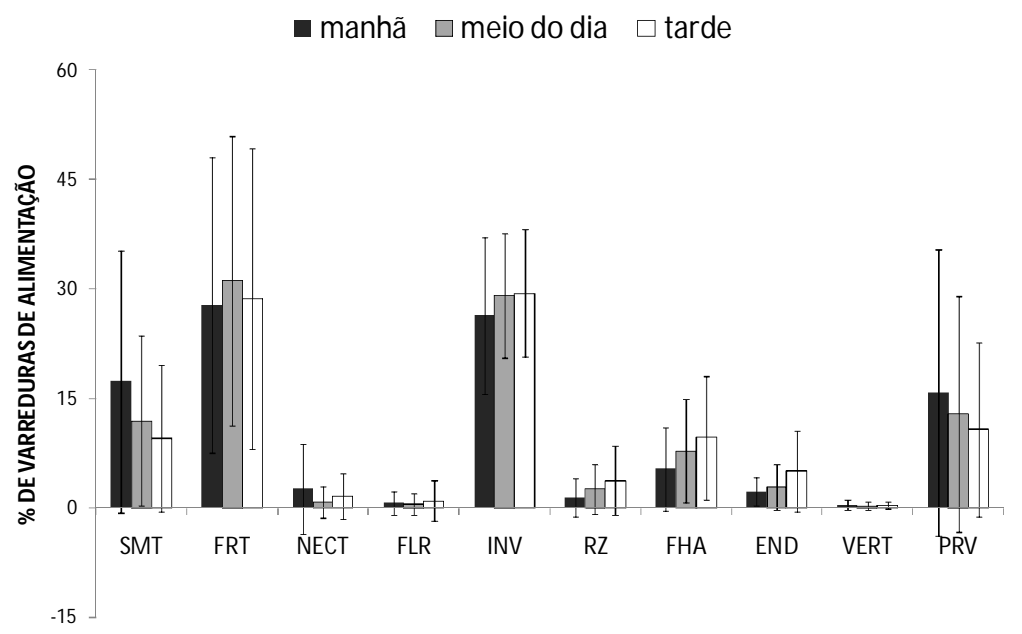

Figura 41: Dieta do grupo $\mathrm{CH}$ nos períodos da manhã, meio do dia e tarde. Smt=semente; Frt=fruto; Nect=néctar; Flr=flor; Inv=invertebrado; Rz=raiz; Fha=folha; End=endosperma de fruto de palmeira; Vert=vertebrado; Prv=alimento aprovisionado.

Houve efeito significativo do sexo $(\mathrm{F}=4,193 ; \mathrm{gl}=46 ; \mathrm{p}<0,001)$ e da idade $(\mathrm{F}=2,631 ; \mathrm{gl}=46 ; \mathrm{p}<0,05)$ dos indivíduos do grupo sobre a dieta. Machos dedicaram mais tempo à alimentação por raízes e vertebrados e tenderam a despender mais tempo à alimentação por endosperma do que fêmeas (raiz: $F=7,278$; $p<0,01$; vertebrado: $F=5,466 ; p<0,05$; endosperma: $F=3,770 ; p=0,057$ ) (Figura 42). Entre as fêmeas, houve tendência para maior tempo de alimentação por invertebrados $(F=3,326 ; p=0,074)$. Juvenis dedicaram mais tempo ao consumo de invertebrados em comparação com os adultos $(\mathrm{F}=5,057 ; \mathrm{p}<0,05)$ (Figura 43). 


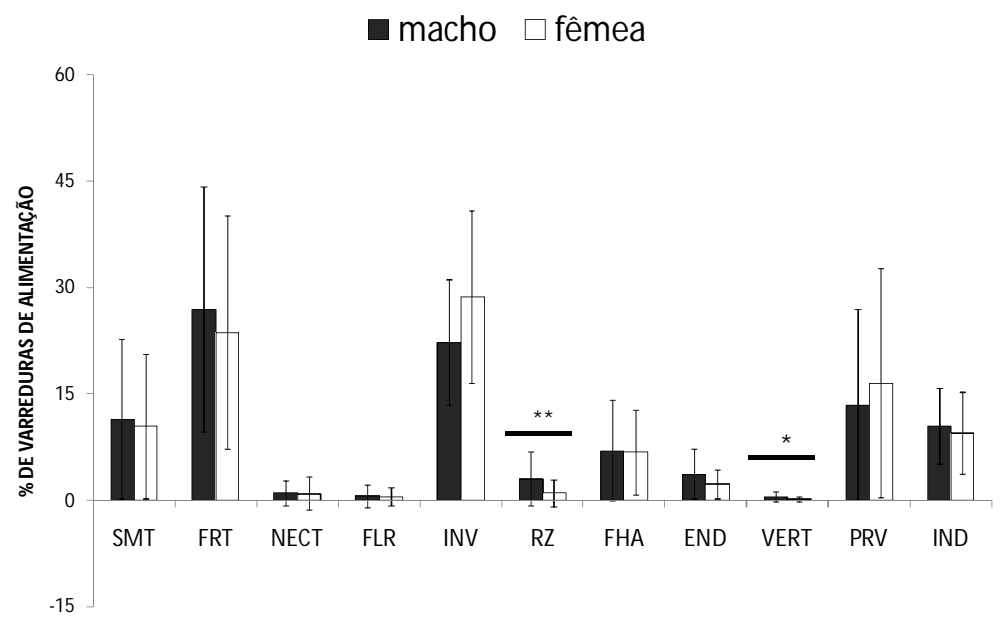

Figura 42: Dieta de machos e fêmeas do grupo $\mathrm{CH}$. Smt=semente; Frt=fruto; Nect=néctar; Flr=flor; Inv=invertebrado; $\mathrm{Rz}=$ raiz; Fha=folha; End=endosperma de fruto de palmeira; Vert=vertebrado; Prv=alimento aprovisionado; Ind=indeterminado; ${ }^{*} \mathrm{p}<0,05 ; * * \mathrm{p}<0,01$.

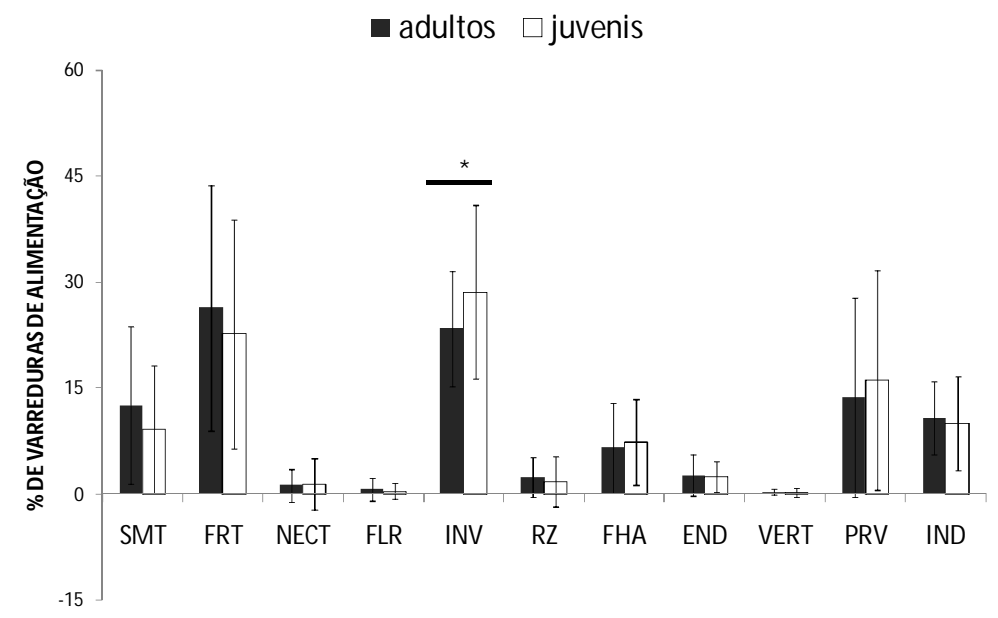

Figura 43: Dieta de adultos e juvenis do grupo $\mathrm{CH}$. Smt=semente; Frt=fruto; Nect=néctar; Flr=flor; Inv=invertebrado; Rz=raiz; Fha=folha; End=endosperma de fruto de palmeira; Vert=vertebrado; Prv=alimento aprovisionado; Ind=indeterminado; $* \mathrm{p}<0,05$.

Não houve efeito significativo da interação entre sexo e idade dos indivíduos sobre a dieta $(\mathrm{F}=1,496 ; \mathrm{gl}=46 ; \mathrm{p}=0,166)($ Figura 44$)$. 


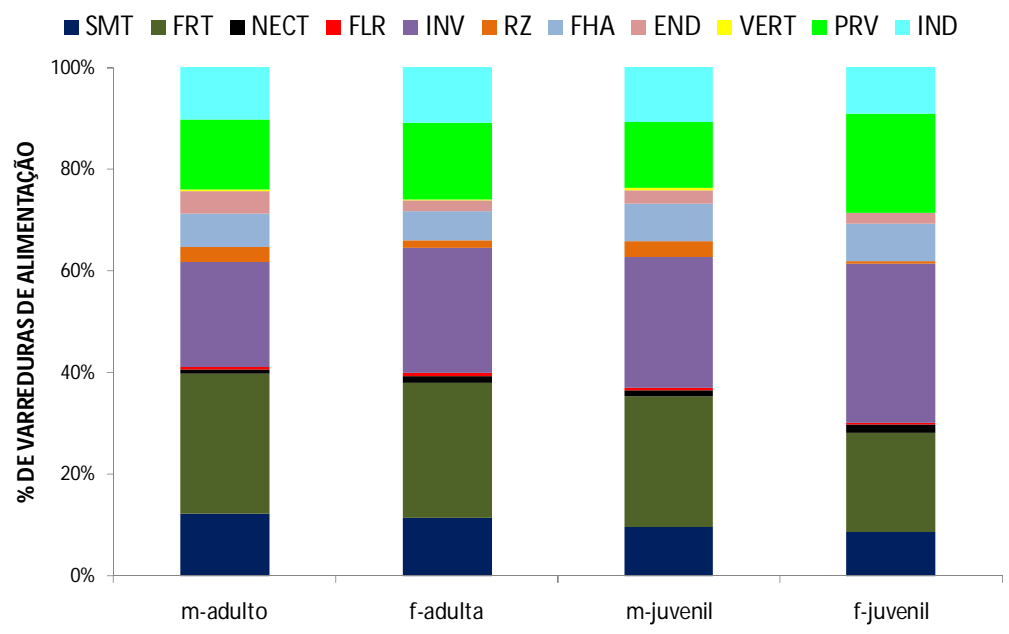

Figura 44: Dieta dos indivíduos do grupo $\mathrm{CH}$ por sexo e idade. Smt=semente; Frt=fruto; Nect=néctar; Flr=flor; Inv=invertebrado; Rz=raiz; Fha=folha; End=endosperma de fruto de palmeira; Vert=vertebrado; Prv=alimento aprovisionado; Ind=indeterminado; $\mathrm{M}=$ macho; $\mathrm{F}=$ fêmea.

\subsubsection{Dieta: Comparação entre grupos}

O teste GLM mostrou um efeito significativo de grupo $(\mathrm{F}=8,982 ; \mathrm{gl}=16$; $\mathrm{p}<0,001)$, estação $(\mathrm{F}=3,127 ; \mathrm{gl}=16 ; \mathrm{p}<0,05)$ e da interação entre grupo e estação $(\mathrm{F}=4,940 ; \mathrm{gl}=16 ; \mathrm{p}<0,01)$ sobre a composição da dieta dos grupos (Tabela 7).

Os membros do grupo ZA dedicaram maior de tempo à alimentação por frutos $(\mathrm{F}=4,634 ; \mathrm{p}<0,05)$ e invertebrados $(\mathrm{F}=7,985 ; \mathrm{p}<0,01)$ do que os membros do grupo $\mathrm{CH}$. Já no grupo $\mathrm{CH}$ houve maior tempo dedicado à alimentação por raízes $(\mathrm{F}=4,463$; $\mathrm{p}<0,05)$, endosperma $(\mathrm{F}=9,531 ; \mathrm{p}<0,01)$ e alimento aprovisionado $(\mathrm{F}=24,867 ; \mathrm{p}<0,001)$ do que no grupo ZA.

A estação afetou a proporção de tempo de alimentação dedicada à maior parte dos recursos alimentares que compuseram a dieta dos grupos. Durante a estação seca, houve mais tempo de alimentação por semente $(\mathrm{F}=5,501 ; \mathrm{p}<0,05)$, flores $(\mathrm{F}=7,568$; $\mathrm{p}<0,05)$, raízes $(\mathrm{F}=6,823 ; \mathrm{p}<0,05)$, endosperma $(\mathrm{F}=4,526 ; \mathrm{p}<0,05)$ e alimentos aprovisionados $(\mathrm{F}=5,244 ; \mathrm{p}<0,05)$, enquanto o tempo dedicado à alimentação por frutos $(F=13,119 ; p<0,01)$ e vertebrados $(F=6,208 ; p<0,05)$ foi maior na estação. 
A interação entre grupo e estação afetou apenas a proporção de amostras de varreduras dedicadas à alimentação por recursos aprovisionados $(\mathrm{F}=5,244 ; \mathrm{p}<0,05)$, sendo significativamente maior no grupo $\mathrm{CH}$, tanto na estação seca, quanto na chuvosa.

Não houve interação significativa entre grupo e a proporção de amostras de varreduras dedicadas à alimentação por recursos com distribuição discreta ou uniforme $(\mathrm{F}=2,379 ; \mathrm{gl}=1 ; \mathrm{p}=0,129)$.

Tabela 7: Comparação da dieta (porcentagem das amostras de varredura de alimentação e desvio padrão) dos grupos ZA e CH durante as estações seca e chuvosa.

\begin{tabular}{l|l|cccccccccc}
\hline Estação & Grupo & ST & FT & NC & FL & INV & RZ & FHA & END & VET & PRV \\
\hline \multirow{2}{*}{ Geral } & Zangado & 14,9 & 34,4 & 3,8 & 1,4 & $37,2^{*}$ & 1,5 & 5,0 & $1,1^{*}$ & 0,7 & $-*$ \\
& Chicão & 13,5 & 29,8 & 1,6 & 0,7 & $27,6^{*}$ & 2,5 & 7,7 & $3,0^{*}$ & 0,4 & $13,1^{*}$ \\
\hline \multirow{2}{*}{ Seca } & Zangado & 20,5 & 22,7 & 8,4 & 2,8 & 35,2 & 2,8 & 5,3 & 2,1 & 0,4 & - \\
& Chicão & 22,9 & 14,2 & 1,9 & 1,9 & 23,7 & 4,4 & 5,1 & 3,8 & 0,3 & 22,0 \\
\hline \multirow{2}{*}{ Chuvosa } & Zangado & 10,8 & 42,8 & 0,6 & 0,4 & 38,6 & 0,6 & 4,7 & 0,4 & 1,0 & - \\
& Chicão & 8,9 & 37,6 & 1,5 & 0,1 & 29,6 & 1,5 & 9,0 & 2,6 & 0,5 & 8,8 \\
\hline
\end{tabular}

St=semente; $\quad \mathrm{Ft}=$ fruto; $\quad \mathrm{Nc}=$ néctar; $\quad \mathrm{Fl}=$ flor; $\quad \mathrm{Inv}=$ invertebrado; $\quad \mathrm{Rz}=$ raiz; $\quad$ Fha=folha; End=endosperma; Vet=vertebrado; Prv=alimento aprovisionado. ${ }^{*} \mathrm{p} \leq 0,01$.

A comparação entre grupos por classe de sexo e idade revelou que a dieta foi afetada pelo sexo $(\mathrm{F}=2,937 ; \mathrm{gl}=102 ; \mathrm{p}<0,01)$ e idade $(\mathrm{F}=4,399 ; \mathrm{gl}=102 ; \mathrm{p}<0,001)$ dos indivíduos e pela interação entre grupo e sexo ( $\mathrm{F}=2,096$; $\mathrm{gl}=102 ; \mathrm{p}<0,05)$.

Machos dedicaram mais tempo à alimentação por raízes $(\mathrm{F}=6,021 ; \mathrm{p}<0,05)$ e endosperma $(\mathrm{F}=13,884 ; \mathrm{p}<0,001)$ do que fêmeas. Houve tendência para maior tempo de alimentação por invertebrados entre fêmeas $(\mathrm{F}=3,654 ; \mathrm{p}=0,058)$ do que entre machos. Adultos despenderam mais tempo do que juvenis alimentando-se de frutos $(\mathrm{F}=4,917$; $\mathrm{p}<0,05)$ e endosperma $(\mathrm{F}=7,071 ; \mathrm{p}<0,01)$, enquanto juvenis dedicaram mais tempo do que adultos ao consumo de invertebrados $(\mathrm{F}=15,535 ; \mathrm{p}<0,001)$.

Machos do grupo $\mathrm{CH}$ passaram mais tempo alimentando-se de raízes do que machos do grupo ZA (F=4,729; $\mathrm{p}<0,05)$, enquanto machos e fêmeas do grupo Zangado 
dedicaram mais tempo à alimentação por vertebrados do que machos e fêmeas do grupo Chicão $(F=5,064 ; p<0,05)$.

Embora a interação entre sexo e idade não tenha sido significativa, machos adultos e machos juvenis dedicaram mais tempo à alimentação por endosperma do que fêmeas adultas e fêmeas juvenis $(\mathrm{F}=5,161 ; \mathrm{p}<0,05)$. Não houve efeito significativo das interações entre grupo e idade $(\mathrm{F}=0,802 ; \mathrm{gl}=102 ; \mathrm{p}=0,638)$ e grupo, sexo e idade $(\mathrm{F}=0,697 ; \mathrm{gl}=102 ; \mathrm{p}=0,739)$.

\section{5-DISCUSSÃO}

\section{$\underline{\text { 5.1. Disponibilidade de alimento no ambiente }}$}

No geral, a oferta de frutos e flores no ambiente variou ao longo dos meses dos anos de estudo, mas essa variação não diferiu entre as estações seca e chuvosa. Já a oferta de invertebrados esteve fortemente associada ao regime de chuvas, sendo mais abundante durante os meses com índices pluviométricos maiores. Em contrapartida, a oferta de frutos de palmeiras no ambiente foi maior nos meses secos, especialmente de frutos da espécie Attalea barreirensis (catulé), mas esses recursos estiveram disponíveis ao longo de toda a pesquisa. Esses resultados mostram que, ao longo da pesquisa, os macacos não enfrentaram nenhum período de redução drástica na oferta de alimentos. Mais importante, frutos, considerados o recurso limitante de sucesso reprodutivo do gênero Cebus (Terborgh, 1983; Peres, 1993; Zhang, 1995; di Bitetti, 2001; Spironello, 2001; Izar, 2004), ocorreram em abundância ao longo de todo o período de estudo.

\subsection{Orcamento de atividades de C. libidinosus na BV}

Os macacos da Boa Vista (BV) passaram, em média, 46\% do tempo em atividade de alimentação (sendo $20 \%$ em forrageamento e 26\% em alimentação), 21,5\% 
em deslocamento, $9 \%$ em descanso, $9 \%$ em interação social, $8,5 \%$ em observação/vigilância e $6 \%$ em outras atividades. O uso de ferramentas correspondeu ao menor percentual do tempo de atividades de animais de ambos os grupos (menos de $2 \%$ no grupo $\mathrm{ZA}$ e menos de $4 \%$ no grupo $\mathrm{CH}$ ). Esse último resultado é similar ao observado por Moura (2004) para um grupo selvagem de Cebus libidinosus no Parque Nacional da Serra da Capivara e pode indicar que o uso de ferramentas teve pouca contribuição para o forrageamento dos animais da BV.

O padrão de atividades exibido pelos macacos deste estudo apresentou semelhanças e divergências em relação ao padrão de atividades encontrado para outras populações C. libidinosus selvagens, tanto em área onde os animais utilizam ferramentas (Parque Nacional Serra da Capivara: Moura, 2004), como onde não há utilização desses artefatos (Parque Nacional de Brasília: Sabbatini et al., 2008) (Tabela 8). Por exemplo, o percentual de tempo dedicado à interação social foi bastante similar entre essas três populações. Já a alimentação foi a principal atividade dos animais da BV e do Parque Nacional Serra da Capivara, que são ambientes com vegetação e topografia parecidas, porém não o foi para os macacos estudados por Sabbatini et al. (2008) no Parque Nacional de Brasília. A diferença mais acentuada, contudo, refere-se ao tempo despendido em locomoção; maior entre os animais do Parque Nacional Serra da Capivara e Parque Nacional de Brasília do que entre os animais do presente estudo. Muitos trabalhos mostram que o tempo que os primatas gastam em locomoção é positivamente correlacionado ao tamanho dos grupos sociais (Isbell, 1991; Gillespie \& Chapman, 2001; Steenbeek \& van Schaik, 2001; ver Capítulo III para mais detalhes e Snaith \& Chapman, 2007 para revisão). Não obstante, as diferenças apontadas aqui não podem ser atribuídas à variação no tamanho dos grupos em cada área, já que na BV os grupos foram maiores, porém, despenderam menos tempo em locomoção comparados 
aos animais das demais áreas. Diferenças na distribuição de recursos limitantes (p. ex., fontes alimentares e de água e/ou sítios de dormida com distribuição mais discreta ou menos abundantes no Parque Nacional Serra da Capivara e Parque Nacional de Brasília) e/ou na definição das categorias comportamentais e critérios metodológicos utilizados em cada pesquisa são explicações possíveis para as diferenças encontradas aqui que, contudo, precisam ser investigadas.

Diferenças ecológicas, principalmente no padrão de oferta, qualidade e distribuição de recursos alimentares, são apontadas como as maiores causas de variações comportamentais entre populações de espécies aparentadas (Wrangham, 1980; Robinson, 1986; Boinski, 1987b; Chapman \& Chapman, 1990; Isbell, 1991; Sterck et al., 1997; Masi et al., 2009). Comparado a outras espécies do gênero, o padrão de atividades $C$. libidinosus na $\mathrm{BV}$ assemelhou-se mais ao padrão encontrado para $C$. capucinus e C. olivaceus em áreas de floresta tropical seca (Robinson, 1986; Rose, 1994; Tabela 8). Por outro lado, as diferenças mais notórias foram observadas em relação a populações de $C$. nigritus em áreas de florestas tropicais úmidas (Reserva Biológica de Caratinga: Rímoli et al., 2008; Parque Estadual Carlo Botelho: Santos, 2010). Nessas populações, os animais dedicaram mais tempo às atividades de alimentação e locomoção e passaram menos tempo descansando e interagindo socialmente, em comparação com os animais da BV. Diversos estudos mostram que os primatas despendem mais tempo e esforço em atividades relacionadas à busca de alimentos durante períodos de escassez ou em ambientes onde a oferta de recursos alimentares é limitada (Post, 1981; Iwamoto \& Dunbar, 1983, 1992b), conseqüentemente, dispondo de menos tempo livre para descansar e interagir socialmente. Segundo Dunbar (1992b), quando os animais precisam alocar muito tempo em atividades necessárias para atingir suas demandas energéticas básicas, o tempo de interação social é sacrificado, o que 
resulta em grupos sociais mais instáveis e estressados, que se fragmentam para forragear, podendo, até mesmo, limitar o tamanho dos grupos sociais. Esse argumento é perfeitamente compatível com a observação de que os grupos de $C$. nigritus estudados na Reserva Biológica de Caratinga (atualmente Reserva Particular do Patrimônio Natural-Feliciano Miguel Abdala, Caratinga, MG) e no Parque Estadual Carlos Botelho (São Miguel Arcanjo, SP) apresentam maior grau de fissão. Nesse sentido, é possível supor que essas populações estão submetidas a níveis mais elevados de competição por alimento do que a população de $C$. libidinosus do presente estudo, seja porque a oferta e/ou qualidade dos alimentos disponíveis nessas áreas é baixa (Santos, 2010), seja porque enfrentam variações sazonais mais severas na oferta desses recursos ou, ainda, porque vivem em grupos sociais maiores.

É importante ressaltar que as populações de Cebus acima comparadas não utilizam ferramentas, portanto, as semelhanças e diferenças observadas estão mais associadas a fatores ambientais do que à utilização desses artefatos pelos macacos-prego da BV. 
Tabela 8: Orçamento de atividades (em porcentagem) de diferentes populações e espécies do gênero Cebus.

\begin{tabular}{|c|c|c|c|c|c|c|c|c|c|c|}
\hline Espécie & Habitat & Tamanho & FR $(\%)$ & $\begin{array}{l}\mathrm{CM} \\
(\%)\end{array}$ & $\begin{array}{l}\mathrm{LC} \\
(\%)\end{array}$ & $\begin{array}{l}\text { DS } \\
(\%)\end{array}$ & $\begin{array}{l}\text { OB } \\
(\%)\end{array}$ & $\begin{array}{l}\mathrm{SC} \\
(\%)\end{array}$ & Método & Fonte \\
\hline C. libidinosus & $\begin{array}{l}\text { Cerrado/ } \\
\text { Caatinga }\end{array}$ & $8-14$ & 20 & 26 & 26 & 8 & 8,5 & 7,5 & VR & $\begin{array}{c}\text { Presente estudo } \\
\text { (ZA) - BV/PI/Brasil }\end{array}$ \\
\hline C. libidinosus & $\begin{array}{l}\text { Cerrado/ } \\
\text { Caatinga }\end{array}$ & $17-19$ & 20 & 27 & 18 & 10,5 & 9 & 10 & VR & $\begin{array}{c}\text { Presente estudo } \\
(\mathrm{CH})- \\
\text { BV/PI/Brasil }\end{array}$ \\
\hline C. libidinosus & Cerrado & $6-8$ & 18 & 16 & 41 & 15 & - & 8 & VR & $\begin{array}{c}\text { Sabbatini et } \\
\text { al.(2008)- } \\
\text { PNB/DF/Brasil }\end{array}$ \\
\hline C. libidinosus & Caatinga & $5-11$ & 30 & 20 & 37 & $\sim 5,5$ & $\sim 3,0$ & $\sim 6,5$ & VR & $\begin{array}{l}\text { Moura (2004) - } \\
\text { PNSC/PI/Brasil }\end{array}$ \\
\hline C. xanthosternos & Floresta ombrófila & $24-27$ & $30^{*}$ & & 53 & 10 & - & 7 & VR & $\begin{array}{c}\text { Gouveia (2009) - } \\
\text { RBU/BA/Brasil }\end{array}$ \\
\hline C. nigritus & Mata Atlântica & $24-29$ & 26 & 38 & 26 & 5,5 & - & 3,5 & VR & $\begin{array}{l}\text { Rímoli et al. (2008) } \\
\text { - RBC/MG/Brasil }\end{array}$ \\
\hline C. nigritus & Mata Atlântica & $14-15$ & $54,5^{*}$ & & 38,5 & 5,5 & - & $<0,5$ & VR & $\begin{array}{l}\text { Santos (2009) - } \\
\text { PECB/SP/Brasil }\end{array}$ \\
\hline C. apella & $\begin{array}{c}\text { Floresta tropical } \\
\text { úmida }\end{array}$ & 10 & 50 & 16 & 21 & 12 & - & $<1$ & VR & $\begin{array}{c}\text { Terborgh }(1983)- \\
\text { CC/Peru }\end{array}$ \\
\hline C. olivaceus & $\begin{array}{l}\text { Floresta tropical } \\
\text { seca (Llanos) }\end{array}$ & 20 & $\sim 62^{*}$ & & $\sim 20$ & $\sim 10$ & - & $\sim 6$ & VR & $\begin{array}{l}\text { Robinson (1986) - } \\
\text { FPM/Venezuela }\end{array}$ \\
\hline C. olivaceus & $\begin{array}{l}\text { Floresta tropical } \\
\text { seca (Llanos) }\end{array}$ & $36 / 16$ & 19 & 17 & 22 & 25 & - & 2 & $\mathrm{AF}$ & $\begin{array}{l}\text { Miller (1997) - } \\
\text { HP/Venezuela }\end{array}$ \\
\hline C. capucinus & $\begin{array}{l}\text { Floresta tropical } \\
\text { seca }\end{array}$ & $13 / 17$ & $\sim 50^{*}$ & & $\sim 16$ & $\sim 18$ & $\sim 7,5$ & $\sim 8$ & $\mathrm{AF}$ & $\begin{array}{c}\text { Rose (1994)- } \\
\text { SRNP/Costa Rica }\end{array}$ \\
\hline C. albifrons & $\begin{array}{c}\text { Floresta tropical } \\
\text { úmida }\end{array}$ & 15 & 39 & 22 & 21 & 18 & - & $<1$ & VR & $\begin{array}{c}\text { Terborgh }(1983)- \\
\text { Peru/CC }\end{array}$ \\
\hline
\end{tabular}

Tamanho=tamanho do grupo social. FR=forragear; $\mathrm{CM}=$ comer; LC=locomoção; $\mathrm{DS}=$ descanso; $\mathrm{OB}=$ observação; SC=interação social. Método:

$\mathrm{VR}=$ varredura; $\mathrm{AF}=$ animal focal; *o valor inclui as atividades de comer e forragear. (-) Valores não relatados. Em alguns estudos o total das porcentagens de atividades não chega a $100 \%$ por que a tabela não apresenta a categoria outras atividades. 
Argumenta-se que a inclusão de alimentos de origem antrópica na dieta de primatas tem impactos profundos sobre o padrão de atividades (p. ex., diminuição do tempo de forrageamento e locomoção e aumento das interações agonísticas - Altmann \& Muruthi, 1988; Brennan et al., 1985; Ferreira et al., 2008) e sobre o uso do espaço (p. ex., redução das distâncias percorridas diariamente e da área de uso - Altmann \& Muruthi, 1988; Brennan et al., 1985; Fa, 1986). Embora os grupos deste estudo tenham apresentado um padrão de atividades bastante similar, as poucas diferenças observadas (maior tempo de locomoção no grupo ZA e maior tempo de descanso e uso de ferramentas no grupo $\mathrm{CH}$ ) podem ser atribuídas ao aprovisionamento alimentar. $\mathrm{O}$ fato dos membros do grupo $\mathrm{CH}$ permanecerem na área de aprovisionamento durante várias horas consecutivas, a cada dia em que visitavam esse local, pode ter sido o maior responsável pela diferença no tempo de locomoção. Da mesma maneira, após consumir o suprimento de alimentos aprovisionados, os indivíduos do grupo $\mathrm{CH}$ freqüentemente engajavam-se em longos períodos de descanso, intercalados por interações sociais (principalmente catação e brincadeira), o que pode ter levado à diferença no tempo de interação social. Ferreira et al. (2008) também relatam picos de interação social (especialmente catação) após o consumo de alimentos aprovisionados em um grupo semi-livre de Cebus spp no Parque Ecológico do Tietê. Esses resultados estão de acordo com as observações de Izawa (1980) e de Janson (1988), de que as atividades sociais em primatas do gênero Cebus ocorrem, principalmente, durante os períodos de descanso do grupo. Já a diferença no tempo de uso de ferramentas entre os dois grupos pode estar relacionada ao suplemento de cocos oferecidos como parte do aprovisionamento, conforme observado por Spagnoletti (2009) nesse mesmo grupo. Ainda, é possível que a presença de mais indivíduos proficientes no uso de ferramentas (capazes de realizar a tarefa com sucesso) no grupo $\mathrm{CH}$ (principalmente machos subadultos) tenha contribuído 
para essa diferença. É importante observar que o tempo de alimentação do grupo $\mathrm{CH}$ não foi afetado pelo aprovisionamento. Uma explicação plausível para esse resultado é a de que o maior tamanho de grupo $\mathrm{CH}$ (em relação ao ZA) elevou a competição intragrupo por alimento (van Schaik, 1989; Isbell, 1991; Sterck et al., 1997) o que, por sua vez, minimizou o aporte energético per capita fornecido pelos alimentos aprovisionados. Sendo assim, apesar das diferenças verificadas entre os dois grupos, é possível afirmar que, no geral, o impacto do aprovisionamento sobre o tempo de atividades do grupo $\mathrm{CH}$ foi pequeno. Resultados semelhantes foram encontrados por Moura (2004) para um grupo selvagem de C. libidinosus e por Ferreira et al. (2008) para um grupo de Cebus spp em semi-liberdade, ambos aprovisionados.

O ciclo de atividades diárias também foi muito parecido entre os grupos de estudo, com um maior tempo despendido em alimentação no período da manhã, mais tempo de descanso durante o meio do dia e mais tempo em locomoção à tarde (no caso do grupo ZA também no período da manhã). Esses resultados são similares aos encontrados para outras populações de Cebus (Cebus spp: Freese \& Oppenheimer, 1981; Cebus apella e C. albifrons: Terborgh, 1983; C. xanthosternos: Gouveia, 2009; C. nigritus: Santos, 2010). O maior investimento em alimentação no período da manhã pode ser uma estratégia para repor as energias após passar a noite sem se alimentar (Terborgh, 1983). O aumento do descanso no meio do dia é consistente com os resultados encontrados para outros grupos de macacos-prego (Freese \& Oppenheimer, 1981; Terborgh, 1983; Robinson, 1984a; Gouveias, 2009). Robinson (1984a) argumenta que, em C. olivaceus, a redução no esforço de forrageamento no meio do dia está relacionada ao aumento da temperatura e à necessidade de conservar água e energia durante o período mais quente do dia. De fato, em diversas ocasiões, entre 11:00 e 15:00h (quando as temperaturas chegavam a atingir $40^{\circ} \mathrm{C}$ ), os macacos da $\mathrm{BV}$ foram 
observados buscando refúgio em cavernas, onde as temperaturas costumam ser mais amenas (Verderane et al., dados não publicados). Por fim, o aumento da locomoção no final do dia pode estar relacionado ao deslocamento das áreas de alimentação para os sítios de dormidas (já que os animais utilizaram um número restrito de locais de dormida) e/ou ser consequiência da redução no tempo gasto em locomoção durante os períodos mais quentes do dia (meio do dia).

Ajuste sazonal no tempo de atividades é uma característica comum a primatas que vivem em ambiente com grande flutuação na oferta de recursos (Fragaszy et al., 2004a). Na BV, apesar da marcada sazonalidade no regime de chuvas, não houve variações significativas na oferta de recursos alimentares durante esta pesquisa. Conseqüentemente, a ausência de grandes ajustes no orçamento de atividades dos grupos (apenas algumas atividades do grupo ZA foram afetadas) entre as estações seca e chuvosa corrobora a previsão da literatura. Durante a estação seca, houve aumento do tempo dedicado à observação/vigilância. Esse resultado pode estar relacionado à redução da cobertura vegetal, típica de períodos de estiagem em áreas de Cerrado e Caatinga. Com a redução do dossel e, conseqüentemente, maior exposição visual, os animais podem ter aumentado o tempo de observação/vigilância por duas razões: (1) aumentar a vigilância anti-predador e/ou (2) aumentar a vigilância social. Estudos com populações selvagens mostram que a maior parte da observação/vigilância em grupos de macacos Cebus está relacionada ao monitoramento social (Ruiter, 1986; Gould et al., 1991; Rose \& Fedigan, 1995; Jack, 2001; Hirsch, 2002). Durante a estação chuvosa houve aumento do tempo de interações sociais, principalmente de brincadeira social. Existem três explicações possíveis e não exclusivas para esses resultados: (1) o maior consumo de frutos observado nesse período pode ter fornecido aos indivíduos um maior retorno energético, assim, disponibilizado mais tempo e/ou energia para as interações 
sociais; (2) a diminuição da necessidade de vigilância com o aumento da cobertura vegetal disponibilizou mais tempo e forneceu mais segurança para que os animais investissem em interações sociais; (3) a concentração de nascimentos no final da estação seca e início da chuvosa aumentou o número de díades possíveis e, por conseqüência, o tempo despendido em atividades sociais. Há, ainda, uma hipótese alternativa de que durante a estação seca parte das interações sociais ocorreu intercalada a períodos de descanso dentro de cavernas, portanto, fora do campo de visão dos pesquisadores.

Já o tempo de atividades do grupo $\mathrm{CH}$ não variou entre as estações seca e chuvosa. Esse resultado é consistente com os encontrados para outras populações de macacos-prego aprovisionados (C. libidinosus: Moura, 2004; Sabbatini et al., 2008; Cebus spp: Ferreira et al., 2008), indicando que o principal impacto do aprovisionamento foi o de eliminar a necessidade de ajustes comportamentais para lidar com variações ambientais.

\subsection{Uso de substratos e fisionomias por $C$. libidinosus da Boa Vista}

Os macacos-prego são considerados primatas arborícolas, que utilizam, preferencialmente, estratos médios e inferiores das florestas (Terborgh, 1983), podendo exibir terrestrialidade facultativa, de acordo com as condições ecológicas encontradas no habitat (Napier \& Napier, 1967). Entre os mamíferos, a locomoção arbórea é mais custosa do que a locomoção terrestre (Steudel, 2000) e, de acordo com Fragaszy et al., (2004a), os custos associados a essa forma de deslocamento fazem parte de um alto orçamento energético de primatas do gênero Cebus. No presente estudo, os macacosprego passaram, em média, 60-65\% do tempo de atividades em substratos arbóreos de diferentes alturas, 29-33\% no chão das chapadas, morros e brejos e 2,5-3\% em cavernas. Trabalhos acerca da escolha de substrato em macacos Cebus, principalmente 
os que relatam o tempo de permanência desses animais no solo, são escassos na literatura. Ainda assim, foi possível verificar que o uso do chão pelos macacos da BV foi similar a padrão observado para outras populações de C. libidinosus (Sabbatini et al., 2006; Moura, 2004) e consideravelmente divergente do padrão relatado para populações de C. nigritus em florestas tropicais úmidas (Izar, comunicação pessoal; B. Wheeler apud Spagnoletti, 2009). Por exemplo, calcula-se que os C. nigritus do Parque Estadual Carlo Botelho passem menos de $1 \%$ de seu tempo de atividades no solo da floresta (Izar, comunicação pessoal).

O uso de substratos é afetado por características do ambiente, como a estrutura da vegetação, a distribuição dos recursos alimentares no tempo e no espaço e o risco de predação (Enstam \& Isbell, 2004). A vegetação da BV, constituída por arbustos e árvores de pequeno e médio porte, e o extensivo uso das encostas dos morros de arenito, para forrageamento, descanso e abrigo contra intempéries, estão diretamente relacionados ao elevado grau de terrestrialidade dos macacos da BV. Resultados similares foram encontrados para uma população de $C$. libidinosus que utiliza ferramentas no Parque Nacional Serra da Capivara (Moura, 2004), que possui vegetação e morros de arenitos similares aos da BV. De acordo com Visalberghi et al. (2005), a freqüente utilização do solo para forrageamento, associada à disponibilidade de cocos e bigornas, é o fator chave para a emergência do uso de ferramentas para abertura de cocos em macacos-prego. As correlações positivas entre o tempo de permanência no solo e o de uso de ferramentas e consumo de endosperma por C. libidinosus na BV fornecem subsídios favoráveis a essa hipótese.

Variações sazonais no regime de chuvas e temperaturas podem alterar a estrutura da vegetação e a disponibilidade de recursos alimentares, portanto, também são apontadas como fontes potenciais de variações no padrão de uso dos substratos e 
comportamento posicional dos primatas. No entanto, no presente estudo não foram observadas variações significativas no padrão de uso de substrato.

\subsection{Dieta de C. libidinosus na BV}

A análise da dieta de C. libidinosus na BV revelou que frutos e invertebrados foram os principais recursos alimentares consumidos pelos animais. Esse resultado é consistente com a maioria dos estudos prévios realizados com populações de Cebus selvagens que não utilizam ferramentas (Terborgh, 1983; Peres, 1993; Zhang, 1995; di Bitetti, 2001; Spironello, 2001; Izar, 2004) (Tabela 9), que mostraram que frutos e invertebrados são, respectivamente, as principais fontes de carboidrato/açúcar e proteína desses primatas (Fragaszy et al., 2004a). De acordo com Janson \& Robinson (1987), os macacos Cebus dedicam mais tempo à busca de invertebrados, porém, proporcionalmente, consomem mais frutos, já que o sucesso de forrageamento por invertebrados (razão entre o tempo de procura/processamento e ingestão de alimentos) é menor do que por frutos. De fato, quando consideradas apenas as amostras de varredura em que houve ingestão dos alimentos, verificou-se que os frutos foram o principal recurso consumido pelos macacos da BV (Tabela 9). Mais importante, nos dois grupos estudados a proporção de amostras de varreduras dedicada ao consumo de alimentos (ingestão) foi maior que a de forrageamento (busca por alimentos). Embora comparações entre diferentes populações exijam interpretações cuidadosas, já que há diferenças quanto aos métodos utilizados em cada pesquisa, esse último resultado indica que o sucesso de forrageamento na $\mathrm{BV}$ é bastante alto se comparado a algumas populações de Cebus (Terborgh, 1983; Moura, 2004) e reforça a hipótese de que na BV há abundância na oferta de recursos alimentares (Capítulo III). 
Os alimentos extraídos com auxílio de ferramentas, por outro lado, corresponderam ao menor percentual das amostras de varreduras de alimentação de ambos os grupos (tanto nas amostras de comer, quanto de forragear). Moura (2004) e Moura \& Lee (2004) sugerem que utilização de ferramentas é uma estratégia chave para a sobrevivência de primatas em ambientes que apresentam "gargalos energéticos", como o semi-árido Nordestino. Não obstante, os resultados encontrados aqui indicam que essa técnica teve pouca contribuição para o forrageamento dos macacos da BV (ver também a discussão do Capítulo III).

A comparação entre populações quanto à composição da dieta revelou que as diferenças mais acentuadas foram em relação a $C$. nigritus selvagens no Parque Nacional El Rey, no Noroeste da Argentina (Brown \& Zunino, 1990), no Parque Estadual Carlos Botelho, na Mata Atlântica de São Paulo (Izar, 2004) e na Reserva Biológica de Caratinga, na Mata Atlântica de Minas Gerais (Rímoli et al., 2008) (Tabela 9). Nessas populações, uma grande parcela da dieta é constituída por partes não reprodutivas de plantas (especialmente base foliar de bromélias), que são recursos de baixo valor nutricional, porém, abundantes no ambiente e de fácil obtenção. Izar (2004) considera que a mudança de uma dieta rica em frutos para uma fortemente baseada em base foliar de bromélias e invertebrados, observada em C. nigritus no PECB ao longo de sua pesquisa, foi uma estratégia para lidar com a severa redução na oferta de frutos durante a estação seca. Da mesma maneira, o grande consumo de base foliar de bromélias por C. nigritus no Parque Nacional El Rey pode ser explicado pela baixa produtividade de frutos carnosos nessa região e pela ausência de palmeiras, que são alimentos de reserva (fallback food) importantes para macacos-prego em períodos de escassez de frutos carnosos (Janson, 1984). Essas diferenças entre populações parecem estritamente relacionadas à variação na disponibilidade de recursos alimentares em cada 
ambiente, mais do que a preferências geneticamente determinadas, já que populações de C. nigritus que habitam a porção nordeste da Argentina (no Parque Nacional Iguaçu) exibem dietas fortemente baseadas em frutos (Brown \& Zunino, 1990). Esses resultados evidenciam, ainda, a grande capacidade adaptativa dos macacos-prego em explorar uma vasta diversidade de recursos.

Tabela 9: Relação dos itens alimentares (em porcentagem) consumidos por diferentes populações e espécies do gênero Cebus.

\begin{tabular}{|c|c|c|c|c|c|c|c|c|}
\hline Espécie & Habitat & $\begin{array}{l}\text { FT } \\
(\%)\end{array}$ & $\begin{array}{l}\text { FH } \\
(\%) \\
\end{array}$ & $\begin{array}{l}\mathrm{F} / \mathrm{N} \\
(\%)\end{array}$ & $\begin{array}{l}\text { SM } \\
(\%)\end{array}$ & $\begin{array}{l}\text { IV } \\
(\%)\end{array}$ & $\begin{array}{l}\text { OT } \\
(\%)\end{array}$ & Fonte \\
\hline C. libidinosus & $\begin{array}{l}\text { cerrado/ } \\
\text { caatinga }\end{array}$ & 35 & 5 & 5 & 15 & 37 & 3 & $\begin{array}{c}\text { presente estudo } \\
(\mathrm{ZA})- \\
\text { BV/PI/Brasil }\end{array}$ \\
\hline C. libidinosus & $\begin{array}{l}\text { cerrado/ } \\
\text { caatinga }\end{array}$ & 30 & 7,5 & 2 & 13,5 & 28 & 19 & $\begin{array}{c}\text { presente estudo } \\
(\mathrm{CH})- \\
\mathrm{BV} / \mathrm{PI} / \mathrm{Brasil}\end{array}$ \\
\hline C. libidinosus & cerrado & $\sim 21$ & & $\sim 4$ & & & $\sim 75$ & $\begin{array}{l}\text { Moura (2004) - } \\
\text { PNSC/PI/Brasil }\end{array}$ \\
\hline $\begin{array}{c}C . \\
\text { xanthosternos }\end{array}$ & $\begin{array}{c}\text { floresta } \\
\text { ombrófila }\end{array}$ & 39 & 4,5 & 4,5 & & 48 & & $\begin{array}{l}\text { Gouveia (2009) - } \\
\text { RBU/BA/Brasil }\end{array}$ \\
\hline C. nigritus & $\begin{array}{c}\text { mata } \\
\text { atlântica }\end{array}$ & 20 & 36 & & & 23,5 & 20 & $\begin{array}{l}\text { Rímoli et al. (2008) } \\
\text { - RBC/MG/Brasil }\end{array}$ \\
\hline C. nigritus & $\begin{array}{l}\text { mata } \\
\text { atlântica }\end{array}$ & 42,5 & 20 & & & 31,5 & & $\begin{array}{l}\text { Izar (2004) - } \\
\text { PECB/SP/Brasil }\end{array}$ \\
\hline C. apella & $\begin{array}{l}\text { floresta } \\
\text { tropical } \\
\text { úmida }\end{array}$ & 19,5 & 4,5 & & & 75 & & $\begin{array}{c}\text { Terborgh }(1983)- \\
\text { CC/Peru }\end{array}$ \\
\hline C. apella & $\begin{array}{l}\text { floresta } \\
\text { semi- } \\
\text { decídua }\end{array}$ & 54 & 6,5 & 11 & 16 & & 15,5 & $\begin{array}{l}\text { Galetti \& Pedroni } \\
\text { (1994) - SG/SP }\end{array}$ \\
\hline C. apella & $\begin{array}{l}\text { floresta } \\
\text { tropical }\end{array}$ & 37 & 13,5 & & & 42,5 & 4 & $\begin{array}{l}\text { Brown \& Zunino } \\
(1990)- \\
\text { IG/Argentina }\end{array}$ \\
\hline C. apella & $\begin{array}{l}\text { floresta } \\
\text { tropical }\end{array}$ & 3 & 72 & & & 25 & & $\begin{array}{c}\text { Brown \& Zunino } \\
(1990)- \\
\text { ER/Argentina }\end{array}$ \\
\hline C. olivaceus & $\begin{array}{l}\text { floresta } \\
\text { tropical seca } \\
\text { (llanos) }\end{array}$ & 49 & 8 & & & 35 & & $\begin{array}{c}\text { Robinson (1986) - } \\
\text { FPM/Venezuela }\end{array}$ \\
\hline C. albifrons & $\begin{array}{l}\text { floresta } \\
\text { tropical } \\
\text { úmida }\end{array}$ & 30 & 3,5 & & & 62 & & $\begin{array}{c}\text { Terborgh }(1983)- \\
\text { CC/Peru }\end{array}$ \\
\hline
\end{tabular}


Os dois grupos de estudo apresentaram diferenças importantes quanto à dieta, a maior parte relacionada ao aprovisionamento. Por exemplo, o menor consumo de frutos e invertebrados pelos membros do grupo $\mathrm{CH}$ pode estar relacionado ao suprimento de frutas (bananas e manga) e sementes (como milho), que reduziu a necessidade de procurar carboidratos e proteínas em fontes naturalmente disponíveis. Já o maior consumo de endosperma parece relacionado ao suprimento de cocos oferecidos como parte do aprovisionamento, bem como a disponibilidade de bigornas e martelos apropriados para quebra de cocos na área de aprovisionamento. Além, é claro, do fato desse grupo contar com mais indivíduos capazes de utilizar essas ferramentas adequadamente (conforme discutido acima). A única diferença que, aparentemente, não pode ser explicada pelo aprovisionamento refere-se ao maior consumo de raízes pelo grupo $\mathrm{CH}$. Existem três explicações possíveis para esse resultado: (1) maior oferta de raízes nas áreas utilizadas pelo grupo $\mathrm{CH}$, (2) esse recurso é preferido por uma classe de sexo/idade que se encontra em maior número no grupo $\mathrm{CH}$ ou (3) o consumo de raízes é uma tradição alimentar no grupo $\mathrm{CH}$. A primeira hipótese parece pouco provável uma vez que houve grande sobreposição entre as áreas de uso dos dois grupos. O fato do grupo $\mathrm{CH}$ possuir um maior número de machos (principalmente adultos), sendo esses os maiores consumidores de raízes, favorece a segunda hipótese, embora, diferenças relacionadas a preferências alimentares não possam ser descartadas.

A dieta dos primatas pode variar de acordo com a hora do dia e a estação do ano, em função de flutuações em fatores como temperatura, luminosidade, pluviosidade e oferta de alimentos (Fragaszy et al., 2004a). No presente estudo, a proporção de tempo dedicada à exploração dos diferentes itens alimentares pouco variou em função da hora do dia. Contudo, no grupo ZA observou-se que a alimentação por invertebrados foi maior no período do meio do dia. Robinson (1984a) realizou um estudo sobre variação 
diária no forrageamento e dieta de C. olivaceus e também observou maior consumo de invertebrados no meio do dia, mesmo não havendo diferença significativa na disponibilidade desses recursos a cada hora do dia. Como muitos dos invertebrados consumidos pelos animais eram encontrados no chão, o autor argumenta que ao evitar forragear por esses recursos no início da manhã, os macacos diminuíam as chances de encontrar com predadores terrestres noturnos (como felinos e iraras).

Quanto às diferenças na dieta relacionadas às estações do ano, verificou-se que, em ambos os grupos, houve maior consumo de polpa de frutos no período de chuvas. Esse resultado indica uma sazonalidade na oferta das espécies de frutos consumidos por C. libidinosus na BV, muito embora não tenha sido observada variação significativa na oferta total desse recurso. Na estação seca houve aumento de consumo de sementes, raízes, néctar/flores, endosperma e, no caso do grupo $\mathrm{CH}$, de alimentos aprovisionados, indicando que esses itens foram os principais alimentos de reserva dos macacos da BV. Apesar dessas variações, a proporção de amostras de varreduras dedicada à alimentação por recursos com distribuição discreta e uniforme no ambiente não sofreu alteração ao longo desta pesquisa.

\subsection{Existe diferenca no padrão de atividades, dieta e escolha dos substratos em}

\section{funcão do sexo e da idade dos indivíduos?}

Primatas do gênero Cebus exibem grande variabilidade intra-grupo quanto ao orçamento de atividades, forrageamento, dieta e uso de substratos (Rose, 1994; Fragaszy \& Boinski, 1995; Fragaszy et al., 2004a; Benzanson, 2009). Diversos estudos (Fragaszy, 1986, 1990a; Fragaszy \& Boinski, 1995; Rose, 1996) apontam as diferenças sexuais como as principais responsáveis por essas variações. 
As diferenças sexuais no padrão de atividades, escolha de substrato e dieta de $C$. libidinosus na BV foram bastante consistentes entre os grupos estudados. No geral, as fêmeas dedicaram mais tempo à alimentação, sendo que no grupo $\mathrm{CH}$ elas também despenderam mais tempo em locomoção (o que pode estar associado à busca por alimento) e consumo de invertebrados. O maior investimento de fêmeas em alimentação pode indicar uma demanda energética mais onerada em função dos custos reprodutivos (Wrangham, 1980; van Schaik, 1989; Isbell, 1991; Sterck et al., 1997). Entretanto, é possível argumentar que as fêmeas foram excluídas das fontes alimentares mais ricas por machos dominantes e, portanto, forçadas a completar a dieta com recursos de baixo valor nutricional e, conseqüentemente, investir mais tempo para atingir suas necessidades energéticas. Outra explicação plausível é a de que as fêmeas foram menos eficientes na localização e processamento dos alimentos (Fragaszy \& Boinski, 1995; Ferreira et al., 2008). Contudo, é possível que as fêmeas adultas e juvenis tenham alocado mais tempo em alimentação por motivos diferentes (p. ex.; fêmeas adultas pelo alto custo reprodutivo e fêmeas juvenis por aversão ao risco e/ou menor eficiência alimentar). As poucas diferenças entre a dieta de machos e fêmeas em ambos os grupos estudados (ver discussão abaixo), assim como os numerosos episódios de alimentação simultânea de machos e fêmeas em fontes nutritivas (Capitulo III) não favorecem a hipótese de exclusão. Estudos que visem esclarecer essa questão precisam testar cuidadosamente as hipóteses apresentadas aqui, inclusive, diferenciando as fêmeas pelo seu estado reprodutivo.

Os machos da BV despenderam mais tempo com observação/vigilância, interações sociais e, no caso do grupo $\mathrm{CH}$, com o uso de ferramentas. O maior tempo de observação/vigilância entre machos, especialmente os adultos, é consistente com os resultados encontrados para outras populações de Cebus (van Schaik \& van Noordwijk, 
1989; Fragaszy, 1990; Gould et al., 1991; Fedigan, 1993; Rose \& Fedigan, 1995; Jack, 2001, Moura, 2004). Por outro lado, a constatação de que os machos passaram mais tempo do que as fêmeas interagindo socialmente é oposta ao padrão relatado para $C$. capucinus (Rose, 1994). Uma análise mais detalhada mostrou que esse resultado foi fortemente influenciado por machos juvenis, que passaram muito tempo envolvidos em atividades sociais, especialmente em brincadeira social. Esse achado é consistente com os resultados encontrados para macacos-prego (Paukner \& Suomi, 2008 e outras espécies de primatas (Papio hamadryas e Cercopithecus aethiops: Walters, 1987; Saimiri sciureus: Biben, 1998) que mostram que machos juvenis são a classe de sexo e idade que mais se envolve em brincadeira social. Por fim, o maior tempo gasto em uso de ferramentas pelos machos do grupo $\mathrm{CH}$ parece relacionado à presença de subadultos no grupo, tanto pelo interesse que esses indivíduos demonstraram pela atividade, quanto pela menor habilidade para executá-la com sucesso (Ramos da Silva, 2008; Spagnoletti et al., 2010; observação pessoal). No grupo ZA, embora o tempo de uso de ferramentas não tenha variado entre machos e fêmeas, houve maior consumo de endosperma (alimento obtido com auxílio de ferramentas) entre os machos. Isso significa que os machos foram mais proficientes (obtiveram mais sucesso por tentativa de quebra) e/ou eficientes (quebrar mais cocos por unidade de tempo) do que as fêmeas na quebra de cocos (Ramos da Silva; 2008). Os machos do grupo CH também consumiram mais endosperma do que fêmeas, assim como raízes e vertebrados. Spagnoletti et al. (2009) argumentam que a diferença na freqüência de uso de ferramentas entre machos e fêmeas na BV está relacionada ao dimorfismo sexual no tamanho corpóreo (machos adultos são cerca de $30 \%$ maiores do que as fêmeas adultas), que se refletem em custos diferenciados para a execução da tarefa, maiores para as fêmeas. 
Rose (1994) realizou um estudo sobre diferenças sexuais no padrão de forrageamento e dieta de C. capucinus, no Parque Nacional Santa Rosa, e propôs três hipóteses adaptativas para explicar seus resultados: (1) dimorfismo sexual no tamanho corpóreo, (2) custos diferenciados associados à reprodução (gestação e cuidados pósnatal dos infantes) e (3) separação de nicho para evitar a competição por recursos limitantes entre parceiros sexuais e parentes. A autora verificou que os machos permaneceram mais tempo no chão, envolveram-se mais em forrageamento energético e consumiram presas animais maiores e mais móveis, enquanto fêmeas dedicam mais tempo ao consumo de pequenos invertebrados. Para a autora, a hipótese de dimorfismo sexual foi a que melhor explicou as variações encontradas. As diferenças sexuais na dieta de C. libidinosus na BV apóiam essa hipótese apenas quanto ao consumo de alimentos que exigiram força e destreza para obtenção e processamento (raízes precisam ser escavadas e frutos de palmeiras golpeados com pedras para que o endosperma seja exposto), que foi maior entre machos. Por outro lado, a ausência de grandes variações na dieta de machos e fêmeas, especialmente quanto ao consumo de frutos (principal alimento desses animais), não favorece a hipótese de separação de nicho.

O padrão de utilização de substratos pelos macacos da BV não variou em função do sexo dos indivíduos. Esse resultado é idêntico ao observado por Moura (2004) para um grupo selvagem de C. libidinosus no Parque Estadual Serra da Capivara (uma área de Caatinga com vegetação e topografia semelhante a da BV), porém, difere da maior parte dos estudos prévios realizados com macacos do gênero Cebus (C. capucinus: Fedigan, 1993; Rose, 1994; C. olivaceus: Fragaszy, 1986, 1990; Robinson, 1986). Como discutido anteriormente, as características da BV (vegetação arbustiva, grande oferta de alimento no chão, presença de morros que servem como área de forrageamento, descanso e dormida) conduziram os macacos-prego a um estilo de vida 
mais terrestre do que normalmente observa-se entre primatas do gênero Cebus. A familiaridade com o ambiente terrestre pode ter diminuído a percepção de risco desses animais quanto ao uso e permanência no chão, principalmente entre os adultos (ver adiante).

Embora as diferenças sexuais sejam as fontes mais evidentes de variação comportamental dentro de um grupo social de primatas, a faixa etária dos indivíduos que o compõem também pode produzir variações (Fragaszy et al., 2004a). Primatas imaturos (juvenis e infantes) costumam optar por uma dieta de fácil obtenção, consumindo maiores quantidades de alimentos que exigem menos força e destreza para serem obtidos (Janson \& van Schaik, 1993). Na presente pesquisa, as diferenças no orçamento de atividades, dieta e uso de substratos relacionadas à idade dos indivíduos foram ainda mais consistentes nos grupos estudados do que as diferenças sexuais.

Os juvenis da BV alocaram mais tempo em alimentação, principalmente na exploração de invertebrados, e permaneceram menos tempo no chão do que os adultos. O maior investimento dos juvenis em alimentação é consistente com resultados de outros estudos (Fragaszy \& Boinski, 1995: C. olivaceus; Verderane, 2005: Cebus spp; Santos, 2010: C. nigritus) e pode indicar: (1) diferenças na eficiência de forrageamento; (2) diferenças na demanda enérgica e (3) efeito de dominância no acesso a fontes alimentares de alta qualidade. Em um estudo sobre escolha da dieta e eficiência de forrageamento em C. olivaceus selvagem, Fragaszy e Boinski (1995) observaram que os juvenis passaram mais tempo alimentando-se porque foram menos eficientes que os adultos na busca e obtenção dos alimentos. Em $C$. nigritus, no Parque Estadual Carlos Botelho, Santos (2010) observou que os juvenis desprenderam em alimentação cerca de $20 \%$ a mais do que o tempo necessário para que suas demandas energéticas fossem atingidas (com base no peso e tamanho corpóreo - cálculos elaborados com base em 
Janson \& van Schaik, 1993). Assim, o autor concluiu que os juvenis do Parque Estadual Carlos Botelho foram menos eficientes na localização e processamento de alimentos em comparação com os adultos. Como uma parcela significativa da dieta de $C$. libidinosus na BV foi constituída por alimentos que exigem algum grau de processamento antes da ingestão (ver Capítulo III), é plausível supor que as diferenças no tempo de alimentação e dieta de juvenis e adultos, ou pelo menos parte delas, estejam relacionadas à eficiência. O maior percentual de varreduras de alimentação dedicadas à exploração de invertebrados também sugere uma menor eficiência dos juvenis da BV para lidar com esse tipo de recurso, seja pela menor experiência de onde procurar, como pela menor força e destreza necessárias para extrair alguns tipos de invertebrados (p. ex., larvas em oco e casca de árvores: Fragaszy; 2004a). Já o menor percentual de varreduras de alimentação dedicadas à exploração de frutos sugere que os juvenis foram mais vulneráveis à competição direta por alimento. Esse argumento é reforçado pelas freqüentes observações de agressões dirigidas por adultos a juvenis durante episódios de alimentação em fruteiras (Capítulo III). Por fim, a constatação de que os juvenis permaneceram menos tempo no chão, em comparação com os adultos, pode indicar que esses indivíduos foram menos propensos a assumirem riscos, conforme sugerido por Fragaszy e Boinski (1995). Embora os infantes tenham sido excluídos das análises estatísticas, é interessante observar que o consumo de endosperma nessa classe de idade (em ambos os grupos) foi maior do que entre os juvenis, não obstante o fato de que, durante toda a pesquisa, nenhum infante foi observado executando quebra de cocos com sucesso. Esse resultado deve-se à partilha de alimentos por adultos e juvenis e evidencia a tolerância dos membros do grupo para com os infantes (Ramos da Silva, 2008, conforme observado, também, para outras populações de macacos-prego: Izawa, 1980; Izar, 1994; Baldovino, 2005; Verderane, 2005; Verderane et al., 2005). 
Entre os adultos, houve maior investimento de tempo em observação/vigilância, descanso e uso de ferramentas, em comparação com os juvenis. $\mathrm{O}$ maior tempo de observação entre adultos deve-se, principalmente, ao grande investimento de machos adultos nessa atividade (significativamente maior do que de fêmeas adultas), conforme já discutido. O maior tempo dedicado ao descanso é consistente com outros estudos com macacos Cebus (Fragaszy, 1990; Ferreira et al., 2008) e pode estar relacionado a um forrageamento mais eficiente (comparado aos juvenis), que resulta em mais tempo livre para o descanso. A explicação para o fato dos adultos dedicarem mais tempo ao uso de ferramentas segue a mesma argumentação utilizada para explicar as demais variações em forrageamento e dieta de adultos e juvenis: diferenças nas habilidades de forrageamento. A quebra de cocos com a utilização de pedras como martelos e bigornas é considerada a forma mais complexa de uso de ferramenta entre primatas nãohumanos, pois envolve a execução de duas relações espaciais em seqüência (posicionar o coco na bigorna e golpeá-lo com o martelo, Fragaszy et al., 2004b). Um estudo conduzido por Resende (2004), sobre a ontogênese da quebra de cocos em macacosprego (Cebus spp) no Parque Ecológico do Tietê, revelou que a emergência da quebra proficiente (bem sucedida) ocorre por volta de 2,5 a 3 anos de idade. Além disso, os cocos disponíveis para a quebra na BV são muito mais resistentes que os cocos explorados pelo grupo de Resende (Visalberghi et al., 2008) e os martelos utilizados no processo chegam a pesar em média $1 \mathrm{~kg}$, o equivalente a $20-45 \%$ do peso de machos e fêmeas adultos (Fragaszy et al., 2004b; Visalberghi et al., 2007). Ramos da Silva (2008) observou que os juvenis do grupo ZA foram menos proficientes (razão entre total de episódios em que houve o rompimento do coco e a freqüência absoluta de episódios de quebra) do que os adultos na quebra de cocos. Sendo assim, fica claro que a diferença 
entre adultos e juvenis quanto ao uso de ferramentas está relacionada à força e destreza necessárias para execução dessa tarefa.

\subsection{A influência do uso de ferramentas sobre orcamento de atividades, dieta e uso} de substratos

Os dados apresentados aqui mostram que as diferenças e semelhanças no orçamento de atividades, dieta e uso de substratos entre os C. libidinosus da Boa Vista e outras populações do mesmo gênero são mais bem explicadas por fatores ambientais (como abundância e distribuição de recursos limitantes, estrutura da vegetação, topografia e clima), do que propriamente pela utilização de ferramentas ou inércia filogenética. Nesse sentido, o padrão de atividades e a dieta dos animais do presente estudo foram mais semelhantes ao padrão relatado para populações de $C$. capucinus e $C$. olivaceus que habitam florestas tropicais secas e que não utilizam ferramentas (Robinson, 1986; Rose, 1994), enquanto o padrão de uso de substrato aproximou-se mais ao padrão encontrado para outras populações de $C$. libidinosus em ambientes semiáridos (Moura, 2004; Sabbatini et al., 2006). Por outro lado, as maiores diferenças foram em relação às populações de $C$. nigritus, $C$. apella e $C$. xanthosternos que habitam florestas tropicais úmidas (Terborgh, 1983; Brown \& Zunino, 1990; Izar, 2004, Rímoli et al., 2008; Gouveia, 2009; Santos, 2010). Esses resultados evidenciam a grande flexibilidade comportamental dos macacos do gênero Cebus e capacidade de adaptação a diferentes ambientes.

Com base nesses resultados, é possível prever que o impacto do uso de ferramentas sobre o padrão de relações sociais de C. libidinosus na BV também será pequeno. 


\section{6-CONCLUSÕES}

1) A oferta de alimento na BV (avaliada como abundância de frutos, flores, invertebrados e frutos de palmeiras) não sofreu variação drástica ao longo desta pesquisa.

2) $\mathrm{O}$ orçamento de atividades dos macacos da BV foi similar ao padrão encontrado para outras populações selvagens de $C$. libidinosus, em regiões semi-áridas, e de $C$. capucinus e C. olivaceus, em regiões de florestas tropicais secas, enquanto as maiores diferenças foram observadas em relação a populações de $C$. nigritus em regiões de florestas tropicais úmidas.

3) A alimentação foi a principal atividade dos grupos da BV, enquanto o uso de ferramentas correspondeu menor percentual do tempo de atividades, indicando que essa técnica teve pouca contribuição para o forrageamento dos animais.

4) Entre os grupos de estudo, o orçamento de atividades anual, sazonal e diário foi bastante parecido, não obstante ao aprovisionamento do grupo $\mathrm{CH}$. Não houve grandes ajustes no tempo de atividades entre as estações seca e chuvosa, o que é coerente com a ausência de escassez na oferta de alimentos na BV.

5) O padrão de utilização de substratos pelos macacos da BV foi similar a padrão observado para outras populações selvagens de C. libidinosus e consideravelmente divergente do relatado para populações de Cebus em florestas tropicais úmidas. Destaca-se o elevado percentual de tempo de permanência no chão pelos animais da BV.

6) Frutos e invertebrados foram os principais alimentos consumidos pelos animais deste estudo. Já os alimentos extraídos com auxílio de ferramentas corresponderam ao menor percentual das amostras de varreduras de alimentação em ambos os grupos. 
7) A dieta dos macacos da BV variou em função da estação, com maior consumo de polpa de frutos no período de chuvas e maior consumo de sementes, raízes, néctar/flores e endosperma (e alimentos aprovisionados no grupo $\mathrm{CH}$ ) no período de seca. Entre os grupos de estudo, a maior parte das diferenças foi relacionada ao aprovisionamento.

8) Diferenças sexuais no padrão de atividades e dieta sugerem que as fêmeas possuem uma demanda energética maior e/ou que são forrageadoras menos eficientes do que os machos, porém, ambas as hipóteses precisam ser testadas.

9) As diferenças no orçamento de atividades e dieta entre faixas etárias indicam que os juvenis são menos eficientes do que os adultos na busca e processamento de alimentos, enquanto diferenças no uso de substratos sugerem que juvenis são menos propensos a aceitar os riscos associados ao uso do chão.

10) Diferenças e semelhanças no orçamento de atividades, dieta e uso de substratos entre os C. libidinosus da Boa Vista e outras populações de macacos Cebus são mais bem explicadas por fatores ambientais (como abundância e distribuição de recursos limitantes, estrutura da vegetação, topografia e clima), do que propriamente pela utilização de ferramentas ou inércia filogenética. 
CAPÍTULO III: Socioecologia de macacos-prego selvagens (Cebus libidinosus) em área de ecótono Cerrado/Caatinga no Piauí: o efeito do uso de ferramentas nas relações sociais de fêmeas. 


\section{1-INTRODUÇÃO}

\subsection{Socioecologia de primatas}

A ordem dos primatas é uma das mais sociais dentre o reino animal, pois possui um grande número de espécies em que um ou mais indivíduos adultos co-específicos deslocam-se conjuntamente (cerca de 73\% das espécies ou 94 de 129 - Isbell, 1994). Entre as espécies de hábitos diurnos, a gregariedade de fêmeas é uma característica difundida (ocorre em aproximadamente $81 \%$ dos taxa - Sterck et al., 1997). Existem duas hipóteses principais para a evolução da socialidade em primatas: (1) redução do risco de predação ou (2) vantagem de forrageamento. A primeira considera os benefícios da redução do risco de predação em função do aumento da vigilância, da defesa coletiva e do efeito de diluição, como a pressão seletiva para socialidade. A segunda considera a partilha de informação sobre localização e qualidade de recursos alimentares e a defesa coletiva desses recursos como principal pressão seletiva para a vida em grupo (Wrangham, 1980). Estudos com primatas selvagens vêm acumulando descobertas que apóiam a primeira hipótese, como a observação de que em muitas espécies de primatas o tamanho do grupo social é negativamente correlacionado ao sucesso reprodutivo das fêmeas (van Schaik, 1983). A ameaça de predação, por outro lado, determina um limite mínimo para o tamanho do grupo, enquanto a competição alimentar intra-grupo impõe o limite máximo (van Schaik, 1989).

A socialidade, portanto, também impõe custos aos indivíduos de um grupo, principalmente em termos de aumento da competição intra-grupo por recursos limitantes (Dunbar, 1988; Janson \& van Schaik, 1988; van Schaik, 1989; van Hooff \& van Schaik, 1992, Sterck et al., 1997). Entre os primatas, estudos demonstraram que esses custos decorrem, principalmente, do aumento nos níveis de competição intragrupo por alimento (Janson, 1988), sendo que fêmeas adultas são os indivíduos do 
grupo que mais sofrem com os seus efeitos (Hamilton, 1985; Watts, 1985; van Schaik, 1989, Isbell, 1991; Sterck et al., 1997). De acordo com van Schaik (1983), as fêmeas primatas só viveriam em grupos sociais, enfrentando os custos da competição intragrupo por alimento, se os benefícios conferidos pela redução do risco de predação fossem maiores. Embora o risco de predação seja considerado a causa evolutiva da socialidade de primatas, muitos autores concordam que seu impacto está apenas indiretamente envolvido nas causas proximais de variações nas relações sociais de fêmeas (Isbell, 1991; Boinski et al., 2002; Izar, 2004), por exemplo, através do efeito sobre o tamanho (Dunbar, 1988; Hill \& Lee, 1998) e a composição dos grupos sociais (van Schaick \& Horstermann, 1994).

A socioecologia é uma abordagem que busca explicar a evolução dos diversos sistemas sociais dos primatas como um resultado coletivo de estratégias individuais, moldadas por fatores ecológicos que afetam o sucesso reprodutivo individual, particularmente a distribuição dos riscos e dos recursos no habitat (Kappeler \& van Schaik, 2002). Essas estratégias individuais refletem as diferenças entre machos e fêmeas quanto à fisiologia reprodutiva e o investimento parental. Entre os primatas, como na maioria dos mamíferos, as fêmeas geralmente investem mais tempo e energia na gestação e criação de filhotes, enquanto os machos maximizam sua aptidão copulando com o maior número de fêmeas (Trivers, 1972). Por essa razão, os modelos socioecológicos consideram que fêmeas primatas distribuem-se no ambiente em função da distribuição dos riscos (especialmente o de predação) e dos recursos (especialmente de alimentos), e enfocam, principalmente, a competição por alimento entre fêmeas e as suas consequiências para as relações sociais entre elas. Os modelos assumem que os machos distribuem-se no habitat em função da distribuição das fêmeas (Wrangham, 1980; van Schaik, 1989). 
A premissa central a todos os modelos socioecológicos estabelece que as características do principal recurso alimentar consumido pela espécie determinam o tipo e a intensidade de competição a que fêmeas primatas estão submetidas. O tipo de regime competitivo, por sua vez, afeta o padrão de relações sociais estabelecidas entre as fêmeas (Wrangham, 1980; van Schaik, 1989; Isbell, 1991; Sterck et al., 1997). As fêmeas podem competir por alimento direta (contest) ou indiretamente (scramble), tanto intra quanto entre grupos (Janson \& van Schaik, 1988; van Schaik, 1989; Sterck et al., 1997). Recursos alimentares de alto valor energético e que possuem distribuição discreta no ambiente (como frutos) e tamanho intermediário em relação ao tamanho do grupo, podem ser monopolizáveis ou usurpáveis (Isbell \& Van Vuren, 1996). Isso significa que um ou alguns indivíduos podem impedir que outros membros do grupo tenham acesso a esses recursos (geralmente os indivíduos dominantes excluem os subordinados). Dessa forma, a competição direta por alimento ocorre quando alguns indivíduos interferem diretamente no ganho energético de membros do seu próprio grupo. A competição direta intra-grupo por alimento está associada à formação de hierarquias de dominância. Recursos alimentares de baixo valor energético, uniformemente distribuídos no ambiente (como folhas e invertebrados), ou em fontes muito grandes ou pequenas em relação ao tamanho do grupo, não precisam ou não podem ser monopolizáveis ou usurpáveis. Seja porque o recurso pode ser encontrado em todas as partes do ambiente, ou porque é pequeno ou grande demais para ser defendido. Nessas condições, espera-se que ocorra competição indireta intra-grupo, isto é, quando a taxa de alimentação e/ou eficiência na localização e processamento dos recursos é o que determina o sucesso de forrageamento individual e, à medida que o tamanho do grupo aumenta, todos os indivíduos são igualmente afetados pela redução na eficiência de forrageamento (seja porque são incapazes de forragear em locais que já 
foram depletados, ou porque precisam andar mais para encontrar alimento para todos os membros do grupo). A competição direta e a indireta também podem ocorrer entre grupos de mesma espécie (Janson \& van Schaik, 1988; van Schaik, 1989; Sterck et al., 1997). A competição direta entre grupos ocorre quando indivíduos de um grupo interferem diretamente no ganho energético de membros de outro grupo. A competição direta entre grupos é considerada, portanto, um efeito da distribuição dos recursos alimentares no ambiente e da densidade populacional de uma determinada espécie de primatas. Já a competição indireta entre grupos é considerada uma conseqüência da densidade populacional de uma espécie de primatas no ambiente e, aparentemente, não influencia as relações sociais de fêmeas (van Schaik, 1989).

A combinação do tipo e da intensidade de competição por alimento a que fêmeas primatas estão submetidas pode resultar em quatro padrões de relacionamentos sociais entre fêmeas, ou síndromes sociais (Sterck et al., 1997): (1) Dispersor-Igualitário: quando a competição direta intra e entre grupos é fraca; (2) Residente-Igualitário: quando a competição direta é fraca intra-grupo e forte entre grupos; (3) ResidenteNepotista: quando a competição direta entre grupos é forte e fraca entre grupos; (4) Residente-Nepotista-Tolerante: quando a competição direta intra e entre grupos é forte (ver Capítulo I para uma descrição mais detalhada das síndromes sociais).

A filopatria de fêmeas, com estabelecimento de fortes laços sociais entre elas, emerge em função da competição direta por alimento, já que a cooperação entre fêmeas aparentadas aumenta as chances de vitória em competições alimentares e, assim, a aptidão abrangente (Wrangham, 1980). A dispersão de fêmeas é esperada quando a competição direta por alimento é baixa, já que há poucas vantagens em permanecer no grupo e estabelecer hierarquias de dominância ou coalizões para competir por alimento. Entretanto, Isbell \& Van Vuren (1996) argumentam que a dispersão de fêmeas de seu 
grupo natal deve ocorrer sempre que as chances de sucesso reprodutivo intra-grupo são menores do que em outro local.

Implícita ao arcabouço teórico dos modelos socioecológicos está a noção de que, em face à grande variação no tamanho, qualidade, densidade e distribuição dos recursos alimentares, as organizações sociais resultantes serão igualmente variáveis (Chapman \& Rothman, 2009). Não obstante, mesmo diante de grande variação ecológica, a organização social pode ser bastante conservativa em função da inércia filogenética de algumas linhagens (di Fiore \& Rendall, 1994; Rendall \& di Fiore, 2007). Uma abordagem para identificar a relativa contribuição de determinantes ecológicos e da inércia filogenética sobre a estrutura social são estudos comparativos de linhagens de primatas intimamente aparentadas, mas que habitam ecossistemas variados.

Tendo apresentado os principais argumentos dos modelos socioecológicos, é importante ressaltar as críticas que se fazem a essa abordagem. A maior parte concentrase em duas premissas sustentadas pelos modelos: (1) a formulação dos regimes competitivos em termos binários (forte/fraco) e a classificação dos relacionamentos sociais de fêmeas primatas em sistemas categóricos, que não abarcam toda diversidade de sistemas sociais observados entre os primatas atuais (Thierry, 2008; Strier, 2009), e (2) o argumento de que a competição por alimento entre espécies de primatas folívoros é fraca ou inexiste, e de que o tamanho dessas populações e grupos não é limitado pela disponibilidade de alimento (Snaith \& Chapman, 2007).

Apesar das críticas, diversos estudos de campo vêm apresentando resultados que apóiam as previsões dos modelos socioecológicos, especialmente entre espécies de cercopitecóides (Sterck \& Steenbeek, 1997; Isbell et al., 1998; Pruetz \& Isbell, 2000; Harris, 2006; Su \& Birky, 2007; Nakagawa, 2008; Teichroeb \& Sicotte, 2009) e lêmures (Kappeler, 1999; Eberle \& Kappeler, 2002; White et al., 2007; Dammhahn \& 
Kappeler, 2009). Em relação aos primatas do Novo Mundo, argumenta-se que a sua longa trajetória evolutiva separada dos primatas do Velho Mundo (cerca de $30 \mathrm{MA}-$ Fleagle, 1999), provavelmente resultou em sistemas sociais fundamentalmente diversos dos observados em primatas do Velho Mundo (Isbell \& Young, 2002). De fato, vários estudos de campo estão revelando que os primatas do Novo Mundo divergem dos primatas do Velho Mundo em alguns aspectos, especialmente em relação à dispersão de fêmeas (Strier, 1994). Apesar dessas constatações, poucos estudos de campo propuseram-se a testar as previsões dos modelos socioecológicos utilizando dados de primatas do Novo Mundo (Boinski, 1999; Boinski et al, 2002; Izar, 2004; Mathews, 2009).

Nesse contexto, particularmente interessante é o sistema social de macacos do gênero Cebus, porque, diferente da maioria dos Platyrrhine, assemelha-se mais ao padrão dos primatas Catarrhine (Robinson \& Janson, 1987; Fedigan, 1993; Perry, 1996a, 1997). Embora a filopatria de fêmeas e a coesão dos grupos sociais sejam consideradas típicas dessas espécies, um estudo recente com uma população de $C$. nigritus selvagens em área de Mata Atlântica, no Parque Estadual Carlos Botelho (PECB), observou migração de fêmeas entre grupos e a fissão de grupos sociais em subgrupos menores (Izar, 2004). Resultados semelhantes também foram observados em outras populações (C. nigritus: Alfaro-Lynch, 2007; C. capucinus: Jack \& Fedigan, 2009), indicando que esses comportamentos são mais comuns do que se supunha anteriormente.

Os macacos-prego, como são popularmente conhecidas as espécies que pertencem ao grupo dos Cebus "com tufos" ("tufted capuchin": C. apella, C. xanthosternos, C. nigritus, e C. libidinosus: Groves, 2001), apresentam uma ampla distribuição geográfica, ocorrendo em ecossistemas tão diversos como a Mata Atlântica, 
Amazônia, Cerrado e Caatinga (ver Capítulo I). Por essa razão, esses primatas são modelos ideais para o teste das previsões dos modelos socioecológicos através da comparação entre diferentes populações. No entanto, a maior parte dos estudos com populações selvagens restringe-se a habitats de floresta (Amazônia: Terborgh, 1983; Izawa, 1980; Spironello, 2001; Mata Atlântica: Rímoli, 2001; Izar, 2004; Alfaro-Lynch, 2007; Floresta semi-decíduas da América do Sul: Torres de Assumpção, 1983; Janson, 1985, 1988; Galetti \& Pedroni, 1994). Estudos com populações de macacos-prego selvagens em ambientes semi-áridos, como o Cerrado e a Caatinga, só tiveram início em meados deste século (Fragaszy et al., 2004b; Moura, 2004; Moura \& Lee, 2004; Waga et al., 2006; Ottoni \& Izar, 2008; Sabbatini et al., 2008; Mannu \& Ottoni, 2009; Ramos da Silva, 2008; Spagnoletti, 2009; Ferreira et al., 2010). Esses trabalhos já revelaram comportamentos surpreendentes em populações selvagens, particularmente, o uso difundido e espontâneo de ferramentas para acessar e processar alimentos encapsulados (Fragaszy et al., 2004b; Moura \& Lee, 2004; Waga et al., 2006; Visalberghi et al., 2007; Ottoni \& Izar, 2008; Mannu \& Ottoni, 2009). Apesar do crescente aumento no número de pesquisa com $C$. libidinosus em regiões do semi-árido brasileiro, ainda pouco se sabe sobre ecologia e comportamento social dessas populações, já que a maior parte desses trabalhos tem por objetivo descrever o uso de ferramentas e investigar o impacto de variáveis ambientes e demográficas sobre a freqüência de exibição desse comportamento.

Considerando a grande variabilidade comportamental relatada para populações de floresta (Rímoli, 2001; Izar, 2004; Alfaro-Lynch, 2007; Nakai, 2007), a investigação da ecologia e do comportamento social de macacos-prego que utilizam ferramentas em ambiente semi-árido, além de ampliar o conhecimento sobre a adaptabilidade desses primatas, pode fornecer um novo e instigante teste de modelos socioecológicos. 


\subsection{Uso de ferramentas e socialidade}

Como descrito acima, os modelos socioecológicos consideram que as características dos recursos alimentares determinam o tipo e a intensidade de competição por alimento a que fêmeas primatas estão submetidas, o que, por sua vez, afeta as relações sociais entre elas (Wrangham, 1980; van Schaik, 1989; Isbell, 1991; Sterck et al., 1997). Por definição, uma ferramenta é qualquer objeto externo, solto no ambiente, utilizado por um animal como extensão funcional do seu corpo (boca, bico ou mãos) para alterar a forma, posição ou a condição de outro objeto, organismo ou o próprio usuário (Beck, 1980). Neste contexto, é plausível supor que uma ferramenta, capaz de alterar o modo de distribuição, tamanho e qualidade das fontes alimentares, terá sobre o sistema social o mesmo impacto que qualquer outra característica ambiental que afete essas propriedades dos recursos alimentares.

A idéia de que o uso de ferramentas alimentares permite a exploração de recursos que seriam inacessíveis de outra maneira (como raízes, frutos encapsulados e ninho de insetos) e aumenta a ingestão calórica e/ou a qualidade da dieta dos indivíduos (Anderson, 1990; McGrew, 1992; Boesch \& Boesch-Achermann, 2000) é amplamente aceita pelos pesquisadores. Entretanto, o impacto que essa técnica pode ter sobre o regime de competição por alimento e, conseqüentemente, sobre as relações sociais de fêmeas, até o momento, não foi incorporado às previsões dos modelos socioecológicos.

A utilização de ferramentas alimentares por primatas tem sido considerada uma estratégia chave para aquisição de energia em ambientes com gargalos energéticos (Fox et al., 1999; Moura \& Lee, 2004) ou em períodos de baixa disponibilidade de alimentos (Marshall \& Wrangham, 2007). Existem duas hipóteses principais para explicar a emergência do uso de ferramentas em primatas não-humanos: (1) hipótese da necessidade e (2) hipótese da oportunidade para invenção (opportunity to invention). De 
acordo com a hipótese da necessidade, o uso de ferramentas seria uma resposta para lidar com a escassez do principal recurso alimentar (Fox et al., 1999; van Schaik \& Knott, 2001; van Schaik et al., 2003; Fox et al., 2004). Neste cenário, os recursos alimentares obtidos com o auxílio de ferramentas podem ser determinantes para o sucesso reprodutivo das fêmeas. De acordo com a hipótese da oportunidade (Fox et al., 1999; van Schaik \& Knott, 2001; van Schaik et al., 2003; Fox et al., 2004), por outro lado, o surgimento do uso de ferramentas é mais provável em populações que exibem um alto grau de tolerância social e coesão grupal (Coussi-Korbel \& Fragaszy, 1995), que são características acentuadas em ambientes com farta oferta de alimentos (van Schaik et al., 1999; Boesch \& Boesch-Achermann, 2000). Nessa situação, os alimentos obtidos com auxílio de ferramentas não são, necessariamente, essenciais para o sucesso reprodutivo das fêmeas.

Com base nessas hipóteses, é possível prever que o uso de ferramentas para obtenção de alimentos afetará a competição entre fêmeas de maneira distinta em cada um dos dois cenários propostos acima. Assim, se os alimentos acessados com ferramentas forem os principais recursos consumidos por fêmeas de uma população (portanto, limitante do sucesso reprodutivo), então, espera-se que as propriedades dos sítios de ferramentas e dos recursos obtidos com essa técnica sejam os maiores determinantes dos regimes de competição entre fêmeas. Por outro lado, se o uso de ferramentas ocorrer em populações que habitam ambiente com farta oferta de alimentos, então, espera-se que as propriedades do principal alimento consumido pelas fêmeas determinem o tipo de competição por alimento entre elas. Nessa situação, o uso de ferramentas poderá reforçar o regime competitivo, se as propriedades dos sítios de ferramentas forem semelhantes às propriedades do principal recurso alimentar, ou 
poderá alterar o regime competitivo, se as propriedades dos sítios de ferramentas divergirem das propriedades do principal recurso consumido pela espécie.

No intuito de investigar se o uso de ferramentas afeta o regime de competição por alimento e o padrão de relações sociais entre fêmeas, a presente pesquisa consistiu num estudo socioecológico de uma população de macacos-prego (Cebus libidinosus) selvagens, que utiliza ferramentas rotineiramente (Ramos da Silva, 2008; Spagnoletti, 2009) em ambiente de ecótono Cerrado/Caatinga no Piauí. Para tanto, foram analisados dois anos de dados sobre comportamento alimentar, tamanho das fontes alimentares, regimes competitivos e relações sociais entre fêmeas. O risco de predação não foi analisado, já que diversos trabalhos indicam que esse fator tem apenas um efeito indireto na organização social observada nos primatas atuais (Isbell, 1991).

Este é o primeiro trabalho a apresentar dados sobre a socioecologia de uma população selvagem de $C$. libidinosus em ambiente semi-árido, bem como o primeiro a testar as previsões dos modelos usando dados de uma espécie de primata do Novo Mundo que utiliza ferramentas.

\section{2-OBJETIVOS}

\subsection{Gerais}

Analisar, à luz dos modelos sócio-ecológicos, as relações sociais entre fêmeas de uma população de macacos-prego (Cebus libidinosus) que utiliza ferramentas rotineiramente, em uma área do ecótono Cerrado/Caatinga no Piauí, Brasil. Considerando que ferramentas alimentares podem alterar as características dos recursos consumidos por uma população, o presente estudo também se propôs a avaliar se essa técnica (martelos e bigornas de pedras como ferramentas para acessar alimentos 
encapsulados) afeta o regime de competição por alimento e, conseqüentemente, o padrão de relações sociais estabelecido entre fêmeas.

\subsection{Específicos}

1) Estimar a densidade populacional de C. libidinosus na área de estudo;

2) Acompanhar as mudanças na composição dos grupos de estudo que permitam compreender o padrão de dispersão dos macacos-prego na BV;

3) Avaliar o risco de predação ao qual está submetida a população de estudo;

4) Identificar os principais itens alimentares consumidos e o tempo dedicado ao uso de ferramentas e ao consumo de alimentos obtidos com auxílio de ferramentas por fêmeas de C. libidinosus na área de estudo;

5) Mensurar o tamanho das fontes alimentares que apresentam distribuição discreta no ambiente e o tamanho das unidades de forrageamento (número de indivíduos do grupo que se alimentam numa mesma fonte);

6) Identificar os regimes de competição por alimento ao qual as fêmeas dessa população de estudo estão submetidas, tanto intra como entre grupos;

7) Caracterizar o padrão de relações sociais estabelecido entre as fêmeas de $C$. libidinosus na área de estudo.

\section{3-HIPÓTESES}

1) Se o principal recurso alimentar consumido pelas fêmeas em áreas de ecótono Cerrado/Caatinga for de baixo valor energético, pequeno e apresentar uma distribuição uniforme no ambiente (como folhas), então, espera-se que haja pouca competição direta por alimento; os grupos sociais deverão se organizar em sistemas mais fluídos (Aureli et al., 2008) e as relações entre fêmeas serão fracas ou inexistentes. 
2) Se o principal recurso alimentar consumido pelas fêmeas for de alta qualidade nutricional, distribuição discreta no ambiente (como frutos de palmeiras: Terborgh, 1983; Spironello, 2001) e com tamanho intermediário ao tamanho dos grupos, então, espera-se que haja forte competição direta por alimento; os grupos sociais deverão ser coesos, as fêmeas permanecerão no seu grupo natal durante a fase adulta e estabelecerão fortes laços sociais entre si. Para este cenário, espera-se também:

2a) Se o principal recurso alimentar for obtido com ajuda de ferramentas em sítios de quebra (que são recursos com distribuição discreta na área de estudo: Visalberghi et al., 2007; Visalberghi et al., 2009a; conforme detalhado na parte de Métodos deste Capítulo), e se os sítios de quebra forem usurpáveis e não permitirem que todos os membros do grupo alimentem-se simultaneamente nesses recursos, então, em comparação com outras fontes alimentares de distribuição discreta, os sítios de quebra deverão apresentar: (A) maior tempo de depleção, (B) maior número de animais se alimentando juntos na mesma fonte e (C) maior tolerância entre fêmeas;

2b) Se o principal alimento consumido for frutos de palmeiras, então, esses recursos deverão apresentar (A) maior tempo de depleção, (B) maior número de animais alimentando-se simultaneamente na mesma fonte e (C) maior tolerância entre fêmeas, em comparação aos sítios de ferramentas. Nessa situação, prevê-se, também, que o uso de ferramentas reforce o regime competitivo, se os sítios de ferramentas apresentarem características semelhantes às características das palmeiras, ou altere o regime de competição, se as características dos sítios de ferramentas diferirem das características das palmeiras. 


\section{4-MÉTODO}

\section{1. Área e grupos de estudo}

A pesquisa foi realizada na Fazenda Boa Vista (BV), uma área de ecotóno Cerrado/Caatinga, localizada no município de Gilbués, no Sul do estado do Piauí. Os sujeitos desse estudo foram os membros de dois grupos selvagens de macacos-prego (Cebus libidinosus): grupo Zangado (ZA) e grupo Chicão $(\mathrm{CH})$. Uma descrição mais detalhada da área e dos grupos de estudo encontra-se no Capítulo I. Uma análise detalhada da oferta de alimento ao longo desta pesquisa e da densidade de palmeiras na área de estudo encontra-se no Capítulo II.

\subsection{Censo populacional}

Os modelos socioecológicos consideram que a competição indireta (intra e entre grupos) é afetada pela densidade populacional de uma espécie em um determinado habitat. Para estimar a densidade de macacos-prego na BV foi realizado um censo populacional durante toda a duração da pesquisa, utilizando-se o método de transecto de linha (como detalhado por Sutherland, 1996). Esse método consiste em caminhar lentamente por trilhas lineares (em média, $1 \mathrm{~km} / \mathrm{hora}$ ), registrando o número de animais observados e a distância do primeiro animal avistado em relação: (1) à trilha e (2) ao observador. O registro da distância de avistamento e da distância percorrida permite o cálculo da área amostrada, e a densidade populacional é calculada em função do número de avistamentos nesta área. Esses dados foram coletados ao longo de duas trilhas: uma localizada em uma área utilizada pelos dois grupos de estudo, com $3 \mathrm{~km}$ de extensão, e outra em uma área freqüentada por outros grupos de macacos-prego, com extensão de 4 $\mathrm{km}$. A cada mês as duas trilhas foram percorridas, a uma velocidade média de $1 \mathrm{~km} / \mathrm{h}$, sempre no início do dia, seguindo a metodologia descrita acima. Para calcular a 
densidade populacional utilizou-se a distância total percorrida e o número total de avistamentos. A densidade populacional também foi calculada considerando apenas os grupos de estudos. Para essa estimativa, considerou-se o número total de indivíduos em cada grupo e o tamanho da área utilizada por eles ao longo deste estudo.

\subsection{Risco de predação}

O risco de predação ao qual a população de estudo esteve submetida ao longo desta pesquisa foi estimado através do levantamento de predadores potenciais de macacos-prego na BV e com base na taxa de vocalização de alarme emitida pelos macacos e de encontro entre os grupos de estudo e possíveis predadores.

O levantamento de predadores foi realizado concomitantemente ao censo populacional de C. libidinosus, seguindo os mesmos procedimentos acima descritos. Episódios de vocalização de alarme e encontros com predadores potenciais foram coletados através do método de "todas as ocorrências" (Altmman, 1974). Sempre que possível, registrou-se, também, o contexto das vocalizações ou a espécie do predador e a identidade do emissor do alarme.

\subsection{Comportamento alimentar}

O tempo dedicado à utilização de ferramentas e a caracterização da dieta, incluindo o tempo dedicado à exploração dos diferentes itens alimentares consumidos pela população de estudo, foram obtidos com base no orçamento de atividades, conforme apresentado no Capítulo II. 


\subsection{Caracterizacão e tamanho das fontes alimentares}

A distribuição dos recursos alimentares no ambiente é considerada uma das características mais importantes afetando o padrão de relações sociais entre fêmeas primatas (Wrangham, 1980; Isbell, 1991). A distribuição discreta de alguns recursos favorece a sua monopolização por um ou alguns indivíduos do grupo, ou de um grupo em detrimento de outro (Sterck \& Steenbeek, 1997). No geral, alimentos de alta qualidade (como partes reprodutivas de plantas) ocorrem em manchas discretas no ambiente (Wrangham, 1980; van Schaik, 1989; Sterck \& Steenbeek, 1997). Isso significa que árvores de uma determinada espécie podem estar separadas entre si por alguns metros, ou que árvores de uma mesma espécie cresceram tão próximas umas das outras que suas copas se entrelaçam como se fossem uma única árvore (Strier, 2007). Por outro lado, alimentos de baixa qualidade (como partes não reprodutivas de plantas e invertebrados) são considerados recursos com distribuição uniformemente dispersa (Wrangham, 1980; van Schaik, 1989; Sterck \& Steenbeek, 1997). Com base nessa classificação, no presente estudo frutos, flores, néctar, sementes, sítios de quebra e alimento aprovisionado foram considerados como recursos discretos, e folhas, raízes, invertebrados e vertebrados, como recursos dispersos.

O tamanho da fonte alimentar pode ser medido através do volume da copa ou com medidas correlacionadas, como o diâmetro do tronco à altura do peito. Contudo, Isbell et al. (1998) argumentam que "o tempo de depleção do sítio de alimentação" (food site depletion time - FSDT) é a medida mais acurada do tamanho da fonte alimentar, já que o volume da copa não varia com a floração e frutificação. Os autores concluem que o tempo de depleção é a característica mais importante da fonte alimentar que afeta o relacionamento social de fêmeas de um mesmo grupo, já que indica se as fontes podem ser monopolizadas ou usurpadas. Uma fonte alimentar é usurpável se ela 
puder ser tomada de um indivíduo (Isbell \& Young, 2002). Um pequeno tempo de depleção indica que a fonte é pequena, que já foi visitada ou que o recurso exige pouca manipulação. Assim, quanto menor o tempo gasto para que uma fonte seja depletada, menores são as chances de que outro indivíduo do grupo consiga tomá-la para si. Por outro lado, quanto mais tempo um recurso leva para ser depletado, maior é a chance de que outros indivíduos do grupo (geralmente os mais dominantes) usurpem o recurso (Isbell et al., 1998). O tempo de depleção foi calculado para três tipos de fontes discretas:

1) fruteiras: incluiu polpa de frutos, sementes, néctar e flores.

2) palmeiras: incluiu polpa de cocos (mesocarpo) e água de coco (endosperma líquido). A maioria das espécies de palmeiras que ocorrem na BV, com exceção do buriti (Mauritia flexuosa), possui caule subterrâneo e produção de único cacho de frutos próximo ao solo, como mostra a Figura 1. A densidade média das espécies de palmeiras mais consumidas pelos macacos na área de estudo é de 488 indivíduos/ha, sendo 343 catules/ha e 145 piaçavas/ha (conforme apresentado no Capítulo II).

3) sítios de quebra: constituídos por, pelo menos, um martelo de pedra e uma bigorna, de pedra ou de madeira (Figuras 2 e 3); referido no texto, daqui em diante, como bigorna. Um estudo realizado por Visalberghi et al. (2007), sobre as características das bigornas e martelos da $\mathrm{BV}$, encontrou que na área há cerca de um sítio de quebra a cada 332 metros (em média, 1,82 sítios/ha). Esse estudo também revelou que as bigornas possuem, em média, uma área de $1,89 \mathrm{~m}^{2}$ e 1,1 martelos apropriados para quebra. Além disso, $45 \%$ das bigornas ficam a mais de 3 metros de qualquer palmeira, indicando que os animais precisam, freqüentemente, transportar os cocos até as bigornas. O tempo de depleção foi registrado para todos os alimentos obtido com auxílio desses instrumentos. 


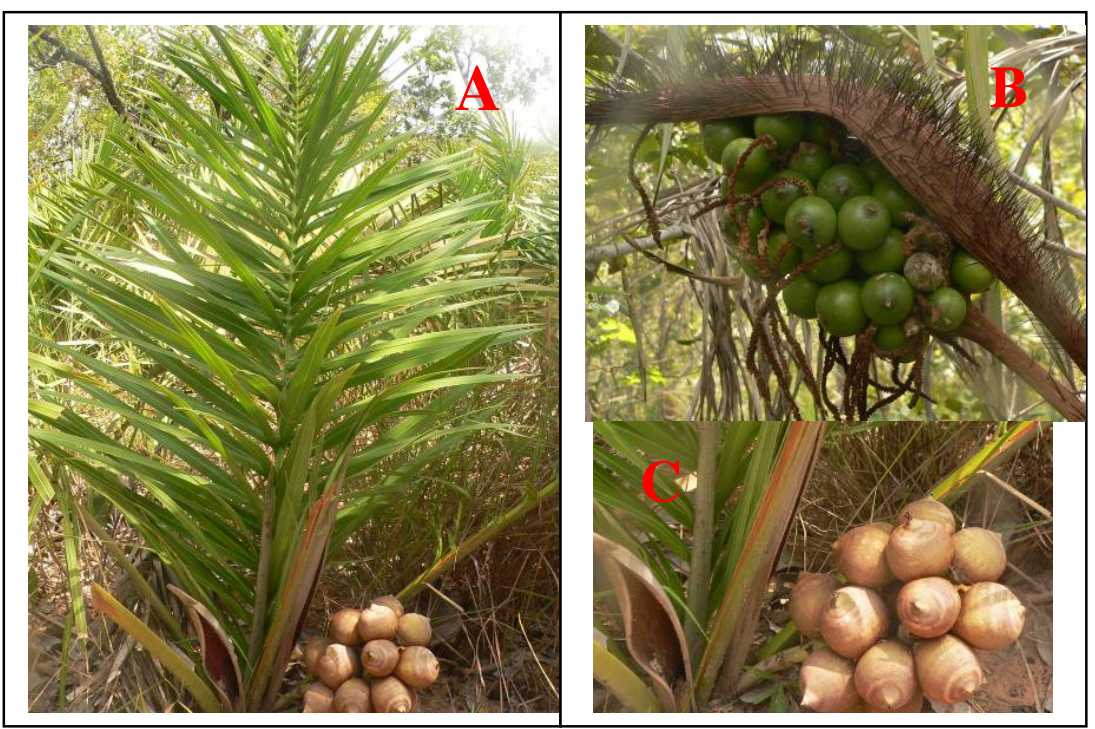

Figura 1: A- Palmeira da espécie catulé. B- Cacho de cocos da palmeira tucum. C- Cacho de coco da palmeira catulé (Fotos: Eduardo D. R. da Silva e Noemi Spagnoletti).

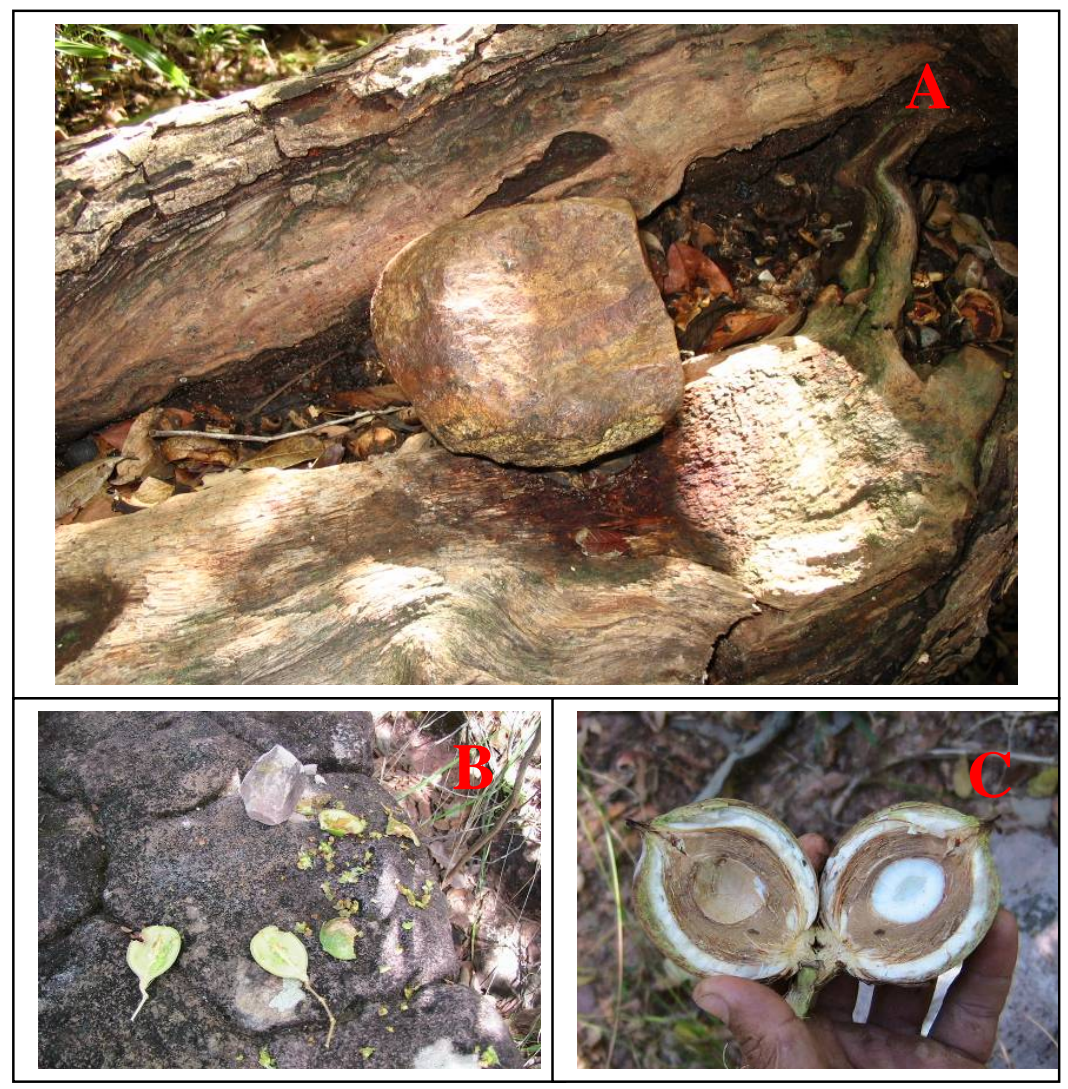

Figura 2: A- Sítio de quebra utilizado pelos macacos-prego da BV (bigorna de madeira e martelo de siltito). B- Sítio de quebra no chão do morro com restos de fruto de caroba. C- Coco da palmeira catulé, recurso processado com auxílio de ferramentas para extração do endosperma pelos animais da BV (Fotos: Eduardo D. R. da Silva e Noemi Spagnoletti). 


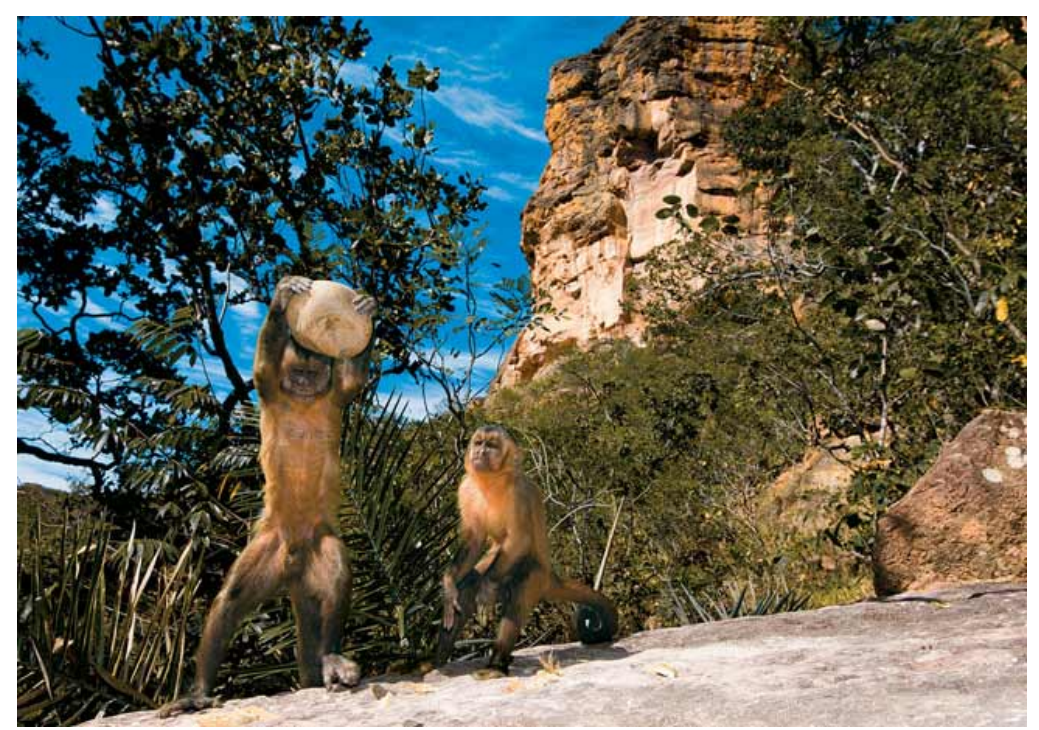

Figura 3: Macho adulto (Chicão) utilizando pedras (como martelo e bigorna) para quebrar cocos. Ao lado, o juvenil, Tucum, observa a execução da tarefa (Foto: Luciano Candisani).

A definição de fonte alimentar utilizada neste estudo foi a de "uma área onde os animais podem se alimentar e locomover continuamente" (White \& Wrangham, 1988). Assim, duas ou mais árvores ou palmeiras da mesma espécie foram consideradas uma única fonte alimentar se suas copas estivessem unidas. Bigornas distintas, separadas por menos de $30 \mathrm{~cm}$ também foram consideras como uma única fonte alimentar, considerando que a essa distância um macaco-prego pode deslocar-se de uma bigorna para outra em um único salto. A classificação das fontes discretas em três categorias permitiu analisar as características de cada tipo de recurso, bem como compará-las em suas especificidades.

Seguindo a metodologia utilizada por Izar (2004), o tempo de depleção das fontes alimentares deste estudo foi calculado através do método de "focal da fonte de alimentação" (feeding tree focal sample - FTFS) desenvolvido por Strier (1989). Esse método consiste em registrar o tempo decorrido entre o primeiro animal que consumiu o recurso e o último a consumi-lo. Além do tempo de depleção, registrou-se, também, o número de indivíduos que se alimentaram juntos em uma mesma fonte. Esse registro 
forneceu uma medida de tamanho das unidades de alimentação em fonte discreta (quantos animais conseguem se alimentar em uma mesma fonte). O registro do tempo de depleção era interrompido sempre que os animais paravam de se alimentar e iniciavam outras atividades, como socialização e descanso, sem com isso deixar a fonte, e continuava se os animais reiniciavam a alimentação naquela fonte (Vogel \& Janson, 2007). Nas situações em que uma determinada fonte era visitada em dois momentos distintos em um mesmo dia, o tempo de depleção de cada visita foi somado. Para fontes revisitadas em dias diferentes, considerou-se, separadamente, o tempo de depleção de cada visita. Esse ajuste permitiu uma avaliação temporal da produtividade das fontes. Quando os membros do grupo estavam divididos, se alimentando em mais de uma árvore, palmeira, ou bigorna, ao mesmo tempo (alimentação simultânea em diferentes árvores ou palmeiras de mesma espécie ou diferentes bigornas), o tempo de depleção foi calculado para o conjunto das fontes. Nessas situações, o cálculo do tamanho dos subgrupos de alimentação seguiu o mesmo parâmetro, contudo, cada indivíduo foi contabilizado uma única vez, não importando em quantas fontes do conjunto ele tenha se alimentado. Esse cálculo permitiu avaliar com maior precisão por quanto tempo e quantos indivíduos do grupo são capazes de se alimentar de um mesmo recurso discreto ao mesmo tempo, o que não seria acurado caso as fontes fossem tratadas isoladamente. Sempre que possível, foram coletadas informações sobre: 1) nome popular da espécie consumida; 2) status do episódio (A- completo: observador acompanhou o episódio do início ao fim e B- incompleto: observador chegava até a fonte e já havia um animal consumindo o recurso ou quando o observador precisava deixar a fonte antes que o último animal a tenha deixado para, por exemplo, acompanhar a maior parte do grupo que iniciava um deslocamento rápido; 3) localização fisionômica da fonte (A- chapada; B- encosta; C- Grota; D- Brejo, E- topo e F- área de aprovisionamento, conforme 
descrito no Capítulo I) e 4) todas as ocorrências de episódios agonísticos nas fontes, registrando-se, sempre que possível, a identidade dos indivíduos envolvidos e o resultado das interações.

A dieta dos macacos-prego da BV incluiu uma grande variedade de alimentos encapsulados, que exigem algum grau de manipulação para que possam ser ingeridos. De acordo com Isbell et al. (1998), o tempo de depleção pode ser afetado pela necessidade de processamento do alimento, assim, um curto tempo de depleção pode indicar que o recurso exige pouco tempo de manipulação e vice-versa. Além disso, a necessidade de manipulação de determinados alimentos pode impedir que alguns indivíduos tenham acesso a esses recursos; por exemplo, imaturos que ainda não possuem a força necessária ou a técnica apropriada para extração do recurso (Resende et al., 2008). Para verificar se a necessidade de manipulação do recurso alimentar afetou o tempo de depleção e o tamanho das unidades de forrageamento, os episódios de alimentação em fruteira foram divididos em itens que requerem e itens que não requerem manipulação. O tempo de depleção e o tamanho das unidades de alimentação foram comparados entre essas duas categorias. Os episódios de alimentação em palmeiras e bigornas não foram incluídos nessa análise, visto que esses recursos exigem, necessariamente, algum grau de manipulação.

As análises estatísticas foram realizadas em duas etapas. Primeiro, os resultados foram analisados separadamente para cada grupo de estudo, comparando-se o tempo de depleção e o tamanho das unidades de alimentação em função do tipo de fonte discreta, do status dos episódios, da necessidade de manipulação e da estação. Essas análises foram efetuadas através do teste ANOVA. Posteriormente, foram feitas comparações entre os grupos quanto ao tempo de depleção e ao tamanho das unidades de alimentação através do teste GLM. Como o período de observação do grupo ZA foi maior que o do 
grupo $\mathrm{CH}$, para essas análises foram utilizados apenas os dados coletados entre fevereiro de 2007 e abril de 2008, período em que também houve observação do grupo $\mathrm{CH}$.

\subsection{Regime de competição por alimento e padrão de relações sociais entre fêmeas}

A ocorrência de interação agressiva entre fêmeas de um mesmo grupo é um indicativo comportamental de competição direta intra-grupo, enquanto agressão ou evitação entre fêmeas de grupos distintos reflete competição direta entre grupos (van Schaik, 1989). Para avaliar se as fêmeas estiveram submetidas à competição direta intragrupo, foram feitos registros de todas as ocorrências (Altmann, 1974) de interações agonísticas entre membros do grupo, que incluíram: (1) contato físico, em que um animal morde, bate ou agarra outro indivíduo; (2) perseguição; (3) exibição agressiva e (4) deslocamento. Foram registrados, sempre que possível, a identidade dos indivíduos envolvidos, o contexto e o resultado das interações e a ocorrência de coalizões. A taxa de interação agonística entre os membros do grupo foi calculada por hora de observação. Os episódios foram classificados em: (1) disputas por alimento, registrando, sempre que possível, o item alimentar sob disputa; (2) disputas por fontes de água e (3) disputas em contexto social (p. ex., parceiros sociais, fêmeas no estro e conflito mãefilhote). As relações de dominância entre fêmeas foram determinadas com base nos resultados das interações agonísticas através do método de Árvores de Dominância (DDT - Izar et al., 2006). Os modelos consideram que a tolerância entre membros de um grupo social é expressa em termos de indivíduos dominantes permitindo que os subordinados tenham acesso regular a fontes alimentares importantes (van Schaik, 1989). Aqui, o grau de tolerância entre fêmeas foi avaliado através de episódios de alimentação conjunta numa mesma fonte alimentar discreta (conforme Boinski et al., 
2002). Para tanto, utilizou-se o Índice de Jaccard $(I J=a / a+b+c$; onde $a=$ número de episódios em que X e Y alimentaram-se juntos em uma mesma fonte discreta; $b=$ número de episódios em que $\mathrm{X}$ alimentou-se em uma fonte discreta e $\mathrm{Y}$ não; c = número de episódios em que Y alimentou-se em uma fonte discreta e X não. O Índice de Jaccard (IJ) foi calculado para cada díade possível de fêmeas nos três tipos de fontes discretas. Para verificar o efeito do posto de dominância sobre o grau de tolerância, as fêmeas de cada grupo foram classificadas como: (1) alto posto; (2) médio posto e (3) baixo posto. A análise estatística foi realizada através do teste GLM medidas repetidas. As relações afiliativas entre fêmeas foram inferidas com base em episódios de catação, coletados através do método de Todas as Ocorrências. Para avaliar se as fêmeas do presente estudo estiveram submetidas à competição direta entre grupos, foram registradas todas as ocorrências de encontros dos grupos $\mathrm{ZA}$ e $\mathrm{CH}$ entre si e com outros grupos de macacos-prego, anotando-se a localização dos encontros, o comportamento dos indivíduos dos grupos envolvidos e o resultado das interações.

Ajustes no tamanho da área de uso e nas distâncias percorridas diariamente são considerados efeitos da competição indireta por alimento em primatas (Isbell, 1991; Janson, 2000). Distâncias maiores percorridas diariamente por grupos maiores são consideradas indicativos de competição indireta intra-grupo, já que em grupos maiores as fontes alimentares são depletadas mais rapidamente, levando os grupos a percorrerem distâncias maiores para encontrar alimento para todos os membros, enquanto áreas de uso maiores em grupos maiores são indicativas de competição indireta entre grupos (Isbell, 1991). Para calcular o tamanho da área de uso (área utilizada durante toda a pesquisa) e da área explorada mensalmente e as distâncias percorridas diariamente, a posição (coordenadas geográficas) do grupo foi registrada a intervalos de 20 minutos usando um aparelho de GPS (Garmin e-Trex). Através do programa GPS-Utility (versão 
4.54), os pontos amostrais foram plotados em um mapa da área de estudo e o tamanho da área de uso foi calculado conectando-se os pontos mais externos. O mesmo método foi utilizado para calcular o tamanho da área explorada a cada mês pelos dois grupos de estudo. Finalmente, a distância percorrida diariamente foi calculada somando-se a distância entre cada par de pontos consecutivos coletados para o grupo em um dia. Para análise estatística das distâncias percorridas diariamente, foram considerados apenas os dados de dias “completos de observação", isto é, dias em que os animais foram seguidos do amanhecer ao anoitecer, sem a perda do grupo. Assim, foram contabilizados 179 dias completos para o grupo ZA e 126 dias para o grupo $\mathrm{CH}$.

A competição indireta intra-grupo também foi avaliada com "minuto individual per capita" (per capita individual minutes- PCIM), considerado por Janson (1988) um correlato da "energia ingerida per capita". O cálculo do PCIM foi feito dividindo o número de minutos de alimentação de todos os membros do grupo que visitaram uma fonte (individual minutes - IM: tempo de depleção multiplicado por tamanho da unidade de alimentação em fonte discreta) pelo tamanho total do grupo (Janson, op cit). Foram feitos cálculos mensais de IM e PCIM médios para os dois grupos de estudos, em cada um dos três tipos de fontes discretas.

As análises das distâncias percorridas diariamente, tamanho da área de uso explorada mensalmente, IM e PCIM seguiram o mesmo procedimento apresentado no tópico anterior, isto é, as comparações intra-grupo foram feitas através do teste ANOVA, enquanto as comparações entre os grupos foram realizadas com testes GLM. Análises de regressão foram utilizadas para investigar se o orçamento de atividades, dieta e variáveis ambientais afetaram as distâncias percorridas diariamente e o tamanho das áreas exploradas mensalmente pelos grupos. 


\section{5-RESULTADOS}

\subsection{Densidade populacional de Cebus libidinosus na Boa Vista}

A densidade de macacos-prego na área de estudo foi calculada utilizando-se dois bancos de dados distintos. Através do primeiro cálculo, que considerou o tamanho das áreas de uso (aproximadamente $6 \mathrm{~km}^{2}$ - Spagnolletti, 2009) e a soma do tamanho máximo dos dois grupos de estudo (ZA=14 indivíduos; $\mathrm{CH}=19$ indivíduos; $\sum=33$ indivíduos), a densidade obtida durante o período de estudo foi de 5,5 indivíduos $/ \mathrm{km}^{2}$. Pelo segundo cálculo, que utilizou o número de macacos avistados $(\mathrm{n}=31)$ ao longo de $110 \mathrm{~km}$ de trilhas percorridas pelo método de transecto linear durante o período de estudo, a densidade obtida foi de 2,3 indivíduos $/ \mathrm{km}^{2}$.

O resultado obtido a partir do primeiro conjunto de dados pode ter sido superestimado, porque assume que toda a área de estudo é uniformemente habitada por macacos-prego. Além disso, o aprovisionamento pode ter influenciado o tamanho do grupo $\mathrm{CH}$, seja diminuindo o intervalo entre partos, aumentando a taxa de sobrevivência de filhotes e/ou diminuindo a competição intra-grupo, permitindo, assim, que um maior número de indivíduos permanecesse no grupo.

\subsection{Dinâmica de populacão e tamanho dos grupos de macacos-prego na Boa Vista}

As mudanças no tamanho e na composição dos grupos ocorreram em função de migrações de machos, óbitos/desaparecimentos e nascimentos. O tamanho médio do grupo ZA ao longo desta pesquisa foi de ( \pm DP) $9,7 \pm 1,4$ indivíduos e o do grupo $\mathrm{CH}$ foi de 18,0 \pm 0,7 indivíduos. 


\subsubsection{Grupo Zangado}

Foi registrado um total de dois desaparecimentos, quatro emigrações, algumas tentativas de imigração e dois nascimentos no grupo ZA.

No final de maio de 2006, ocorreu o desaparecimento da fêmea adulta Pretinha e seu filhote, Pretinho. É muito provável que essa fêmea tenha falecido devido a complicações de saúde, uma vez que possuía uma grande ferida (que se estendia do ombro à mama), que comprometera os movimentos de uma de suas mãos. Em decorrência do ferimento, Pretinha não conseguia transportar seu filhote e tinha muita dificuldade em amamentá-lo. Pretinho, por sua vez, estava visivelmente debilitado e, mesmo com os cuidados oferecidos por outros membros do grupo, apresentava dificuldade para se alimentar e acompanhar os deslocamentos de grupo. O esqueleto de Pretinha foi encontrado praticamente intacto menos de um mês após o seu desaparecimento, próximo a um sito de dormida do grupo. Já o corpo de Pretinho não foi encontrado.

No final de junho do mesmo ano, houve a migração de dois machos subadultos (Dengoso e Mansinho) e um macho juvenil (Jatobá) do grupo ZA para o grupo aprovisionado $\mathrm{CH}$. Um mês após o ocorrido, o macho juvenil Teimoso também migrou para o grupo de $\mathrm{CH}$.

Entre setembro e novembro de 2006, o grupo ZA foi freqüentemente acompanhado por quatro machos desconhecidos, cujas classes de idade foram estimadas entre adulta e subadulta. Um macho em especial, chamado de Aparecido, permaneceu no grupo durante um período mais longo, e já interagia afiliativamente com os membros do grupo, especialmente jovens, quando foi visto pela última vez no grupo em 28 de novembro de 2006. 
Entre dezembro de 2006 e janeiro de 2007, a fêmea Moça Chita deu à luz seu primeiro filhote (Café) e, no final de fevereiro do mesmo ano, nasceu o filhote de Emília (Elisa).

\subsubsection{Grupo Chicão}

Nesse grupo, foi registrado um total de três desaparecimentos, quatro imigrações e quatro nascimentos.

Em julho de 2007, o macho adulto Segundo Chefe desapareceu do grupo e até o final da coleta de dados não foi visto sozinho e nem em companhia de membros do grupo ZA. Em novembro de 2007, ocorreu o desaparecimento da fêmea adulta Dendê de Coco. Segundo moradores da região, que conheciam os membros do grupo $\mathrm{CH}$ há cerca de 10 anos, Dendê de Coco era a fêmea mais velha do grupo. De fato, era possível observar sinais de calvície ao longo da pelagem e um andar letárgico, além disso, essa fêmea não foi vista em estro durante toda a pesquisa e não engravidava há pelo menos cinco anos. Dois meses após o seu desaparecimento, partes de um esqueleto de macacoprego adulto foram encontradas em uma área de uso restrita aos grupos $\mathrm{CH}$ e ZA. Entre 01 e 10 de fevereiro de 2008, o macho juvenil Pico desapareceu do grupo e não foi mais visto ao longo dos dois meses de coleta que se seguiram.

Entre os meses de junho e julho de 2006, houve a imigração de quatro machos juvenis e subadultos oriundos do grupo ZA.

Em 05 de fevereiro de 2007, Chuchu deu à luz seu segundo filhote (Catu) e, entre setembro e novembro de 2007, foram registrados três nascimentos (Cangaceiro, filho de Chiquinha; Pati, filho de Piaçava; Doree, filha de Dita). 


\subsection{Risco de predacão}

Vocalizações de alarme foram emitidas pelos grupos a uma taxa de 0,15 episódios/hora de observação ( $n=408 ; Z A: n=293 ; C H: n=115)$. Contudo, nenhum evento de predação foi observado ao longo deste estudo.

\subsubsection{Grupo Zangado}

O contexto das vocalizações de alarme foi determinado em $60 \%(n=293)$ dos episódios. A maior parte $(58,0 \%, \mathrm{n}=103)$ foi emitida em função de encontros ou vocalizações de outras espécies, sendo 47,5\% (n=49) para pássaros de pequeno porte, 13,5\% $(n=14)$ para gaviões de pequeno e médio porte, $27,0 \%(n=27)$ para diferentes espécies de urubus, 7,0\% $(n=7)$ para serpentes, 4,0\% $(n=4)$ para sapos e 1,0\% $(n=1)$ para vocalização de raposa. Uma parte considerável dos alarmes $(38,0 \%, n=67)$ ocorreu em função de perturbações antrópicas, sendo 56,5\% (n=38) devido a aproximações ou barulho de moradores locais e pesquisadores e 43,5\% (n=29) devido à aproximação ou vocalização de animais domésticos. Vocalizações emitidas em função de vocalizações de animais que não puderam ser identificados somaram $2,0 \%(n=5)$ dos alarmes.

Foi possível identificar os indivíduos que emitiram as vocalizações de alarmes em 30,5\% (n=87) dos episódios. Adultos foram responsáveis por 62,0\% (n=54) dessas vocalizações, sendo que $65,0 \%(n=35)$ foram emitidas pelo macho alfa. Juvenis foram responsáveis por $35,5 \%(n=7)$ e infantes por apenas $2,5 \%(n=2)$ das vocalizações de alarme.

\subsubsection{Grupo Chicão}

O contexto das vocalizações de alarme foi determinado em $50,5 \%(n=58)$ dos episódios. A maior parte dos alarmes $(69,0 \% ; n=40)$ foi emitida em função de encontros 
ou vocalizações de outras espécies, sendo 72,5\% (n=29) para pássaros $(42,5 \%$ para urubus e 30,0\% para outros pássaros), 15,0\% (n=6) devido a encontros com serpentes e 2,5\% ( $\mathrm{n}=1)$ devido a encontro com cotia. Alarmes suscitados por perturbações antrópicas representaram 31,0\% dos $(n=18)$ dos episódios, sendo que 72,0\% (n=13) foram devido a aproximação ou barulho de moradores ou pesquisadores e 28,0\% (n=5) devido a aproximação ou vocalização de animais domésticos. Por fim, 10,0\% (n=4) foram emitidos devido a vocalizações de animais não identificados.

Foi possível identificar os indivíduos que emitiram os alarmes em 26,5\% (n=29) dos episódios. A maior parte $(48,0 \%$; $=14)$ foi emitida por adultos, sendo que $43,0 \%$ $(\mathrm{N}=6)$ foram emitidas pelo macho alfa. Juvenis foram responsáveis por 34,5\% ( $\mathrm{n}=10)$ dos alarmes, enquanto infantes nunca foram observados emitindo alarme.

\subsection{Comportamento alimentar de fêmeas adultas}

A atividade de alimentação (que inclui as atividades de comer e forragear, conforme descrito no Capítulo II) representou em média ( \pm DP) 50,0 \pm 8,4\% do tempo de atividade das fêmeas adultas do grupo ZA e 51,6 \pm 6,7\% do tempo de atividade das fêmeas adultas do grupo $\mathrm{CH}$. Não houve diferença significativa na proporção de tempo que fêmeas adultas de ambos os grupos dedicaram à atividade de alimentação entre as estações seca (ZA: 49,5 \pm 8,4\%; $\mathrm{CH}: 49,7 \pm 3,9 \%)$ e chuvosa (ZA: 50,4 $\pm 10,1 \%$, $\mathrm{F}=0,65 ; \mathrm{gl}=23 ; \mathrm{p}=0,801 ; \mathrm{CH}: 50,9 \pm 7,7 \%, \mathrm{~F}=0,618 ; \mathrm{gl}=14 ; \mathrm{p}=0,446)$, bem como entre as fêmeas do grupo ZA e do grupo $\mathrm{CH}(\mathrm{F}=0,181$; $\mathrm{gl}=29$; $\mathrm{p}=0,674)$. Esses resultados indicam que o aprovisionamento de alimentos do grupo $\mathrm{CH}$ não afetou significativamente o comportamento alimentar das fêmeas adultas.

Os grupos incluíram uma grande diversidade de itens alimentares em suas dietas (ver Capítulo II para mais detalhes). Os principais alimentos consumidos por fêmeas 
adultas de ambos os grupos foram polpa de frutos (ZA: $37,4 \pm 16,7 \%$; $\mathrm{CH}: 26,4 \pm$ $18,2 \%$, sendo que no grupo ZA, $24 \%$ desse total foram mesocarpo de frutos de palmeiras, e 39,5\% no grupo $\mathrm{CH}$ ) e invertebrados (ZA: $27,0 \pm 9,2 \%$; $\mathrm{CH}: 24,6 \pm 7,9 \%$ ). Alimentos obtidos com auxílio de ferramentas (principalmente endosperma de frutos de palmeiras) representaram apenas uma pequena proporção da dieta das fêmeas adultas, tanto no grupo ZA $(0,6 \pm 0,6 \%)$, quanto no grupo $\mathrm{CH}(2,2 \pm 1,9 \%)$. A proporção do tempo de alimentação de fêmeas adultas dedicada ao consumo dos diferentes itens alimentares variou entre as estações seca e chuvosa em ambos os grupos (Figuras 4 e 5). No grupo ZA, fêmeas adultas dedicaram mais tempo ao consumo de frutos na estação chuvosa $(\mathrm{F}=13,239 ; \mathrm{gl}=23 ; \mathrm{p}<0,001)$ e mais tempo ao consumo de néctar $(\mathrm{F}=6,179$; $\mathrm{gl}=23 ; \mathrm{p}<0,05)$ e raízes $(\mathrm{F}=9,355 ; \mathrm{gl}=23 ; \mathrm{p}<0,01)$ na estação seca (Figura 4). Fêmeas adultas do grupo $\mathrm{CH}$ dedicaram mais tempo ao consumo de frutos durante a estação chuvosa $(\mathrm{F}=7,480 ; \mathrm{gl}=14 ; \mathrm{p}<0,05)$ e mais tempo ao consumo de sementes $(\mathrm{F}=7,647$; $\mathrm{gl}=14 ; \mathrm{p}<0,05)$ e alimentos aprovisionados $(\mathrm{F}=8,372 ; \mathrm{gl}=14 ; \mathrm{p}<0,05)$ durante a seca (Figura 5). Apesar do aprovisionamento do grupo $\mathrm{CH}$, a comparação entre fêmeas adultas dos grupos $\mathrm{ZA}$ e $\mathrm{CH}$ revelou poucas diferenças quanto ao tempo alocado ao consumo dos diferentes itens alimentares. A proporção do tempo de alimentação dedicada ao consumo de frutos foi maior entre fêmeas adultas do grupo ZA ( $F=7,952$; $\mathrm{gl}=29 ; \mathrm{p}<0,01$ ), enquanto a proporção do tempo dedicada ao consumo de alimentos obtidos com ferramentas $(\mathrm{F}=9,613 ; \mathrm{gl}=29 ; \mathrm{p}<0,01)$ e de alimentos aprovisionados $(\mathrm{F}=15,124 ; \mathrm{gl}=29 ; \mathrm{p}<0,001)$ foi maior entre fêmeas adultas do grupo $\mathrm{CH}$ (Figura 6).

Alimentos com distribuição discreta no ambiente representaram, em média, 63,1 $\pm 11,3 \%$ de todos os recursos consumidos pelas fêmeas adultas do grupo ZA e 64,1 \pm 11,2\% dos alimentos consumidos pelas fêmeas adultas do grupo $\mathrm{CH}$. Em ambos os grupos, o consumo de alimentos discretos foi significativamente maior do que de 
alimentos dispersos (ZA: F=64,477; gl=47; p<0,001; CH: F=47, 363; gl=29; p<0,001), e não variou significativamente entre estações seca e chuvosa.

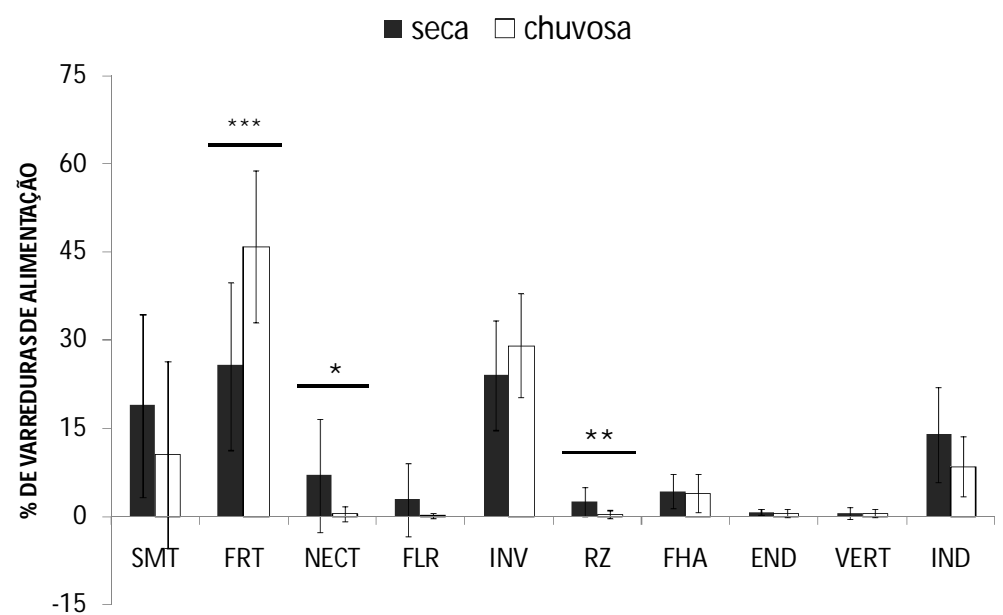

Figura 4: Dieta de fêmeas adultas do grupo ZA nas estações seca e chuvosa (média e desvio padrão). Smt=semente; Frt=fruto; Nect=néctar; Flr=flor; Inv=invertebrado; Rz=raiz; Fha=folha, End=endosperma; Vert=vertebrado; Ind=indeterminado; $* \mathrm{p}<0,05$; $* * \mathrm{p}<0,01 ; * * * \mathrm{p}<0,001$.

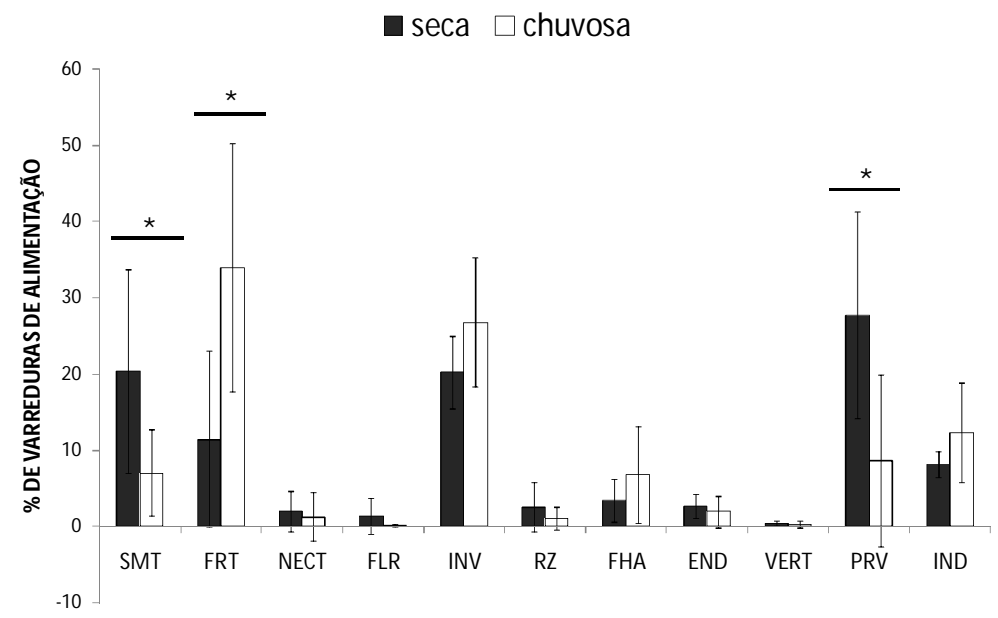

Figura 5: Dieta de fêmeas adultas do grupo $\mathrm{CH}$ nas estações seca e chuvosa. Smt=semente; Frt=fruto; Nect=néctar; Flr=flor; Inv=invertebrado; $\mathrm{Rz}=$ raiz; Fha=folha, End=endosperma; $\quad$ Vert=vertebrado; $\quad$ Prv=alimento aprovisionado; Ind=indeterminado; ${ }^{*} \mathrm{p}<0,05$. 


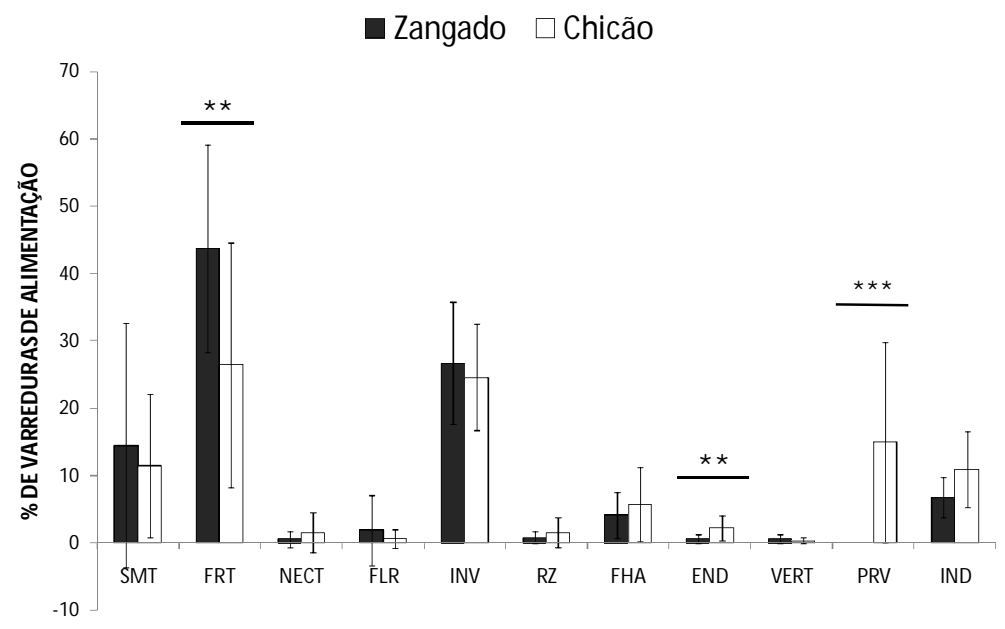

Figura 6: Comparação da dieta de fêmeas adultas do grupo ZA e $\mathrm{CH}$ entre o período de fevereiro de 2007 e abril de 2008. Smt=semente; Frt=fruto; Nect=néctar; Flr=flor; Inv=invertebrado; Rz=raiz; Fha=folha, End=endosperma; Vert=vertebrado; Prv=alimento aprovisionado; Ind=indeterminado; $* * \mathrm{p}<0,01 ; * * * \mathrm{p}<0,001$.

\subsection{Tamanho das fontes alimentares}

\subsubsection{Grupo Zangado}

Foram registrados 2070 eventos de alimentação em fontes discretas no grupo ZA, sendo 1559 de alimentação em fruteiras, 302 em palmeiras e 209 de uso de bigornas. A maior parte foi acompanhada do início ao fim: para fruteiras foram 934 (59\%) episódios completos, para as bigornas 202 (96,5\%) e para as palmeiras 197 $(65,5 \%)$. Episódios de alimentação simultânea representaram 26\% dos registros $(\mathrm{n}=522)$. A taxa de exploração de fruteiras foi de 1,1 árvores/hora de observação, de palmeiras foi de 0,21 e de bigornas de 0,15 .

Nos episódios de alimentação em fontes discretas, os animais consumiram frutos, sementes, flores e néctar de 51 espécies vegetais, entre fruteiras e palmeiras. Considerando os episódios de alimentação em fruteiras e palmeiras ( $n=1861$ ), foi possível identificar pelo menos a família da espécie explorada em $82 \%$ das amostras $(\mathrm{n}=1526)$. As famílias mais importantes para a dieta do grupo, em termos do número de episódios de alimentação observados, foram Anacardiacea, Arecaceae, Annonaceae, 
Icacionaceae, Lecythidaceae e Leguminosae (Mimosoideae, Caesalpinaceae e

Papilionoideae; Tabela 1).

Tabela 1: Relação das famílias botânicas exploradas pelo grupo ZA nos episódios de alimentação em fontes discretas (fruteiras e palmeiras).

\begin{tabular}{c|c|c|c}
\hline Família & N espécies & N episódios & \% episódios \\
\hline Anacardiaceae & 3 & 373 & 20,3 \\
Arecaceae & 5 & 302 & 16,5 \\
Annonaceae & 3 & 276 & 15,1 \\
Icacinaceae & 1 & 144 & 7,9 \\
Lecythidaceae & 1 & 141 & 7,7 \\
Leguminosae-Mimosoideae & 2 & 93 & 5,1 \\
Leguminosae-Caesalpinaceae & 6 & 81 & 4,4 \\
Caryocaraceae & 1 & 53 & 2,9 \\
Tiliaceae & 1 & 36 & 2,0 \\
Ebenaceae & 1 & 5 & 0,3 \\
Bignoneaceae & 1 & 5 & 0,3 \\
Bromeliaceae & 1 & 4 & 0,2 \\
Dilleniaceae & 1 & 3 & 0,2 \\
Malpighiaceae & 1 & 3 & 0,2 \\
Leguminosae-Papilionoideae (Fabaceae) & 1 & 3 & 0,2 \\
Euphorbiaceae/Araliaceae & 1 & 2 & 0,1 \\
Rubiaceae & 1 & 2 & 0,1 \\
Não identificadas & $\mathbf{2 0}$ & $\mathbf{3 0 7}$ & $\mathbf{1 6 , 7}$ \\
\hline
\end{tabular}

$\mathrm{N}$ espécies=número de espécies exploradas pelo grupo em cada família botânica; $\mathrm{N}$ episódios=total de episódios de alimentação registrado em cada família botânica; \% episódios=proporção de episódios de alimentação em cada família botânica.

Em apenas um episódio de uso de bigornas não foi possível identificar o item alimentar explorado. Na maior parte dos episódios, o alimento extraído com ajuda de ferramentas foi endosperma de cocos das palmeiras catulé, piaçava e tucum, conforme detalhado na Tabela 2. A média de cocos quebrados por episódio de alimentação em bigorna foi de $2,0 \pm 1,4(n=49)$.

Tabela 2: Relação dos itens alimentares explorados durante episódios de uso de bigornas no grupo ZA.

\begin{tabular}{c|c|c}
\hline ITEM & EPISÓDIOS (N) & EPISÓDIOS (\%) \\
\hline Cocos & 179 & 86 \\
Castanha de caju & 24 & 11,5 \\
Castanha de pequi & 2 & 1 \\
Mandioca brava & 2 & 1 \\
Caroba & 1 & 0,5 \\
\hline
\end{tabular}

$\mathrm{N}$ episódios=valor absoluto de episódios; \% episódios=proporção de episódios em porcentagem. 
O tempo médio de depleção e o tamanho médio das unidades de alimentação em fruteiras foram maiores nos episódios incompletos (tempo de depleção: incompleto=13,2 $\pm 13,9$ minutos; completo $=11,4 \pm 14,8$ minutos, $\mathrm{F}=6,109 ; \mathrm{gl}=1555$ $\mathrm{p}<0,05$; unidade de alimentação: incompleto=3,2 $\pm 2,1$ indivíduos; completo $=2,7 \pm 2,0$ indivíduos, $\mathrm{F}=28,798 ; \mathrm{gl}=1556 ; \mathrm{p}<0,001)$, assim como o tamanho médio das unidades de alimentação de palmeiras (incompleto $=4,2 \pm 2,1$; completo $=3,6 \pm 2,4$ indivíduos, $\mathrm{F}=4,192 ; \mathrm{gl}=301 ; \mathrm{p}<0,05)$. O tempo médio de depleção de palmeiras não variou em função do tipo do episódio e as bigornas não foram testadas, pois apenas sete episódios foram incompletos. Esses resultados mostram que tanto o tempo de depleção quanto o tamanho das unidades de alimentação não serão subestimados com a inclusão dos registros incompletos nas análises subseqüentes.

O tempo médio de depleção de fruteiras foi de 15,5 \pm 19,1 minutos, o de palmeiras de 20,9 $\pm 27,4$ minutos e o de alimentos acessados com ferramentas de 10,1 \pm 11,8 minutos. Houve variação significativa no tempo de depleção em função da fonte explorada $(\mathrm{F}=16,823 ; \mathrm{df}=2 ; \mathrm{p}<0,001)$, sendo que o tempo de depleção de palmeiras foi maior que o de fruteiras $(\mathrm{p}<0,001)$ e bigornas $(\mathrm{p}<0,001)$ e o de fruteiras maior que o de bigornas $(\mathrm{p}<0,01)$. O tamanho médio das unidades de alimentação em fruteiras foi de 3,5 $\pm 2,4$ indivíduos, em palmeiras de 4,2 $\pm 2,7$ indivíduos e em bigornas $2,1 \pm 1,4$ indivíduos. O tamanho das unidades de alimentação também variou em função do tipo de fonte explorada $(F=45,938 ; d f=2 ; p<0,001)$. As unidades de alimentação de palmeiras foram maiores do que fruteiras $(\mathrm{p}<0,001)$ e bigornas $(\mathrm{p}<0,001)$ e as unidades de alimentação de fruteiras foram maiores do que bigornas $(\mathrm{p}<0,001)$. Houve tendência para variação significativa no tempo de depleção em função do tipo de fonte explorada e da estação $(\mathrm{F}=2,906 ; \mathrm{gl}=2 ; \mathrm{p}=0,055)$, de modo que o tempo de depleção de bigornas foi maior na estação seca $(12,1 \pm 14,3$ minutos $)$ do que na chuvosa (7,5 $\pm 6,2$ minutos). Já o 
tamanho das unidades de alimentação foi afetado significativamente pela interação entre tipo de fonte e estação $(\mathrm{F}=8,681 ; \mathrm{gl}=2 ; \mathrm{p}<0,001)$, sendo que o tamanho médio em fruteiras foi maior na estação chuvosa $(3,8 \pm 2,5$ indivíduos $)$ do que na seca $(3,1 \pm 2,3$ indivíduos), enquanto o tamanho médio em palmeiras e bigornas foi maior na estação seca (palmeiras: 4,6 \pm 2,9 indivíduos; bigornas: 2,2 \pm 1,6 indivíduos) do que na chuvosa (palmeiras: 3,5 $\pm 2,1$ indivíduos; bigornas: $1,9 \pm 1,2$ indivíduos), como mostram as Figuras 7 e 8.

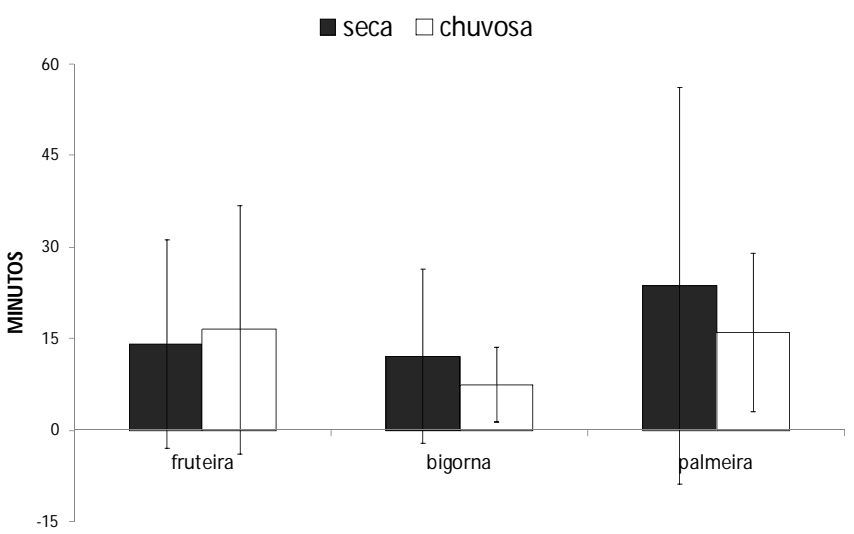

Figura 7: Tempo médio de depleção (em minutos) de fontes com distribuição discreta exploradas pelo grupo ZA nas estações seca e chuvosa.

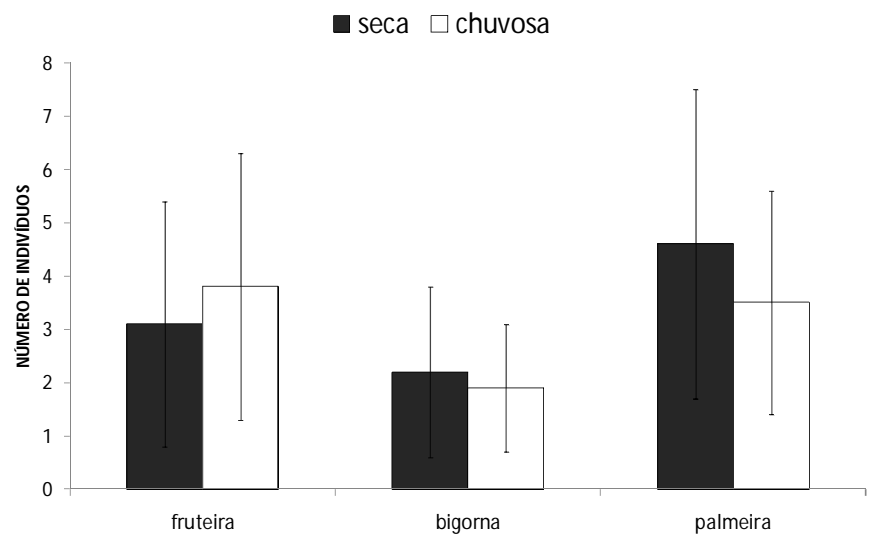

Figura 8: Tamanho médio das unidades de alimentação (número de indivíduos) em fontes com distribuição discreta exploradas pelo grupo ZA nas estações seca e chuvosa. 
O tempo médio de depleção de fruteiras que exigiram manipulação $(n=550 ; 52 \%$ das fruteiras visitadas) foi de 16,5 \pm 19,7 minutos e o tamanho médio das unidades de alimentação foi de 3,3 $\pm 2,3$ indivíduos. Para as fruteiras que não exigiram manipulação $(n=511 ; 48 \%)$ esses valores foram, respectivamente, de $14,4 \pm 18,8$ minutos e 3,6 $\pm 2,5$ indivíduos. Houve tendência para maior tempo de depleção em fruteiras que demandaram manipulação $(\mathrm{F}=3,121 ; \mathrm{gl}=1049 ; \mathrm{p}=0,078)$, e tendência para unidades de alimentação maiores em fruteiras que não demandaram manipulação ( $F=3,366$; $\mathrm{gl}=1049 ; \mathrm{p}=0,067)$.

Houve tendência para variação no tempo de depleção na comparação entre os itens alimentares classificados como fruteiras (fruto, flor, semente, néctar; $F=2,535$; $\mathrm{gl}=1105 ; \mathrm{p}=0,056)$. O teste post hoc mostrou que o tempo de depleção de frutos foi significativamente maior do que o de néctar $(\mathrm{p}<0,05)$. Não houve diferença na comparação entre os demais itens, como indica a Tabela 3. O tamanho das unidades de alimentação também variou em função do recurso explorado $(\mathrm{F}=13,774 ; \mathrm{gl}=1105$; $\mathrm{p}<0,001$ ), sendo significativamente maior quando o item consumido era fruto do que quando era semente $(p<0,001)$ e néctar $(p<0,001)$. Comparações entre os outros itens não foram significativas (Tabela 3). Para as palmeiras, o tempo de depleção e o tamanho do subgrupo de alimentação foram maiores quando o recurso explorado era polpa de cocos do que quando era água de coco (tempo de depleção: $F=15,772 ; g l=240 ; p<0,001$; unidade de alimentação: $\mathrm{F}=42,352 ; \mathrm{gl}=241 ; \mathrm{p}<0,001$; Tabela 3). 
Tabela 3: Discriminação do tempo médio de depleção e tamanho médio das unidades de alimentação no grupo ZA para sete itens alimentares com distribuição discreta no ambiente.

\begin{tabular}{|c|c|c|c|}
\hline ITEM & $\mathbf{N}$ & TD (min) & UA $(\Delta)$ \\
\hline Fruto & 825 & $15,8 \pm 18,4^{*}$ & $3,9 \pm 2,6^{* *}$ \\
\hline Semente & 516 & 15,6 & $2,3 * *$ \\
\hline Néctar & 183 & $10,8 \pm 13,3^{*}$ & $2,8 \pm 1,9 * *$ \\
\hline Flor & 25 & $14,8 \pm 11,9$ & $3,3 \pm 2,2$ \\
\hline Coco & 441 & $24,2 \pm 29,2 \#$ & $4,7 \pm 2,6 \#$ \\
\hline Água de coco & 61 & $6,7 \pm 7,3 \#$ & $12,0 \pm 1,6 \#$ \\
\hline
\end{tabular}

$\mathrm{Td}=$ tempo médio de depleção e desvio padrão (minutos); Ua= tamanho médio da unidade de alimentação e desvio padrão (indivíduos). * indica diferença estatística entre itens de fruteiras $(* \mathrm{p}<0,05 ; * * \mathrm{p}<0,001)$; \# indica diferença estatística entre itens de palmeiras $(\# \mathrm{p}<0,001)$.

\subsubsection{Grupo Chicão}

Para o grupo $\mathrm{CH}$ foram registrados 1031 eventos de alimentação em fontes discretas, sendo 775 de alimentação em fruteiras, 124 em palmeiras e 132 em bigornas. Para as fruteiras foram $352(45,5 \%)$ episódios completos, para as bigornas foram 115 (87\%) e para as palmeiras 76 (61,5\%). Episódios de alimentação simultânea ocorreram em 35\% dos registros $(n=361)$. A taxa de exploração de fruteiras foi de 1,53 árvores/hora de observação, de palmeiras foi de 0,25 e de bigornas de 0,26.

Os animais alimentaram-se de frutos, sementes, flores e néctar de 38 espécies vegetais. Em 85,7\% (n=771) dos episódios foi possível identificar a família das espécies exploradas, sendo que as mais importantes para a dieta do grupo (em termos do número de episódios observados) foram Anacardiaceae, Icacinaceae, Annonaceae e Arecaceae (Tabela 4). Em todos os episódios de alimentação em bigornas o item explorado foi endosperma de cocos das palmeiras catulé, piaçava e tucum. A média de cocos quebrados por episódio de alimentação em bigorna foi de 2,6 $\pm 1,7$ (n=99). 
Tabela 4: Relação das famílias botânicas exploradas pelo grupo $\mathrm{CH}$ nos episódios de alimentação em fontes discretas (fruteiras e palmeiras).

\begin{tabular}{c|c|c|c}
\hline Família & N espécies & N episódios & \% episódios \\
\hline Anacardiaceae & 2 & 235 & 26,2 \\
Icacinaceae & 1 & 183 & 20,4 \\
Annonaceae & 2 & 128 & 14,3 \\
Arecaceae & 5 & 124 & 13,8 \\
Lecythidaceae & 1 & 20 & 2,2 \\
Malpighiaceae & 1 & 17 & 1,9 \\
Tiliaceae & 1 & 13 & 1,4 \\
Dilleniaceae & 1 & 13 & 1,4 \\
Leguminosae-Caesalpinaceae & 3 & 11 & 1,2 \\
Caryocaraceae & 1 & 11 & 1,2 \\
Leguminosae-Mimosoideae & 1 & 8 & 0,9 \\
Ebenaceae & 1 & 7 & 0,8 \\
Bignoneaceae & 1 & 1 & 0,1 \\
Não identificadas & $\mathbf{1 7}$ & $\mathbf{1 2 6}$ & $\mathbf{1 4 , 0}$ \\
\hline
\end{tabular}

$\mathrm{N}$ espécies $=$ número de espécies exploradas pelo grupo em cada família botânica; $\mathrm{N}$ episódios= total de episódios de alimentação registrado em cada família botânica; \% episódios= proporção de episódios de alimentação em cada família botânica.

Assim como observado no grupo ZA, o tempo de depleção e o tamanho das unidades de alimentação em fruteiras foram significativamente maiores nos episódios incompletos (tempo de depleção: incompleto=12,9 \pm 11,6 minutos; completo=10,6 \pm 10,4 minutos, $\mathrm{F}=8,174 ; \mathrm{gl}=772 ; \mathrm{p}<0,01 ;$ unidade de forrageamento: incompleto $=4,1 \pm$ 3,1 indivíduos; completo=3,1 $\pm 2,5$ indivíduos, $\mathrm{F}=20,304 ; \mathrm{gl}=772 ; \mathrm{p}<0,001)$. Para as palmeiras não foram encontradas variações significativas e as bigornas não foram testadas, pois foram registrados apenas 17 episódios incompletos. Esses resultados indicam que os episódios incompletos podem ser incluídos nas análises gerais sem subestimar o resultado.

O tempo médio de depleção de fruteiras foi de 16,6 \pm 15,2 minutos, o das palmeiras de 19,6 $\pm 21,4$ minutos e o de alimento acessado com ferramentas de 16,7 \pm 17,9 minutos. Não houve diferença estatística entre o tempo de depleção de fruteiras, palmeiras e bigornas $(\mathrm{F}=0,072 ; \mathrm{gl}=2 ; \mathrm{p}=0,93)$. $\mathrm{O}$ tamanho médio das unidades de alimentação em fruteiras foi de 5,1 \pm 3,6 indivíduos, em palmeiras de 5,6 \pm 4,1 indivíduos e em bigornas 3,2 $\pm 2,3$ indivíduos. Houve variação do tamanho das 
unidades de alimentação em função do tipo de fonte explorada $(\mathrm{F}=8,791 ; \mathrm{gl}=2$; $\mathrm{p}<0,001)$, sendo significativamente maior em fruteiras $(\mathrm{p}<0,001)$ e palmeiras $(\mathrm{p}<0,001)$ do que em bigornas. Não houve diferença entre fruteiras e palmeiras. A estação afetou o tempo de depleção $(\mathrm{F}=6,974 ; \mathrm{gl}=1 ; \mathrm{p}<0,01)$ e o tamanho das unidades de alimentação $(\mathrm{F}=4,828 ; \mathrm{gl}=1 ; \mathrm{p}<0,05)$, sendo que ambas as medidas foram maiores na estação chuvosa (Figuras 9 e 10). Não houve efeito significativo da interação entre tipo de fonte e estação $(\mathrm{F}=1,421 ; \mathrm{gl}=1326 ; \mathrm{p}=0,225)$.

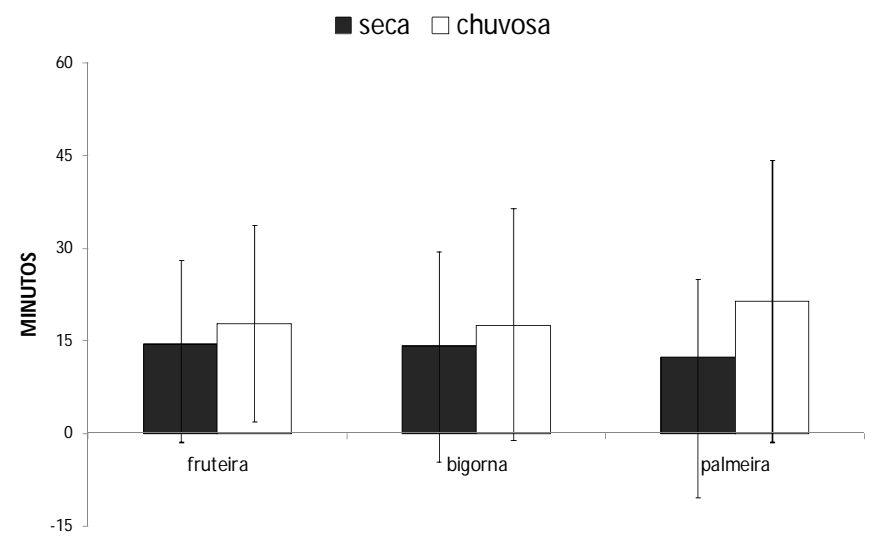

Figura 9: Tempo médio de depleção (em minutos) de fontes com distribuição discreta exploradas pelo grupo $\mathrm{CH}$ durante as estações seca e chuvosa.

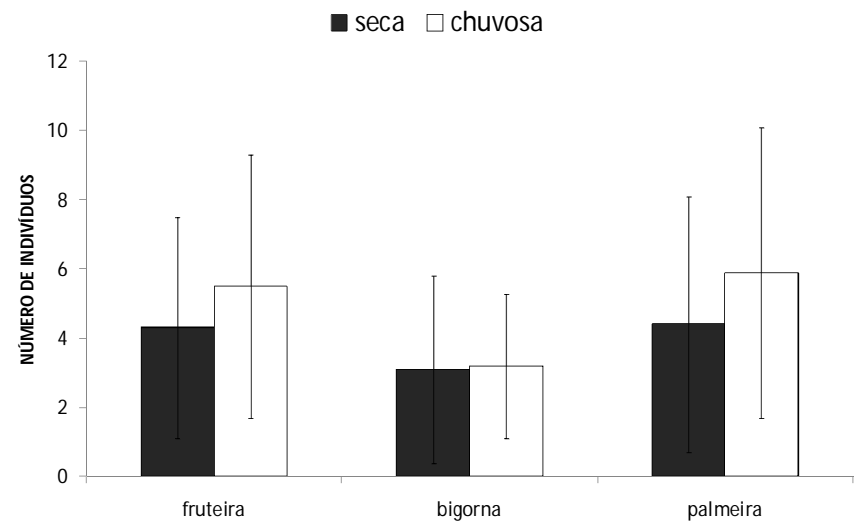

Figura 10: Tamanho médio das unidades de alimentação (número de indivíduos) de fontes com discretas exploradas pelo grupo $\mathrm{CH}$ durante as estações seca e chuvosa. 
O tempo médio de depleção de fruteiras que exigiram manipulação (n=248; 52\% das fruteiras visitadas) foi de $17,3 \pm 15,5$ minutos e o tamanho das unidades de alimentação foi de 4,6 \pm 3,3 indivíduos. Para fruteiras que não exigiram manipulação $(\mathrm{n}=229 ; 48 \%)$, esses valores foram de 16,1 \pm 14,9 minutos e 5,7 $\pm 3,9$ indivíduos, respectivamente. O tempo de depleção não variou significativamente em função da necessidade de manipulação do recurso, já o tamanho das unidades de alimentação foi maior nas fontes que não demandaram manipulação ( $F=9,847$; $g l=476 ; p<0,01)$.

A comparação entre os itens classificados como "fruteiras" mostrou que houve variação significativa no tamanho das unidades de alimentação em função do tipo de recurso explorado $(\mathrm{F}=7,532 ; \mathrm{gl}=479 ; \mathrm{p}<0,001)$, mas não no tempo de depleção $(\mathrm{F}=1,384 ; \mathrm{gl}=479 ; \mathrm{p}=0,247) . \quad \mathrm{O}$ tamanho das unidades de alimentação foi significativamente maior quando o recurso explorado era fruto do que quando era semente $(\mathrm{p}<0,001)$. Não houve diferença na comparação entre os demais itens, como apresenta a Tabela 5. Para as palmeiras, o tempo de depleção e o tamanho das unidades de alimentação foram significativamente maiores quando o recurso explorado era polpa dos cocos (tempo de depleção: $\mathrm{F}=8,829 ; \mathrm{gl}=88 ; \mathrm{p}<0,01$; unidade de alimentação: $\mathrm{F}=12,337 ; \mathrm{gl}=88 ; \mathrm{p}<0,001)$, em comparação à água (Tabela 5).

Tabela 5: Tempo médio de depleção e tamanho médio das unidades de alimentação no grupo $\mathrm{CH}$, para sete itens alimentares com distribuição discreta no ambiente.

\begin{tabular}{c|c|c|l}
\hline ITEM & N & TD $(\mathbf{m i n})$ & \multicolumn{1}{|c}{ UA $(\boldsymbol{\Delta})$} \\
\hline Fruto & 427 & $17,7 \pm 15,7$ & $5,8 \pm 3,9^{* *}$ \\
Semente & 325 & $14,2 \pm 14,2$ & $4,2 \pm 3,1^{* *}$ \\
Néctar & 13 & $18,4 \pm 20,8$ & $4,3 \pm 3,7$ \\
Flor & 10 & $18,6 \pm 7,6$ & $4,4 \pm 2,6$ \\
Coco & 108 & $16,7 \pm 22,1 \#$ & $5,4 \pm 4,1 \# \#$ \\
Água de coco & 16 & $3,7 \pm 2,1 \#$ & $2,1 \pm 1,4 \# \#$ \\
\hline
\end{tabular}

$\mathrm{Td}=$ tempo médio de depleção e desvio padrão (minutos); Ua= tamanho médio da unidade de alimentação e desvio padrão (indivíduos); * indica diferença estatística entre itens de fruteiras $\left({ }^{*} \mathrm{p}<0,001\right)$; \# indica diferença estatística entre itens de palmeiras $(\# \mathrm{p}<0,01 ; \# \# \mathrm{p}<0,001)$. 


\subsubsection{Comparação entre grupos}

A comparação entre os grupos ZA e $\mathrm{CH}$ mostrou que não houve diferença na taxa de exploração (visitas/hora de observação) de fruteira $(\mathrm{F}=0,104 ; \mathrm{gl}=27 ; \mathrm{p}=0,750)$, palmeira $(\mathrm{F}=0,151 ; \mathrm{gl}=27 ; \mathrm{p}=0,701)$ e bigornas $(\mathrm{F}=1,517 ; \mathrm{gl}=27 ; \mathrm{p}=0,229)$. A análise GLM revelou que o tempo de depleção foi afetado pelo tipo de fonte explorada $(\mathrm{F}=7,623 ; \mathrm{gl}=2 ; \mathrm{p} \leq 0,001)$ e pelas interações entre grupo e tipo de fonte explorada $(\mathrm{F}=3,363 ; \mathrm{gl}=2 ; \mathrm{p}<0,05)$ e grupo e estação $(\mathrm{F}=4,061 ; \mathrm{gl}=1 ; \mathrm{p}<0,05)$. O tempo de depleção de palmeiras foi maior que de fruteiras $(\mathrm{p}<0,05)$ e bigornas $(\mathrm{p}<0,001)$ e o de fruteiras maior que o de bigornas $(\mathrm{p}<0,05)$. O tempo de depleção de fruteira e palmeiras foi maior no grupo ZA, enquanto o de bigornas foi maior no grupo $\mathrm{CH}$. De uma maneira geral, o tempo de depleção de fontes discretas foi maior no grupo ZA durante a estação chuvosa, e maior no grupo $\mathrm{CH}$ durante a estação seca (Tabela 5). A análise GLM também mostrou que o tamanho das unidades de alimentação foi afetado pelo grupo $(\mathrm{F}=34,85 ; \mathrm{gl}=1 ; \mathrm{p}<0,0001)$, tipo de fonte $(\mathrm{F}=37,12 ; \mathrm{gl}=2 ; \mathrm{p}<0,0001)$ e pela interação entre grupo e estação $(\mathrm{F}=4,291 ; \mathrm{gl}=1 ; \mathrm{p}<0,05)$. As unidades de alimentação foram maiores no grupo $\mathrm{CH}$ do que no grupo ZA. Fruteira e palmeiras apresentaram unidades de alimentação maiores do que bigornas $(\mathrm{p}<0,001)$. As unidades de alimentação foram maiores no grupo $\mathrm{CH}$ do que no grupo ZA, tanto na estação seca, quanto na chuvosa (Tabela 6). 
Tabela 6: Comparação entre os grupos ZA e CH quanto ao tempo médio de depleção e ao tamanho médio das unidades de alimentação em fontes discretas durante todo o período e nas estações seca e chuvosa.

\begin{tabular}{|c|c|c|c|c|c|}
\hline \multirow{2}{*}{ PERÍODO } & \multirow{2}{*}{ FONTE } & \multicolumn{2}{|c|}{ TD (min) } & \multicolumn{2}{|c|}{$\mathbf{U A}(\Delta)$} \\
\hline & & Zangado & Chicão & Zangado & Chicão \\
\hline \multirow{3}{*}{ GERAL } & Frute & $15,5 \pm 19,1^{*}$ & $16,6 \pm 15,2^{*}$ & $3,5 \pm 2,4$ & $5,1 \pm 3,6$ \\
\hline & & $20,9 \pm 27,4^{*}$ & 19,6 & $4,2 \pm 2,7$ & $5,6 \pm 4,1$ \\
\hline & B & $10,1 \pm 11,8^{*}$ & 16,7 & $2,1 \pm 1,4$ & $3,2 \pm 2,3$ \\
\hline \multirow{3}{*}{ SECO } & $\mathrm{ra}$ & $14,1 \pm 17,1$ & $14,5 \pm 13,5$ & $3,1 \pm 2,3$ & $4,3 \pm 3,2$ \\
\hline & & $23,7 \pm 32,6$ & 12 & $4,6 \pm 2,9$ & $4,4 \pm 3,7$ \\
\hline & Bigorna & $12,1 \pm 14,3$ & $14,2 \pm 15,2$ & $2,2 \pm 1,6$ & $3,1 \pm 2,7$ \\
\hline \multirow{3}{*}{ CHUVOSO } & & $16,5 \pm 20,4$ & $17,8 \pm 15,9$ & $3,8 \pm 2,5$ & $5,5 \pm 3,8$ \\
\hline & & $16 \pm 13,0$ & $21,4 \pm 22,8$ & $3,5 \pm 2,1$ & $5,9 \pm 4,2$ \\
\hline & Bigorna & $7,5 \pm 6,2$ & $17,6 \pm 18,8$ & $1,9 \pm 1,2$ & $3,2 \pm 2,1$ \\
\hline
\end{tabular}

$\mathrm{Td}=$ tempo médio de depleção e desvio padrão (minutos); Ua= tamanho médio da unidade de alimentação e desvio padrão (indivíduos). * Variação significativa entre os grupos ZA e CH.

\subsection{Competicão direta intra-grupo}

\subsubsection{Grupo Zangado}

Foram registrados 944 episódios de interação agonística entre membros do grupo Zangado, uma taxa de 0,6 episódios/hora de observação. A taxa de agressão não variou entre as estações seca $(0,63 \pm 0,20$ interações/hora) e chuvosa $(0,70 \pm 0,26$ interações/hora; $\mathrm{F}=0,522 ; \mathrm{gl}=23 ; \mathrm{p}=0,478$ ). A maior parte das interações agonísticas envolveu agressões brandas (em 81\% dos 544 episódios para os quais foi possível identificar a forma de agressão); 59,2\% (n=322) foram exibições faciais e vocais, $16,1 \%$ $(n=88)$ foram deslocamentos passivos e ativos, $4,4 \%(n=24)$ choro de imaturos e $1,3 \%$ $(n=7)$ roubo de alimentos. Em apenas 19,0\% (n=103) dos episódios agonísticos observaram-se formas mais severas de agressões; em 7,4\% (n=40) houve agressão física (mordidas, tapas e puxões de pêlos), em 1,8\% (n=10) houve perseguição, em 9,2\% $(n=50)$ houve duas formas de agressão envolvida (geralmente, ameaça e perseguição ou perseguição e agressão física) e em 0,6 (n=3) houve mais de duas formas de agressão.

O contexto das agressões foi determinado em 71,0\% dos episódios ( $\mathrm{n}=668)$ : $76,1 \%(n=508)$ foram disputas por recursos alimentares, $21,1 \%(n=141)$ ocorreram em 
contexto social (disputas por parceiros sociais ou conflito mãe-filhote) e 2,8\% (n=19) foram disputas por fontes de água (Figura 11).

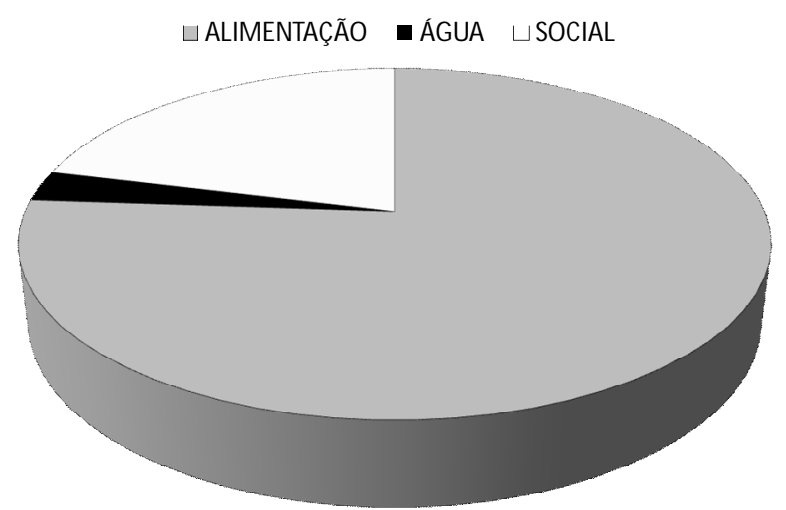

Figura 11: Contexto (em porcentagem) das interações agressivas entre membros do grupo ZA.

Das disputas geradas por competição alimentar, 53,3\% (n=271) foram competição por frutos, $12,4 \%(n=63)$ por acesso a bigornas, martelos e restos de alimentos resultante da atividade de quebra, 9,6\% $(n=49)$ por sementes, 6,9\% $(n=35)$ por invertebrados, 3,1\% $(\mathrm{n}=16)$ por flores, 2,8\% $(\mathrm{n}=14)$ por néctar, 1,2\% $(\mathrm{n}=6)$ por folhas, 1,0\% $(n=5)$ por raízes e 0,4\% $(n=2)$ por vertebrados (Figura 12). Em 9,3\% $(n=47)$ das disputas alimentares não foi possível identificar o recurso sob disputa. A frequiência de disputa por cada tipo de recurso alimentar diferiu do esperado em relação à proporção de tempo dedicada ao consumo de cada item $\left(\chi^{2}=926,40 ; \mathrm{gl}=5 ; \mathrm{p}<0,0001\right)$. Disputas por frutos e acesso a bigornas ocorreram acima do esperado, enquanto disputas por invertebrados, sementes, folhas, raízes e vertebrados ocorreram abaixo do esperado. Dentre as disputas por itens alimentares identificados, 89,6\% ( $\mathrm{n}=413)$ foram por recursos com distribuição discreta no ambiente. 


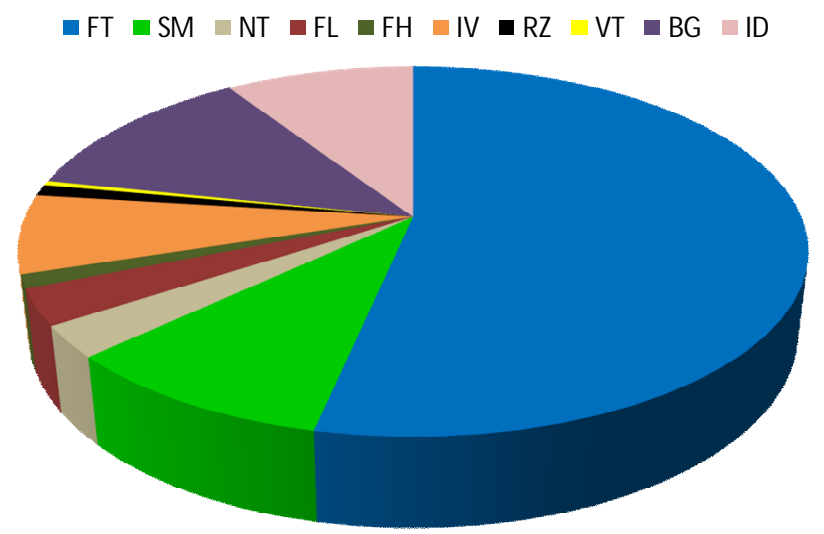

Figura 12: Proporção (em porcentagem) das disputas alimentares por tipo de recurso no grupo $\mathrm{ZA}$. Ft=fruto; $\mathrm{Sm}=$ semente; $\mathrm{Nt}=$ néctar; $\mathrm{Fl}=$ flor; $\mathrm{Fh}=$ folha; $\mathrm{Iv}=$ invertebrado; $\mathrm{Rz}=$ raiz; $\mathrm{Vt}=$ vertebrado; $\mathrm{Bg}=$ bigorna; $\mathrm{Id}=$ intederminado.

A identidade dos indivíduos envolvidos em interações agressivas foi determinada em 55,5\% $(\mathrm{n}=525)$ dos episódios. Fêmeas de todas as idades participaram de 74,3\% (n=390) dessas interações, sendo 50,5\% (n=197) em disputas contra machos e 49,5\% ( $\mathrm{n}=193)$ em disputas contra outras fêmeas do grupo. Fêmeas adultas foram as principais agressoras do grupo, respondendo por 39,0\% ( $\mathrm{n}=202)$ de todas as ameaças, e suas vítimas mais freqüentes foram fêmeas juvenis (em 25\% dos episódios, n=219). Fêmeas adultas foram vítimas de agressão em 16,8\% ( $\mathrm{n}=88)$ dos conflitos, enquanto fêmeas juvenis foram agressoras em $6 \%(n=25)$ e vítimas em 48,3\% ( $n=202)$ dos episódios. Fêmeas infantes não foram observadas agredindo outros membros do grupo, mas foram vítimas de agressão em 7,7\% (n=32) dos episódios agressivos (Tabela 7). Das interações agonísticas em que fêmeas adultas foram agressoras, 74\% (n=149) foram disputas for alimento (Figura 13), 23,5\% $(n=48)$ foram em contexto social e 2,5\% $(n=5)$ foram disputas por fontes de água. 
Tabela 7- Proporção (em porcentagem) de conflitos agonísticos entre classes de sexo e idade no grupo ZA.

\begin{tabular}{c|cccccc}
\hline & MA & FA & MJ & FJ & MI & FI \\
\hline MA & & 3,3 & 13,2 & 7,2 & 3,8 & 4,3 \\
FA & 0,0 & 8,4 & 3,3 & 25,1 & 1,0 & 1,2 \\
MJ & 0,0 & 6,7 & 0,0 & 11,0 & 3,1 & 1,2 \\
FJ & 0,0 & 0,2 & 0,2 & 4,8 & 0,7 & 0,0 \\
MI & 0,0 & 0,0 & 0,0 & 0,2 & 0,0 & 1,0 \\
FI & 0,0 & 0,0 & 0,0 & 0,0 & 0,0 & 0,0 \\
\hline
\end{tabular}

$\mathrm{MA}=$ macho adulto, $\mathrm{FA}=$ fêmea adulta, $\mathrm{MJ}=$ macho juvenil, FJ=fêmea juvenil, $\mathrm{MI}=$ macho infante e FI=fêmea infante. A linha indica os agressores e a coluna as vítimas.

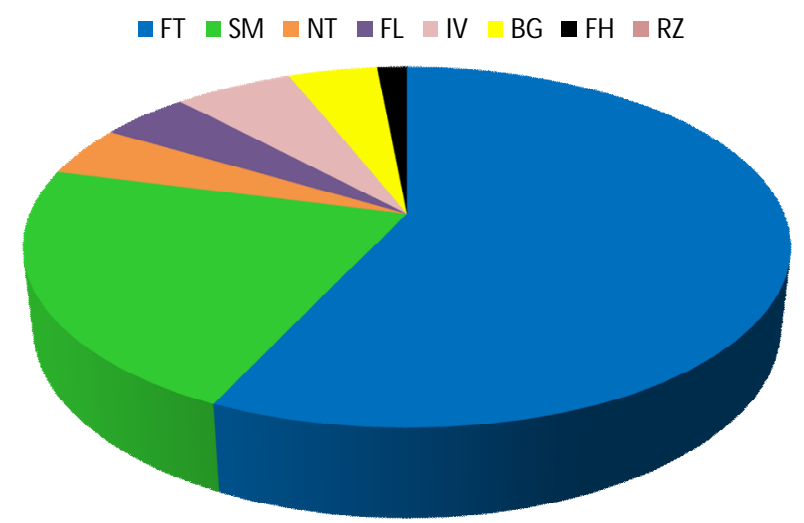

Figura 13: Proporção (em porcentagem) das disputas por diferentes tipos de alimentos protagonizadas por fêmeas do grupo $\mathrm{ZA}$. $\mathrm{Ft}=$ fruto; $\mathrm{Sm}=$ semente; $\mathrm{Nt}=$ néctar; $\mathrm{Fl}=$ flor; $\mathrm{Iv}=$ invertebrado; $\mathrm{Bg}=$ bigorna; $\mathrm{Fh}=$ folha; $\mathrm{Rz}=$ raiz.

\subsubsection{Grupo Chicão}

Para o grupo $\mathrm{CH}$ foram registrados 1177 episódios agonísticos, uma taxa de 2,2 episódios/hora de observação (quatro vezes maior que a taxa registrada para o grupo ZA). Não houve variação significativa na taxa de interação agonística entre as estações seca $(2,6 \pm 0,7)$ e chuvosa $(2,0 \pm 0,9 ; \mathrm{F}=1,483 ; \mathrm{gl}=14 ; \mathrm{p}=0,245)$. Embora a taxa de conflitos agonísticos tenha sido elevada, a maior parte dos episódios envolveu formas bandas de agressão $(77,5 \%$ dos 886 episódios para os quais foi possível identificar a forma de agressão envolvida); 59,5\% ( $\mathrm{n}=525)$ foram exibições faciais e vocais de ameaça, 8,7\% $(\mathrm{n}=77)$ choro de imaturos, 8,9\% $(\mathrm{n}=79)$ deslocamentos ativos e passivos e $0,3 \%(n=3)$ roubo de alimentos. Em 22,5\% $(n=199)$ dos episódios foram observadas formas mais severas de agressão; em 4,8\% (n=42) houve agressão física, em 2,7\% 
$(n=24)$ houve perseguição, 13,6\% (n=120) envolveram duas formas de agressão e em $1,5 \%(\mathrm{n}=13)$ houve mais de duas formas de agressão.

O contexto das agressões pode ser determinado em 84,0\% ( $\mathrm{n}=987)$ dos episódios. Tal como observado para o grupo ZA, a maior parte das interações $(73,0 \%$; $\mathrm{n}=724)$ foi disputas por recursos alimentares (39\% por recursos naturalmente disponíveis no ambiente e 34\% por alimentos aprovisionados), 24\% ( $\mathrm{n}=166)$ ocorreram em contexto social, 3,0\% $(\mathrm{n}=30)$ foram disputas por fontes de água $(0,5 \%$ por fontes naturalmente disponíveis e $2,5 \%$ por água fornecida na área de aprovisionamento), como mostra a Figura 14. Das 724 agressões geradas por disputas alimentares, 39,8\% $(n=288)$ foram por alimento aprovisionado, 26,5\% $(n=192)$ por frutos, 13,6\% $(n=99)$ em sítios de quebra (7,7\% por bigornas, martelos encontradas na área de aprovisionamento ou por cocos aprovisionados e 5,9\% por bigornas, martelos ou restos de alimentos resultantes de quebra fora da área de aprovisionamento), 6,1\% (n=44) por sementes, $3,6 \%(\mathrm{n}=26)$ por invertebrados, $1,1 \%(\mathrm{n}=8)$ por néctar, $1,1 \%(\mathrm{n}=8)$ por raízes, $0,7 \%$ $(n=5)$ por folhas, $0,6 \%(n=4)$ por flores e $0,6 \%(n=4)$ por vertebrados (Figura 15). Em $6,4 \%(n=46)$ dos conflitos alimentares não foi possível identificar o recurso sob disputa. A frequiência de disputas por tipo de alimento diferiu do esperado em função do tempo dedicado à exploração de cada recurso $\left(\chi^{2}=1131,85, \mathrm{gl}=7, \mathrm{p}<0,0001\right)$. Disputas por alimentos aprovisionados e pelo acesso a bigornas ocorreram acima do esperado, enquanto disputas por invertebrados, frutos, sementes, folhas, raízes e vertebrados ocorreram abaixo do esperado. Considerando apenas as disputas em que o recurso alimentar foi identificado, 94,0\% ( $\mathrm{n}=635)$ foram por recursos com distribuição discreta e apenas $6,0 \%(n=43)$ por recursos distribuídos de maneira dispersa no ambiente. 


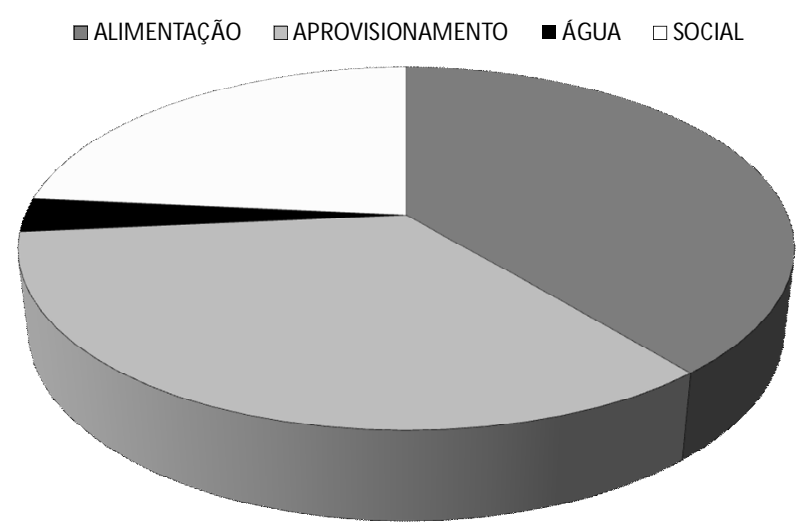

Figura 14: Contexto (em porcentagem) das interações agressivas entre membros do grupo $\mathrm{CH}$.

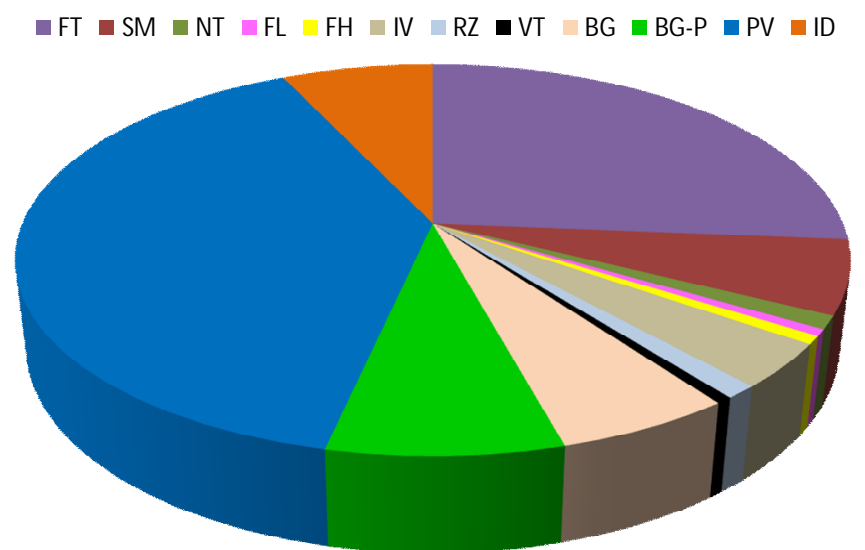

Figura 15: Proporção (em porcentagem) das disputas alimentares por tipo de recurso no grupo $\mathrm{CH}$. Ft=fruto; $\mathrm{Sm}=$ semente; $\mathrm{Nt}=$ néctar; $\mathrm{Fl}=$ flor; $\mathrm{Iv}=$ invertebrado; $\mathrm{Rz}=$ raiz; $\mathrm{Vt}=$ =ertebrado; $\mathrm{Bg}=$ bigorna; $\mathrm{Bg}-\mathrm{P}=$ bigorna aprovisionada; $\mathrm{Pv}=$ alimentos aprovisionados; $\mathrm{Id}=$ indeterminado.

A identidade dos indivíduos envolvidos em interações agressivas foi determinada em 60,5\% (n=712) dos episódios. Ao contrário do que foi observado no grupo ZA, aqui, as interações mais freqüentes ocorreram entre machos $(50,5 \%$; $n=360)$ e entre machos e fêmeas (38\%, n=269), enquanto agressões entre fêmeas representaram apenas $11,5 \%(\mathrm{n}=83)$. Ainda assim, as fêmeas adultas foram as maiores agressoras do grupo, respondendo por 33,6\% (n=239) dos episódios, e suas principais vítimas foram machos subadultos $(16,2 \% ; n=115)$. Fêmeas adultas foram vítimas em 21,9\% $(n=156)$ das interações, enquanto fêmeas juvenis foram agressoras em 1,3\% (n=9) e vítimas em 
4,2\% ( $\mathrm{n}=20)$ dos episódios agressivos. Fêmeas infantes não foram observadas agredindo ou sendo agredidas por outros membros do grupo (Tabela 8). Das interações agonísticas em que fêmeas adultas foram agressoras, $72,5 \%(n=173)$ foram disputas for alimento (Figura 16), 25\% $(n=60)$ foram conflitos sociais e 2,5\% $(n=6)$ foram disputas por fontes de água.

Tabela 8- Proporção (em porcentagem) de conflitos agonísticos entre classes de sexo e idade no grupo $\mathrm{CH}$.

\begin{tabular}{c|ccccccc}
\hline & MA & FA & MS & MJ & FJ & MI & FI \\
\hline MA & 0,6 & 4,1 & 9,3 & 12,9 & 0,3 & 4,8 & 0,0 \\
FA & 0,4 & 8,3 & 16,2 & 4,6 & 2,5 & 1,5 & 0,0 \\
MS & 1,0 & 2,2 & 9,4 & 3,2 & 0,1 & 0,6 & 0,0 \\
MJ & 0,0 & 6,2 & 1,8 & 2,9 & 0,8 & 4,4 & 0,0 \\
FJ & 0,0 & 0,8 & 0,4 & 0,0 & 0,0 & 0,0 & 0,0 \\
MI & 0,0 & 0,0 & 0,0 & 0,1 & 0,1 & 0,3 & 0,0 \\
FI & 0,0 & 0,0 & 0,0 & 0,0 & 0,0 & 0,0 & 0,0 \\
\hline
\end{tabular}

$\mathrm{MA}=$ macho adulto, $\mathrm{FA=fêmea} \mathrm{adulta,} \mathrm{MS}=$ macho subadulto, $\mathrm{MJ}=$ macho juvenil, $\mathrm{FJ}=$ fêmea juvenil, MI=macho infante e FI=fêmea infante. A linha indica os agressores e a coluna as vítimas.

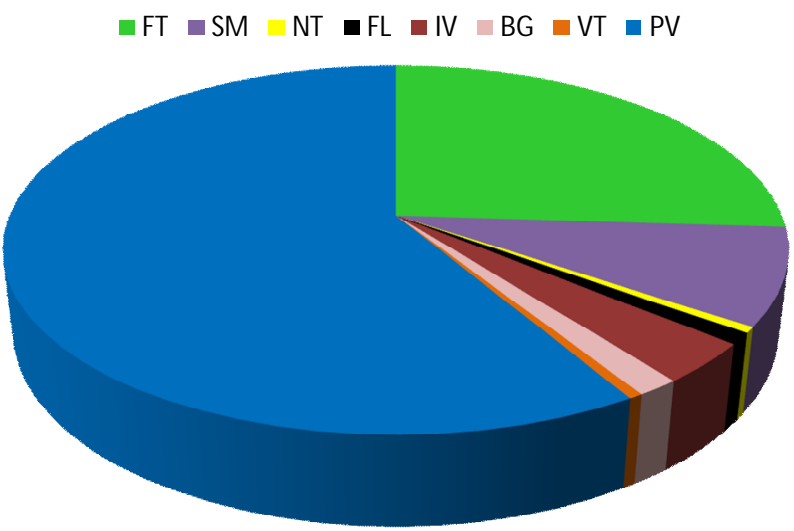

Figura 16: Proporção (em porcentagem) das disputas por diferentes tipos de alimentos protagonizadas por fêmeas do grupo $\mathrm{CH}$. $\mathrm{Ft}=$ fruto; $\mathrm{Sm}=$ semente; $\mathrm{Nt}=$ néctar; $\mathrm{Fl}=\mathrm{fl}$ or; $\mathrm{Iv}=$ invertebrado; $\mathrm{Bg}=$ bigorna; $\mathrm{Vt}=$ vertebrado; $\mathrm{Pv}=$ alimentos aprovisionados.

\subsubsection{Competição direta por fontes discretas}

A taxa de interações agonísticas registrada durante episódios de alimentação em fontes discretas foi de 0,16 interações/fonte visitada no grupo ZA e de 0,18 
interações/fonte visitada no grupo $\mathrm{CH}$. Em ambos os grupos, a alimentação em palmeiras foi o contexto que mais suscitou disputas ( $\mathrm{ZA}=0,28$ interações/fonte visitada; $\mathrm{CH}=0,38$ interações/fonte visitada), seguida da alimentação em bigornas $(\mathrm{ZA}=0,18$ episódios/fonte visitada; $\mathrm{CH}=0,15$ episódios/fonte visitada) e fruteiras ( $\mathrm{ZA}=0,13$ episódios/fonte visitada; $\mathrm{CH}=0,15$ episódios/fonte visitada).

A análise GLM uni-variada revelou que a freqüência de interação agressiva em fontes discretas registrada para os grupos $\mathrm{ZA}$ e $\mathrm{CH}$ foi afetada pelo tipo de fonte explorada $(\mathrm{F}=12,377 ; \mathrm{gl}=2 ; \mathrm{p}<0,001)$, estação $(\mathrm{F}=5,442 ; \mathrm{gl}=1 ; \mathrm{p}<0,001)$ e pela interação entre tipo de fonte explorada e estação $(\mathrm{F}=5,933 ; \mathrm{gl}=2 ; \mathrm{p}<0,01)$. A freqüência de interação agressiva foi maior em palmeiras (0,36 disputas/visita) do que em bigornas $(0,17$ disputas/visita; $\mathrm{p}<0,001)$ e em fruteiras $(0,16$ disputas/visita; $\mathrm{p}<0,001)$. Disputas por fontes discretas foram mais freqüentes durante a estação seca $(0,27$ disputas/visita; chuvosa: 0,18 disputas/visita). A freqüência de disputas por palmeiras e bigornas foi maior durante a estação seca (palmeiras=0,44 disputas/visita; bigornas=0,25 disputas/visita; estação chuvosa: palmeiras=0,29 disputas/visita; bigornas=0,09 disputas/visita), enquanto a freqüência de disputas em fruteiras foi maior durante a estação chuvosa (0,18 disputas/visita; seca=0,13 disputas/visita). Não houve variação significativa na freqüência de interação agressiva entre os grupos, entre grupo e tipo de fonte explorada e entre grupo e estação.

Análises de regressão mostraram uma correlação positiva entre o tempo de depleção e a freqüência de interação agonística em palmeiras $(r=0,573$; p<0,001) e em fruteiras $(r=0,276 ; \mathrm{p}<0,001)$ no grupo ZA. Para o grupo $\mathrm{CH}$, o tempo de depleção foi positivamente correlacionado à freqüência de interação agonística nos três tipos de fontes discretas (fruteira: $r=0,411 ; \mathrm{p}<0,001$; bigornas: $r=0,452 ; \mathrm{p}<0,001$; palmeiras: $r=0,409 ; \mathrm{p}<0,001)$. 


\subsection{Competicão direta entre grupos}

Em média, houve 0,9 encontros a cada 100 horas de observação $(n=25)$, sendo que a maior parte $(88,0 \% ; n=22)$ ocorreu durante a estação chuvosa. Encontros entre os grupos ZA e CH representaram 80,0\% dos episódios ( $\mathrm{n}=20)$, enquanto $20 \%(\mathrm{n}=5)$ foram encontros entre o grupo ZA e pequenos grupos de machos adultos e subadultos e machos solitários. Não foram observados encontros entre o grupo $\mathrm{CH}$ e outros grupos além do ZA.

Em todos os encontros foram observadas exibições com "lançamento de pedras", que eram atiradas do alto dos morros por membros do grupo ZA, especialmente pelo macho alfa (conforme descrito por Moura, 2007). Em todos os episódios registrados, membros de um grupo comportaram-se agressivamente para com os membros do outro grupo, emitindo vocalizações e exibindo expressões faciais e posturas de ameaça. Agressões físicas foram observadas em apenas um episódio, no qual cinco fêmeas adultas e juvenis do grupo $\mathrm{CH}$ bateram e perseguiram duas fêmeas adultas do grupo ZA durante encontro em uma grande fruteira. Embora todas as classes de sexo e idade tenham participado agressivamente desses encontros (incluindo juvenis e infantes de ambos os sexos), fêmeas adultas de ambos os grupos foram os indivíduos mais ativos durante encontros. Apesar do contexto predominantemente agonístico dos encontros entre grupos, em alguns episódios, houve também interações afiliativas entre os membros dos dois grupos. A maior parte foi "exibição de encontro" (Matheson et al., 1996; Alfaro-Lynch, 2008) entre o macho alfa do grupo ZA e os machos subadultos que migraram deste grupo para o grupo $\mathrm{CH}$. Esses machos também foram observados brincando com infantes do grupo ZA durante episódios de encontros entre grupos. O grupo $\mathrm{CH}$ venceu todos os encontros com o grupo ZA (independente do contexto e local onde essas interações ocorreram), e o desfecho dos episódios foi marcado pela retirada 
apressada do grupo ZA para locais mais distantes da área de uso, algumas vezes, perseguidos por mais de 500 metros pelo grupo $\mathrm{CH}$.

Já os encontros entre o grupo ZA e os pequenos grupos de machos foram tentativas de imigração desses machos. Apesar das constantes ameaças recebidas, especialmente do macho alfa e de fêmeas adultas e jovens, em alguns casos, os machos "visitantes" chegaram a seguir o grupo por mais de uma semana. Contudo, durante a presente pesquisa, nenhuma dessas tentativas de imigração foi bem sucedida.

\subsection{Competicão indireta intra-grupo}

A distância média percorrida diariamente pelo grupo ZA foi de $1967 \pm 0,670$ metros e pelo grupo $\mathrm{CH}$ foi de $1729 \pm 0,732$ metros (Figura 17). A distância percorrida diariamente variou conforme o grupo $(\mathrm{F}=9,855 ; \mathrm{gl}=1 ; \mathrm{p}<0,01)$, sendo que o grupo ZA percorreu distâncias maiores que o grupo $\mathrm{CH}$, e a estação $(\mathrm{F}=9,336 ; \mathrm{gl}=1 ; \mathrm{p}<0,01)$, de modo que ambos os grupos percorreram distâncias maiores durante a estação chuvosa $(\mathrm{ZA}=2140 \pm 373$ metros; $\mathrm{CH}=1832 \pm 584$ metros; seca: $\mathrm{ZA}=1733 \pm 170$ metros; $\mathrm{CH}=1545 \pm 271$ minutos). Análises de regressão múltipla revelaram que a distância percorrida diariamente pelo grupo ZA foi afetada pela proporção de tempo dedicada às atividades de alimentação (comer + forragear) e locomoção, porém a única variável significativa na equação foi o tempo despendido em locomoção $(\beta=0,759 ; p<0,001)$. A distância diária percorrida pelo grupo ZA também foi afetada pela proporção de tempo dedicada à alimentação por frutos, sementes e néctar $\left(\mathrm{R}^{2}=0,366 ; \mathrm{F}=4,717 ; \mathrm{gl}=22\right.$; $\mathrm{p}<0,05)$, sendo que o consumo de frutos foi a variável que mais contribuiu para equação $(\beta=0,716 ; \mathrm{p}<0,05)$. Variáveis ecológicas (como oferta de alimento no ambiente, temperatura e precipitação) não afetaram significativamente as distâncias percorridas pelo grupo ZA. Os resultados obtidos para o grupo $\mathrm{CH}$ foram muito semelhantes aos do 
grupo ZA. A análise de regressão múltipla mostrou que a distância percorrida diariamente foi afetada pela proporção de tempo dedicada às atividades de alimentação e locomoção $\left(R^{2}=0,363 ; \quad F=4,987 ; p<0,05\right.$ : forrageamento: $\beta=0,649 ; \quad p<0,05$ e locomoção: $\beta=0,552 ; \mathrm{p}<0,05)$ e pela proporção de tempo dedicada ao consumo de frutos $\left(R^{2}=0,296 ; F=6,878 ; p<0,05\right.$ : tempo de consumo de frutos: $\left.\beta=0,588 ; p<0,05\right)$. Variáveis ecológicas também não afetaram as distâncias percorridas diariamente pelo grupo $\mathrm{CH}$.

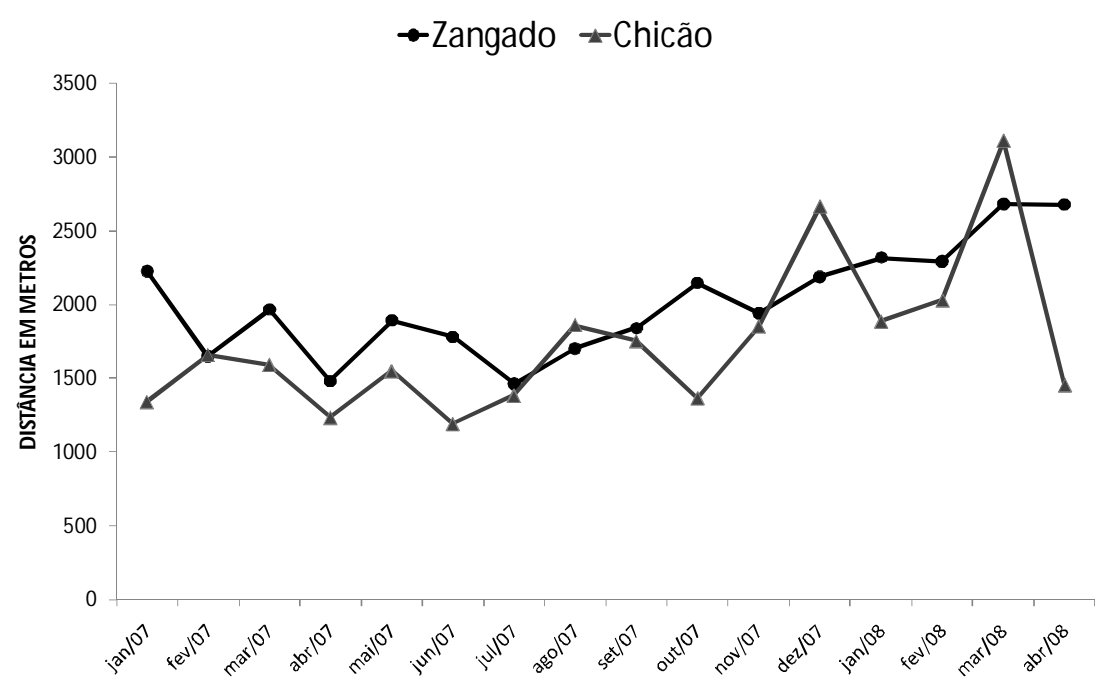

Figura 17: Distâncias médias (em metros) percorridas diariamente pelos grupos ZA e CH entre o período de janeiro de 2007 e abril de 2008.

A "energia ingerida" média (medida como IM) e a "energia ingerida per capita" média (medida como PCIM) de fontes discretas exploradas pelos grupos ZA e CH estão apresentadas na Tabela 9. A análise GLM mostrou que o IM foi afetado apenas pelo tipo de fonte $(\mathrm{F}=7,856 ; \mathrm{gl}=2 ; \mathrm{p}<0,001)$, sendo que o $\mathrm{IM}$ de palmeiras foi significativamente maior que o de fruteiras $(\mathrm{p}<0,05)$ e bigornas $(\mathrm{p}<0,001)$ e o IM de fruteiras maior que o de bigornas $(\mathrm{p} \leq 0,001)$. Já o PCIM foi afetado pelo grupo $(\mathrm{F}=4,078 ; \mathrm{gl}=1 ; \mathrm{p}<0,05)$, o PCIM do grupo $\mathrm{ZA}$ foi maior que o do $\mathrm{CH}$, e pelo tipo de fonte $(\mathrm{F}=7,815 ; \mathrm{gl}=2 ; \mathrm{p}<0,001)$, o PCIM de palmeiras foi maior que o de árvores 
$(\mathrm{p}<0,05)$ e bigornas $(\mathrm{p}<0,001)$ e o PCIM de árvores foi maior que de bigornas $(\mathrm{p}<0,001)$.

Não houve correlação entre as distâncias percorridas diariamente pelo grupo ZA e o IM dos três tipos de fontes discretas. Para o grupo $\mathrm{CH}$, as distâncias percorridas diariamente foram fracamente correlacionadas com o IM de palmeiras $\left(\mathrm{R}^{2}=0,127\right.$; $\mathrm{F}=5,839 ; \mathrm{p}<0,05)$.

Tabela 9: IM médio e PCIM médio de fontes discretas exploradas pelos grupos ZA e CH durante todo o período de pesquisa e durante as estações seca e chuvosa.

\begin{tabular}{c|l|cc|cc}
\hline \multirow{2}{*}{ PERÍODO } & \multirow{2}{*}{ FONTE } & \multicolumn{2}{|c}{ IM } & \multicolumn{2}{c}{ PCIM } \\
\cline { 3 - 6 } & & Zangado & Chicão & Zangado & Chicão \\
\hline \multirow{3}{*}{ TOTAL } & Fruteira & $85,0 \pm 169,4$ & $124,5 \pm 184,4$ & $9,1 \pm 17,8$ & $7,1 \pm 10,5$ \\
& Palmeira & $132,6 \pm 264,9$ & $174,0 \pm 299,0$ & $13,9 \pm 27,1$ & $4,6 \pm 17,1$ \\
& Bigorna & $33,2 \pm 68,6$ & $80,3 \pm 133,3$ & $3,0 \pm 5,4$ & $9,9 \pm 7,5$ \\
\hline \multirow{3}{*}{ SECA } & Fruteira & $71,8 \pm 145,2$ & $92,9 \pm 145,8$ & $7,6 \pm 15,1$ & $5,4 \pm 8,5$ \\
& Palmeira & $164,7 \pm 317,4$ & $96,1 \pm 156,0$ & $16,8 \pm 32,3$ & $5,7 \pm 9,2$ \\
& Bigorna & $43,7 \pm 87,6$ & $78,6 \pm 154,1$ & $3,7 \pm 6,7$ & $4,6 \pm 9,1$ \\
\hline \multirow{3}{*}{ CHUVOSA A } & Fruteira & $95,0 \pm 185,0$ & $140,8 \pm 199,8$ & $10,2 \pm 19,5$ & $7,9 \pm 11,3$ \\
& Palmeira & $74,6 \pm 102,1$ & $193,7 \pm 323,3$ & $8,7 \pm 11,9$ & $10,9 \pm 18,5$ \\
& Bigorna & $17,8 \pm 23,9$ & $80,9 \pm 126,3$ & $1,9 \pm 2,6$ & $4,6 \pm 7,0$ \\
\hline
\end{tabular}

$\mathrm{IM}=$ energia ingerida média (minutos) e desvio padrão, PCIM=energia ingerida per capita média (minutos) e desvio padrão.

\subsection{Competicão indireta entre grupos}

O tamanho da área de uso do grupo ZA, calculado para o período da pesquisa, foi de 250 ha e o tamanho da área de uso do grupo $\mathrm{CH}$ foi de 355 ha. O tamanho médio da área explorada mensalmente pelo grupo ZA foi de 58,9 $\pm 30,5$ ha e do grupo $\mathrm{CH}$ foi de 51,0 \pm 38,5 ha. O tamanho da área explorada mensalmente não variou entre os grupos e as estações (Tabela 10), nem foi afetada pelo orçamento de atividades, dieta ou variáveis ecológicas. 
Tabela 10: Tamanho médio ( \pm DP) da área explorada mensalmente (em hectares) pelos grupos ZA e CH durante as estações seca e chuvosa.

\begin{tabular}{c|cc}
\hline \multirow{2}{*}{ PERÍODO } & \multicolumn{1}{|c}{ ÁEA EXPLORADA MENSALMENTE } \\
\cline { 2 - 3 } & Zangado & Chicão \\
\hline SECO & $65,9 \pm 17,2$ & $44,9 \pm 25,6$ \\
CHUVOSO & $54,8 \pm 31,3$ & $53,5 \pm 44,1$ \\
\hline
\end{tabular}

\subsection{Padrão de relacões sociais entre fêmeas}

\subsubsection{Grupo Zangado}

A análise das relações de dominância revelou que as fêmeas do grupo ZA estabeleceram uma hierarquia de dominância perfeitamente linear (Figura 18). Os postos hierárquicos foram afetados pela idade das fêmeas, sendo que as adultas ocuparam as posições mais dominantes; Moça Branca foi identificada como fêmea alfa, seguida de Moça Chita (possivelmente sua filha) e Emília. Entre as coetâneas juvenis, Dunga (provavelmente filha de Moça Branca) ocupou a quarta posição, seguida de Catuaba, depois Ervilha. A fêmea infante Elisa ocupou a última posição na hierarquia de dominância das fêmeas. Não foi observada reversão de postos de dominância ao longo da pesquisa.

O grau de tolerância entre fêmeas durante episódios de alimentação em fontes discretas foi avaliado através do Índice de Jaccard (IJ). Fêmeas do grupo ZA foram significativamente mais tolerantes durante alimentação em palmeiras $(I J=0,29)$ e fruteiras $(\mathrm{IJ}=0,22)$ do que durante alimentação em bigornas ( $\mathrm{IJ}=0,04 ; \mathrm{F}=694,719 ; \mathrm{gl}=1$ $\mathrm{p}<0,001)$. Nos três tipos de fontes discretas, houve maior tolerância entre fêmeas que ocuparam postos de dominância similares, especialmente entre fêmeas de alto posto. Ainda assim, o IJ médio para díades formadas por fêmeas de postos distintos foi maior em palmeiras e fruteiras do que em bigornas. 


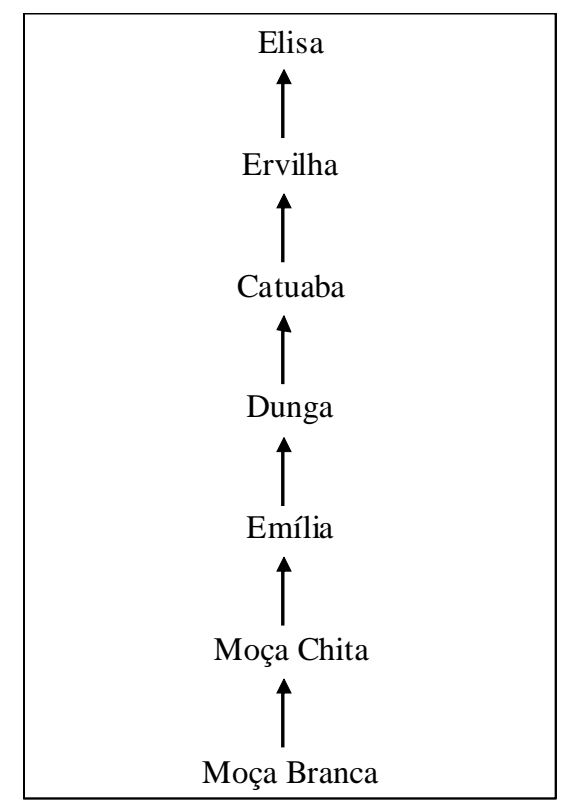

Figura 18: Árvore de Dominância entre as fêmeas do grupo ZA. Indivíduos dominantes originam as setas que atingem os subordinados.

Coalizões foram formadas a uma taxa de 0,08 episódios/hora de observação (em $12,0 \% ; \mathrm{n}=115$ das agressões em que os participantes puderam ser identificados), e não variaram entre as estações seca $(0,10 \pm 0,06$ episódios/hora) e chuvosa $(0,09 \pm 0,06$ episódios/hora; $\mathrm{F}=0,051 ; \mathrm{gl}=23 ; \mathrm{p}=0,823$ ). Fêmeas participaram das coalizões, como ajudantes ou recebendo suporte, em 95,5\% (n=110) dos episódios registrados; 55,5\% $(n=61)$ com machos e 44,5\% (n=49) com fêmeas. O contexto dessas coalizões pode ser determinado em 88\% ( $\mathrm{n}=97)$ dos episódios; $70 \%$ ( $\mathrm{n}=68)$ ocorreram em contexto de alimentação (64\% em recursos de distribuição discreta e 6\% em recurso de distribuição dispersa), $26 \%(n=25)$ em contexto social e $4 \%(n=4)$ em defesa de fontes de água. $O$ parentesco foi um bom preditor de formação de coalizão entre fêmeas, sendo que em 61,5\% ( $\mathrm{n}=60)$ dos episódios as fêmeas aliadas eram aparentadas ou supostamente aparentadas.

Catações ocorreram a uma freqüência de 0,32 episódios/hora de observação $(n=453)$ e não variaram em função da estação (seca= 0,34 \pm 0,20 episódios/hora; 
chuvosa $=0,30 \pm 0,20$ episódios/hora; $F=0,336 ; \mathrm{gl}=23 ; \mathrm{p}=0,568)$. Dos 386 episódios de catação registrados após a emigração dos machos subadultos, 65,3\% (n=252) ocorreram entre machos e fêmeas, 30,0\% $(n=116)$ entre fêmeas e apenas 4,7\% $(n=18)$ entre machos. Fêmeas adultas realizaram catação em 69,4\% (n=268) dos episódios e foram os "catadores" mais ativos do grupo, e receberam catação em 23,1\% (n=89). Fêmeas juvenis cataram em 11,1\% (n=43) e receberam catação em 11,4\% (n=44) dos episódios. Fêmeas infantes cataram outros indivíduos em $0,3 \%(\mathrm{n}=1)$ dos episódios e receberam catação em $10,1 \%(n=39)$.

\subsubsection{Grupo Chicão}

As fêmeas do grupo $\mathrm{CH}$ estabeleceram uma hierarquia de dominância quase linear, porque três fêmeas adultas dividiram o posto mais baixo na hierarquia de dominância. Neste grupo, a idade das fêmeas não foi um determinante tão forte para a ocupação de postos mais elevados, por exemplo, Dita e Chuchu (respectivamente segunda e terceira na hierarquia de dominância de fêmeas) eram adultas jovens (primíparas), Amarelinha (quarto posto na hierarquia) era juvenil, enquanto as três fêmeas que dividiram o último posto de dominância eram fêmeas multíparas (Figura 19). Não foi observada interação agonística entre a fêmea infante Doree e as demais fêmeas. Também não houve reversão de postos de dominância ao longo da pesquisa. 


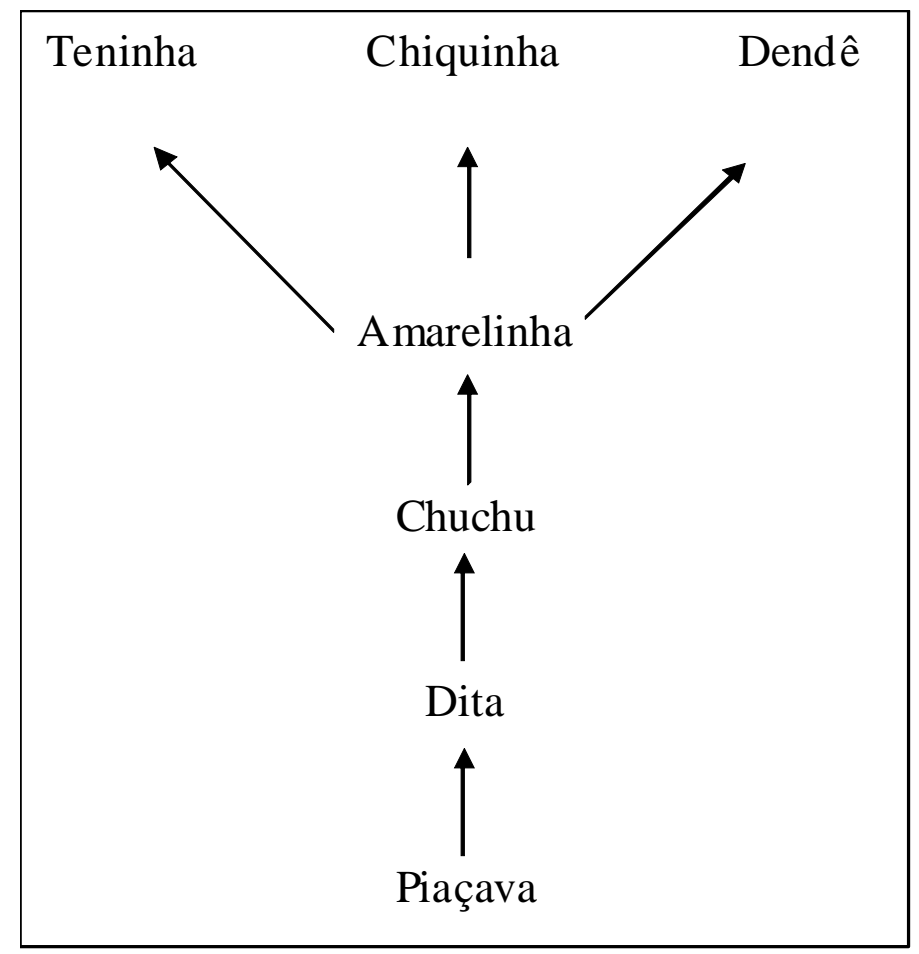

Figura 19: Árvore de Dominância entre as fêmeas do grupo CH. Indivíduos dominantes originam as setas que atingem os subordinados.

O grau de tolerância entre fêmeas durante episódios de alimentação em fontes discretas seguiu um padrão semelhante ao observado no grupo ZA. Fêmeas foram mais tolerantes durante alimentação em fruteiras $(I J=14,2)$ e em palmeiras ( $I J=13,2)$ do que em alimentação em bigornas ( $\mathrm{IJ}=0,04 ; \mathrm{F}=57,261 ; \mathrm{gl}=1 ; \mathrm{p}<0,001)$. Houve mais tolerância entre fêmeas de postos similares do que entre fêmeas de postos distintos, principalmente entre fêmeas de alto posto. Ainda assim, fêmeas dominantes foram mais tolerantes com fêmeas de médio e baixo posto durante episódios de alimentação em fruteiras e palmeiras, do que em episódios de alimentação em bigornas.

Coalizões foram observadas em 25,0\% (n=297) dos episódios agonísticos nos quais a identidade dos envolvidos foi determinada, uma taxa de 0,6 episódios/hora de observação. Embora a freqüência de interações agonísticas não tenha variado entre estações, houve significativamente mais coalizões na estação seca $(0,9 \pm 0,4$ 
episódios/hora; chuvosa $=0,4 \pm 0,2$ episódios/hora; $\mathrm{F}=6,155 ; \mathrm{gl}=14 ; \mathrm{p}<0,05)$. Fêmeas participaram, como ajudantes ou recebendo ajuda, de 77,5\% (n=229) das coalizões registradas, sendo $73 \%(n=167)$ com machos e $27 \%(n=62)$ com fêmeas. O contexto dessas coalizões foi determinado em 90,5\% ( $\mathrm{n}=207)$ dos episódios; 71\% (n=147) ocorreram em contexto de alimentação (43\% foram defesa de alimentos aprovisionados, $26 \%$ de alimentos com distribuição discreta e $2 \%$ de alimentos de distribuição dispersa), $26 \%(n=54)$ ocorreram em contexto social e $3 \%(n=6)$ foram defesa de fontes de água.

A taxa de catação no grupo $\mathrm{CH}$ foi cinco vezes maior do que a observada no grupo ZA, 1,4 episódios/ hora de observação $(n=768)$, e não variou entre as estações seca $(1,6 \pm 1,0$ episódios/hora) e chuvosa $(1,3 \pm 1,1$ episódios/hora; F=0,244; gl=14; $\mathrm{p}=0,629)$. A maior parte $(66,0 \% ; n=508)$ ocorreu entre machos e fêmeas; $28 \%(n=215)$ foram entre fêmeas e apenas 6,0\% $(n=45)$ entre machos. Fêmeas adultas foram os principais "catadores" do grupo (responsáveis por 76,5\% das catações; n=586) e também os indivíduos mais catados (em 40,0\% dos episódios; $\mathrm{n}=307$ ). Fêmeas juvenis foram responsáveis por $1,6 \%(n=12)$ das catações e receberam 1,6\% $(n=12)$ das catações. Fêmeas infantes não foram observadas realizando catação em outros membros do grupo, mas receberam $2,9 \%(n=22)$.

\section{6- DISCUSSÃO}

\subsection{Socioecologia de $C$. libidinosus na Boa Vista}

Os modelos socioecológicos consideram que as características dos recursos alimentares (distribuição, tamanho e qualidade) governam os regimes de competição por alimento a que fêmeas primatas estão submetidas, o que afeta o padrão de relacionamento social entre elas (Wrangham, 1980; van Schaik, 1989; Isbell, 1991; Sterck et al., 1997). Este é o primeiro estudo sobre socioecologia de Cebus libidinosus 
selvagens em área de ecótono Cerrado/Caatinga, e o primeiro a investigar se o uso rotineiro de ferramentas para alimentação afeta o regime competitivo e as relações sociais entre fêmeas de primatas.

O principal item alimentar consumido pelas fêmeas deste estudo foi polpa de frutos, um recurso distribuído em manchas discretas no ambiente. Este resultado coincide com os resultados de estudos prévios que mostraram que frutos são os recursos alimentares mais importantes para macacos-prego que ocupam áreas de floresta (Terborgh, 1983; Peres, 1993; Zhang, 1995; di Bitetti, 2001; Spironello, 2001; Izar, 2004). É importante notar que o comportamento alimentar das fêmeas do grupo $\mathrm{CH}$ foi muito similar ao das fêmeas do grupo ZA, não obstante o aprovisionamento regular de alimentos e água durante toda a pesquisa.

Os frutos disponíveis na BV são alimentos de alto valor energético. Por exemplo, algumas das espécies consumidas pelas fêmeas deste estudo possuem uma alta proporção de carboidratos (p. ex., Annona crassiflora: Roesler et al., 2007; Anacardium othonianum: Silva et al., 2008; Byrsonima verbascifolia: Guimarães \& Silva; 2008), enquanto outras, apresentam uma polpa rica em lipídios (p. ex., Caryocar brasiliense: Almeida, 1998). De fato, muitos dos frutos consumidos pelos macacos da BV são também ingeridos (frescos ou processados) pelos moradores locais devido às suas qualidades nutricionais e propriedades medicinais (Silva et al., 2008; observação pessoal).

Durante a estação seca, quando o consumo de frutos diminuiu, as fêmeas aumentaram o consumo de flores/néctar, endosperma de frutos de palmeiras (obtido com auxílio de ferramentas), raízes e, no caso do grupo $\mathrm{CH}$, de alimentos aprovisionados. Por essa razão, esses recursos podem ser considerados "alimentos de reserva" ou fallback foods (Wright et al., 2009), que são, por definição, alimentos 
consumidos durante períodos de redução na oferta dos alimentos preferidos de uma espécie (Marshall \& Wrangham, 2007; Altmann, 2009). Segundo Marshall e Wrangham (2007), a qualidade e a distribuição dos recursos de reserva podem influenciar a organização social de primatas, podendo afetar substancialmente os níveis de agressão intra-grupo e as interações afiliativas (Wrangham, 1986; White, 1998). De uma maneira geral, os alimentos de reserva de primatas possuem baixa qualidade nutricional e são uniformemente distribuídos no ambiente (Marshall \& Wrangham, 2007; Strier, 2007; Altmann, 2009). No entanto, os alimentos de reserva na BV, assim como os frutos, são distribuídos em manchas discretas e possuem alto valor nutricional (p. ex., sementes são essencialmente ricas em gorduras e amido, enquanto flores e néctar possuem altas concentrações de açúcares solúveis - Garber, 1987; Strier, 2007). Particularmente, as palmeiras catulé (Atallea. barreirensis) e piaçava (Orbignya sp), cujos frutos são os principais alimentos processados com ferramentas pelos macacos na BV (Visalberghi et al., 2008; Spagnoletti, 2009), possuem um endosperma altamente energético (contendo cerca de $60 \%$ de gorduras, $30 \%$ de carboidratos e $10 \%$ de proteína: Fragaszy, Mattos \& Wright, dados não publicados). Os resultados apresentados aqui revelam que, ao longo de todo o período de estudo, as fêmeas de macacos-prego da BV alimentaram-se principalmente de recursos de alto valor nutricional e discretamente distribuídos no ambiente.

Alimentos obtidos com auxílio de ferramentas constituíram uma proporção pequena da dieta de fêmeas nos dois grupos de estudo ao de todo o período de pesquisa (em média, menos de $2 \%$ no grupo ZA e menos de $4 \%$ no grupo $\mathrm{CH}$ ), apesar do aumento do consumo desses recursos durante os meses de seca. Apesar disso, é possível argumentar que esses alimentos (mais de 90\% dos itens extraídos com auxílio de ferramentas foram constituídos por endosperma de frutos de palmeiras) forneceram às 
fêmeas um maior aporte energético por unidade de tempo/ingestão (Anderson, 1990; Boesch \& Boesch-Achermann, 2000), em comparação aos frutos e demais alimentos. Entretanto, o fato de fêmeas adultas terem dedicado significativamente menos tempo do que machos adultos à utilização de ferramentas e ao consumo de endosperma (Ramos da Silva, 2008; Spagnoletti et al., submetido e conforme apresentado no Capítulo II) não apóia esse argumento. Além disso, o uso de ferramentas exibido pelos macacos da BV é considerado uma atividade extremamente custosa para esses animais (Liu et al., 2009). Isso porque os frutos de palmeiras são muito duros e difíceis de serem quebrados (Visalberghi et al., 2008), exigindo a utilização de martelos que pesam em média $1 \mathrm{~kg}$ (Visalberghi et al., 2007), o que corresponde a aproximadamente metade do peso de uma fêmea adulta (Fragaszy et al., 2004a). Esses resultados sugerem que os alimentos obtidos com auxílio de ferramentas contribuíram pouco para a dieta das fêmeas e, portanto, não foram limitantes de sucesso reprodutivo.

De uma maneira geral, o tempo de depleção e as unidades de alimentação foram maiores em palmeiras do que em fruteira e bigornas e maiores em fruteiras do que em bigornas. No entanto, o longo tempo de depleção (em média, maior que 10 minutos) e o grande tamanho das unidades de alimentação (igual ou um pouco menor que a metade do tamanho do grupo) registrados para palmeiras, fruteiras e bigornas indicam que o tamanho dessas fontes variou de grande a intermediário (p. ex., Boinski et al., 2002 descrevem fontes alimentares pequenas exploradas por Saimiri sciureus na Reserva Natural do Suriname, em que apenas um indivíduo era capaz de se alimentar a cada vez e Izar, 2004 considerou que C. nigritus no Parque Estadual Carlos Botelho (PECB) alimentaram-se em fontes intermediárias a pequenas porque $75 \%$ delas foram depletadas em menos de 10 minutos). Por essa razão, os três tipos de fontes discretas na BV podem ser considerados potencialmente usurpáveis. Esses resultados indicam que, 
embora os alimentos obtidos com auxílio de ferramentas não tenham sido limitantes para fêmeas, o uso de ferramentas pode ter reforçado a competição direta intra-grupo na população de estudo. Isso porque os sítios de quebra (tanto martelos, quanto bigornas) apresentaram características que os tornaram potencialmente usurpáveis por indivíduos mais dominantes do grupo. De fato, a taxa de disputas em fontes alimentares discretas foi positivamente correlacionada ao tempo de depleção. Esse resultado é consistente com a suposição formulada por Isbell (1991), de que quanto mais tempo uma fonte alimentar leva para ser depletada, maiores são as chances de que outro (s) indivíduo (s) do grupo a usurpe. O tempo de depleção vem sendo considerado um importante determinante de interações agonísticas intra-grupo em diversas espécies de primatas $(C$. apella: Janson, 1990a e b; C. capucinus: Vogel \& Janson, 2007; Cercopithecus aethiops e E. patas: Isbell et al., 1998; Pruetz \& Isbell, 2000; Papio cynocephalus: Post et al., 1980; Piliocolobus tephrosceles: Snait \& Chapman, 2005).

Resultados intrigantes foram obtidos para os dois grupos na comparação entre episódios completos e incompletos de alimentação em fontes discretas, de modo que o tempo de depleção foi significativamente maior nos registros incompletos. Um estudo realizado com $C$. nigritus no PECB revelou que os animais deslocam-se mais rápido e linearmente para fontes alimentares de alta qualidade (Presotto, 2009). Da mesma maneira, a maior parte dos episódios incompletos deste estudo foi conseqüência do deslocamento dos grupos em alta velocidade para fontes com grande produtividade, de modo que os observadores não foram capazes de acompanhá-los na mesma velocidade. Nos dois grupos, também, o tamanho das unidades de alimentação foi significativamente menor em fontes que exigiram algum tipo de manipulação. É possível que alguns indivíduos do grupo, principalmente imaturos, tenham sido impedidos de alimentar-se nessas fontes por não possuírem as técnicas de 
processamento necessárias para extração do recurso (Fragaszy \& Boinski, 1995; Resende et al., 2008). É importante salientar que o tempo de depleção praticamente não variou entre as fontes que exigiram manipulação e as que não exigiram. Esse resultado indica que o longo tempo de depleção registrado neste estudo reflete o grande tamanho das fontes da BV, mais do que a necessidade de manipulação dos recursos.

Em resumo, os resultados sobre comportamento alimentar e tamanho de fontes alimentares indicam que as fêmeas de $C$. libidinosus da BV alimentaram-se essencialmente de recursos de alta qualidade nutricional, discretamente distribuídos no ambiente e potencialmente usurpáveis, durante toda a duração deste estudo. De acordo com os modelos socioecológicos, essas características do recurso alimentar deveriam levar a forte competição direta intra-grupo e, dependendo da densidade de macacosprego na área de estudo, à competição direta entre grupos, (Wrangham, 1980; van Schaik, 1989; Isbell, 1991; Sterck et al., 1997). A densidade de macacos-prego na BV foi muito similar à densidade relatada para $C$. nigritus no PECB, onde os animais estão submetidos a forte competição direta entre grupos (Izar, 2004). Desta maneira, é plausível supor que os macacos do presente estudo também estiveram submetidos aos efeitos da competição direta entre grupos.

Em ambos os grupos, as disputas alimentares ocorreram freqüentemente e principalmente por recursos com distribuição discreta. Esse resultado coincide com vários estudos que relatam correlações positivas entre a distribuição discreta dos principais recursos alimentares e as taxas de interações agressivas intra-grupo em diversas espécies de primatas (p. ex., Presbytis entellus: Koenig et al., 1998; Saimiri ssp: Boinski et al., 2002; C. capucinus: Vogel, 2005; Macaca spp: Su \& Birky, 2007; Lemur catta: White et al., 2007; Gorilla beringei: Robbins, 2008; Erythrocebus patas: Nakagawa, 2008; Microcebus berthae e M. murinus: Dammhahn \& Kappeler, 2009). 
Esse resultado também corrobora a principal previsão dos modelos socioecológicos, que associa as características dos itens alimentares (distribuição discreta, alta qualidade nutricional e usurpabilidade) à intensidade de competição direta intra-grupo por alimento. É interessante observar que a taxa de interações agressivas foi maior no grupo aprovisionado $(\mathrm{CH})$ do que no grupo não-aprovisionado (ZA). Uma possível explicação para esse resultado pode ser a diferença de tamanho entre os dois grupos. Segundo Vogel e Janson (2007), primatas que vivem em grupos sociais pequenos enfrentam menos competição intra-grupo por alimento porque os indivíduos são capazes de se espalharem mais durante o forrageamento. Entretanto, o fato da maior parte das agressões no grupo $\mathrm{CH}$ ter ocorrido em contexto de alimento aprovisionado (acima do esperado pelo tempo dedicado à exploração desse recurso), sugere que o aprovisionamento de comida foi o maior responsável pelas diferenças entre grupos. Esse argumento é apoiado por estudos como os de Ferreira et al. (2008) e Izar \& Sato (1997), que relatam picos de agressão durante a distribuição de alimento aprovisionado em grupos de Cebus spp em semi-liberdade. A taxa de disputas por sítios de quebra (martelos, bigornas e itens submetidos ou resultantes da quebra) também ocorreu acima do esperado nos dois grupos. Esse último resultado é particularmente importante porque favorece a hipótese $2 \mathrm{~b}$ deste trabalho, de que o uso rotineiro de ferramentas pelos macacos-prego da BV reforça a competição direta intra-grupo por alimento. De fato, as taxas de agressão registradas neste estudo ( 0,13 episódios/indivíduo/hora de observação no grupo $\mathrm{CH}$ e 0,06 episódios/indivíduo/hora de observação no grupo ZA) foram maiores que as registradas para grupos de macacos-prego que não utilizam ferramentas; C. apella na Amazônia (0,02 ep/ind/h; Janson, 1985) e C. nigritus na Mata Atlântica (0,03 ep/ind/h; Nakai, 2007). Corroborando a previsão dos modelos, é possível concluir 
que as fêmeas de $C$. libidinosus da BV estiveram submetidas a forte competição direta intra-grupo por alimento.

Tradicionalmente, agressão entre fêmeas de grupos distintos é considerada um indicativo comportamental de competição direta entre grupos (Isbell, 1991). No entanto, autores como Snaith e Chapman (2007) argumentam que a não participação de fêmeas em encontros entre grupos não pode ser interpretada como ausência de competição direta por alimento entre grupos. Esses mesmos autores sugerem que a evitação e o estabelecimento de relações hierárquicas entre grupos distintos também devem ser considerados efeitos da competição direta entre grupos. No presente trabalho, foram observados todos os indicadores comportamentais de competição direta entre grupos descritos acima. Fêmeas adultas participaram de quase todos os encontros entre grupos comportando-se agressivamente em relação a membros dos outros grupos. De fato, o único episódio de encontro em que houve agressão física entre membros de grupos distintos contou com a participação exclusiva de fêmeas. Além disso, durante toda a pesquisa, o grupo ZA foi constantemente observado monitorando e evitando o grupo $\mathrm{CH}$, sendo que todos os episódios foram vencidos pelo grupo $\mathrm{CH}$, independente do local e contexto dos encontros. Em conjunto, esses resultados mostram que as fêmeas de macacos-prego da BV também enfrentaram competição direta entre grupos.

Contrariando os resultados encontrados para outras populações de Cebus ( $C$. capucinus: Perry, 1996a, Crofoot et al., 2008; C. nigritus: Izar, 2004), superioridade numérica parece ter sido o fator mais decisivo para o resultado de encontro entre grupos nesta população. Contudo, a importância de fatores demográficos, como o número de machos e fêmeas adultos no grupo, precisa ser mais bem avaliada nesta população. Foi interessante observar que, em todos os episódios de encontro entre o grupo ZA e outros grupos de machos, as fêmeas ameaçaram vigorosamente os "machos desconhecidos", 
mesmo nas situações em que alguns deles acompanharam o grupo por vários dias consecutivos. Reações similares foram observadas entre as fêmeas no grupo $\mathrm{CH}$ durante o processo de imigração de quatro machos subadultos oriundos do grupo ZA. O risco de infanticídio por machos invasores é apontado como uma importante pressão seletiva para organização social de primatas, levando ao desenvolvimento de contra-adaptações de fêmeas, como a defesa coletiva contra machos invasores (Hrdy 1979; Treves \& Chapman, 1996; van Schaik 1996; Izar et al., 2007).

Ajuste nas distâncias percorridas diariamente por grupos de primatas é considerado o principal indicador comportamental de competição indireta intra-grupo. Como em grupos maiores as fontes alimentares são depletadas mais rapidamente, todos os indivíduos precisam percorrer distâncias maiores para visitar mais fontes em um dia. Assim, o efeito da competição indireta intra-grupo ocorre em termos de dispêndio de energia em deslocamento, e afeta igualmente todos os membros do grupo. Entretanto, mudanças no padrão de coesão dos grupos sociais, no tempo despendido em alimentação e na dieta também podem indicar competição indireta intra-grupo (Snaith \& Chapman, 2007). Já mudanças no tamanho da área de uso e nas áreas exploradas mensalmente são indicativos de competição indireta entre grupos (Clutton-Brock \& Harvey, 1977; Isbell, 1991). De acordo com o modelo proposto por Isbell (1991), fêmeas primatas estarão submetidas a competição indireta intra-grupo quando o principal recurso alimentar apresentar distribuição discreta no ambiente, e a competição indireta entre grupos quando a abundância de alimento no ambiente for limitante para o sucesso reprodutivo das fêmeas. A autora também conclui que a competição direta e indireta co-variam, intra e entre grupos. Desta forma, se fêmeas de uma população de primatas estiverem submetidas a competição direta intra-grupo, necessariamente estarão submetidas também aos efeitos da competição indireta intra-grupo, e assim por diante. 
Por outro lado, van Schaik, (1989) e Sterck et al. (1997) consideram que a competição indireta entre grupos não afeta significativamente as relações sociais de fêmeas e predizem que competição direta e indireta podem variar independentemente.

Os resultados obtidos neste estudo não apóiam a previsão de que grupos maiores percorrem distâncias diárias maiores. Ao contrário, observou-se um padrão oposto a essa previsão, com o grupo menor (ZA) percorrendo distâncias maiores do que o grupo maior $(\mathrm{CH})$. Contudo, uma vez que o grupo $\mathrm{CH}$ recebeu provisões de alimentos durante toda pesquisa, é possível argumentar que o aprovisionamento mitigou o efeito da competição indireta, conseqüentemente, reduzindo a necessidade de percorrer longas distâncias para encontrar alimento para todos os membros do grupo. Além disso, mais do que percorrer longas distâncias no dia, é possível que os macacos-prego da BV tenham adotado outras estratégias para lidar com a competição indireta intra-grupo (p. ex., mudando de grupo coeso para um padrão de organização mais fluído: Izar, 2004; Alfaro-Lynch, 2007; Asensio et al., 2008; Snaith \& Chapman, 2008; Asensio et al., 2009, ou aumentando o tempo alocado à alimentação: Janson, 1987; Pazol \& Cords, 2005; Teichroeb \& Sicotte, 2009). Todavia, durante a duração da pesquisa, não foram observadas mudanças significativas no padrão de coesão do grupo, nem no tempo dedicado à atividade de alimentação entre os grupos ou estações. Uma explicação plausível é a de que alimentos de alto valor nutricional estiveram disponíveis o ano inteiro, embora os itens ofertados a cada período tenham variado ao longo do estudo. Essa hipótese é apoiada pela constatação de que a energia ingerida pelos animais (medida como IM) não variou entre grupos ou estação. Além disso, as distâncias diariamente percorridas foram positivamente correlacionadas ao tempo dedicado ao consumo de frutos e ao tempo de depleção de fruteira. Esses resultados mostram que os macacos-prego da BV percorrem longas distâncias nos dias em que se alimentam mais 
de recursos preferidos (frutos), exatamente no período em que esses recursos foram mais abundantes no ambiente, mais do que para manter o nível de ingestão calórica em grupos grandes ou durante redução da oferta dos alimentos preferidos. Desta forma, é possível concluir que as fêmeas de macacos-prego da BV não enfrentaram os efeitos da competição indireta intra-grupo.

O efeito da competição indireta entre grupos é esperado em termos de aumento no tamanho da área de uso e da área explorada mensalmente (Isbell, 1991). Aqui, o tamanho da área explorada mensalmente não variou entre grupos ou estação, nem foi afetado pelo padrão de atividades, dieta ou variáveis ecológicas, indicando que os macacos-prego da BV não estiveram submetidos aos efeitos da competição indireta entre grupos.

A análise dos regimes competitivos revelou que as fêmeas deste estudo enfrentaram forte competição direta, tanto intra, como entre grupos, mas são sofreram com os efeitos da competição indireta intra e entre grupos. Esses achados apóiam a previsão de van Schaik (1989) e Sterck et al. (1997) de que competição direta e indireta podem variar independentemente intra e entre grupos. Conforme o modelo proposto por Isbell (1991), deveria haver pouca ou nenhuma competição por alimento (conseqüentemente, pouca agressão intra-grupo e ausência de hierarquias de dominância) em situações em que o sucesso reprodutivo de fêmeas não é limitado pela oferta de alimento no ambiente. Os resultados encontrados neste trabalho, entretanto, sugerem que o sucesso reprodutivo das fêmeas da BV não foi limitado pela oferta de alimento no ambiente. Por exemplo, as fêmeas alimentaram-se de recursos de alto valor energético durante o ano inteiro, o intervalo entre partos (média de 22,2 meses) foi similar aos menores intervalos relatados para populações de Cebus selvagens (Robinson, 1988a; Di Bitetti \& Janson, 2001) e alta taxa de sobrevivência de filhotes 
(pelo menos até a idade de desmame). Além disso, eventos incomuns observados nessa população de estudo, como a adoção de um infante de outra espécie de primata por uma fêmea do grupo CH (Izar et al., 2006b) e dois nascimentos de gêmeos (um no grupo ZA e outro no $\mathrm{CH}$; Biondi, dados não publicados), reforçam esse argumento. Ainda assim, as fêmeas estiveram submetidas a forte competição direta intra-grupo e estabeleceram relações de dominância entre si, contrariando a previsão do modelo proposto por Isbell (1991).

Outro ponto de desacordo entre os modelos socioecológicos refere-se à influência da pressão de predação nas relações sociais de fêmeas primatas (Isbell \& Young, 2002). Para Isbell (1991), a distribuição e abundancia dos recursos alimentares é o que governa a competição entre fêmeas; o impacto do risco de predação está apenas indiretamente envolvido nas causas proximais de variação nas relações sociais de fêmeas (p. ex., através do efeito sobre o tamanho e a composição dos grupos sociais van Schaick \& Horstermann, 1994; Hill \& Lee, 1998). Já van Schaik (1989) e Sterck et al. (1997) sustentam que o risco de predação (em conjunto com as características dos recursos alimentares) afeta diretamente as relações entre fêmeas e propõem as seguintes previsões: (1) em ambientes com baixo risco de predação, os grupos sociais serão menos coesos e a densidade populacional será elevada, conseqüentemente, a competição entre grupos prevalecerá; (2) em ambientes onde o risco de predação é alto, os grupos sociais serão mais coesos e a competição por alimento intra-grupo será a variável mais importante. Os resultados obtidos nesta pesquisa mostram que a percepção do risco de predação pelos macacos da BV (taxa de vocalização e encontro com possíveis predadores) foi alta, embora nenhum episódio de predação tenha sido observado. A densidade populacional de macacos-prego observada na BV está entre as mais baixas relatadas para Cebus spp (Rylands, 1982; Terborgh, 1983; Torres de Assumpção, 1983; 
Peres, 1993; Pinto et al., 1993; Di Bitetti, 2001; Izar, 2004). Por fim, os grupos sociais foram coesos e a competição intra-grupo por alimento foi intensa. A princípio, esses resultados corroboram as previsões de van Schaik e Sterck e colaboradores acerca dos efeitos da pressão de predação. Contudo, é possível questionar que a baixa densidade de macacos-prego na BV seja um artefato de um padrão de utilização da área (uma vez que se pode observar na área de estudo que há regiões preferidas pelos macacos, como os morros e proximidades, e regiões pouco usadas, como as chapadas). Sendo assim, não é possível chegar a uma conclusão definitiva sobre esse assunto, já que a densidade populacional na BV pode ter sido afetada por outros fatores que não a pressão de predação.

O padrão de relações sociais entre fêmeas da BV correspondeu à síndrome social chamada de Residente-Nepotista-Tolerante, caracterizada por filopatria de fêmeas, relações de dominância, coalizões, catação e tolerância. Esse padrão é consistente com a previsão de Sterck et al. (1997) para populações submetidas a forte competição direta intra e entre grupos.

Embora filopatria de fêmeas e coesão social sejam consideradas a norma para primatas do gênero Cebus, trabalhos com diferentes populações vêm relatando migração de fêmeas entre grupos (C. capucinus: Jack \& Fedigan; 2009; C. nigritus: Izar, 2004; Alfaro-Lynch, 2007) e padrão de coesão grupal mais fluído, com divisão do grupo social em subgrupos de forrageamento menores (C. nigritus: Izar, 2004; Alfaro-Lynch, 2007; Nakai, 2007). Na BV, durante o período de estudo, não foi observado nenhum episódio de migração de fêmeas entre grupos ou qualquer desaparecimento que pudesse ser atribuído à dispersão de fêmeas (ao contrário dos machos), nem mudanças significativas no padrão de coesão dos grupos. Esses resultados indicam que fêmeas de 
C. libidinosus da BV são filopátricas (enquanto os machos transferem-se entre grupos) e os grupos sociais coesos.

Competição direta intra-grupo conduz à formação de hierarquia de dominância linear e estável (Wrangham, 1980; van Schaik, 1989; Isbell, 1991; Sterck et al., 1997). Coerentemente, as fêmeas da BV estabeleceram hierarquia de dominância estável (não houve reversão de postos), completamente linear no grupo ZA e quase linear no grupo CH. Esse resultado é consistente com o trabalho de Janson (1985), que encontrou que em C. apella a intensidade da competição direta por recursos com distribuição discreta resultou na formação de hierarquias de dominância lineares, e com vários estudos que mostraram que fêmeas primatas estabelecem hierarquias mais lineares quanto submetidas a forte pressão de competição direta por alimento (p. ex., Macaca spp: Su \& Birky; 2007; Hanya et al., 2008; Saimiri spp: Mitchell et al., 1991; Boinski et al., 2002; Pan troglodytes: Wittig \& Boesch, 2003; Semnopithecus entellus: Koenig, 2000; Presbytis entellus: Koenig et al., 1998; P. thomasi e M. fascicularis: Sterck \& Steenbeek, 1997; E. patas e C. aethiops: Nakagawa, 2008). Alguns trabalhos apontam que, em espécies do gênero Cebus, fêmeas dominantes têm maior sucesso reprodutivo (C. apella: Janson, 1984; C. olivaceous: O’Brien \& Robinson, 1993; C. capucinus: Rose \& Fedigan, 1995; Vogel, 2005). Aqui, a duração do intervalo entre partos não diferiu entre fêmeas de alto e baixo posto de dominância, nem entre fêmeas do grupo ZA e CH (Verderane, dados não publicados). Entretanto, dados longitudinais são necessários para avaliar se os postos hierárquicos das fêmeas afetam a duração do intervalo entre partos e a sobrevivência dos filhotes até a idade reprodutiva (esses dados continuam sendo coletados) na população da BV.

A competição direta entre grupos é um elemento importante de uma sociedade Residente-Nepotista-Tolerante (van Schaik, 1989; Sterck et al., 1997). Sendo assim, 
espera-se que as fêmeas de alta posição hierárquica sejam tolerantes em relação a fêmeas de posições mais baixas (permitindo que elas tenham acesso regular às fontes alimentares), como uma estratégia para garantir a ajuda dessas fêmeas durante encontros entre grupos (van Schaik, 1989; Sterck et al., 1997). Apesar das elevadas taxas de interação agonística e a formação de hierarquias de dominância lineares e estáveis, as fêmeas da BV podem ser consideradas tolerantes, já que as dominantes permitiram, com regularidade, que fêmeas de posições inferiores se alimentassem simultaneamente em fontes com distribuição discreta. Consistente com a hipótese $2 \mathrm{~b}$ deste trabalho, houve mais fêmeas alimentando-se juntas (mais tolerância entre elas) em palmeiras do que em sítios de quebra (bigornas). Paradoxalmente, a freqüência absoluta de interações agonísticas foi maior em palmeiras do que em fruteiras e bigornas, provavelmente, porque as palmeiras permitiram que um maior número de animais se alimentasse juntos a cada episódio. Contudo, as características morfológicas das palmeiras da BV (caule subterrâneo e produção de único cacho de frutos) proporcionaram aos animais uma situação na qual os recursos alimentares de alta qualidade encontravam-se concentrados em uma área com poucos sítios de alimentação (espaços individuais dentro da fonte Izar, 2004; Vogel \& Janson, 2007). Assim, na medida em que o número de animais alimentando-se em uma mesma palmeira aumentou, maiores também foram as chances de agressão, devido à excessiva aproximação de dominantes e subordinadas (assim como observado por Vogel \& Janson, op cit em C. capucinus). Por outro lado, as bigornas da BV apresentaram, geralmente, um único martelo disponível para quebra (Visalberghi et al., 2007) e exigiram que os animais coletassem o alimento em outro lugar e o transportassem até o sítio de quebra (Visalberghi et al., 2008; Visalberghi et al., 2009a; observação pessoal). Essas características (poucos martelos e alimentos disponíveis para a quebra) fizeram das bigornas fontes alimentares mais facilmente 
monopolizáveis por indivíduos dominantes (ou menos compartilháveis). Isso pode ter levado as fêmeas a adotarem uma estratégia de evitação em bigornas, já que o risco de interações agressivas em recursos monopolizáveis é muito elevado quando outro(s) indivíduo tenta utilizar o mesmo recurso simultaneamente. Esse último argumento é corroborado pelo fato das disputas em bigornas terem ocorrido acima do esperado pelo tempo dedicado ao uso de ferramentas, embora a freqüência absoluta de disputas em palmeiras tenha sido maior que em fruteiras e bigornas. Os resultados apresentados aqui são consistentes com a hipótese $2 \mathrm{~b}$ deste trabalho, de que o uso de ferramentas diminui a tolerância entre fêmeas e fortalece a competição direta intra-grupo.

Coalizões e catações entre fêmeas foram freqüentemente observadas ao longo deste estudo. Seguindo as previsões de Sterck et al. (1997) para uma sociedade Residente-Nepotista-Tolerante, as fêmeas de ambos os grupos participaram ativamente das coalizões, sendo que as coalizões entre fêmeas ocorreram, principalmente, em forma de defesa de recursos alimentares discretos. Embora as coalizões entre machos e fêmeas tenham sido também comuns, aparentemente, na população de estudo, a coalizão entre duas fêmeas foi um dos fatores que possibilitou a aquisição de postos de dominância mais elevados, como descrito para C. capucinus (Manson et al., 1999). As fêmeas também participaram ativamente das interações de catação com indivíduos de todas as classes de sexo/idade, porém, cataram preferencialmente seus próprios filhotes dependentes, fêmeas com filhotes novos e o macho dominante, tal como descrito para outras espécies de Cebus (Perry, 1996a; Izar, 1994; Verderane, 2005). Fêmeas cataram mais indivíduos de postos de dominância inferiores aos seus próprios, assim como observado em estudos prévios com outras espécies de Cebus (C. nigritus selvagens: Di Bitetti, 1997; C. olivaceus selvagens: O’Brien, 1993; C. apella cativo: Parr et al., 1997; Schino et al., 2009). 


\subsection{O uso de ferramentas e a socialidade}

A presente pesquisa testou a hipótese de que o uso rotineiro de ferramentas pode impactar o regime de competição por alimento e, conseqüentemente, as relações sociais entre fêmeas primatas de populações selvagens que utilizam ferramentas. As fêmeas desta pesquisa alimentaram-se principalmente de polpa de frutos (incluindo o mesocarpo de frutos de palmeiras), enquanto os alimentos acessados com auxílio de ferramentas representaram uma pequena parcela da dieta dos grupos. Para esse cenário, previu-se que o que uso de ferramentas poderia afetar o regime competitivo de duas maneiras: (1) reforçando a competição por alimento, se os sítios de uso de ferramentas dividissem as mesmas propriedades do principal recurso alimentar, ou (2) alterando o regime competitivo, se os sítios de ferramentas possuíssem propriedades distintas das do principal recurso alimentar. O principal alimento consumido pelas fêmeas (frutos de fruteiras e palmeiras) foi de alta qualidade nutricional, discretamente distribuído no ambiente e usurpável. Como previsto pela segunda hipótese desse trabalho, durante episódios de alimentação em palmeiras e fruteiras, as fêmeas foram mais tolerantes entre si, mais membros do grupo puderam se alimentar simultaneamente e por períodos mais longos, em comparação com as bigornas. Embora o tempo de depleção e o tamanho das unidades de alimentação em bigornas tenham sido menores, ainda assim, esses recursos foram usurpáveis. Mais do que isso, devido à limitada quantidade de martelos e alimentos disponíveis em cada sítio de quebra, as bigornas foram menos compartilháveis do que fruteiras e palmeiras. Assim, durante episódios de alimentação em bigornas, houve mais disputas (proporcionalmente ao esperado em relação ao tempo dedicado á utilização de ferramentas) e menos tolerância entre fêmeas. Esses resultados mostram que o impacto gerado pelo uso de ferramentas sobre o regime de competição por alimento e sobre as relações sociais das fêmeas $C$. libidinosus na BV ocorreu na 
mesma direção do regime de competição gerado pelos principais recursos alimentares (frutos). De fato, o impacto do uso de ferramentas sobre o regime competitivo foi ainda mais semelhante ao impacto gerado pelo alimento aprovisionado; reforçando a competição direta intra-grupo e diminuindo a tolerância social entre fêmeas.

Em conseqüência dos altos níveis de competição direta intra-grupo, as fêmeas da BV organizaram-se em hierarquias de dominância formais e muito lineares. Essa descoberta diverge de estudos prévios com outras espécies do gênero Cebus (Robinson, 1981; Janson, 1985; Hall \& Fedigan, 1997; Izar, 2004; Verderane, 2005; Izar et al., 2006; Izar \& Ferreira, 2007) que relatam hierarquias de dominância parciais (Izar et al., 2006a), com interações de dominância ausentes para um grande número de díades. Entre espécies de Cebus, fêmeas dominantes são conhecidas por possuírem maior sucesso reprodutivo em relação às subordinadas ( $C$. apella: Janson, 1984; $C$. olivaceous: O’Brien \& Robinson, 1993; C. capucinus: Rose \& Fedigan, 1995). Sendo assim, a longo prazo, o impacto do uso rotineiro de ferramentas sobre a competição direta intra-grupo por alimento pode ser traduzido em viés no sucesso reprodutivo entre fêmeas dominantes e subordinadas na população da BV.

Apesar desses resultados, o fato da estrutura social de C. libidinosus da BV não divergir significativamente da estrutura social de populações de Cebus que não utilizam ferramentas, mostra que uso de ferramentas por si só não altera significativamente os regimes de competição por alimento, nem a dinâmica das relações sociais de fêmeas. Estudos com populações que dependem predominantemente de recursos obtidos com auxílio de ferramentas são necessários para melhor avaliar o papel do uso de ferramentas na socioecologia de primatas. Por exemplo, a população de chimpanzés que habita a floresta de Taï, na Costa do Marfim, é conhecida por depender do uso de ferramentas como parte do forrageamento ao longo do ano inteiro (Boesch \& Boesch- 
Achermann, 2000). As fêmeas dessa população freqüentemente dividem o alimento obtido através de ferramentas com seus filhotes dependentes e também entre irmãos. Em Taï, a principal forma de uso de ferramenta em contexto alimentar é a quebra de cocos com pedras ou troncos, sendo que as nozes representam o principal alimento durante a estação seca. Boesch e Boesch-Achermann (2000) observaram que nos anos em que as nozes estiveram disponíveis para a quebra, os chimpanzés formaram subgrupos de forrageamento maiores e mais estáveis, e quanto maiores eram as fontes de nozes, maiores também eram os subgrupos.

Assim, é provável que as características dos sítios de quebra sejam a principal força modeladora dos regimes de competição por alimento e das relações sociais de fêmeas em populações que ocupam áreas onde os alimentos obtidos com auxílio de ferramentas são limitantes do sucesso reprodutivo das fêmeas. As recentes descobertas de populações selvagens de $C$. libidinosus que fazem uso de ferramentas em ecossistemas tão diversos como Cerrado, Caatinga e Mangue (Ottoni \& Izar, 2008) são animadoras para futuros estudos que objetivem investigar a relação entre uso de ferramentas, competição alimentar e relações sociais de fêmeas. 


\section{7-CONCLUSÕES}

1) As fêmeas da BV alimentaram-se predominantemente de recursos de alto valor energético, discretamente distribuídos no ambiente e potencialmente usurpáveis ao longo de toda a pesquisa.

2) Alimentos obtidos com auxílio de ferramentas representaram uma pequena proporção da dieta de fêmeas dos dois grupos.

3) $\mathrm{O}$ comportamento alimentar de fêmeas do grupo $\mathrm{CH}$ foi similar ao das fêmeas do grupo ZA, indicando que houve pouca influência do aprovisionamento de alimentos e água.

4) O tamanho das fontes alimentares de distribuição discreta variou entre intermediário a grande (em relação ao tamanho do grupo), sendo que, dentre elas, as palmeiras apresentaram maior tempo de depleção e unidades de alimentação. Ainda assim, tempo de depleção e tamanho de unidades de alimentação registrados para fruteiras e bigornas revelou que esses recursos também foram potencialmente usurpáveis.

5) Conforme as previsões do modelos socioecológicos para populações que se alimentam majoritariamente de recursos de alto valor energético, distribuição discreta e usurpáveis, as fêmeas da BV estiveram submetidas a forte competição direta intra e entre grupos por alimento, mas não sofreram os efeitos da competição indireta por alimento, tanto intra como entre grupos.

6) A percepção do risco de predação entre os macacos-prego da BV é alta, a densidade populacional está entre as mais baixas encontradas para espécies de Cebus, os grupos sociais são coesos e a competição intra-grupo por alimento é intensa. Esses resultados sugerem que o risco de predação afeta diretamente o padrão de relações sociais entre fêmeas. Entretanto, não foi possível chegar a uma conclusão definitiva sobre esse 
assunto, uma vez que a densidade populacional na BV pode ter sido afetada por outros fatores que não a pressão de predação.

7) O sistema social da população de estudo correspondeu à síndrome social ResidenteNepotista-Tolerante. Consistente com a previsão de Sterck e colaboradores (1997), as fêmeas da BV foram filopátricas, organizaram-se em hierarquias de dominância formais, lineares e estáveis e estabeleceram relações de catação e formação de coalizões.

8) De acordo com a hipótese $2 \mathrm{~b}$ deste trabalho, as características dos sítios de quebra foram similares às características do principal alimento consumido pelas fêmeas da BV (frutos). O impacto mais evidente do uso de ferramentas sobre os regimes competitivos e as relações sociais de fêmeas ocorreu na forma de intensificação da competição direta intra-grupo e diminuição da tolerância entre fêmeas.

9) A estrutura social de $C$. libidinosus na BV não divergiu consideravelmente da organização de populações de Cebus que não utilizam ferramentas, indicando que o uso de ferramentas não alterou significativamente os regimes competitivos, nem a dinâmica das relações entre fêmeas.

10) Estudos com populações que dependam predominantemente de alimentos extraídos com auxílio de ferramentas são fundamentais para melhor avaliar o impacto do uso de ferramentas sobre os regimes de competição por alimento e as relações sociais de fêmeas. 


\section{CONCLUSÃO GERAL}

A presente pesquisa é parte de um esforço para compreensão dos diversos sistemas sociais dos primatas humanos e não humanos sob a perspectiva evolucionista. A maior contribuição deste trabalho está na geração de informações sobre ecologia e comportamento de uma espécie de primata Neotropical ainda pouco conhecida, em um habitat onde estudos com primatas de vida livre são escassos. A incorporação do uso de ferramentas às previsões dos modelos socioecológicos também confere ao trabalho um caráter inovador.

Os principais resultados obtidos nesta pesquisa mostram que a área de ecótono Cerrado/Caatinga da Fazenda Boa Vista, no sul do Piauí, apresenta uma abundante oferta de alimento, ao contrário do que seria esperado para uma região com uma estação seca bem marcada, caracterizada por déficit hídrico acentuado (p. ex., Moura \& Lee, 2004). As principais atividades de C. libidinosus na BV foram a alimentação e a locomoção, e os principais alimentos consumidos foram polpa de frutos, seguido de invertebrados. Alimentos obtidos com ferramentas foram pouco freqüentes na dieta dos animais. O padrão de utilização de substratos foi particularmente interessante nessa população, especialmente em função do extensivo uso do chão, já que esses primatas são descritos como preferencialmente arborícolas. Além disso, o uso de cavernas como abrigo contra temperaturas elevadas e chuva é um comportamento raro entre primatas não humanos e precisa ser mais bem investigado. As fontes alimentares exploradas pelos macacos da BV são de tamanho intermediário a grande, com recursos de alto valor nutricional. Os animais estiveram submetidos a forte competição direta intra e entre grupos por alimento e o padrão relações sociais entre fêmeas corroborou as 
previsões dos modelos de van Schaik (1989) e Sterck et al., (1997) para primatas submetidos a esses regimes competitivos.

A comparação dos resultados encontrados na presente pesquisa com estudos realizados com populações de macacos-prego que não utilizam ferramentas para obtenção de alimento revela poucas diferenças no que se refere aos padrões de orçamento de atividades, dieta e estrutura social. Nesse sentido, diferenças e semelhanças observadas entre os macacos da BV e outros grupos de Cebus foram mais bem explicadas por variações em fatores ambientais. Ainda assim, é possível prever que relações mais evidentes entre uso de ferramentas, orçamento de atividades, dieta, competição alimentar e relações sociais de fêmeas sejam mais claras em populações que dependam prioritariamente de alimentos extraídos com ferramentas para sua sobrevivência e sucesso reprodutivo. Essa é uma linha investigativa promissora para pesquisas futuras, principalmente considerando as recentes descobertas de populações selvagens de $C$. libidinosus que fazem uso de ferramentas em ecossistemas tão diversos como Cerrado, Caatinga e Mangue (Ottoni \& Izar, 2008). 


\section{REFERÊNCIAS BIBLIOGRÁFICAS}

Alfaro-Lynch, J.W. (2007). Subgrouping patterns in a group of wild Cebus apella nigritus. Int J Primatol, 28: 271-289.

Alfaro-Lynch, J.W. (2008). Scream-embrace displays in wild black-horned capuchin monkeys. Am. J. Primatol, 70: 551-559.

Almeida SP. 1998. Frutas nativas do cerrado: caracterização físicoquímica e fonte potencial de nutrientes. Em: Cerrado: ambiente e flora. Sano, S.M., Almeida, S.P. (Eds). Planaltina, DF: EMBRAPA-CPAC, pp. 247-285.

Anderson, J. (1990). Use of objects as hammers to open nuts by capuchin monkeys (Cebus apella). Folia Primatol, 54: 138-145.

Asensio, N., Korstjens, A.H., Schaffner, C.M. \& Aureli, F. (2008). Intragroup aggression, fission-fusion dynamics and feeding competition in spider monkeys. Behaviour, 145: 983-1001.

Asensio, N., Korstjens, A.H. \& Aureli, F. (2009). Fissioning minimizes ranging costs in spider monkeys: a multiple-level approach. Behav Ecol Sociobiol, 63: 649-659.

Altmann, J. (1974). Observational study of behavior sampling methods. Behaviour, 49: 227-267.

Altmann, S.A. (2009). Fallback foods, eclectic omnivores, and the packaging problem. Am J Phys Anthropol, 140: 615-629.

Altmann, J. \& Muruthi, P. (1988). Differences in daily life between semi-provisioned and wild-feeding baboons. Am. J. Primatol, 15:213-221.

Aureli, F., Colleen, M., Schaffner, C.M., Boesch, C., Bearder, S.K., Colin, J.C., Chapman, A., Connor, R., Di Fiore, A., Dunbar, R.I.M., Henzi, S.P., Holekamp, K., Korstjens, A.H., Layton, R., Lee, P., Lehmann, J., Manson, J.H., Ramos- 
Fernandez, G., Strier, K.B. \& van Schaik, C.P. (2008). Fission-Fusion dynamics. Current Anthropology, 49(4): 627-654.

Baldovino, M.C. (2005). Los comportamientos aloparentales en los monos cai (Cebus apella) silvestres del Parque Nacional Iguazú, Argentina. Em: Anais do XI Congresso Brasileiro de Primatologia, pp. 55. Porto Alegre, RS.

Baldwin, J.D. \& Baldwin, J.I. (1972). The ecology and behavior of squirrel monkeys (Saimiri oerstedii) in a natural forest in western Panama. Folia primatol, 18: 161-184.

Bearder, S.K. (1987). Lorises, bushbabies, and tarsiers: Diverse societies in solitary foragers. Em: Primates Societies. Smuts, B.B., Cheney, D.L., Seyfarth, R.M., Wrangham, R.W., Struhasaker, T.T. (Eds). The University of Chicago Press, Chicago and London.

Beck, B. (1980). Animal Tool Behavior: The use and manufacture of tools by animals. New York: Garland Press. pag. 17.

Bezanson, M. (2009). Life history and locomotion in Cebus capucinus and Alouatta palliate. Am J Phys Anthropol, 140: 508-517.

Biben, M. (1998). Squirrel monkey play fighting: making the case for a cognitive training function for play. Em: Animal play: Evolutionary, comparative, and ecological perspectives. Beckoff, M. \& Byers, J. (Orgs.). Cambridge University Press. pp. 161-182.

Boesch, C. \& Boesch-Achermann, H. (2000). The chimpanzees of the Ta1" forest. Behavioural ecology and evolution. Oxford, Oxford University Press.

Boinski, S. (1987b). Habitat use by squirrel monkeys (Saimiri oerstedi) in Costa Rica. Folia Primatol, 49: 151-167. 
Boinski, S. (1989). The positional behavior and substrate use of squirrel monkeys: ecological implications. J. Hum. Evol, 18: 659-677.

Boinski, S. (1999). The social organizations of squirrel monkeys: implications for ecological models of social evolution. Evol Anthropol, 8: 101-112.

Boinski, S., Sughrue, K., Selvaggi, L., Quatrone, R., Henry, M. \& Cropp, S. (2002). An expanded test of the ecologicalmodel of primate social evolution: competitive regimes and female bonding in three species of squirrel monkeys (Saimiri oerstedii, S. boliviensis and S. sciureus). Behaviour, 139: 227-261.

Brennan, E. J., Else, J. G., \& Altmann, J. (1985). Ecology and behaviour of a pest primate: Vervet monkeys in a tourist lodge habitat. Afr. J. Ecol. 23: 35-44.

Bronikowski A.M. \& Altmann J. (1996). Foraging in a variable environment: weather patterns and the behavioural ecology of baboons. Behav Ecol Sociobiol, 39: 1125.

Brown, A.D. \& Zonino, G.E. (1990). Dietary variability in Cebus apella in extreme habitats: evidence for adaptability. Folia Primatol, 54 (3-4): 187-195.

Di Bitetti, M.S. (1997). Evidence for an important role of allogrooming in a platyrrhine primate. Anim Behav, 54: 199-211.

Di Bitetti, M.S. (2001). Home-range use by the tufted capuchin monkey (Cebus apella nigritus) in a subtropical rainforest of Argentina. J. Zool. Lond, 253: 33-45.

Di Bitetti, M.S. \& Janson, C. (2001a). Reproductive socioecology of tufted capuchins (Cebus apella nigritus) in northeastern Argentina. Int J Primatol, 22(2): 127142.

Carosi, M. \& Visalberghi, E. (2002). Analysis of tufted capuchin (Cebus apella) courtship and sexual behavior repertoire: changes throughout the female cycle and female interindividual differences. Am. J. Primatol, 118: 11-24. 
Chapman, C.A. \& Rothman, J.M. (2009). Within-species differences in primate social structure: evolution of plasticity and phylogenetic constraints. Primates, 50:1222.

Clutton-Brock, T.H. \& Harvey, P.H. (1977). Primate ecology and social organization. $J$ Zool Soc Lond, 183: 1-39.

Cords, M. (1987). Mixed species association of Cercopithecus monkeys in the Kakamega Forest, Kenya. Univ. Calif. Publ. Zool. Berkeley, University of California Press, 117: 1-109.

Coussi-Korbel, S. \& Fragaszy, D.M. (1995). On the relation between social dynamics and social learning. Anim Behav, 50: 1441-1453.

Crofoot, M.C., Gilby, I.C., Wikelski, M.C. \& Kays, R.W. (2008). Interaction location outweighs the competitive advantage of numerical superiority in Cebus capucinus intergroup contests. PNAS 105(2): 577-581.

Crook, J.H. \& Gartland, J.S. (1966). On the evolution of primate societies. Nature, 210: 1200-1203.

Dammhahn, M. \& Kappeler, P.M. (2009). Females go where the food is: does the socioecological model explain variation in social organisation of solitary foragers? Behav Ecol Sociobiol, 63: 939-952.

Defler, T.R. (1995). The time budget of a group of wild woolly monkeys (Lagothrix lagotricha). Int. J. Primatol, 16:107-120.

Defler, T.R. (1996). Aspects of the ranging pattern in a group of wild woolly monkeys (Lagothrix lagothricha). Am. J. Primatol, 38: 289-302.

Di Fiore, A. \& Rendall, D. (1994). Evolution of social organization: a reappraisal for primates by using phylogenetic methods. Proc. Natl. Acad. Sci. 91: 9941-9945. 
Dunbar, R.I.M. (1988). Primate social systems. Cornell University Press, Ithaca, New York.

Dunbar, R.I.M. (1992b) Time: a hidden constraint on the behavioural ecology of baboons. Behav Ecol Sociobiol, 31: 35-49.

Eberle, M. \& Kappeler, P.M. (2002). Mouse lemurs in space and time: a test of the socioecological model. Behav Ecol Sociobiol, 51: 131-139.

Enstam. K.L. \& Isbell, L.A. (2004). Microhabitat preference and vertical use of space by Patas Monkeys (Erythrocebus patas) in relation to predation risk and habitat structure. Folia Primatol, 75: 70-84.

Fa, J.E. (1986). Use of time and resources by provisioned troops of monkeys: Social behavior, time and energy in the barbary macaque (Macaco sylvanus I.) at Gibraltar. Em: Contributions to Primatology Vol. 23, Karger, Basel.

Fashing,P.J., Mulindahabi, F., Gakima, J., Masozera, M., Mununura, I., Plumptre, A.J. \& Nguyen, N. (2007). Activity and ranging patterns of Colobus angolensis ruwenzorii in Nyungwe Forest, Rwanda: Possible Costs of large group size. Int J Primatol, 28(3): 529-550.

Fedigan, L.M. (1993). Sex differences and intersexual relations in adult white-faced capuchins (Cebus capucinus). Int J Primatol, 14: 853-877.

Ferreira, R.G., Resende B.D., Mannu, M., Ottoni, E.B. \& Izar, P. (2002). Bird predation and prey-pransference in brown capuchin monkeys (Cebus apella). Neotropical Primates, 10: 84-89.

Ferreira, R.G., Izar, P. \& Lee, P.C. (2006). Exchange, affiliation, and protective interventions in semifree-ranging brown capuchin monkeys (Cebus apella). Am. J. Primatol, 68: 765-776. 
Ferreira, R.G., Lee, P.C. \& Izar, P. (2008). Food competition in a semi-free-ranging Cebus apella group. Folia Primatol, 79: 463-475.

Ferreira, R.G, Emidio, R.A. \& Jerusalinsky, L. (2010). Three stones for three seeds: natural occurrence of selective tool use by capuchins (Cebus libidinosus) based on an analysis of the weight of stones found at nutting sites. Am. J. Primatol, 72(3): 270-275.

Fleagle, J.G. (1999). Primate Adaptation and Evolution. $2^{\circ}$ Edição. London: Academic Press.

Fox, E.A., Sitompul, A.F. \& van Schaik, C.P. (1999). Intelligent tool use in wild Sumatran orangutans. Em: The mentalities of gorillas and orangutans. Parker, S.T., Mitchell, R.W., Miles, H.L. (Eds.). Cambridge: Cambridge University Press. pp. 99-116.

Fox, E.A., van Schaik, C.P., Sitompul, A. \& Wright, D.N. (2004). Intra-and interpopulational differences in orangutan (Pongo pygmaeus) activity and diet: implications for the invention of tool use. Am J Phys Anthropol, 125: 162-174.

Fragaszy, D.M. (1986). Time budgets and foraging behavior in wedge-capped capuchins (Cebus olivaceus): Age and sex differences. Em: Current Perspectives in Primate Social Dynamics.Taub, D.M., King, F.A. (Eds.), Van Nostrand Reinhold, New York, pp. 159-174.

Fragaszy, D.M. (1990a). Age and sex differences in the organization of behavior in wedge-capped capuchins, (Cebus olivaceus). Behav. Ecol, 1: 81-94.

Fragaszy, D.M. (1990b). Early behavioral development in capuchins (Cebus). Folia Primatol, 54: 119-128.

Fragaszy, D.M., Baer, J. \& Adams-Curtis, L. (1991). Behavioral development and maternal care in tufted capuchins (Cebus apella) and squirrel monkeys (Saimiri 
sciureus) from birth through seven months. Developmental Psychobiology, 24 (6): 375-393.

Fragaszy, D.M. \& Boinski, S. (1995). Patterns of individual diet choice and efficiency of foraging in wedge-capped capuchin monkeys (Cebus olivaceus). Journal of Comparative Psychology, 109(4): 339-348.

Fragaszy, D.M. \& Bard, K. (1996). Comparison of development and life history in Pan and Cebus. Int J Primatol, 18(5): 683-701.

Fragaszy, D.M. \& Adams-Curtis, L.E. (1997). Developmental changes in manipulation in tufted capuchins (Cebus apella) from birth through 2 years and their relation to foraging and weaning. Journal of Comparative Psychology, 111(2): 201-211.

Fragaszy, D.M. \& Adams-Curtis, L.E. (1998). Growth and reproduction in captive tufted capuchins (Cebus apella). Am. J. Primatol, 44(3): 197-203.

Fragaszy, D.M., Visalberghi, E. \& Fedigan, L. (2004a). The complete capuchin. Cambridge: Cambridge University Press.

Fragaszy, D.M., Izar, P., Visalberghi, E., Ottoni, E.B. \& Oliveira, M.G. (2004b). Wild capuchin monkeys (Cebus libidinosus) use anvils and stone pounding tools. Am J Primatol, 64(4): 359-366.

Freese, C.H. \& Oppenheimer, J.R. (1981). The Capuchin Monkeys, Genus Cebus. Em: Ecology and Behaviour of Neotropical Primates, vol. 1. Coimbra-Filho, A.F. \& Mittermeier, R.A. (Eds). Academia Brasileira de Ciências, Rio de Janeiro.

Galetti, M. \& Pedroni, F. (1994). Seasonal diet of capuchin monkeys (Cebus apella) in a semideciduous forest in south-east Brazil. J Trop Ecol, 10(1): 27-39.

Garber, P.A. (1987). Foraging strategies among living primates. Ann Rev Anthropol, 16: 339-364. 
Garber, P.A. \& Leigh, S.R. (1997). Ontogenetic variation in small-bodied New World primates: implications for patterns of reproduction and infant care. Folia Primatol, 68: 1-22.

Gillespie T.R. \& Chapman, C.A. (2001). Determinants of group size in the red colobus monkey (Procolobus badius): an evaluation of the generality of the ecologicalconstraints model. Behav Ecol Sociobiol, 50:3 29-338.

Gould, L., Fedigan, L.M. \& Rose, L.M. (1991). Why be vigilant? The case of the alpha animal. Int J Primatol, 18(3): 401-414.

Gouveia, P.S. (2009). Padrão de atividades, deita e uso do espaço de um grupo de Cebus xanthorsternos (Wied-Neuwies, 1820) (Primates, Cebidae), na Reserva Biológica de Una, Bahia, Brasil. Dissertação de mestrado. Universidade Estadual de Santa Cruz.

Goldizen, A.W. (1987a). Facultative polyandry and the role of infant-carrying in wild saddlebacktamarins (Saguinus fuscicollis). Behav. Ecol. Sociobiol, 20: 99-109.

Groves, C.P. (2001). Primate taxonomy. Washington, D.C. Smithsonian Institution Press.

Guimarães, M.G. \& Silva, M.S. (2008). Valor nutricional e características químicas e físicas de frutos de murici-passa (Byrsonima verbascifolia). Ciênc Tecnol Aliment Campinas, 27(1): 787-792.

Gursky, S. (2000). Effect of Seasonality on the Behavior of na Insectivorous Primate, Tarsius spectrum. Int J Primatol, 21(3): 477-495.

Hall, C.L. \& Fedigan, L.M. (1997). Spatial benefits afforded by high rank in whitefaced capuchins. Anim Behav, 53: 1069-1082.

Hamilton, W.J. (1985). Demographic consequences of a food and water shortage to desert Chacma Baboons, Papio ursinus. Int J Primatol, 6(5): 451-462. 
Hanya, G. (2004). Seasonal variations in the activity budget of Japanese macaques in the coniferous forest of Yakushima: effects of food and temperature. Am $J$ Primatol, 63:165-177.

Hanya, G., Matsubara, M., Hayaishi, S., Zamma, K., Yoshihiro, S., Kanaoka, M.M., Sugaya, S., Kiyono, M., Nagai, M., Tsuriya, Y., Hayakawa, S., Suzuki, M., Yokota, T., Kondo, D. \& Takahata, Y. (2008). Food conditions, competitive regimes, and female social relationships in Japanese macaques: withinpopulation variation on Yakushima. Primates, 49: 116-125.

Harcourt, A.H. (1981). Intermale competition and the reproductive behavior of the great apes. Em: Reproductive Biology of the Great Apes. Graham, C.E. (Ed). pp. 301318. New York: Academic Press.

Harris, T.A. (2006). Between-group contest competition for food in a highly folivorous population of black and white colobus monkeys (Colobus guereza). Behav Ecol Sociobiol, 61: 317-329.

Hershkovitz, P. (1955). Notes on american Monkeys of the Genus Cebus. Journal of Mammalogy, 36(3): 449-452.

Hill1, R.A. \& Lee, P.C. (1998). Predation risk as an influence on group size in cercopithecoid primates: implications for social structure. J. Zool., Lond, 245: 447-456.

Hirsch, B.T. (2002). Social monitoring and vigilance behavior in brown capuchin monkeys (Cebus apella). Behav Ecol Sociobiol, 52: 458-464.

Hrdy, S.B. (1979). Infanticide among animals: a review, classipcation and examination of the implications for the reproductive strategies of females. Ethol Sociobiol, 1: $13-40$. 
Isbell, L.A. (1991). Contest and screamble competition: patterns of female aggression and ranging bahavior in primates. Behav Ecol, 2: 143-133.

Isbell, L.A. (1994). Predation on primates: ecological patterns and evolutionary consequences. Evol. Anthropol, 3: 61-71.

Isbell, L.A. \& Van Vuren, D. (1996). Differential costs of locational and social dispersal and their consequences for female group-living primates. Behaviour, 133: 1-36.

Isbell, L.A., Pruetz, J.D. \& Young, T.P. (1998). Movements of adult female vervets (Cercopithecus aethiops) and patas monkeys (Erythrocebus patas) as estimators of food resource size, density, and distribution. Behav Ecol Sociobiol, 42: 123133.

Isbell, L.A. \& Young, T.P. (2002). Ecological models of female social relationships in primates: similarities, disparities, and some directions for future clarity. Behaviour, 139: 177-202.

Iwamoto, T. \& Dunbar, R.I.M. (1983). Thermoregulation, habitat quality and the behavioural ecology of Gelada Baboons. Journal of Animal Ecology, 52(2): 357366.

Izar, P. (1994). Análise da estrutura social de um grupo de macacos-prego (Cebus apella) em semi-cativeiro. Dissertação de mestrado. Departamento de Psicologia Experimental. Universidade de São Paulo.

Izar, P. \& Sato, T. (1997). Influência da abundância alimentar sobre a estrutura de espaçamento interindividual e relações de dominância em um grupo de macacosprego (Cebus apella). Em: A primatologia no Brasil vol. 5. Ferrari, S.F., Schneider, H. (Eds). Editora Universitária UFPA, Belém. pp. 249-267. 
Izar, P. (2004). Female social relationships of Cebus apella nigritus in a southeastern Atlantic forest: an analysis through ecological models of primate social evolution. Behaviour, 141: 71-99.

Izar P, Ferreira, R.G. \& Sato, T. (2006). Describing the organization of dominance relationships by dominance directed tree methods. Am J Primatol, 68: 189-207.

Izar, P., Verderane, M.P., Visalberghi, E., Ottoni, E.B., Oliveira, M.G., Shirley, J. \& Fragaszy, D.M. (2006). Cross-genus adoption of a marmoset (Callithrix jacchus) by wild capuchin monkeys (Cebus libidinosus): case report. Am J Primatol, 68:692-700.

Izar, P \& Ferreira, R.G. (2007). Socioecologia de macacos-prego (Cebus spp) selvagens e provisionados: uma análise comparativa. Em: A primatologia no Brasil, vol. 10. Bicca-Marques, J.C (Ed.). Sociedade Brasileira de Primatologia, Porto Alegre, RS; pp. 323-338.

Izar, P., Ramos da Silva, E.D., Resende, B.D. \& Ottoni, E.B. (2007). A case of infanticide in tufted capuchin monkeys (Cebus nigritus). Mastozoologia Neotropical, (14): 73-76.

Izawa, K. (1979). Foods and feeding behavior of wild black-capped capuchin (Cebus apella). Primates, 20: 57-76.

Izawa, K. (1980). Social behavior of wild black-capped capuchin (Cebus apella). Primates, 21(4): 443-467.

Jack, K. (2001). Life history patterns of male white-faced capuchins (Cebus capucinus): Male-bonding and the evolution of multimale groups. Doctoral dissertation, University of Alberta.

Jack, K.M. \& Fedigan, L.M. (2009). Female dispersal in a female-philopatric species, Cebus capucinus. Behaviour, 146: 471-497. 
Janson, C.H. (1984). Female choice and mating system of the brown capuchin monkey Cebus apella (Primates: Cebidae). Z Tierpsycol, 65: 177-200.

Janson, C.H. (1985). Aggressive competition and individual food consumption in wild brown capuchin monkeys (Cebus apella). Behav Ecol Sociobiol, 18: 125-138.

Janson, C.H. (1988). Food competition in brown capuchin monkeys (Cebus apella): quantitative effects of group size and tree productivity. Behaviour, 10: 53-76.

Janson, C.H. (1990a). Ecological consequences of individual spatial choice in foraging groups of brown capuchin monkeys, Cebus apella. Anim Behav, 40: 922-934.

Janson, C.H. (1990b). Social correlates of individual spatial choice in foraging groups of brown capuchin monkeys, Cebus apella. Anim Behav, 40: 910-921.

Janson, C.H. (2000). Primate socio-ecology: the end of a golden age. Evol Anthropol, 9: 73-86.

Janson, C.H, Goldsmith, M.L. (1995). Predicting group size in primates: foraging costs and predation risks. Behav Ecol, 6: 326-336.

Janson, C.H. \& van Schaik, C.P. (1988). Recognizing the many faces of primates food competition: methods. Behaviour, 105: 165-186.

Janson, C.H. \& van Schaik, C.P. (1993). Ecological risk aversion in juvenile primates: slow and steady wins the race. Em: Juvenile Primates Pereira, M., Fairbanks, L. (Eds). pp. 62-73. New York: Oxford University Press.

Kappeler, P.M. (1997b). Intrasexual selection in Mirza coquereli: Evidence for scramble competition polygyny in a solitary primate. Behav. Ecol. Sociobiol, 41: 115-128.

Kappeler, P.M. (1999). Convergence and divergence in primate social systems. Em: Primate communities. Fleagle, G, Janson, C.H., Reed, K. (Eds.). Cambridge University Press. pp. 158-170. 
Kappeler, P.M. \& van Schaik, C.P. (2002). Evolution of primates social systems. Int J Primatol, 20(4): 707-740.

Koenig, A., Beise, J., Chalise, M.K. \& Ganzhorn, J.U. (1998). When females should contest for food: testing hypotheses about resource density, distribution, size and quality with hanuman langurs (Presbytis entellus). Behav Ecol Sociobiol, 42: 225-237.

Koenig, A. (2000). Competitive regimes in forest-dwelling hanuman langur females (Semnopithecus entellus). Behav Ecol Sociobiol, 48:93-109.

Kosheleff1, V.P \& Christian N.K. \& Anderson, C.N.K. (2009). Temperature's influence on the Activity budget, terrestriality, and sun exposure of chimpanzeesin the Budongo Forest, Uganda. Am J Phys Anthropol, 139: 172-181.

Liu, Q., Simpson, K., Izar, P., Ottoni, E., Visalberghi, E. \& Fragaszy, E. (2009). Kinematics and energetics of nut-cracking in wild capuchin monkeys (Cebus libidinosus) in Piauí, Brazil. Am J Phys Anthropol, 138(2): 210-220.

Lynch, J.W. \& Rímoli, J. (2000). Demography and social structure of a group of Cebus apella nigritus (Goldfuss, 1809, Primates/Cebidae) at Estação Biológica de Caratinga, Minas Gerais. Neotropical Primates, 8(2): 44-49.

Mannu, M. \& Ottoni, E.B. (2009). The enhanced tool-kit of two groups of wild bearded capuchin monkeys in the caatinga: tool making, associative use, and secondary tools. Am J Primatol, 71: 242-251.

Manson, J.H., Rose, L.M., Perry, S. \& Gros-Louis, J. (1999). Dynamics of femalefemale relationships in wild Cebus capucinus: data from two Costa Rica sites. Int J Primatol, 20: 679-706.

Marshall, A.J \& Wrangham, R.W. (2007). Evolutionary consequences of fallback foods. Int J Primatol, 28: 1219-1236. 
Masi, S., Cipolletta, C. \& Robbins, M.M. (2009). Western Lowland Gorillas (Gorilla gorilla gorilla) Change Their Activity Patterns in Response to Frugivory. Am J Primatol, 71: 91-100.

Matheson, M.D., Johnson, J.S. \& Feuerstein, J. (1996). Male reunion displays in tufted capuchin monkeys (Cebus apella). Am J Primatol, 40: 183-188.

Matthews, L.J. (2009). Activity patterns, home range size, and intergroup encounters in Cebus albifrons support existing models of capuchin socioecology. Int $J$ Primatol, 30: 709-728.

McCabe, M.G. \& Fedigan, L.M. (2007). Effects of reproductive status on energy intake, ingestion rates, and dietary composition of female Cebus capucinus at Santa Rosa, Costa Rica. Int J Primatol, 28: 837-851.

McGrew, W.C. (1992). Chimpanzee material culture: Implications for human evolution. Cambridge, Cambridge University Press.

Mendes, S.L. 1989. Estudo ecológico de Alouatta fusca (Primates: Cebidae) na Estação Biológica de Caratinga, MG. Revista Nordestina de Biologia, 6: 71-104.

Milton, K. (1980). The Foraging Strategy of Howler Monkeys: A Study in Primate Economics. Columbia University Press, New York.

Milton, K. (1980). Physiological Ecology of Howlers (Alouatta): Energetic and Digestive considerations and comparison with the Colobinae. Int J Primatol, 19(3): 513-548.

Mitchell, C.L., Boinski, S. \& van Schaik, C.P. (1991). Competitive regimes and female bonding in two species of squirrel monkeys (Samiri oerstedi and S. sciureus). Behav Ecol Sociobiol, 28: 55-60. 
Mittermeier, R.A. \& Coimbra-Filho, A.C. (1982). Distribution and conservation of New World primate species used in biomedical research. Em: Reproduction in New World Primates. Hearn, J. (Ed). MTP press, Hingham.

Monteiro da Cruz, M.A.O. (1998). Dinâmica reprodutiva de uma população de sagüido-nordeste (Callithrix jacchus) na Estação Ecológica do Tapacurá, Pernambuco. Tese de Doutorado. Departamento de Psicologia Experimental, Instituto de Psicologia, Universidade de São Paulo.

Moura, A.C.A (2004). The capuchin monkey and the caatinga dry forest: a hard life in a harsh habitat. Tese de Doutorado. University of Cambridge, Cambridge (UK).

Moura, A.C.A. \& Lee, P.C. (2004). Capuchin stone tool use in caatinga dry forest. Science, 306(5703): 1909-1910.

Moura, A.C.A. (2007). Stone banging by wild capuchin monkeys: an unusual auditory display. Folia Primatol, 78: 36-45.

Nakagawa, N. (2008). Despotic wild patas monkeys (Erythrocebus patas) in Kala Maloue, Cameroon. Am J Primatol, 70: 238-246.

Nakai, E.S. (2007). Fissão-fusão em Cebus nigritus: flexibilidade social como estratégia de ocupação de ambientes limitantes. Dissertação de mestrado apresentado ao Instituto de Psicologia da Universidade de São Paulo.

Napier, J.R. \& Napier, P.H. (1967). A Handbook of living primates. Academic Press, New York.

Nicolson, N.A. (1987). Infants, mothers, and other females. Em: Primates Societies. Smuts, B.B., Cheney, D.L., Seyfarth, R.M., Wrangham, R.W., Struhasaker, T.T. (Eds). pp. 330-342. The University of Chicago Press, Chicago and London.

Nishida, T. \& Hiraiwa-Hasegawa, M. (1987). Chimpanzees and bonobos: cooperative relationships among males. Em: Primates Societies. Smuts, B.B., Cheney, D.L., 
Seyfarth, R.M., Wrangham, R.W., Struhasaker, T.T. (Eds). The University of Chicago Press, Chicago and London.

Nishimura, A., Fonseca, G.A.B., Mittermeier, R.A., Young, A.L., Strier, K.B. \& Valle, C.M.C. (1988). The muriqui, genus Brachyteles. Em: Ecology and Behaviour of Neotropical Primates, vol. 2. Mittermeier, R.A., Rylands, A.B. Coimbra-Filho, A.F., Fonseca, G.A.B. (Eds). World Wildlife Fund, Washington.

O'Brien, T.G. (1993). Allogrooming behavior among adult female wedge-capped capuchin monkeys. Anim Behav, 46: 499-510.

O'Brien, T.G \& Robinson, J.G. (1993). Stability of social relationships in female wedge-capped capuchin monkeys. Em: Juvenile primates. Pereira, M., Fairbanks, M. (Eds). Oxford, Oxford University Press, pp. 197-210.

Oates, J. F. (1977a). The guereza and its food. Em: Primate Ecology: Studies of feeding and ranging behavior in lemurs, monkeys and apes. Clutton-Brock, T.H. (Ed). Academic Press, New York, pp. 275-321.

Ottoni, E.B. \& Mannu, M. (2001). Semifree-ranging tufted capuchins (Cebus apella) spontaneously use tools to crack open nuts. Int J Primatol, 22: 347-358.

Ottoni, E.B., Resende, B.D., \& Izar, P. (2005). Watching the best nutcracking: what capuchin monkeys (Cebus apella) know about other's tool-using skills. Animal Cognition, 24: 215-219.

Ottoni, E.B \& Izar, P. (2008). Capuchin monkey tool use: overview and implications. Evol Anthropol, 17: 171-178.

Panger, M. A., Perry, S., Rose, L., Gros-Louis, J., Vogel, E., Mackinnon, K. C., \& Baker, M. (2002). Cross-site differences in foraging behavior of white-faced capuchins (Cebus capucinus). Am J Phys Anthropol, 119: 52-66. 
Parr, A.L., Matheson, M.D., Bernstein, I.S \& de Wall, F.B.M. (1997). Grooming down the hierarchy: allogrooming in captive brown capuchins monkeys, Cebus apella. Anim Behav, 54: 361-367.

Paukner, A. \& Suomi, S.J (2009). Sex differences in play behavior in juvenile tufted capuchin monkeys (Cebus apella). Primates, 49: 288-291.

Pazol, K. \& Cords, M. (2005). Seasonal variation in feeding behavior, competition and female social relationships in a forest dwelling guenon, the blue monkey (Cercopithecus mitis stuhlmanni), in the Kakamega Forest, Kenya. Behav Ecol Sociobiol, 58: 566-577.

Peres, C.A. (1993). Structure and spatial organization of an Amazonian terra firme forest primate community. J Trop Ecol, 9: 259-276.

Peres, C.A. (1994). Primate responses to phenological changes in an Amazonian terra firm forest. Biotropica, 26(1): 98-112.

Perry, S. (1996a). Intergroup encounters in wild white-faced capuchins (Cebus capucinus). Int J Primatol, 17(3): 309-330.

Perry, S. (1997). Male-female social relationships in wild white-faced capuchins (Cebus capucinus). Behaviour, 134: 477-510.

Pinto, L.P.S., Costa, C.M.R., Strier, K.B. \& Fonseca, G.A.B. (1993). Habitat, density and group size of primates in a Brazilian tropical forest. Folia Primatol, 61: 135143.

Post, D.G. (1981). Activity patterns of yellow baboons (Papio cynocephalus) in the Amboseli National Park, Kenya. Anim Behav, 29: 357-374.

Post, D.G., Hausfater, G. \& McCuskey, S.A. (1980). Feeding behavior of yellow baboons (Papio cynocephlaus): relationship to age, gender and dominance rank. Folia Primatol, 34: 170-195. 
Presotto, A. (2009). Mapas Cognitivos de primatas: análise de movimentos e rotas de Cebus apella nigritus apoiada por sistemas de informação geográfica. Tese de Doutorado. Departamento de Geografia, Faculdade de Filosofia Letras História e Ciências Sociais USP.

Pruetz, J.D. \& Isbell, L.A. (2000). Correlations of food distribution and patch size with agonistic interactions in female vervets (Chlorocebus aethiops) and patas monkeys (Erythrocebus patas) living in simple habitats. Behav Ecol Sociobiol, 49: 38-47.

Ramos da Silva, E. D. (2008). Escolha de alvos coespecíficos na observação do uso de ferramentas por macacos-prego (Cebus libidinosus) selvagens. Dissertação de Mestrado. Departamento de Psicologia Experimental, Instituto de Psicologia, Universidade de São Paulo.

Recabarren, M.P., Vergara, M., Gordon, K. \& Serón-Ferré, M. (2000). Impact of lactation upon fertility in the new world primate capuchin monkey (Cebus apella). Journal of Medical Primatology, 29: 350-360.

Reichard, U.H. (2003). Social monogamy in gibbons: the male perspective. Em: Monogamy. Reichard, U.H., Boesch, C. (Eds). Cambridge: Cambridge University Press. pp. 190-213.

Rendall, D. \& Di Fiore, A. (2007). Homoplasy, homology, and the perceived special status of behavior in evolution. J Hum Evol, 52: 504-521.

Resende, B.D. (2004). Ontogenia do comportamentos manipulativos em um grupo de macacos-prego (Cebus apella) em situação de semi-liberdade. Tese de doutorado. Departamento de Psicologia Experimental, Instituto de Psicologia, Universidade de São Paulo. 
Resende, B.D., Grecco, V.L.G., Ottoni, E.B. \& Izar, P. (2003). Some observations on the predation of small mammals by tufted capuchin monkeys (Cebus apella). Neotropical Primates, 11(2): 103-104.

Resende, B.D., Ottoni, E.B. \& Fragaszy D.M. (2008). Ontogeny of manipulative behavior and nut-cracking in young tufted capuchin monkeys (Cebus apella): a Perception-action perspective. Developmental Science, 11(6): 828-840.

Rímoli, J. (2001). Ecologia de macacos-prego (Cebus apella nigritus, Goldfuss, 1809) na Estação Biológica de Caratinga (MG): Implicações para a conservação de fragmentos de Mata Atlântica. Dissertação de mestrado. Universidade do Pará. Belém do Pará.

Rímoli, J., Strier, K.B. \& Ferrari, S.F (2008). Seasonal and longitudinal variation in the behavior of free-ranging black tufted capuchins cebus nigritus (goldfuss, 1809) in a fragment of atlantic forest in southeastern brazil. Em: A primatologia no brasil Vol. 9. Ferrari, S.F., Rímoli, J. (Eds). Aracaju.

Robbins, M.M. (2008). Feeding competition and agonistic relationships among bwindi gorilla beringei. Int J Primatol, 29: 999-1018.

Robinson, J.G. (1981). Spatial structure in foraging groups of wedge-capped capuchin monkeys Cebus nigrivittatus. Anim Behav, 29: 1036-1056.

Robinson, J.G. (1984a). Diurnal-variation in foraging and diet in the wedge-capped capuchin Cebus olivaceus. Folia Primatol, 43(4): 216-228.

Robinson, J.G. (1986). Seasonal variation in use of time and space by wedge-capped capuchin monkey, Cebus olivaceus: Implications for foraging theory. Smithson. Contrib. Zool. 431: 1-60. 
Robinson, J.G. (1988a). Group size in wedge-capped capuchin monkeys Cebus olivaceus and the reproductive success of males and females. Behav Ecol Sociobiol, 23(3): 187-197.

Robinson, J.G \& Janson, C.H. (1987). Capuchins, squirrel monkeys and atelines: socioecological convergence with Old World primates. Em: Primate societies. Smuts, B.B., Cheney, D.L., Seyfarth, R.M., Wrangham, R.W \&, Struhsaker, T.T (Eds). University of Chicago Press, Chicago and London, pp. 69-82.

Rodman, P.S \& Mitani, J.C. (1987). Orangutans: sexual dimorphism in a solitary species. Em: Primate Societies. Smuts, B., Cheney, D.L., Seyfarth, R.M., Struhsaker, T., Wrangham, R.W. (Eds). University of Chicago Press, Chicago and London, pp. 146-154.

Roesler, R., Malta, L.G, Carrasco, L.C., Holanda, R.B., Sousa, C.A.S. \& Pastore, G.M. (2007). Atividade antioxidante de frutas do cerrado. Ciênc Tecnol Aliment, Campinas, 27(1): 787-792.

Rose, L.M. (1994). Sex differences in diet and foraging behavior in white-faced capuchins (Cebus capucinus). Int J Primatol,15: 95-114.

Rose, L.M. (1997 Vertebrate Predation and Food-Sharing in Cebus and Pan. Int J Primatol, 18(5): 727-765.

Rose, L.M. \& Fedigan, L.M. (1995). Vigilance in white-faced capuchins, Cebus capucinus, in Costa Rica. Anim Behav, 49: 63-70.

Ross, C. (2001). Park or ride? Evolution of infant carrying in primates. Int J Primatol, 22(5): 749-771.

De Ruiter, J.R. (1986). The influence of group size on predator scanning and foraging behavior of wedge-capped capuchin monkeys (Cebus olivaceus). Behaviour, 98: 240-258. 
Rylands, A.B. (1982). The behaviour and ecology of three species of marmosets and tamarins (Callitrichidae:Primates) in Brazil. Tese de doutorado. University of Cambridge.

van Schaik, C.P. (1983). Why are diurnal primates living in groups? Behaviour, 87: 120144.

Rylands, A.B., Schneider, H., Mittermeier, R.A, Groves, C.P \& Rodriguez-Luna, E. (2000). An assessment of the diversity of New World Primates. Neotropical Primates, 8: 61-93.

Sabbatini, G., Stammati, M., Tavares, M.C.H. \& Visalberghi, E. (2008). Behavioral flexibility of a group of bearded capuchin monkeys (Cebus libidinosus) in the National Park of Brasília (Brazil): consequences of cohabitation with visitors. Brazilian Journal of Biology, 68(4): 685-693.

Santos, L.P.C. (2010). Diferenças sexo/etárias no Forrageamento de Cebus nigritus em área de Mata Atlântica. Dissertação de mestrado. Departamento de Psicologia Experimental. Universidade de São Paulo. São Paulo.

Schino, G., Giuseppe, F.D. \& Visalberghi, E. (2009). Grooming, rank, and agonistic support in tufted capuchin monkeys. Am J Primatol, 71: 101-105.

Schradin, C. \& Anzenberger, G. (2001). Infant carrying in family groups of goeldi's monkeys (Callimico goeldii). Am J Primatol, 53: 57-67.

Silva, M.R., Lacerda, D.B.C.L., Santos, G.G. \& Martins, D.M.O. (2008). Caracterização química de frutos nativos do cerrado. Ciência Rural, 38(6): $1790-1793$.

Snaith, T.V. \& Chapman, C.A. (2005). Towards an ecological solution to the folivore paradox: patch depletion as an indicator of withingroup scramble competition in red colobus. Behav Ecol Sociobiol, 25: 185-190. 
Snaith, T.V. \& Chapman, C.A. (2007). Primate group size and socioecological models: do folivores really play by different rules? Evol Anthropol, 16: 94-106.

Snaith, T.V. \& Chapman, C.A. (2008). Red colobus monkeys display alternative behavioural responses to the costs of scramble competition. Behav Ecol, 19: 1289-1296.

Spagnoletti, N. (2009). Uso di strumenti in una popolazione di Cebus libidinosus allo stato selvatico in Piauí, Brasile. Tese de doutorado. Dipartimento di Biologia Animale e dell'Uomo, Università La Sapienza di Roma, Rome, Italy.

Spironello, W.R. (2001). The brown capuchin monkey (Cebus apella). Ecology and home range requerements in Central Amazonia. Em: The ecology and conservation of a fragmented forest. Bierregaard, R.O., Gascon. C.Jr., Lovejoy, T.E., Mesquita, R. (Eds). Yale University Press, New Haven \& London, pp. 271283.

Stanford, C.B. (1991). The capped langur in Bangladesh: behavioral ecology and reproductive tactics. Contributions to Primatology, 26: 1-179.

Steenbeek, R. \& van Schaik, C.P. (2001). Competition and group size in Thomas's langurs (Presbytis thomasi): the folivore paradox revisited. Behav Ecol Sociobiol, 49:100-110.

Sterck, E.H.M., Watts, D.P \& van Schaik, C.P. (1997). The evolution of female social relationships (in nonhuman primates). Behav Ecol Sociobio, 41: 291-309.

Sterck, E.H.M. \& Steenbeek, R. (1997). Female dominance relationships and food competition in the sympatric thomas langur and long-tailed macaque. Behaviour, 134: 749-774.

Stewart, K.J. \& Harcourt, A.H. (1987). Gorillas: Variation in female relationships. Em: Primates Societies. Smuts, B.B., Cheney, D.L., Seyfarth, R.M., Wrangham, 
R.W., Struhasaker, T.T. (Edts). The University of Chicago Press, Chicago and London.

Steudel, K. (2000). The physiology and energetic of movement: effects on individuals andgroups. Em: On the Move: How and Why Animals Travel in Groups. Boinski, S. Garber, P.A. Chicago: Univ. Chicago Press. pp. 9-23.

Strier, K.B. (1989). Effects of patch size on feeding associations in muriquis (Brachyteles arachnoides). Folia Primatol, 52: 70-77.

Strier, K.B. (1994). Myth of the typical primate. Yearbook of Physical Anthropology, 37: $233-271$.

Strier, K.B. (2007). Primate behavioral ecology. $3^{\circ}$ edição. Pearson, USA.

Strier, K.B. (2009). Seeing the forest through the seeds: mechanisms of primate behavioral diversity from individuals to populations and beyond. Current Anthropology, 50(2): 213-228.

Su, H.H. \& Birky, W.A. (2007). Within-group female-female agonistic interactions in Taiwanese macaques (Macaca cyclopis). Am J Primatol, 69: 199-211.

Sutherland, W.J. (1996). Ecological census techniques: a handbook. Cambridge: Cambridge University Press.

Taira, J.T. (2007). Consumo do palmito Jussara (Euterpe edulis) por macacos-prego (Cebus nigritus): Estratégia de forrageamento ótimo ou requinte de um gourmet? Dissertação de Mestrado apresentado ao Instituto de Psicologia da Universidade de São Paulo.

Taira, J.T., Verderane, M.P., Ottoni, E.B. \& Izar, P. (2002). Exploração das palmeiras Euterpe edulis e Archontophoenix cunninghamiana por duas populações de macacos-prego (Cebus apella). Em: Anais do XX Encontro Anual de Etologia, Albuquerque, F.S. (Ed), pp. 326. 
Teichroeb, J.A. \& Sicotte, P. (2009). Test of the ecological-constraints model on ursine colobus monkeys (Colobus vellerosus) in Ghana. Am J Primatol, 71: 49-59.

Terborgh, J. (1983). Five New World monkeys. Princeton University Press, Princeton.

Terborgh, J. \& Goldizen, A.W. (1985). On the mating system of the cooperatively breeding saddle-backed tamarin (Saguinus fuscicollis). Behav. Ecol. Sociobiol, 16(4): 293-299.

Thierry, B. (2008). Primate socioecology, the lost dream of ecological determinism. Evol Anthropol, 17: 93-96.

Torres de Assumpção, C. (1983). An ecological study of primates of Southeastern Brazil with a reappraisal on Cebus apella races. Tese de doutorado. Edinburgh University. Edinburgh.

Treves A, Chapman CA (1996) Conspecific threat, predation avoidance, and resource defense: implications for grouping in langurs. Behav Ecol Sociobiol, 39: 43-53.

Trivers, R.L. (1972). Parental investment and sexual selection. Em: Sexual selection and the descent of man. Campbell, B. (Ed). Heinemann, London, pp. 136-179.

van doorn, A.C., O'riain, M.J \& Swedell, L. (2010). The effects of extreme seasonality of climate and day length on the activity budget and diet of semi-commensal Chacma Baboons (Papio ursinus) in the cape peninsula of South Africa. Am J Primatol, 72: 104-112.

van Hooff, J.A.R.A.M. \& van Schaik, C.P. (1992). Cooperation in competition: the ecology of primate bonds. Em: Coalitions and alliances in humans and other animals. Harcourt, A.H., de Waal, F.B.M. (Eds). Oxford University Press, Oxford, pp. 357-389.

van Schaik, C.P. (1983). Why are diurnal primates living in groups? Behaviour, 87: 120-144. 
van Schaik, C.P. (1989). The ecology of social relationshipsamongst female primates. Em: Comparative socioecology: the behavioural ecology of humans and other mammals. Standen, V., Foley, R.A. (Eds). Blackwell Scienti Publ, Oxford, pp.195-218.

van Schaik, C.P. (1996). Social evolutionin primates: the role of ecological factors and male behavior. Proceedings of the British academy, (88): 9-31.

van Schaik, C.P. \& van Noordwijk, M. A. (1989). Predation avoidance in Cebus: A special role for males. Behav. Ecol. Sociobiol, 24: 265-276.

van Schaik, C.P. \& Hoerstermann, M. (1994). Predation risk and the number of males in a primate group: a comparative test. Behav. Ecol. Sociobiol, 35: 261-272.

van Schaik, C.P., Deaner, R.O. \& Merrill, M.Y. (1999). The conditions for tool use in primates: implications for the evolution of material culture. J Hum Evol, 36: 719-741.

van Schaik, C.P. \& Knott, C.D. (2001). Geographic variation in tool use on neesia fruits in orangutans. Am J Phys Anthropol, 114: 331-342.

van Schaik, C.P., Fox, E.A. \& Fechtman, L.T. (2003). Individual variation in the rate of use of tree-hole tools among wild orangutans: implications for hominin evolution. J Hum Evol, 44: 11-23.

Verderane, M.P. (2005). Estilos de cuidado materno e desenvolvimento das relações sociais de infantes de macacos-prego, Cebus apella, de 0 a 18 meses de idade. São Paulo. Dissertação de mestrado. Departamento de Psicologia Experimental. Universidade de São Paulo.

Verderane, M.P., Neves, P.M. \& Izar, P. (2005). Ontogênese dos comportamentos alimentar e locomotor de filhotes de macacos-prego (Cebus apella) em um 
grupo em semi-liberdade. Em: Anais do XI Congresso Brasileiro de Primatologia. Porto Alegre, RS. pp. 56.

Visalberghi, E. \& McGrew, W.C. (1997). Cebus meets Pan. Int J Primatol, 18(5): 677681.

Visalberghi, E., Fragaszy, D.M., Izar, P., Ottoni, E.B. (2005). Terrestriality and tool use. Science 308: 951-952.

Visalberghi, E., Fragaszy, D.M., Ottoni, E.B., Izar, P., Oliveira, M.G. \& Andrades, F.R.D. (2007). Characteristics of hammer stones and anvils used by wild bearded capuchin monkeys (Cebus libidinosus) to crack open palm nuts. Am J Phys Anthropol, 132: 426-444.

Visalberghi, E., Sabbatini, G., Spagnoletti, N., Andrade, F.R.D., Ottoni, E., Izar, P. \& Fragaszy, D.M. (2008). Physical properties of palm fruits processed with tools by wild bearded capuchins (Cebus libidinosus). Am J Primatol, 70(9): 884-891.

Visalberghi, E., Spagnoletti, N., Ramos da Silva, E.D., Andrade, F.R.D., Ottoni, E.B., Izar, P. \& Fragaszy, D. (2009a). Transport of hammer tools and nuts by wild capuchin monkeys. Primates, 50(2): 95-104.

Vogel, E.R. (2005). Rank differences in energy intake rates in white-faced capuchin monkeys, Cebus capucinus: the effects of contest competition. Behav Ecol Sociobiol, 58: 333-344.

Vogel, E.R. \& Janson, C. (2007). Predicting the frequency of food-related agonism in white faced capuchin monkeys (Cebus capucinus) using a novel focal-tree method. Am J Primatol, 69: 533-550.

Waga, I., Dacier, A.K., Pinha, P.S. \& Tavares, M.C.H. (2006). Spontaneous tool use by wild capuchin monkeys (Cebus libidinosus) in the Cerrado. Folia Primatol, 77: 337-344. 
Watts, D.P. (1985). Relations between group size and composition and feeding competition in mountain gorilla groups. Anim. Behav, 33: 72-85.

White, F.J. (1998). Seasonality and socioecology: the importance of variation in fruit abundance to bonobo sociality. Int J Primatol, 19: 1013-1027.

White, F.J. \& Wrangham, R.W. (1988). Feeding Competition and Patch Size in the Chimpanzee Species Pan paniscus and Pan troglodytes Behaviour, 105(1/2): 148-164.

White, F.J., Overdorff, D.J., Keith-Lucas, T., Rasmussen, M.A., Kallam, E.W. \& Forward, Z. (2007). Female dominance and feeding priority in a prosimian primate: experimental manipulation of feeding competition. Am J Primatol, 69: 295-304.

Wittig, R.M. \& Boesch, M. (2003). Food competition and linear dominance hierarchy among female chimpanzees of the Ta" 1 National Park. Int J Primatol, 24(4): 847-867.

Wrangham, R.W. (1977). Feeding behavior of the chimpanzees in Gombe National Park, Tanzania. Em: Primate Ecology: Studies of feeding and ranging behavior in lemurs, monkeys and apes. Clutton-Brock, T.H. (Eds.). Academic Press, New York, pp. 5-3-556.

Wrangham, R.W. (1980). An ecological model of female-bonded primate groups. Behaviour, 75: 262-300.

Wrangham, R.W. (1986). Ecology and social relationships in two species of chimpanzee. Em: Ecology and social evolution: birds and mammals. Rubenstein, D.I., Wrangham, R.W. (Eds). Princeton, NJ: Princeton University Press. pp. $352-378$. 
Wright, B.W., Wright, K.A., Chalk, J., Verderane, M.P., Fragaszy, D.M., Visalberghi, E., Izar, P., Ottoni, E.B., Constantino, P. \& Vinyard, C. (2009). Fallback foraging as a way of life: using dietary toughness to compare the fallback signal among capuchins and implications for interpreting morphological variation. Am J Phys Anthropol, 140: 687-699.

Youlatos, D. (1998). Positional behavior of two sympatric guianan capuchin monkeys, the brown capuchin (Cebus apella) and the wedge-capped capuchin (Cebus olivaceus). Mammalia, 62(3): 351-365.

Zhang, S. (1995). Activity and ranging patterns in relation to fruit utilization by brown capuchin monkeys (Cebus apella) in French Guiana. Int J Primatol, 16(3): 489507. 